Trabajo de tesis para optar al título de Doctor en Ciencias Naturales

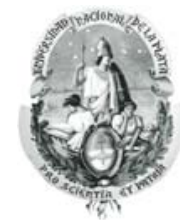

Universidad Nacional de La Plata

Facultad de Ciencias Naturales y Museo

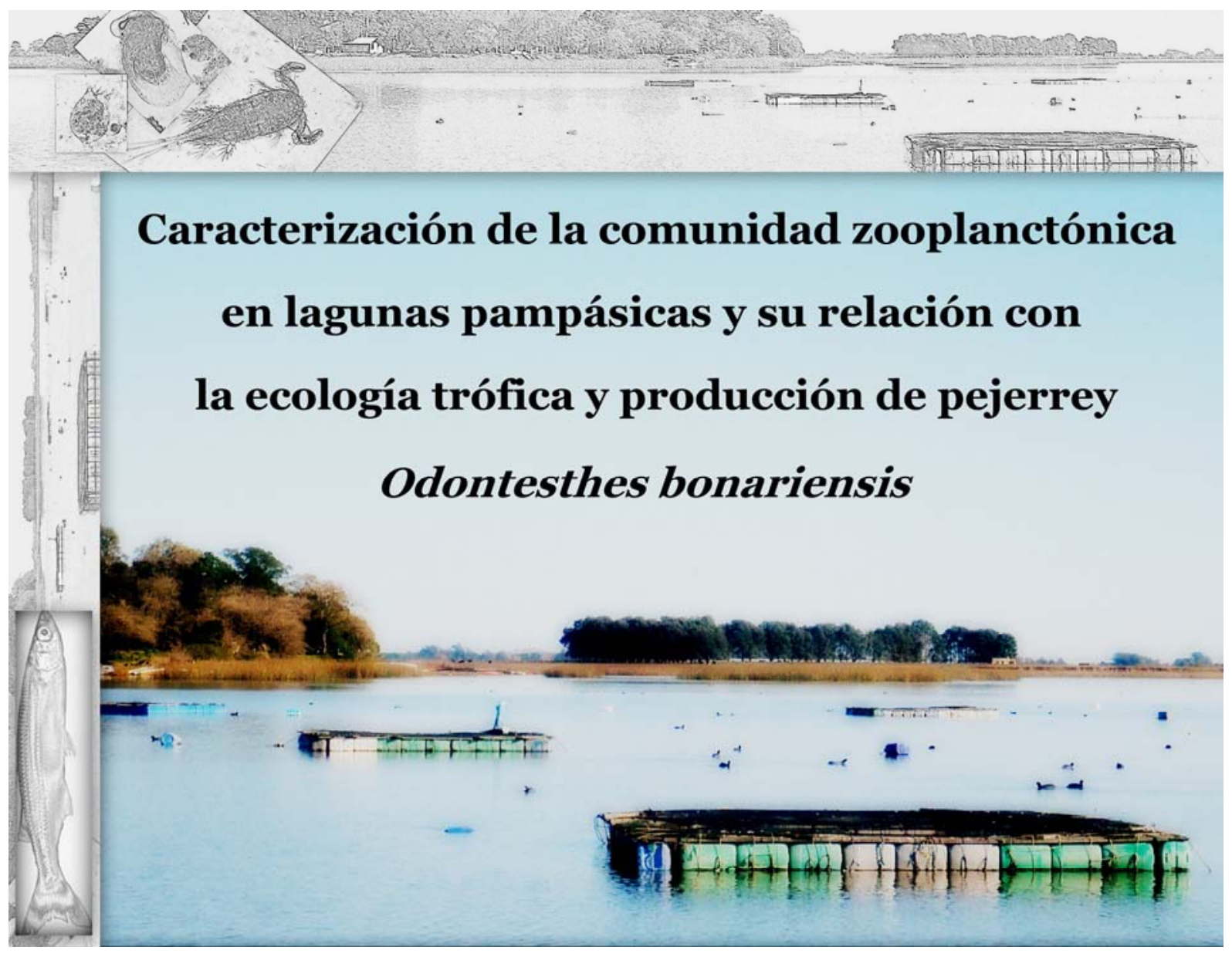

Lic. Javier Ricardo Garcia de Souza

Director: Darío César Colautti

Codirectora: María Cristina Claps

Año 2014 
"Para entender lo invisible hay que mirar con cuidado lo visible" Alberto Rojo (Científico y músico argentino) 


\section{Tabla de contenidos}

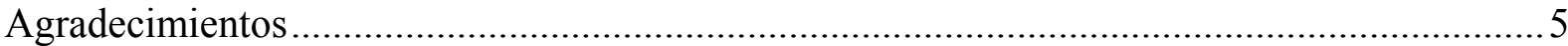

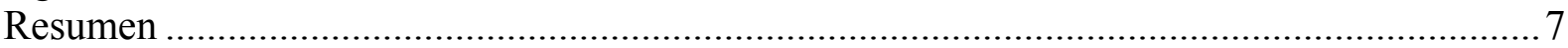

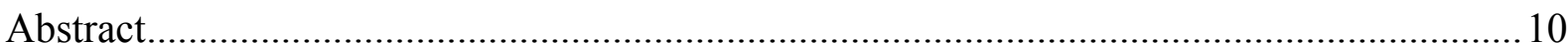

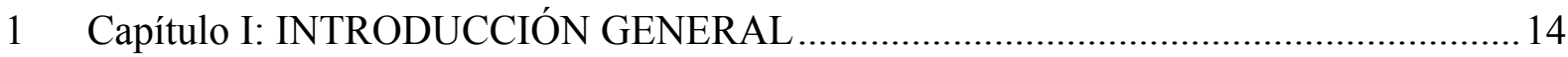

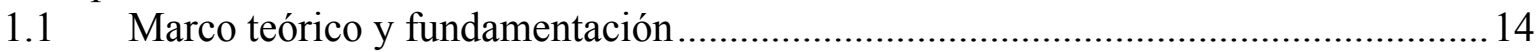

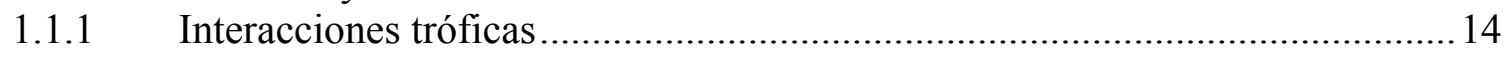

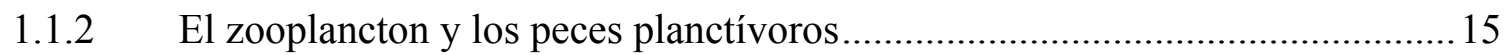

1.1.3 El zooplancton de ecosistemas acuáticos pampeanos ..................................... 18

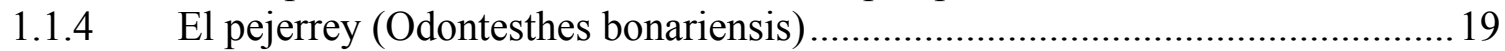

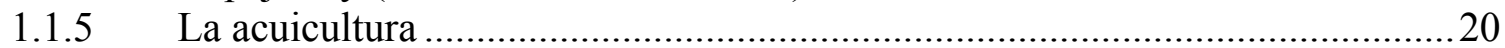

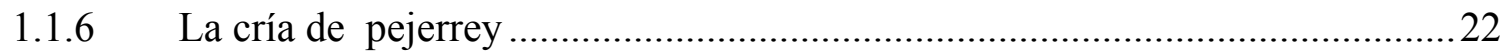

1.1.7 Cavas y jaulas flotantes como unidades experimentales .................................23

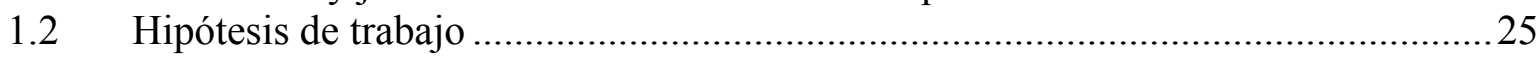

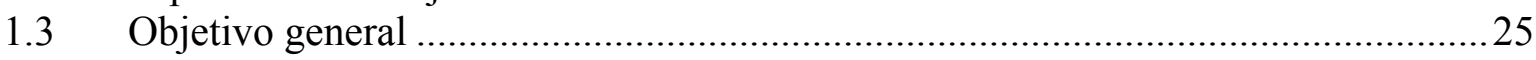

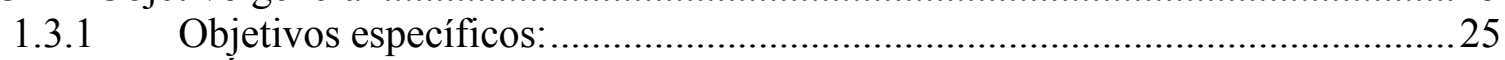

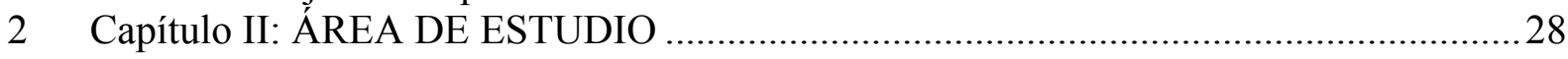

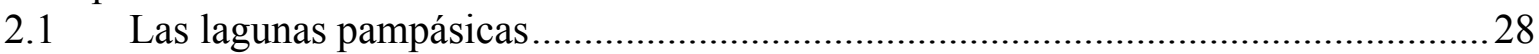

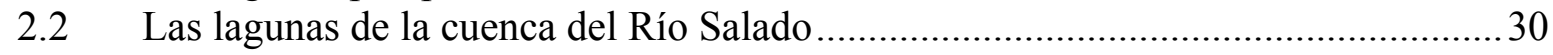

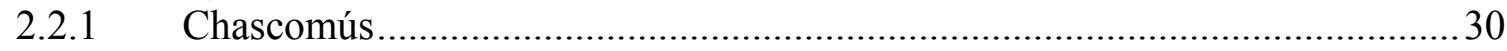

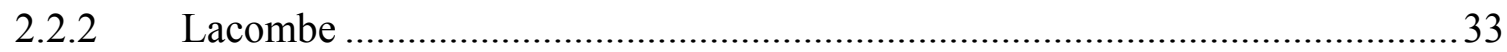

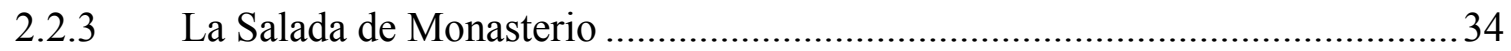

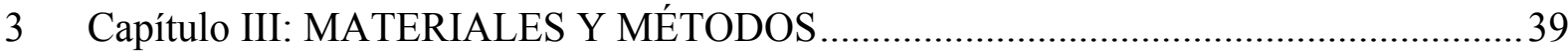

3.1 Materiales y técnicas de cría de pejerrey implementadas........................................40

3.1.1 Obtención de postlarvas de pejerrey en cavas experimentales........................40

3.1.2 Obtención de postlarvas y cría de juveniles de pejerrey en jaulas flotantes..... 42

3.2 Seguimiento de parámetros limnológicos y comunidad zooplanctónica..................44

3.3 Seguimiento del crecimiento del pejerrey bajo cultivo ........................................ 47

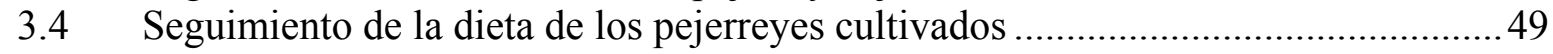

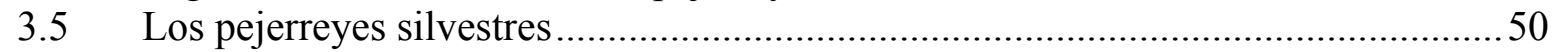

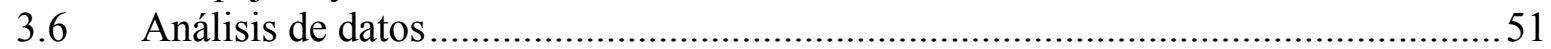

3.6.1 Parámetros limnológicos y comunidad zooplanctónica .................................51

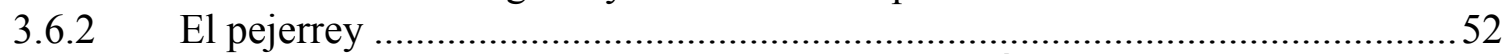

4 Capítulo IV: INFLUENCIA DEL AMBIENTE EN LA CRÍA EXTENSIVA DE

PEJERREY: especial atención a la comunidad zooplanctónica.........................................57

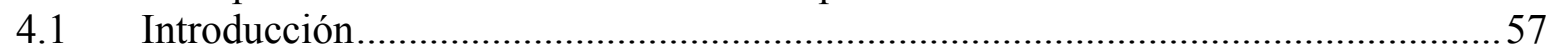

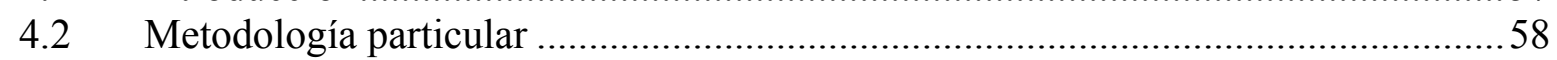

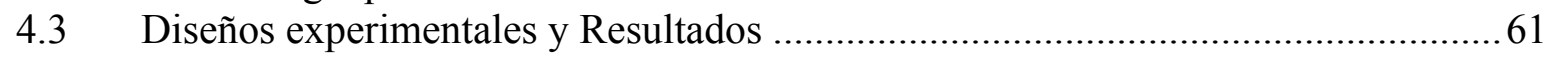

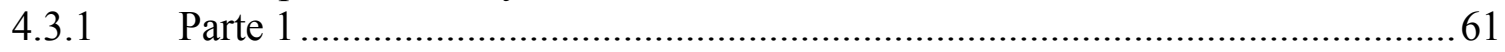

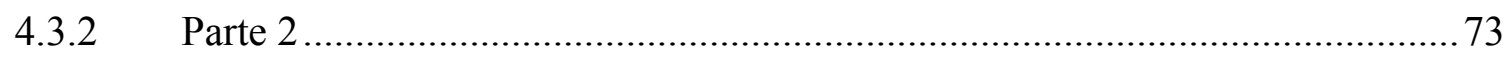

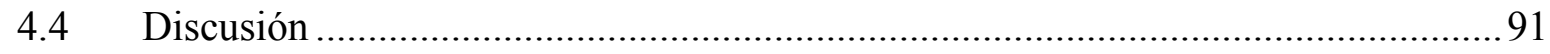

5 Capítulo V: INFLUENCIA DE LA ESTACIONALIDAD EN EL CULTIVO

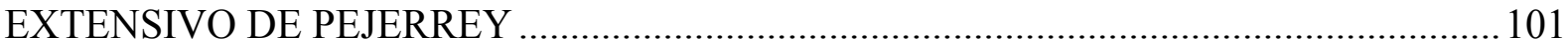

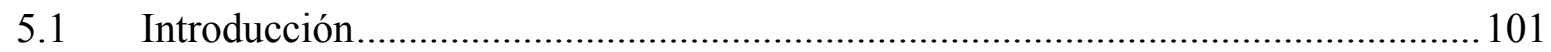

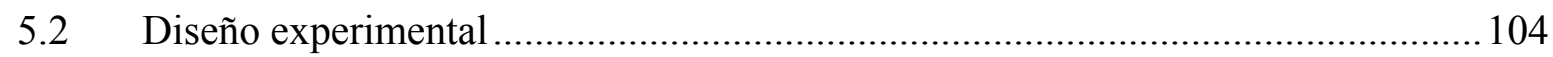

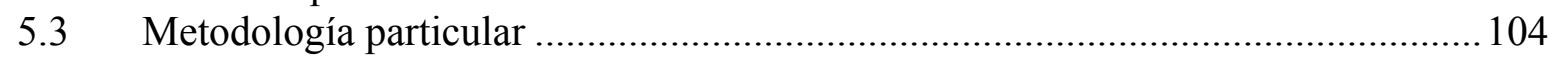

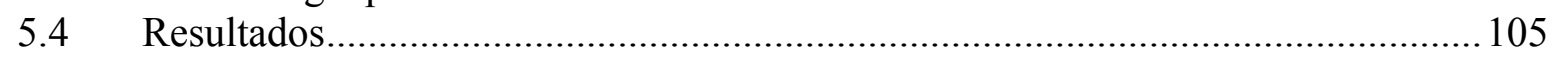

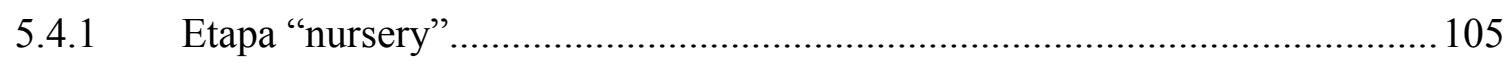




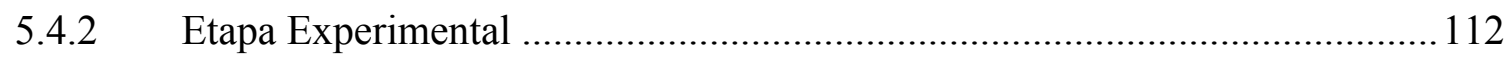

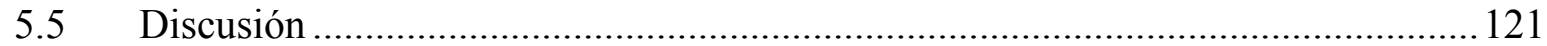

6 Capítulo VI: INFLUENCIA DE LA DENSIDAD DE CRÍA Y LA CALIDAD DE

ALIMENTO NATURAL en el cultivo extensivo de pejerrey .......................................... 127

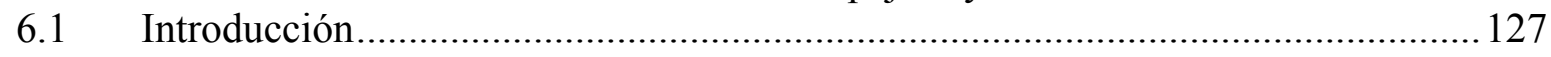

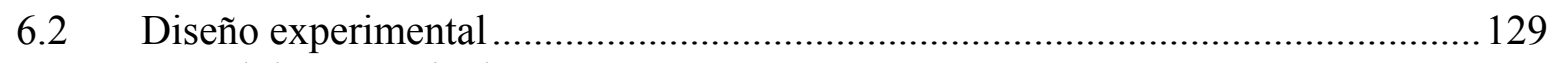

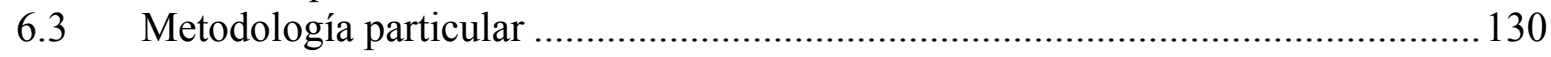

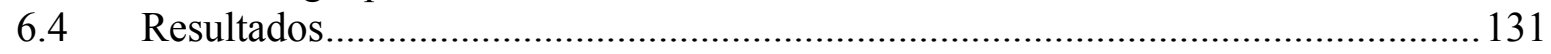

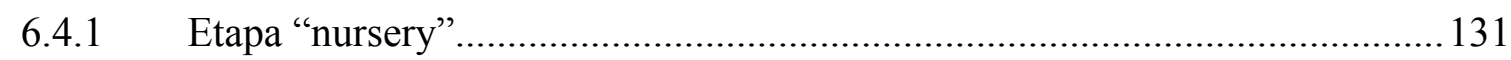

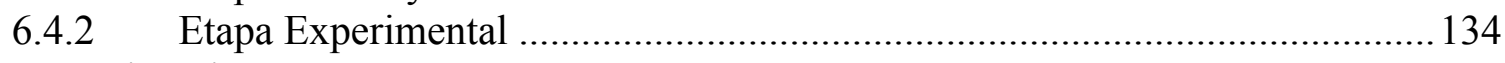

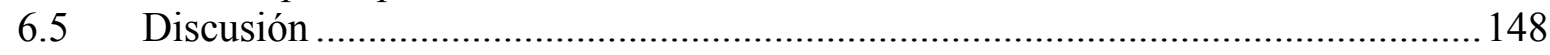

7 Capítulo VII: DESARROLLO ALIMENTARIO DEL PEJERREY: comparaciones en la

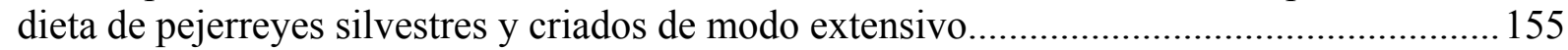

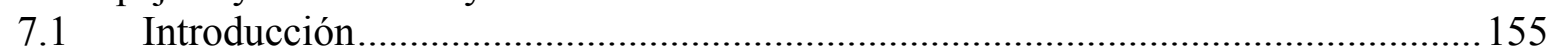

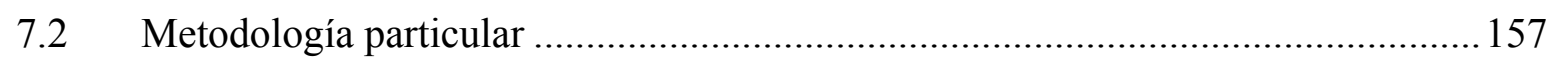

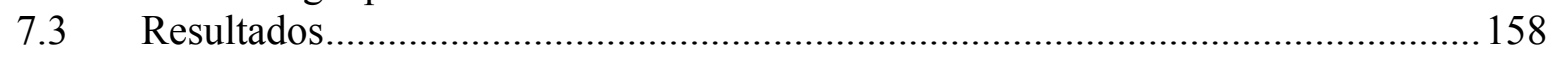

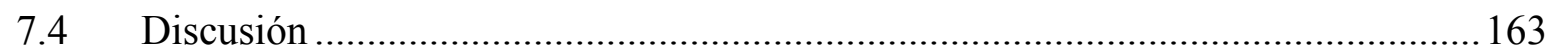

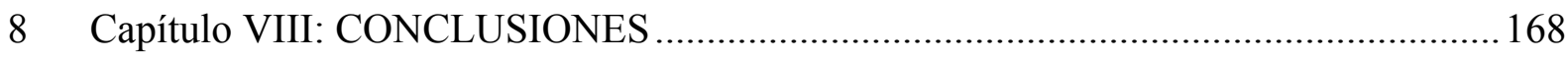

8.1 Obtención de postlarvas de pejerrey en cavas .................................................... 168

8.2 Cría extensiva de juveniles de pejerrey en jaulas flotantes ..................................... 169

8.2.1 La calidad del zooplancton en la cría extensiva de pejerrey ..........................170

8.2.2 La ecología trófica del pejerrey y su vínculo con la producción..................... 171

8.2.3 Manejo adaptativo del cultivo de pejerrey en jaulas flotantes, enfoque

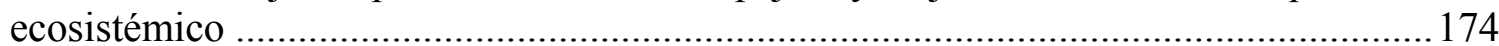

8.3 La estructuración del zooplancton debida a la ecología trófica del pejerrey.......... 175

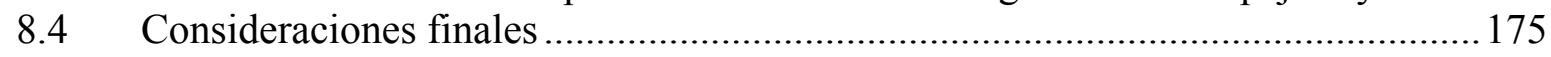

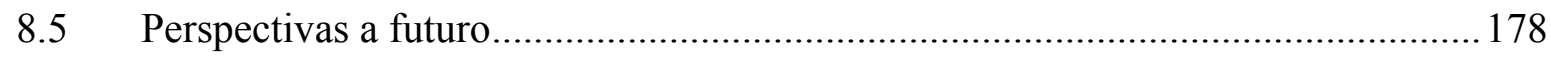

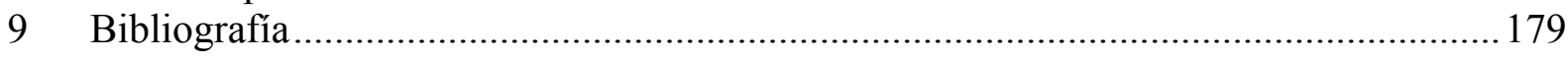

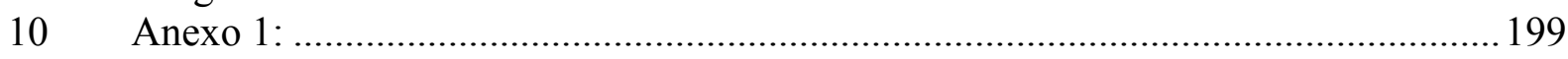

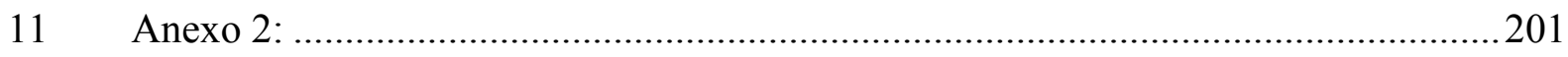




\section{Agradecimientos}

Escribo estos agradecimientos en los confines del mundo, en la Antártida a bordo del Puerto Deseado, donde las sensaciones se vuelven más intensas y no por eso menos reales. Este viaje se ha vuelto un hito fundamental en lo que llevo de carrera y agradezco ser biólogo por estar hoy acá, a mis viejos y mi hermano por ser mi sostén en todo momento y haberme facilitado el camino recorrido en esta profesión como ahora al realizar esta tesis. Numerosas personas son las que crucé en este camino y a quienes tengo motivos para agradecer, como a mis abuelos por su afecto y generosidad que intento llevar a todo lo que hago y a Javi por la compañía, por los diálogos, por la música, y por todos esos momentos únicos que nos construyen como personas.

Agradezco a mi directores, Darío y Cristina, por brindarme la oportunidad de crecer profesionalmente, ofreciéndome material para desarrollar una tesis y un lugar donde realizarla, por las enseñanzas, los consejos y la confianza, lo cual sumado a una gran posibilidad de diálogo ha hecho de este camino, un camino de trabajo y amistad.

A Darío, Lolo, Claudio, Balbon, Pato, Faca y Campi, con quienes compartí campañas, congresos y debates, por las anécdotas, los dibujos en el pizarrón, los apodos (innumerables), los cánticos previos a la levantada de trampas, y todas esas pequeñas cosas que hicieron del laboratorio donde realicé la primera parte de la tesis (Ecología y Producción Pesquera, INTECH) un lugar de amistad y que se continúa ahora con la gente del Laboratorio de Ecología de Peces (ILPLA). Especialmente a Lolo, que de compañeros de facultad y trabajo nos convertimos en amigos a través de una vida de compañía, anécdotas y confidencias.

Al grupo de antes y de ahora del laboratorio de la Cuenca del Salado (ILPLA), Cristina, Néstor, Lía, Hernán, Martín, Gaby, la Colo, Sabi, Fer y Pana, por las enseñanzas, los consejos y por el clima de amistad y "buena onda" que vivimos diariamente los "pichones".

A Gustavo Berasain y toda la Estación Hidrobiológica de Chascomús por las larvas de pejerrey, a Susana Sampietro por las instalaciones de la Laguna La Salada de Monasterio y a Andrés Jaureguizar por la ayuda en cuestiones estadísticas.

A la Facultad de Ciencias Naturales y Museo y Universidad Nacional de La Plata por la educación pública y gratuita que recibí, a la CIC por las becas que permitieron comenzar mis estudios de postgrado y al CONICET que permite que los continúe. 
A los miembros del Jurado: María de los Ángeles Gonzalez Sagrario, Miguel Mancini y Alicia Poi por sus valiosas observaciones, comentarios y sugerencias que mejoraron la interpretación de los resultados y enriquecieron el manuscrito.

Como el zooplancton para el pejerrey, agradezco haberme encontrado con gente de "buena calidad" que optimiza mi rendimiento en esta vida, y por poder ser parte de grupos humanos increíbles como los "Pecetos", por nunca dejar de aplaudir, gritar y reír en este ir y venir de "viajes nostálgicos interdisciplinarios" que profundizan cada vez más nuestra amistad; especialmente a Dai, Fer y Lolo (de nuevo) por los cónclaves y a Belu y Flor por los mates planeando viajes que algún día haremos. A Espiardanza por ser un grupo de "jóvenes y bellos bailarines" sin el cual no me habría "salvado" más de una vez, y especialmente a Mariana por su generosidad, amistad y talento que hizo de esta compañía un hermoso grupo humano. A los cumbristas por estar siempre, por compartir una pasión que nos construyó la identidad, por la amistad fiel, por las palabras siempre presentes, y los oídos siempre dispuestos, a mis amigos de siempre (especialmente a Ani y Chivi), a mis tíos y primos (los de sangre, los del corazón y los antárticos), gracias por estar siempre, y a Ernesto, por brindarme el espacio que necesitaba en la busqueda de una mejor calidad de vida.

Y por último a Gaby, siempre presente en mi corazón, me llevo su enorme sonrisa a todos lados y con ella vuelvo a vivir nuestra amistad, que es para siempre. 


\section{Resumen}

El estudio de las interacciones tróficas, como la que existe entre depredadores y presas, y la determinación de los efectos que estas interacciones tienen en cada uno de los niveles tróficos resultan fundamentales a la hora de conocer los métodos de regulación de las poblaciones animales. Las investigaciones acerca del vínculo entre los peces zooplanctívoros y el zooplancton en ambientes acuáticos continentales han llevado a aseverar que la depredación juega un rol fundamental en la estructuración de la comunidad zooplanctónica. A su vez, existe una controversia entre aquellos que aseguran que la reducción en las tallas medias de los ítems zooplanctónicos, que se observa desde el ecuador hacia los trópicos, está correlacionada con la temperatura, y aquellos que la vinculan directamente con la depredación. Se han desarrollado diversas hipótesis en la búsqueda de un mayor entendimiento del vínculo entre los peces y el zooplancton. Entre ellas están la "Hipótesis de eficiencia por tamaños", la cual vincula los cambios en la composición y tamaño medio de los componentes del zooplancton con la densidad de depredadores, y la "Hipótesis match/mismatch", que postula que el crecimiento y la supervivencia de las larvas de peces están íntimamente relacionados a la superposición temporal y espacial con el zooplancton. Teniendo en cuenta dichas hipótesis y el hecho de que los estudios previos indican que el pejerrey (Odontesthes bonariensis) se alimenta de zooplancton durante la mayor parte de su vida, es que se ha desarrollado la presente tesis doctoral que vincula el estudio de las características ecológicas de la especie, y de su interacción con el zooplancton en lagunas de la provincia de Buenos Aires, con su producción de tipo extensiva (aprovechando el alimento natural disponible) en jaulas flotantes.

En cuanto a la producción de la especie se ha buscado además identificar y evaluar las variables que influyen sobre el éxito de la obtención de postlarvas de pejerrey utilizando cavas, y sobre la eficiencia del sistema de cría de juveniles en jaulas flotantes. Es por esto que en la estructura del presente trabajo emergen como variables clave a evaluar las características limnológicas del ambiente de cría, la estacionalidad, las épocas de desarrollo de los cultivos y otras variables intrínsecas a cada ciclo de cría como ser la edad de los peces, su talla y su densidad de siembra. Considerando todo lo antedicho, el objetivo general de la presente tesis es analizar de qué modo la oferta cualitativa y cuantitativa de zooplancton en lagunas de la provincia de Buenos Aires (Chascomús, Lacombe y La Salada de Monasterio) 
condicionan el crecimiento y la supervivencia del pejerrey (O. bonariensis), y de qué manera la depredación por parte de dicha especie modifica la estructura y dinámica de la comunidad zooplanctónica.

El seguimiento exhaustivo de la comunidad zooplanctónica desarrollada en las cavas permitió identificar la abundancia y composición zooplanctónica ideal para la siembra de larvas de pejerrey recién eclosionadas, en pos de un mejor aprovechamiento de los recursos. Esto es una abundancia mayor a 1000 ind./l compuesta mayoritariamente por rotíferos (por ejemplo Brachionus plicatilis). Además, al considerar la variabilidad obtenida entre estaciones, en cuanto a las tallas, pesos y supervivencias, se ha determinado que el momento ideal para el llenado de las cavas es un mes antes de la finalización del invierno y para la siembra de las larvas el inicio de la primavera, sobre todo si las postlarvas obtenidas serán luego transportadas a jaulas flotantes para la cría de juveniles.

Se observó una relación directa entre el zooplancton hallado en las lagunas y el crecimiento de los pejerreyes obtenidos en las jaulas. Al comparar las lagunas de a pares en el capítulo IV [Experimento 1: Chascomús vs. Lacombe (verano 2006/2007), experimento 2: Chascomús vs. Lacombe (otoño 2007), experimento 3: Chascomús vs. La Salada (verano 2007/2008) y experimento 4: Chascomús vs. La Salada (primavera 2008)] se obtuvieron los mejores crecimientos en Chascomús en los tres primeros casos y en La Salada en el último, vinculado directamente con mayores biomasas zooplanctónicas y mayor representatividad de especies grandes (copépodos y cladóceros) registradas en dichos ambientes. Es decir que a mayores biomasas zooplanctónicas totales, y mayor representatividad de especies zooplanctónicas grandes, se obtienen mejores tasas de crecimiento en la cría extensiva de pejerrey en jaulas. Por consiguiente existen determinados ítems de la comunidad zooplanctónica que serían "mejores" como alimento del pejerrey, y cuya representatividad determinará la calidad del zooplancton para el cultivo. Esta calidad es dinámica ya que depende de las características ambientales, de la estacionalidad y de la estructura del ensamble íctico del ecosistema lagunar. La biomasa de copépodos y cladóceros de más de 0,7 mm resultó la más influyente sobre las tasas de crecimiento de los peces. Particularmente, los juveniles de pejerrey se inclinaron en casi todos los casos por una especie de copépodo Cyclopoida (Acanthocyclops robustus), y en algunos casos por un copépodo Calanoida (Notodiaptomus incompositus) y en otros, donde la oferta de cladóceros fue elevada, lo hizo hacia la especie Ceriodaphnia dubia. 
Los resultados obtenidos al realizar comparaciones entre años diferentes (capítulo IV), entre estaciones (capítulo V) y entre diferentes densidades de cría (capítulo VI) y aquellos obtenidos al comparar la dieta de pejerreyes silvestres con la de los cultivados, permitieron llegar a diversas conclusiones en cuanto a la ecología trófica de la especie y su cultivo en jaulas. La estacionalidad (y con ella la disponibilidad de alimento) y las tallas de los peces son factores clave que determinan la proporción de presas consumidas y la selectividad alimentaria, la cual disminuye ante una baja disponibilidad y ante una elevada densidad de cría (por competencia intraespecífica) provocando una ampliación en el espectro trófico de la especie. Estas observaciones demuestran la plasticidad que posee el pejerrey para adaptarse a escenarios cambiantes de disponibilidad de alimento, como lo son las lagunas pampásicas, teniendo la posibilidad de maximizar el consumo de una especie o consumir alimento alternativo y diversificar la dieta. Por otra parte, el estudio del desarrollo alimentario de la especie permite concluir que el pejerrey presenta selectividad alimentaria desde el comienzo de la alimentación exógena, con la preferencia por consumir rotíferos hasta alcanzar los $2 \mathrm{~cm}$ de longitud total. La dieta monofágica los primeros días de vida sugiere que el tamaño apropiado de primera alimentación del pejerrey no debe superar los 0,3 $\mathrm{mm}$, ya que además pudo acceder a ítems zooplanctónicos de más de 0,7 $\mathrm{mm}$ recién al superar los $2 \mathrm{~cm}$ de longitud total. Estas limitaciones y necesidades alimentarias están vinculadas con la talla (más que con la edad) y con la disponibilidad y deben ser tenidas en cuenta para optimizar la eficiencia de las técnicas de producción de la especie.

Resulta importante destacar que el método de cría extensiva en jaulas flotantes se podría incorporar en el ciclo de producción del pejerrey con el objetivo de sobrepasar algunas de las limitaciones que existen actualmente en el cultivo intensivo de la especie. Además, los resultados obtenidos en la presente tesis demuestran la posibilidad de desarrollar un manejo adaptativo de este tipo de sistemas, mediante un enfoque ecosistémico: Considerando los objetivos de la producción y manejando las densidades de cría de un modo dinámico, teniendo en cuenta las características del zooplancton y de la dieta de los peces, resulta viable optimizar en tiempo real la eficiencia de la acuicultura extensiva del pejerrey en jaulas. Esto podría ser la clave para el desarrollo de una acuicultura ecológica (basada en el ecosistema) para el pejerrey. 


\begin{abstract}
The study of predator-prey interactions, and the determination of the effects they have over each trophic level, are fundamental to understand the methods of regulation of animal populations. The investigations carried out about the relation between the zooplanktivorous fish and the zooplankton in freshwater ecosystems have led to the conclusion that predation plays a major role in structuring the zooplankton community. Moreover, some authors argue that the reduction in zooplankton mean sizes, observed towards the tropics, is related to the temperature, while others link it to the predation. Several hypotheses have been posed to make possible a better understanding of this link between fish and zooplankton. The "Size Efficiency Hypothesis" claims that the changes that occur in zooplankton composition and its mean size are dependent on the density of its predators, while the "Match/mismatch hypothesis" postulates that the growth and survival of fish larvae are deeply related to its temporal and spatial overlap with the zooplankton. This doctoral thesis has been developed taking into account these hypotheses and the previous studies which indicate that the "pejerrey" (Odontesthes bonariensis) feeds on zooplancton over almost its entire life. Besides, the analysis of the ecological characteristics of the pejerrey, and the study of its interaction with the zooplankton in shallow lakes of Buenos Aires, was associated with the extensive production (taking advantage of the natural food supply) of this species in floating cages.

In relation with the pejerrey extensive production systems, the present work has sought to identify and evaluate the variables that influence over the success in pond rearing of pejerrey "post-larvae" and over the efficiency of the juvenile cage culture. Therefore, the following key variables emerge: The limnological characteristics of the rearing environment, the seasonality, the times of development, and others, intrinsic to each culture period, as the age and size of fishes and its stocking density. Considering all the above, the general objective of this thesis was to analyse how the natural food supply (in quantity and quality) of shallow lakes of Buenos Aires province (Chascomús, Lacombe and La Salada de Monasterio) affects the growth and survival of the pejerrey, and in which way its predation modifies the structure and dynamics of the zooplankton community.
\end{abstract}


The comprehensive monitoring of the pond zooplankton community allowed the identification of zooplankton abundance and composition "ideal" for stocking recently hatched pejerrey larvae, in pursuit of better use of the resources. This ideal abundance has to be greater than 1000 ind. $^{-1}$ and be composed mainly of rotifers (for example Brachionus plicatilis). Furthermore, considering the variability in length, weight and survival, observed between seasons, it has been determined that the better moment for filling the ponds is one month before the end of winter, and for stocking the larvae the early spring, especially if the post-larvae are going to be transported to floating cages to continue their growth towards the juvenile stage.

A direct relationship between the zooplankton of the lakes and the growth of the pejerrey cultured in cages was found. The pairwise comparisons of chapter IV [Experiment 1: Chascomús vs. Lacombe (summer 2006/2007), experiment 2: Chascomús vs. Lacombe (autumn 2007), experiment 3: Chascomús vs. La Salada (summer 2007/2008) and experiment 4: Chascomús vs. La Salada (spring 2008)] showed the better growths in Chascomús in the first three cases, and in La Salada in the last one, which was directly related to higher zooplankton biomasses and greater representation of bigger species (copepods and cladocerans) in those environments. With higher total zooplankton biomass, and greater representation of big species, better growth rates are obtained in extensive cage culture of pejerrey. Therefore, there are certain items in the zooplankton community that would be the "best" as food for pejerrey, and which contribution to the community will determine the quality of the zooplankton as food supply for the fish culture. This quality is dynamic because it depends on the features of the environment, the seasonality and on the structure of the freshwater ecosystem fish assemblage. The biomass of copepods and cladocerans larger than $0.7 \mathrm{~mm}$ was the most influential over the pejerrey growth rates. Specifically, the juveniles of pejerrey chose, in almost all the studied cases, the Cyclopoida copepod Acanthocyclops robustus, while in some cases they selected the Calanoida copepod Notodiaptomus incompositus and the Cladocera Ceriodaphnia dubia, when its offer was high.

The results obtained when comparing the same lakes at different years (chapter IV), when analyzing the effects of seasonality in ponds and cages (chapter V), when testing different stocking densities (chapter VI) and when investigating the feeding habits of free and cultured pejerrey, have allowed several conclusions about the trophic ecology of the species and its cage culture. Seasonality (and thus food availability) and fish size are key factors that 
determine the proportion of consumed preys and food selectivity. The latter decreases when the availability does and when the stocking density is high (high intra-specific competition), generating an expansion of the trophic breadth of the fish. These observations show the "plasticity" of the pejerrey, which can adapt to changing environments, as the Pampean shallow lakes, thus having the capability to maximize the consumption of one item or feed on alternative food and diversify its diet. Moreover, the results about the feeding development of the pejerrey shows that it performs zooplankton size selection since the beginning of exogenous alimentation, choosing smaller fractions (rotifers) until reaching $2 \mathrm{~cm}$ of total length. The feeding habits at the first days of life suggest that the appropriate size of the first feeding in aquaculture has to be of less than $0.3 \mathrm{~mm}$, since, in addition, the pejerrey is able to consume zooplanktonic preys of more than $0.7 \mathrm{~mm}$ when it reaches at least $2 \mathrm{~cm}$ total length. These restrictions and needs are related to fish size and food availability, and must be taken into account to optimize the efficiency of the pejerrey rearing techniques.

This work adds new pieces of information and simple predictive models that enlarge our understanding about extensive cage culture of pejerrey, supporting the assumption that the method could be incorporated to the pejerrey production cycle, at least to generate juveniles, overcoming some of the current limitations exhibited by the traditional intensive methods. Furthermore, by handling stocking densities in a dynamic way, considering the zooplankton and fish diet features, it is possible to optimize, in "real-time", the efficiency of the extensive cage aquaculture of the pejerrey, and also focus the system on the aquaculturist needs. The possibility to develop an adaptive management of these kinds of aquaculture systems, based on ecosystem changes and directed to build an ecological aquaculture of pejerrey has been shown. 


\section{I}

INTRODUCCIÓN GENERAL

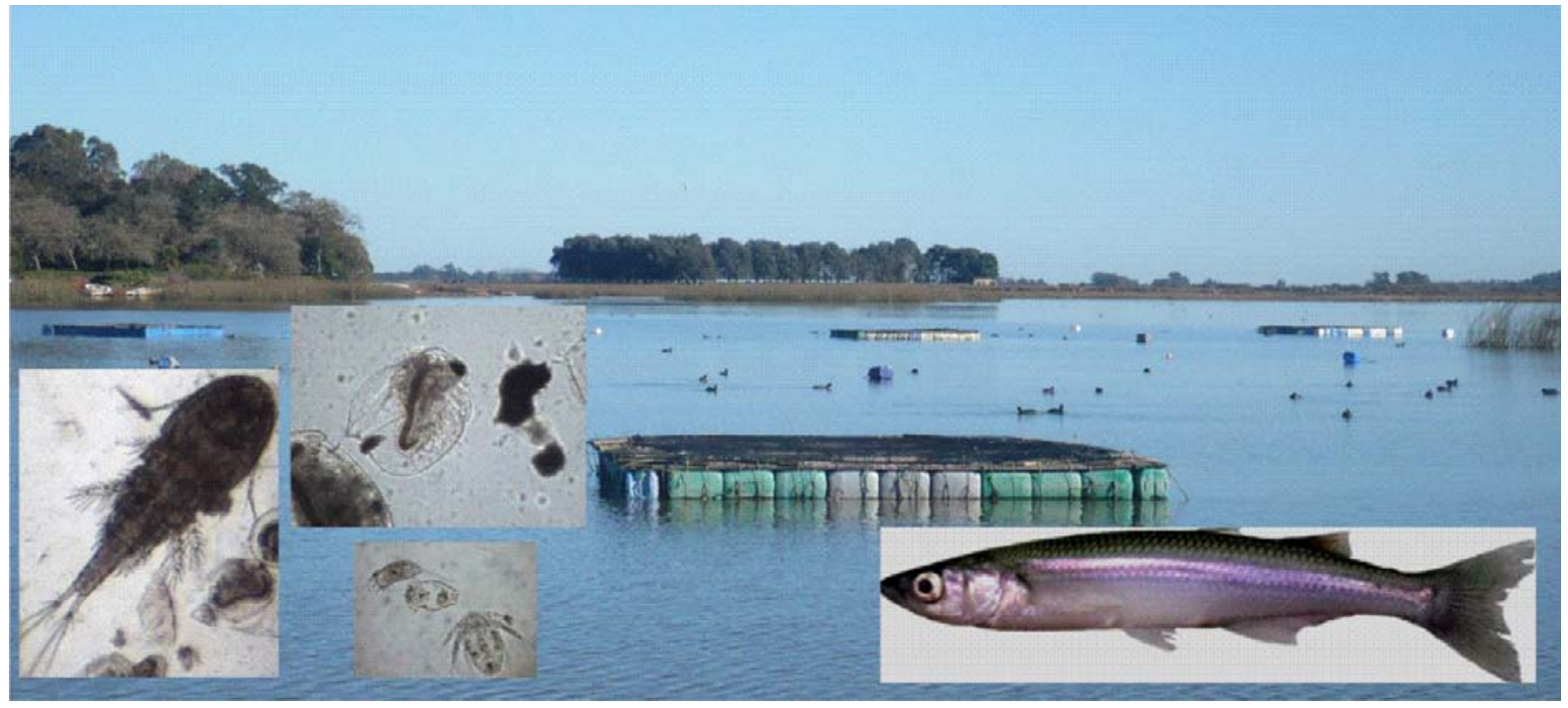




\section{Capítulo I: INTRODUCCIÓN GENERAL}

\subsection{Marco teórico y fundamentación}

\subsubsection{Interacciones tróficas}

Los organismos consumidores o depredadores afectan la distribución y abundancia de presas que consumen, mientras que a la inversa, la distribución y abundancia de las presas afectan a los consumidores, generándose así efectos que son de vital importancia en la ecología (Begon et al. 2006). Determinar cuáles son estos efectos, cómo y por qué varían, y estudiar la naturaleza de la depredación y de la influencia que ésta tiene en los propios depredadores y en sus presas, son tareas propias de la ecología trófica. En particular, entender cómo las interacciones tróficas afectan las distintas tramas tróficas en el ecosistema ha sido y es un tema central en la ecología (Paine 1980, Berlow et al. 2009), ya que resulta esencial conocer los métodos de regulación de las poblaciones para poder así entender la naturaleza y predecir su comportamiento (Hairston et al. 1960).

En el ecosistema acuático, dichas interacciones juegan un papel muy importante en la regulación de la composición específica y la abundancia de las comunidades de los diferentes niveles tróficos (Brook \& Dodson 1965, Kerfoot \& Sih 1987, Northcote 1988). Históricamente, la literatura limnológica toma en cuenta una controversia propia del estudio del ecosistema terrestre acerca de dos clases de regulaciones bajo las cuales se encuentran sometidas las poblaciones: el control desde arriba ("Top-down", control por depredación) y el control desde abajo ("Bottom-up", control por la disponibilidad de alimento) (Hairston et al. 1960, McQueen et al. 1986, Post \& McQueen 1987). El control por depredación influye sobre la estructura de las poblaciones y comunidades de presas generando cascadas tróficas donde también interviene la competencia entre presas o depredadores, acarreando cambios hacia arriba o hacia abajo de los niveles tróficos en los ecosistemas terrestres o acuáticos (Carpenter et al. 1985, González Sagrario 2004, Reissig 2005). Northcote (1988) realiza una revisión de los trabajos vinculados al rol de los peces en esta regulación ecosistémica, donde pone de manifiesto la importancia de los mismos en la regulación de la estructura y función de los ecosistemas acuáticos continentales. En el mismo trabajo identifica la selectividad alimentaria por tallas (y de otro tipo, por ejemplo por la pigmentación) como un factor de 
mucha influencia, con diferentes efectos dependiendo de la especie, la edad del pez o el mecanismo alimentario (planctívoros filtradores vs. visuales, por ejemplo).

En el Hemisferio Norte existen numerosos estudios acerca de los controles que regulan las cascadas tróficas en ambientes acuáticos (Hrbáček et al. 1961, Brooks \& Dodson 1965, Zaret 1972, Zaret \& Suffern 1976, Carpenter et al. 1985, Mc Queen et al. 1986, Carpenter \& Kitchell 1996, Brett \& Goldman 1996, Jeppesen 1998, Scheffer 1998, Cottenie 2002, Scheffer \& Carpenter 2003, Scheffer et al. 2003, Rejas et al. 2005, Borer et al. 2005, Palkovacs \& Post 2008 y otros). En Sudamérica la cantidad de trabajos es menor (Fabián \& Cruz-Pizarro 1997, Iglesias 2010, Mazzeo et al. 2010, Meerhoff et al. 2007 a y b) y en el caso de ambientes lénticos de la región Pampeana la información es todavía escasa, sobre todo teniendo en cuenta la cantidad de este tipo de ambientes que presenta el área (Quirós 1998a y 1998b, Quirós \& Boveri 1999, Renella \& Quirós 2002, González Sagrario \& Balseiro 2003 y Sosnosvky \& Quirós 2008).

En los lagos profundos se ha verificado que las cadenas tróficas en agua libre están controladas por la proporción de peces piscívoros respecto a los planctívoros (Drenner \& Hambright 2002). En los lagos someros, ante la escasa representatividad de peces piscívoros y la elevada abundancia de peces planctívoros y omnívoros, el control desde arriba es incluso más fuerte que en los lagos profundos, provocando una disminución en la tasa zooplancton/fitoplancton con una consecuente menor presión de pastoreo sobre las algas planctónicas (Jeppesen et al. 1997, 1998). Esta situación se observa también en lagos someros tropicales donde dominan los peces planctívoros y omnívoros ejerciendo un fuerte control de tipo "top-down", deprimiendo al zooplancton de gran talla e impidiendo una cascada trófica (Lazzaro 1997, van Leeuwen et al. 2007).

\subsubsection{El zooplancton y los peces planctívoros}

La comunidad zooplanctónica se encuentra controlada en su crecimiento por varios factores, entre ellos: la temperatura, el alimento y la depredación. Gilloly \& Dodson (2000) demostraron que el tamaño medio de los cladóceros disminuye desde los ambientes templado-fríos hacia los tropicales, tanto en el hemisferio Norte como en el Sur, y han notado que dicha correlación del tamaño del cuerpo con la temperatura del agua podría estar reflejando sus efectos tanto directos como indirectos. Por otro lado, también es 
ampliamente aceptado el hecho de que la depredación por parte de invertebrados y vertebrados juega un papel crítico en la determinación de la estructura de la comunidad zooplanctónica en cuerpos de aguas continentales (Zaret 1980, Drener \& Kettle 1982, Lazzaro 1987, Gliwicz \& Pijanowska 1989, Stein et al. 1995, Renella \& Quirós 2002, Balseiro et al. 2007). Recientemente diversos autores han argumentado que es la depredación por peces la responsable de la reducción de la talla promedio observada en la comunidad zooplanctónica hacia los trópicos (Sarma et al. 2005, Jones \& Jeppesen 2007, Meerhoff et al. 2007a, Havens et al. 2009, Havens \& Beaver 2010, Lacerot 2010, Sosnovsky et al. 2010, Iglesias 2010). Según Northcote (1988), las personas que practicaban el cultivo de peces en estanques en China y Europa hace siglos atrás ya habían reconocido la existencia de efectos generados por la depredación por peces sobre la comunidad zooplanctónica. A su vez, el mismo autor menciona que fue Steuer (1910) el primero en registrar que las producciones de zooplancton en cavas de cría de peces se ven modificadas no solo por cambios estacionales y climáticos sino también por la densidad de "stock" de los peces.

La mayoría de los peces atraviesa al menos un estadío planctívoro durante su desarrollo ontogenético (Lazzaro 1987) y muchos se alimentan principalmente de zooplancton también cuando son adultos (Matthews 1998), pudiendo ser planctívoros obligados o bien facultativos (Lazzaro 1987).

Los efectos de la planctivoría realizada por los peces sobre la composición zooplanctónica han sido discutidos desde los trabajos de Hrbáček et al. (1961) y Brooks \& Dodson (1965) y, aunque no han sido completamente dilucidados (Fukushima et al. 1999), se argumenta que podrían producirse cambios estructurales en la comunidad zooplanctónica debido al carácter selectivo de la depredación (Dodson 1970, Wells 1970, Zaret \& Kerfoot 1975, Eggers 1977, Renella \& Quirós 2002). El análisis de estos efectos condujo al planteo de la "Hipótesis de eficiencia por tamaños" (SEH de sus siglas en inglés: "Size Efficiency Hypothesis") (Hrbáček, 1958; Brooks \& Dodson 1965), la cual vincula los cambios en la composición y tamaño medio de los componentes del zooplancton con la presión de depredación. De acuerdo a la SEH el tamaño de los zooplanctontes tiende a ser máximo cuando la densidad de sus depredadores vertebrados es baja, y si la densidad de los depredadores vertebrados aumenta, el tamaño medio del zooplancton disminuye (Figura I.1). Los efectos "top-down" no solo se ven reflejados en las tallas o biomasa de los niveles tróficos inferiores sino que también inciden en la composición de especies, la distribución de 
las frecuencias de tallas, las formas predominantes, la movilidad y la pigmentación (Brooks \& Dodson 1965).

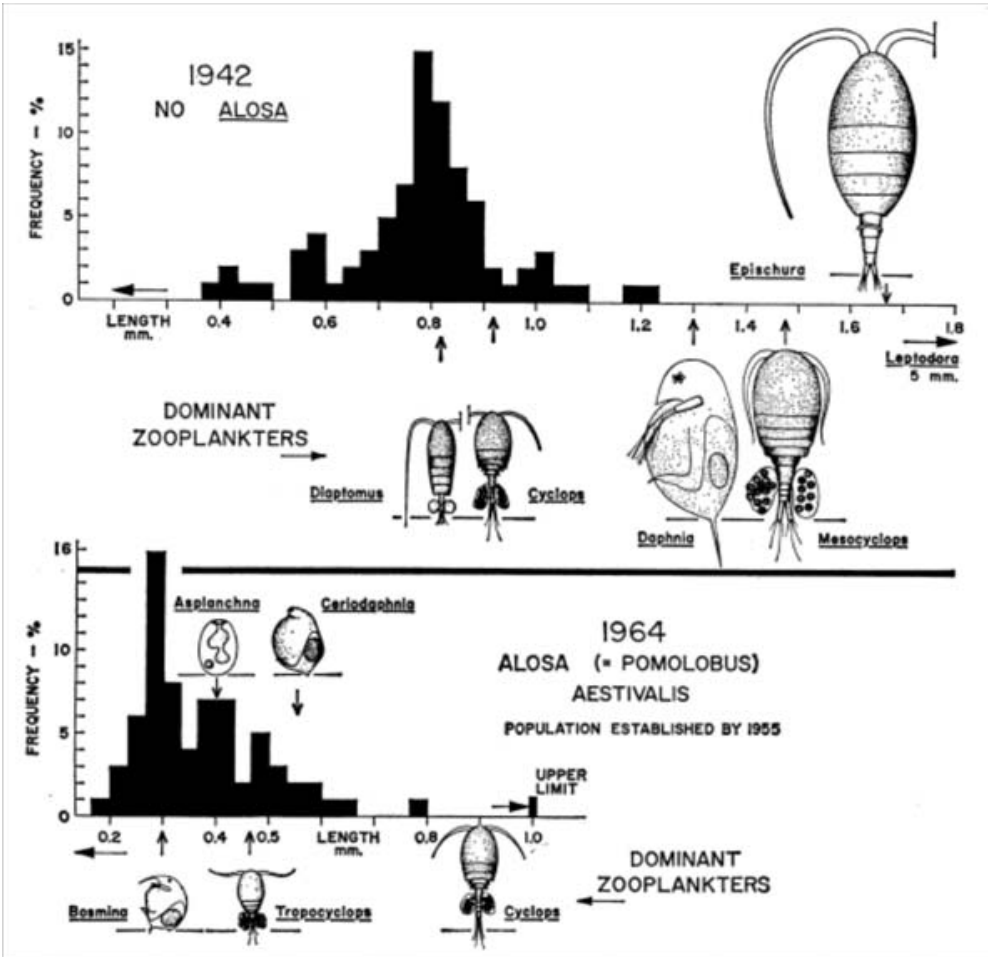

Figura 1.1: Composición de crustáceos zooplanctónicos del lago Crystal antes y después del establecimiento de un pez zooplanctívoro (Alosa aestivalis). Ejemplo tomado de Brooks \& Dodson (1965) como representación de la hipótesis de eficiencia por tamaños (SEH).

Zagarese (1989) por su parte, a través de experiencias de cría donde las larvas de pejerrey Odontesthes bonariensis (Valenciennes, 1835) no consumieron los ítems zooplanctónicos de mayor tamaño, concluye que la SEH no es aplicable a las larvas de esta especie y que la depredación selectiva ejercida por los peces no es una condición necesaria para que se reduzca la talla del zooplancton. Por otro lado Boveri \& Quirós (2002) han evaluado la relación pejerrey-zooplancton en experimentos en mesocosmos y han determinado que el pejerrey selecciona los cladóceros grandes para su consumo, lo cual es típico de planctívoros visuales (Hurlbert \& Mulla 1981) y consistente con la hipótesis SEH. También Renella (2007) encuentra en las interacciones entre el pejerrey y el zooplancton algunos puntos consistentes con las predicciones de la $\mathrm{SEH}$, como la relación entre la abundancia del pez y la estructura de tallas de los cladóceros, pero identifica otros que se alejan de la hipótesis, como parecería ser la falta de efectos del pejerrey sobre los copépodos Cyclopoida. 


\subsubsection{El zooplancton de ecosistemas acuáticos pampeanos}

El zooplancton de las lagunas pampásicas (lagos someros ubicados en la región Pampeana de la Argentina que serán descriptos en el capítulo II: "Área de estudio") de la Provincia de Buenos Aires ha sido estudiado desde mediados del siglo pasado (Olivier 1961, Ringuelet et al. 1962). Dichos estudios relacionan las principales asociaciones de especies con las características de la mineralización del agua. En las últimas décadas se realizaron contribuciones para la laguna de Lobos (Boltovskoy et al. 1990), San Miguel (Partido de Castelli) (Gabellone et al. 2001, Solari et al. 2002), San Miguel del Monte (Benítez \& Claps 2000, Claps et al. 2002), Laguna de Los Padres (González Sagrario et al. 2009), Lacombe (Ardohain 2008, Colautti et al. 2010) y Chascomús (Diovisalvi et al. 2010), los cuales pusieron énfasis en la importancia de los rotíferos y los estadíos larvales de copépodos (larvas nauplii) por su contribución a la densidad zooplanctónica, afirmando que suelen ser los grupos dominantes en una laguna "típica" de la llanura pampeana. Asimismo, en algunos de los trabajos realizados en la zona se han identificado especies ubicuas y otras típicas de ciertas salinidades, como es el caso del rotífero Brachionus plicatilis, especie que Olivier (1961) encuentra en los momentos de mayor salinidad en la laguna Vitel (1,84 g/l de residuo sólido) y en la laguna La Isla $(12,23 \mathrm{~g} / \mathrm{l})$, al igual que lo registrado por otros autores en la laguna San Miguel e incluso en el Río Salado (Gabellone et al. 2001, Ardohain 2008). Acerca de la biomasa zooplanctónica existe menos información, y los aportes en este aspecto se limitan a cinco cuerpos de agua (Renella \& Quirós 2006, Maizels et al. 2003, Claps et al. 2004, Ardohain 2008 y Colautti et al. 2010).

No obstante si se considera el gran número de lagunas que posee la provincia de Buenos Aires, resulta evidente que el conocimiento acerca de las comunidades zooplanctónicas de estos ambientes es todavía reducido, especialmente en lo referido a estudios que evalúen las modificaciones que pueden ocurrir en dicha comunidad provocadas por la depredación por peces.

Quirós (1991) sostiene que la biomasa del zooplancton en las lagunas pampeanas depende de la estructura de la comunidad de peces y que en muchas de ellas la abundancia del macrozooplancton manifiesta el impacto de la presión de depredación ejercida principalmente por el pejerrey. 


\subsubsection{El pejerrey (Odontesthes bonariensis)}

El pejerrey es un pez pelágico, típico de las lagunas pampásicas, que se alimenta principalmente de zooplancton (Ringuelet 1942, Destefanis \& Freyre 1972, Ringuelet et al. 1980, Freyre et al. 2009). Se encuentra entre las especies nativas más estudiadas, tanto en aspectos relacionados a su biología como a su cultivo (Colautti \& Remes Lenicov 2000, Grosman et al. 2001, Freyre et al. 2003, Sendra 2003, Barros et al. 2004, Berasain et al. 2006, Miranda et al. 2006, Freyre et al. 2009, Mancini et al. 2009, Colautti et al. 2009a, Colautti et al. 2010, entre otros). Es un recurso natural renovable, considerado comercial y deportivamente el pez más importante que habita las aguas continentales de la región Pampeana de la Argentina (Bonetto \& Castello 1985, Grosman 1995a, Reartes 1995, Somoza et al. 2008), y en estos términos uno de los más importantes también del país. Presenta en su ambiente natural dos períodos de reproducción en el año: uno en primavera, de mayor magnitud y comprendido entre Septiembre y Noviembre, y otro en otoño, de menor duración e intensidad. Según las condiciones regionales y la temperatura media, el desove puede adelantarse o retrasarse (Ringuelet et al. 1967, Calvo \& Morriconi 1972, Iwaszkiw \& Freyre 1980, Grosman 1995a).

La relación existente entre la biología del pejerrey en la naturaleza y la comunidad zooplanctónica ha sido documentada por Colautti et al. (2003), Freyre et al. (2009) y Baigún et al. (2009). Su dieta ha sido estudiada mediante análisis de contenidos digestivos en diversas lagunas (Ringuelet 1942, Destefanis \& Freyre 1972, Ringuelet et al. 1980, Escalante 1985, Aquino 1991, Grosman 1995b, Colautti \& Remes Lenicov 2000, Sagretti \& Bistoni 2001, Grosman \& Sanzano 2003, entre otros) y en estudios en mesocosmos (Zagarese 1991 y 1996, Boveri \& Quirós 2002), pero no ha sido analizada de manera sistemática y ordenada en cuanto a las variaciones que ocurren desde el comienzo de la alimentación exógena hasta un estadío juvenil avanzado.

Las tasas de crecimiento y supervivencia en peces son altamente dependientes de la disponibilidad de alimento (Houde 1987, Houde \& Zastrow 1993, Chick \& Van den Avyle 1999), y en el caso de los zooplanctófagos dicha disponibilidad resulta muy variable. Vinculado con esto, el crecimiento y la supervivencia de las larvas de peces están íntimamente relacionados a la superposición temporal y espacial con el zooplancton (hipótesis "match/mismatch", Cushing 1972 y 1990). Por ello, resulta esencial explorar las 
relaciones existentes entre la oferta alimentaria y dichos parámetros poblacionales a fin de poder predecir la producción de biomasa de peces, particularmente en el caso de los estadíos postlarvales (Zagarese 1996).

Vale aclarar en este punto que el término "postlarva" será utilizado en el presente manuscrito de acuerdo a su uso más común en la piscicultura, definido como el estadío de vida que se encuentra entre el comienzo de la alimentación exógena (aún aunque no se hayan agotado las reservas vitelinas) y el desarrollo de las aletas pectorales, pélvicas y anales (Zaniboni Filho 2000).

\subsubsection{La acuicultura}

La acuicultura (cultivo de organismos acuáticos) se lleva a cabo a través de la manipulación del ciclo de vida de un organismo y del control de las variables ambientales que tienen influencia sobre el mismo. Apunta a aumentar la producción del organismo, por ejemplo de peces, mediante el manipuleo de los factores de regulación poblacional, principalmente efectuando un control de la reproducción y del crecimiento y eliminando agentes de mortalidad natural (Beveridge 2004). Los sistemas de cría son diseñados con el objetivo de mantener a los organismos seguros mientras estos incrementan su biomasa, minimizando las pérdidas por depredación y enfermedad y excluyéndolos de competidores (Reay 1979).

Cavas excavadas e impermeabilizadas, que reciben agua de red, cumplen la doble función de proveer alimento natural y espacio para la cría de peces (Westers 2001). En ellas es posible obtener los valores deseados de abundancia zooplanctónica mediante el manejo de la fertilización previa al llenado (promoviendo el crecimiento de la comunidad algal sobre la cual pastorea el zooplancton) (Westers 2001). A su vez permitirían obtener una composición zooplanctónica deseada mediante el control de las características del agua (por ejemplo por la salinidad necesaria para el éxito de determinadas especies de rotíferos).

Entre los sistemas de cría de peces también se encuentran las jaulas, que se diferencian de otros por contar con todos sus límites confeccionados por el hombre (diferente de los sistemas que utilizan las costas naturales o el fondo natural de los ambientes como límite del cultivo). Dichas jaulas fueron utilizadas originalmente como 
instalaciones de almacenaje de peces, como un paso previo al proceso de venta (Beveridge $\&$ Little 2002), y constan de diversos tipos: fijas, flotantes, sumergibles y sumergidas.

El sistema de jaulas fue implementado de manera exitosa en la producción de muchas especies de peces en diferentes partes del mundo (Beveridge 2004). Ha sido implementada sobre todo en países de Asia (Masser \& Bridger 2007) y principalmente para salmónidos y tilapia (Oreochromis sp.) en Sudamérica (Rojas \& Wadsworth 2007).

El uso de este tipo de unidades también se extendió a otros usos como: el monitoreo de la calidad de agua (Chamberlain 1978), el tratamiento de los síntomas de eutrofización (Little \& Muir 1987, Costa-Pierce \& Effendi 1988, Costa-Pierce 2002), la conservación de especies, por ejemplo produciendo peces para las pesquerías artesanales con devolución, la experimentación, donde es importante excluir efectos ambientales (Kulikivsky et al. 1994), y la replicación de cavas experimentales (Struve \& Bayne 1991).

Según Beveridge (2004) el cultivo en jaulas puede ser clasificado en tres tipos de acuerdo a la alimentación:

Extensivo: Los peces dependen sólo del alimento natural disponible, como plancton y detritos.

Semi-intensivo: Involucra el uso de alimento bajo en proteínas $(<10 \%)$, usualmente compuesto por subproductos de la agricultura, como suplemento al ingreso de alimento natural.

Intensivo: Los peces dependen exclusivamente del suministro externo de alimento altamente proteico (>20\%), usualmente basado en harina de pescado.

El cultivo extensivo en jaulas flotantes, que aprovecha el alimento natural disponible en el medio, se restringe a las aguas continentales, siendo factible su implementación en dos tipos de ambientes: los altamente productivos (Rai 2000) y los que reciben descargas domésticas. En este sentido, los ambientes acuáticos tropicales con altas concentraciones de nutrientes son los que ofrecen las mejores oportunidades para el cultivo de tipo extensivo (Beveridge 2004). Este tipo de cultivo, cuando se realiza en cuerpos de agua productivos utilizando especies de peces que se alimentan en los "niveles bajos" de la cadena alimentaria, tiene el mayor potencial para una producción de peces a bajo costo (Little \& Muir 1987). Entre las aplicaciones también se encuentran sistemas donde se han instalado jaulas de 
cultivo extensivo dentro de sistemas intensivos, para aprovechar el alimento no consumido y el plancton excedente (Costa-Pierce 2002) y jaulas iluminadas con luz eléctrica para atraer zooplancton y maximizar los recursos disponibles en pos de masificar la producción (Mamczarz \& Nowak 1987).

\subsubsection{La cría de pejerrey}

El cultivo de pejerrey tuvo sus comienzos a principios del siglo veinte (López \& García 2001), y la técnica cobró un verdadero impulso con la instalación de la Estación Hidrobiológica de Chascomús (Provincia de Buenos Aires) en el año 1925 (Somoza et al. 2008). A su vez, recientemente se ha llegado a dar un cierre exitoso al ciclo de producción de la especie bajo el sistema de cultivo de tipo intensivo en tanques (Berasain et al. 2006, Miranda et al. 2006, Velasco et al. 2008). Sin embargo, el cultivo de pejerrey todavía no ha alcanzado una escala productiva, ya que se pueden obtener huevos y larvas de manera masiva, pero aún resulta complicada la producción de juveniles para la siembra, o de ejemplares de talla apta para el consumo humano. Los factores que pueden estar contribuyendo al estancamiento histórico de la acuicultura del pejerrey en la Argentina y otros países de Sudamérica han sido clasificados por Somoza et al. (2008) como aquellos relacionados a la biología de la especie, a los huecos en el conocimiento tecnológico y científico y aquellos de origen cultural o socio-económicos. A su vez, entre las restricciones que frenan el avance de la acuicultura en la Argentina se encuentran especialmente aquellas relacionadas a la escasa disponibilidad energética que puede existir en algunas zonas rurales del país, los altos costos de algunos insumos y la necesidad de contar con personal calificado y de instalaciones específicas para el desarrollo del cultivo intensivo en tanques.

El sistema de cría de pejerrey en jaulas flotantes se propuso como una metodología de cultivo con altas probabilidades de convertirse en una alternativa económicamente viable. Se han realizado diversos ensayos aplicando este método de cultivo, de modo extensivo, semi-intensivo e intensivo, en lagunas pampásicas, cuyas ventajas son útiles a la hora de superar algunas de las restricciones mencionadas. Entre los resultados obtenidos mediante la aplicación de métodos semi-intensivo e intensivo por Solimano (2013), se observa que si durante el periodo crítico para el crecimiento de los pejerreyes bajo condiciones extensivas 
se provee alimento balanceado, el pejerrey puede crecer por encima de los parámetros conocidos para la cría en jaulas sin provisión de alimento, aún a bajas temperaturas.

El hecho de que el pejerrey se alimente de zooplancton, y por ende se ubique en una posición intermedia en la trama alimenticia, hace que su cultivo extensivo en ambientes altamente productivos como las lagunas pampeanas de la Argentina (Quirós \& Drago 1999, Escalante 2001, Quirós et al. 2002a, Claps et al. 2004) sea una alternativa viable para sobrepasar las limitaciones relacionadas con la provisión de alimento apropiado y reducir los mayores costos de producción. Particularmente en el caso del pejerrey esta situación es crítica porque no existe una formulación específica de alimento artificial para maximizar las tasas de conversión y para criar los estadíos más tempranos de la especie sin proveer alimento vivo cultivado artificialmente. A su vez, el método posee otras ventajas como no demandar atención constante por parte del personal, no depender de suministros de energía artificial, y aprovechar los recursos ambientales de las lagunas pampásicas (Colautti et al. 2010).

En concordancia con estos conceptos, los resultados obtenidos en mesocosmos (Zagarese 1991 y 1996, Boveri 2007), en trabajos de campo (Colautti et al. 2003) y en experimentación en jaulas flotantes (Colautti \& Remes Lenicov 2000, Remes Lenicov \& Colautti 2005, Colautti et al. 2009a, Colautti et al. 2010), han demostrado que las tasas de crecimiento de pejerrey están directamente relacionadas con las características cualicuantitativas del zooplancton disponible. Además se ha llegado a demostrar que la técnica de cultivo extensivo en jaulas flotantes en lagunas permite obtener masivamente juveniles de pejerrey, aunque las producciones finales aún resultan impredecibles debido a la alta variabilidad asociada a factores ambientales y disponibilidad de zooplancton (Somoza et al. 2008, Colautti et al. 2010).

\subsubsection{Cavas y jaulas flotantes como unidades experimentales}

Teniendo en cuenta todo lo dicho, se puede observar que existe una carencia de trabajos que vinculen directamente el rendimiento de sistemas de cría extensivos (en cavas y lagunas) con las tasas de crecimiento y la producción de pejerrey, y que identifiquen y evalúen variables de influencia de dichos sistemas. 
Los ensayos en cavas, y aquellos realizados a campo utilizando jaulas flotantes, se convierten en una alternativa muy útil en base a una cierta similitud con lo que ocurre con la experimentación en mesocosmos, donde se permite un cierto grado de control y replicabilidad muy difíciles de obtener en el medio natural (Resetarits Jr. \& Fauth 1998).

El uso de cavas experimentales posibilita un seguimiento exhaustivo del desarrollo "natural" de la comunidad zooplanctónica (con el fin de identificar picos de abundancia y biomasa para la siembra de larvas), además de un control de la calidad del agua. Ambas características ubican al sistema cómo un intermedio entre un sistema netamente artificial y uno que imita las condiciones naturales de un ambiente somero pampeano.

Por otro lado el uso de jaulas en las lagunas pampásicas posibilita además efectuar estudios "in situ" acerca de la depredación del pejerrey sobre el zooplancton y el efecto de esta planctivoría sobre la estructura de dicha comunidad. Al mismo tiempo permite identificar y evaluar las variables que influyen sobre el éxito de la cría de esta especie en este tipo de sistemas. Entre dichas variables, las que emergen como claves sobre la producción de pejerrey, son aquellas que se vinculan directa o indirectamente con las características cualitativas y cuantitativas de la comunidad zooplanctónica: las características limnológicas del ambiente de cría, la estacionalidad climática de los ambientes, las épocas de desarrollo de los cultivos y las cualidades de cada ciclo de cría como ser la edad de los peces, su talla y su densidad de siembra.

Teniendo en cuenta lo dicho se propuso la realización de la presente tesis doctoral, la cual apunta a explorar mediante el uso de cavas experimentales y jaulas flotantes las relaciones existentes entre el pejerrey y la comunidad zooplanctónica. Dicha exploración fue realizada por primera vez en el presente trabajo de tesis. Además, se profundizó el estudio del desarrollo alimentario de la especie ictícola, y se buscó interpretar el vínculo que existe con su producción y con la estructura de la comunidad zooplanctónica de lagunas pampásicas. 


\subsection{Hipótesis de trabajo}

*El pejerrey efectúa un uso selectivo de los componentes del zooplancton generando cambios en la composición de dicha comunidad.

* Los cambios cíclicos estacionales de la comunidad zooplanctónica determinan cambios en la supervivencia y tasas de crecimiento de larvas y juveniles de pejerrey.

* A partir de cierto umbral de biomasa, la producción de pejerrey por unidad de cría depende en mayor grado de la composición cuali-cuantitativa de zooplancton que de la densidad poblacional de este pez.

\subsection{Objetivo general}

El objetivo general de la presente tesis es analizar de qué modo la oferta cualitativa y cuantitativa de zooplancton en lagunas de la provincia de Buenos Aires condiciona el crecimiento y la producción de pejerrey (O. bonariensis), y de qué manera la depredación por parte de dicha especie modifica la estructura y dinámica de la comunidad zooplanctónica a lo largo del ciclo anual.

\subsubsection{Objetivos específicos:}

I. Conocer las características cualitativas y cuantitativas del zooplancton de cavas experimentales con el fin de identificar picos de abundancia necesarios para la siembra exitosa de larvas de pejerrey.

II. Evaluar la relación entre el zooplancton de cavas experimentales, en términos cualitativos y cuantitativos, y la cría de postlarvas de pejerrey.

III. Conocer la composición, densidad y biomasa del zooplancton en tres lagunas y las variaciones que sufren en el ciclo anual, y en diferentes años.

IV. Efectuar un análisis cuali-cuantitativo de la fracción zooplanctónica dentro de unidades de cultivo (jaulas flotantes) sembradas con diferentes densidades de pejerrey. 
V. Caracterizar la dieta de ejemplares de pejerrey que integren los experimentos (cavas y jaulas) y la población silvestre de los cuerpos de agua seleccionados.

VI. Establecer relaciones entre la disponibilidad alimentaria natural y la composición cualicuantitativa de los contenidos digestivos de los peces cautivos y libres.

VII. Determinar los cambios que pueden generar las diferentes intensidades de depredación en la estructura y dinámica del zooplancton.

VIII. Estimar cómo la disponibilidad en número y composición del zooplancton influye sobre el crecimiento, supervivencia y producción del pejerrey, bajo diferentes condiciones de cultivo.

IX. Sobre la base de los conocimientos generados establecer criterios para mejorar el manejo del cultivo del pejerrey en jaulas flotantes instaladas en lagunas pampásicas. 


\section{II}

ÁREA DE ESTUDIO

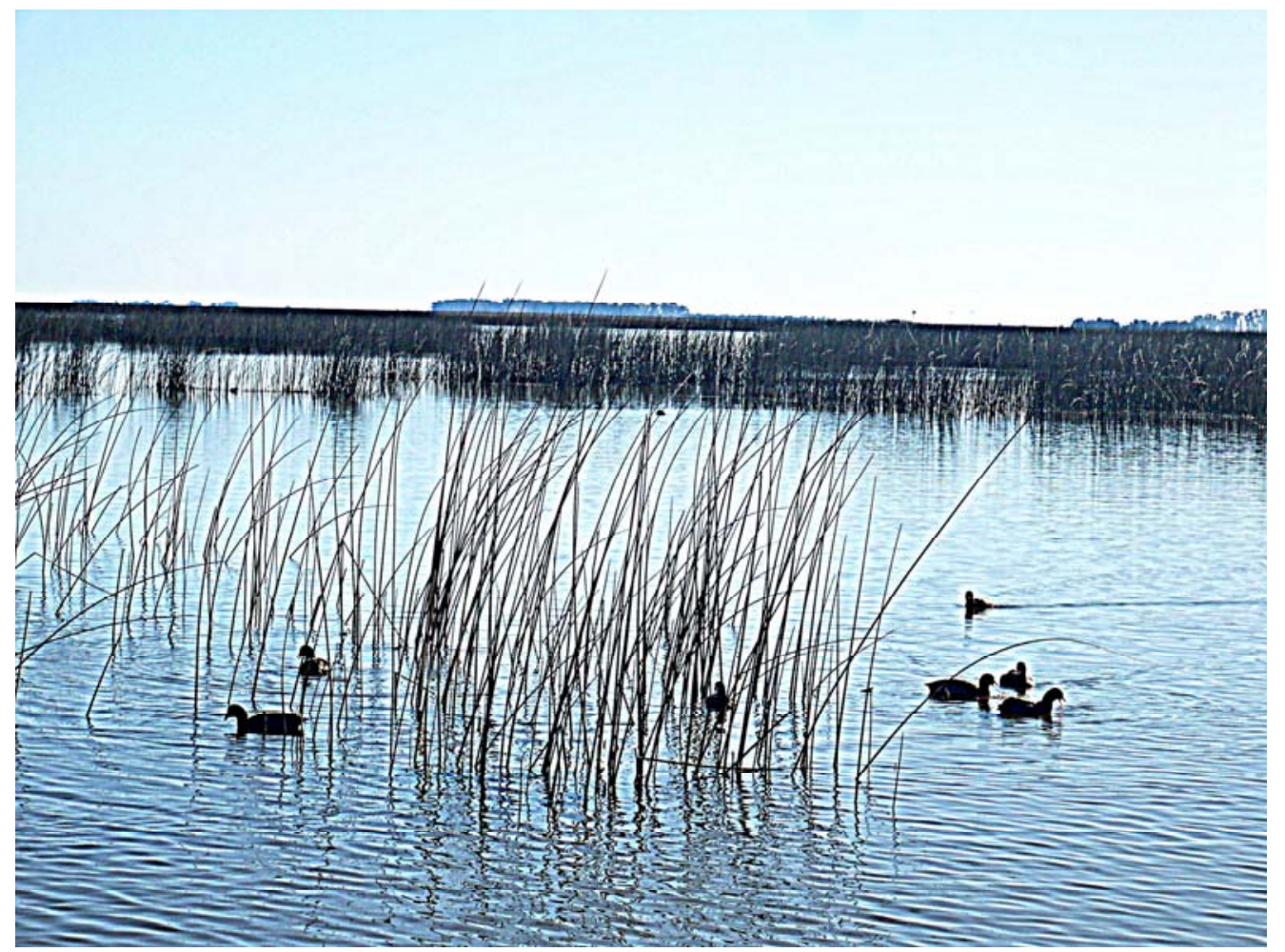




\section{Capítulo II: ÁREA DE ESTUDIO}

\subsection{Las lagunas pampásicas}

Durante el desarrollo de la presente tesis se realizaron trabajos experimentales y de campo en cavas ubicadas en las instalaciones del IIB-INTECH (Chascomús, Buenos Aires) (serán descriptas en el capítulo III) y en tres ambientes lénticos pertenecientes a la cuenca del Río Salado, situados en la región conocida como "Pampeana" (Cabrera 1971) del territorio argentino, en la provincia de Buenos Aires (Figura II.1, al final del presente capítulo).

El pastizal pampeano constituye una de las ecoregiones más extensas de la porción templada de América del Sur. Abarca el Centro-Este de la República Argentina $\left(33^{\circ}-39^{\circ} \mathrm{S}\right.$, $57^{\circ}-66^{\circ}$ O) y cubre una superficie de aproximadamente $500.000 \mathrm{~km}^{2}$. Esta región está constituida por áreas completamente planas que alternan con suaves lomadas cubiertas por pastizales, y donde los relieves montañosos constituyen una porción muy pequeña (Soriano 1992). Posee muy poca pendiente $(0,05 \%$ en promedio) y se caracteriza por la ausencia de accidentes geográficos de importancia (Frenguelli 1950, Dangavs 1976, Dangavs et al. 1996). El clima, según la clasificación de Köppen-Geiger, es templado húmedo (Kottek et al. 2006), y la temperatura media anual varía entre los $17{ }^{\circ} \mathrm{C}$ en el Norte y los $14{ }^{\circ} \mathrm{C}$ en el Sur. La precipitación promedio del área es de unos 800 mm/año (Quirós \& Drago 1999) y gran parte de la planicie presenta drenaje endorreico o arreico (Hall et al. 1992). En relación con esto, una de las características más relevantes de la región es la alternancia entre períodos de sequía o déficit de agua y períodos de exceso de agua o inundación (Vervoorst 1967). Esto último combinado con la geomorfología de la región permite que en las zonas más deprimidas de la planicie se desarrolle un importante sistema de humedales y lagos someros, denominados "lagunas" (Iriondo 1989), que reciben el nombre de "lagunas pampeanas o pampásicas". Muchas de estas lagunas tienen origen en procesos de deflación eólica ocurridos durante el cuaternario (Tricart 1973), pero un número importante ha sido posiblemente remodelado por la acción fluvial. A su vez, existe una variabilidad interanual en las precipitaciones que puede ser significativa, y por lo tanto puede afectar fuertemente el ciclo hidrológico de las lagunas (Diovisalvi et al. 2010, 2014). 
En general, los lagos someros son ambientes que suelen estar en permanente mezcla por efecto del viento, el cual puede ser amortiguado según la cobertura y el tipo de vegetación presente en el cuerpo de agua (Ardohain 2008, Diovisalvi 2013). El hecho de que presenten escasa profundidad, y por ende mucho contacto entre el sedimento y la columna de agua, lo convierte en ambientes donde el reciclado de nutrientes es rápido y la productividad es elevada (Jeppesen et al. 1997).

La mayoría de las lagunas pampeanas son poco profundas y no se estratifican térmicamente, excepto por lapsos muy cortos (Quirós et al. 2002b). El estrecho contacto entre el sedimento y el agua sumado al aporte de grandes cargas de nutrientes proveniente los suelos que las rodean (Morrás 1999), hace que la mayoría de las lagunas pampeanas sean altamente productivas y comúnmente eutróficas (Quirós \& Drago 1999, Escalante 2001, Quirós et al. 2002b, Claps et al. 2004). Por otra parte, estos ambientes experimentan profundos cambios en la superficie, profundidad y salinidad de sus aguas en función de los ciclos de sequía e inundación característicos del paisaje pampeano (Quirós et al. 2002b).

De acuerdo con la teoría de estados de "equilibrio" alternativos (Scheffer et al. 1993), cuando la disponibilidad de nutrientes es relativamente baja, las lagunas tienden a estabilizarse en un estado de aguas claras, sin embargo, a medida que la carga de nutrientes aumenta, las lagunas se estabilizan en un estado de aguas turbias. En base a las crónicas de viajeros desde fines de los siglos XVIII y XIX (Vervoorst 1967), se ha sugerido que las lagunas pampeanas se encontraban originalmente en un estado de aguas claras con abundante desarrollo de vegetación, escasa biomasa fitoplanctónica y elevada abundancia de peces piscívoros (Quirós 1995, Quirós et al. 2002a). A partir de entonces, dichas lagunas habrían experimentado un proceso de eutrofización creciente (Quirós \& Drago 1999) lo que determinó que hoy en día, la mayoría se presente en un estado turbio, con gran desarrollo de la comunidad fitoplanctónica, escaso desarrollo de las macrófitas acuáticas y elevada abundancia de peces planctívoros, visuales en el caso de las lagunas "turbias" y filtradores en un subconjunto de "altamente turbias" (Quirós et al. 2002a).

Al aporte natural de nutrientes debe sumarse la acción antrópica que en épocas recientes ha incrementando sustancialmente sus cargas (Quirós et al. 2002b). A lo largo de los últimos cuatro siglos, la región ha sido utilizada para pastoreo del ganado, y durante el siglo XX la agricultura ha incrementado significativamente su actividad en la región (Vervoorst 1967, Soriano 1992). A esta situación se le suma un aumento en las descargas 
urbanas e industriales, y también el emplazamiento de estructuras de control de inundaciones, tales como canales, compuertas y empalizadas (Chornomaz et al. 2002, Quirós et al. 2002a, Maizels et al. 2003). En este sentido, la fragmentación del paisaje pampeano es una de las consecuencias más evidentes de la acción antrópica (Ghersa et al. 2002).

\subsection{Las lagunas de la cuenca del Río Salado}

Ubicado en la llamada "pampa deprimida" (Frenguelli 1950), en el noreste de la provincia de Buenos Aires, se encuentra un sistema de humedales interconectados que lleva el nombre de lagunas Encadenadas del Río Salado (Figura II.2, al final de este capítulo) cuya cuenca cubre un área de $801 \mathrm{~km}^{2}$ (Dangavs et al. 1996). Este sistema incluye siete lagunas vinculadas por arroyos de escasa longitud (Fernández Cirelli \& Miretzky 2002) que finalmente desaguan en el Río Salado. Entre estas lagunas se encuentra la laguna de Chascomús ( $35^{\circ} 36^{\prime}$ $\mathrm{S}, 58^{\circ} 02^{\prime} \mathrm{O}$ ), uno de los ambientes que forma parte del área de estudio de la presente tesis (Figura II.3, al final de este capítulo).

A su vez, en este sector de la provincia de Buenos Aires, delimitado entre el frente dunar que coincide aproximadamente con la Ruta Nacional $N^{\circ} 2$ y el cordón de conchillas costero, desde el partido de Chascomús hasta el de General Madariaga, existen numerosos cuerpos de agua someros ubicados en cuencas de deflación (Frenguelli, 1950). Algunos de estos ambientes tienen características arreicas y un grado variable de permanencia del agua de acuerdo al desarrollo de sus cuencas y al ciclo hidrológico. Entre estas lagunas se encuentran Lacombe ( $35^{\circ} 55^{\prime} \mathrm{S}, 5^{\circ} 65^{\prime} \mathrm{O}$ ) y La Salada de Monasterio ( $35^{\circ} 47^{\prime} \mathrm{S}, 57^{\circ} 52^{\prime} \mathrm{O}$ ), los otros dos ambientes que son parte del área de estudio (Figura II.2, al final de este capítulo).

\subsubsection{Chascomús}

La laguna Chascomús (Figura II.3) tiene un área de 3000 ha y una profundidad media de $1,53 \mathrm{~m}$ (Dangavs 1976). Es un sistema somero alcalino con altas concentraciones de material particulado en suspensión y baja transparencia (0,19 m disco de Secchi promedio) (Romero \& Conzonno 1997).

Debido a la morfología de la cubeta, la laguna desborda anegando los terrenos circundantes cuando el espejo de agua excede la cota IGM de 8 m s.n.m., momento en el cual 
la laguna tiene una profundidad media aproximada de 3,3 m (Diovisalvi et al. 2010). En base a los registros históricos recientes publicados en Diovisalvi et al. 2010, se sabe que a partir de 1900 Chascomús se secó completamente en 1910, y que experimentó notables descensos de nivel en los años 1916, 1924, 1929/30, 1937, 1944, 1957, 1962, 1970, 1973, 1978, 1996 у 2006/2007 (Figura 3B). Por otra parte, la misma desbordó la mayoría de sus barrancas produciendo importantes anegamientos en los años 1900, 1914, 1940, 1958, 1963, 1978, 1980, 1985, 1993, 2001 y 2002.

Las elevadas cargas de nutrientes, la morfometría de la cubeta, la exposición al viento y la variación estacional del flujo de energía solar son elementos claves que condicionan y modulan el funcionamiento y metabolismo global de la laguna (Diovisalvi et al. 2010). Las concentraciones de nutrientes, que se encuentran entre las más altas reportadas para ambientes acuáticos continentales (Reynolds 2006, Llames et al. 2009), y la escasa profundidad determinan condiciones eutróficas. Con excepción de ocasionales períodos de estratificación, cuya duración no supera unas pocas horas por día, la laguna Chascomús se encuentra en permanente mezcla (Diovisalvi et al. 2010). En la actualidad la vegetación acuática ocupa sólo áreas marginales del cuerpo de agua y está representada casi exclusivamente por juncales de la especie Scirpus californicus.

En cuanto a la microflora y microfauna, la laguna Chascomús durante los años 2005 y 2006, presentó valores de producción primaria fitoplanctónica que se encuentran entre los más altos reportados en la bibliografía (2835 g C/m²/año) (Torremorell et al. 2008). Las diatomeas y las clorofitas fueron las representantes dominantes de dicha comunidad en noviembre de 2005, con especies como Synedra berolinensis, algunas especies de Monoraphidium y Scenedesmus y formas agregadas de cianobacterias como varias especies de Aphanocapsa y Merismopedia (Allende et al. 2009). Para el año 2010 la composición fitoplanctónica estuvo dominada por cianobacterias, clorofitas y diatomeas: las especies más conspicuas fueron Aphanocapsa delicatissima, acompañadas por otras cianobacterias filamentosas como Planktolyngbya contorta y P. limnetica, pequeñas chlorococcales (e.g., Monoraphidium spp. y Scendesmus spp.) y la diatomea Synedra berolinensis (Diovisalvi et al. 2010)

Una gran biomasa de autótrofos de $83,5 \mathrm{mg} \mathrm{C/l}$ se encuentra manteniendo tasas de producción primaria fitoplanctónica altas, es decir, el 75\% del carbono total (110,9 mg C/l) en la columna de agua (Diovisalvi et al. 2010). Para mantener una biomasa de autótrofos alta 
durante todo el año es necesario que el zooplancton herbívoro nunca consiga desarrollar poblaciones importantes que pudieran controlar al fitoplancton, y efectivamente el conjunto de bacterias, flagelados, ciliados, rotíferos y crustáceos constituyen en promedio $2,2 \mathrm{mg} \mathrm{C/L}$, lo que equivale al $2 \%$ del carbono en la columna de agua (Diovisalvi et al. 2010). Además de la baja proporción de la biomasa representada por los heterótrofos, su composición se caracteriza por la ausencia de filtradores eficientes (dáfnidos y otros cladóceros de gran tamaño) (Maizels et al. 2003).

Según Diovisalvi et al. (2010) el zooplancton de Chascomús estuvo dominado en ese momento por rotíferos (Brachionus caudatus, K. tropica, B. havanaensis, Pompholyx sp. y K. americana) y por el copépodo ciclopoideo depredador, Acanthocyclops robustus. Los copépodos calanoideos representados por Notodiaptomus incompositus y los cladóceros (Bosmina longirostris) fueron mucho menos abundantes. Sin dudas la comunidad de peces desempeña un papel muy importante en el control del zooplancton herbívoro, particularmente impidiendo que se desarrollen poblaciones de cladóceros de mayor tamaño (Hrbáček 1962, Brooks \& Dodson 1965).

En lo que respecta al pejerrey, en la década de 1960 era la especie dominante de la laguna de Chascomús representando el $60 \%$ de la biomasa total de peces estimada como CPUEp (captura por unidad de esfuerzo pesquero) (Alaimo \& Freyre 1969). Sin embargo, a partir de entonces, su biomasa ha disminuido notablemente. En la década del 1980, Maroñas (1984) advirtió sobre un cambio global en el funcionamiento del sistema, tendencia que se mantuvo hasta el año 2000, cuando el pejerrey sólo representaba el $10 \%$ de la biomasa ictícola (Berasain et al. 2005). Esta disminución no se debió tanto a la merma de abundancia, sino a una notable disminución del tamaño individual, lo que determinó que la calidad pesquera resulte muy pobre. La disminución de la biomasa de pejerrey ha sido compensada por un aumento de otras especies, pero sin interés comercial o deportivo, tales como el porteño o bagarito ( $P$. valenciennis) y el sabalito (Cyphocharax voga).

Por otra parte, la laguna Chascomús es un cuerpo de agua intensamente utilizado con fines recreativos y comerciales. Se practica la pesca comercial limitada desde el año 1976 y es foco de atención de pescadores deportivos y turistas que practican deportes acuáticos. Gran parte de la costa está amurallada y sobre la costa este de la laguna se ubica la ciudad de Chascomús con una población de 30.277 habitantes (INDEC 2010), ciudad que descarga los pluviales en la laguna. 


\subsubsection{Lacombe}

La laguna Lacombe (Figura II.4) presenta una superficie aproximada de 130 ha, una longitud máxima de $1.750 \mathrm{~m}$ (sentido N-S), un ancho máximo de $1.500 \mathrm{~m}$ y su perímetro es de $5,6 \mathrm{~km}$ (Ardohain 2008). Se trata de una laguna somera, con una profundidad media de 1,07 m (Toresani et al. 1994, Drago 2004), de características arreicas con una zona litoral de barrancas bajas y que suele presentar gran desarrollo de macrófitas tanto emergentes como sumergidas, entre las que se destacan Scirpus californicus, Stukenia pectinatus y Myriophyllum quitense (Ardohain 2008). Las primeras forman un juncal que se ubica principalmente en el área central del cuerpo de agua. Hidrológicamente es un cuerpo de agua que depende de la escorrentía superficial o de los aportes del agua sub-superficial y la proveniente de la elevación del nivel freático. Las condiciones en esta laguna están determinadas no sólo por el tipo de aporte de agua sino también por las características de los suelos circundantes y de sus propios sedimentos (Ardohain 2008).

En cuanto al fitoplancton, Casco et al. (2009) registraron, durante el ciclo anual comprendido entre julio de 2001 y junio de 2002, un período turbio dominado por Planktolyngbya limnetica, seguida de Aphanocapsa delicatissima y de dos especies de Oocystella (O. parva y O. nephrocytoides) y un período de aguas claras con desarrollo de macrófitas sumergidas, con dominancia de Microcystis aeruginosa seguida de Cyclotella meneghiniana y Aphanocapsa holsatica y un período de aguas claras con escasa vegetación sumergida, en el cual Raphidiopsis mediterranea y Coelosphaerium naegelianum fueron las dominantes. Según Allende et al. (2009), en 2005, la comunidad fitoplanctónica presente en esta laguna estuvo dominada por clorofitas (Oocystis nephrocystoides) seguidas por cianobacterias coloniales (Aphanocapsa delicatissima).

En el caso del zooplancton, en los años 2001 y 2002, Ardohain (2008) encontró que dicha comunidad estuvo dominada por rotíferos y larvas nauplii de copépodos Cyclopoida y Calanoida, con picos de abundancia zooplanctónica total en primavera y otoño. Las especies de rotíferos dominantes fueron Pompholyx sulcata, Brachionus havanaensis y Keratella lenzi. Unos años después, en 2006, la comunidad también tuvo un pico de abundancia en primavera y los microcrustáceos dominantes fueron las larvas nauplii de copépodos (Colautti et al. 2010). 
Drago (2004) determinó la composición ictícola de la laguna entre los años 1996 y 1998, con las siguientes especies: O. bonariensis, Hoplias malabaricus, Rhamdia quelen, Oligosarcus jenynsii, Cichlasoma facetum, Cnesterodon decemmaculatus, Jenynsia lineata, Synbranchus marmoratus, Pimelodella laticeps, Bryconamericus iheringi, Gymnogeophagus australis, Corydoras paleatus y Astyanax sp.

La pesca constituye la mayor atracción y el principal uso de la laguna siendo el pejerrey el objeto de la misma durante los meses fríos y la tararira ( $H$. malabaricus) durante los meses cálidos (Ardohain 2008, Drago 2004), aunque la abundancia de esta última se vio muy diezmada durante gran parte de la presente tesis, debido a grandes mortandades por frío, sobre todo en el invierno de 2007. En cuanto al uso de la tierra la laguna Lacombe se encuentra rodeada parcialmente por campos con actividad agrícola-ganadera.

\subsubsection{La Salada de Monasterio}

Se trata de una laguna poco estudiada, perteneciente también al grupo de lagunas arreicas de la cuenca del Salado, que cuenta con aproximadamente 600 ha de superficie, $3.400 \mathrm{~m}$ de longitud máxima, $1.900 \mathrm{~m}$ de ancho máximo y un perímetro de aproximadamente 9,2 km (Figura II.5).

Su superficie está cubierta por abundantes parches de macrófitas emergentes ( $S$. californicus, encontrándose en menor medida Typha latifolia) (Figura II.5 B), macrófitas sumergidas (Stukenia striata, Myriophyllum quitense y Ceratophyllum demersum) (Berasain \& Colautti 1999).

La comunidad fitoplanctónica es similar a la presente en Lacombe, dominada por clorofitas (Oocystis lacustris) seguidas de cianobacterias coloniales (Aphanocapsa delicatissima), según Allende et al. (2009). La comunidad zooplanctónica de esta laguna no había sido estudiada en detalle hasta este momento. Sin embargo su abundancia por litro discriminada por grandes grupos y su llamado "valor calórico" fueron registrados en un informe técnico de la Subsecretaría de Pesca y Recursos Naturales de la Provincia de Buenos Aires (Berasain \& Colautti 1999). Dichos autores observaron diferencias en la abundancia por litro en dos años diferentes, siendo dominantes los rotíferos (1260 ind./l) y cladóceros (130 ind./I) en el año 1997 y las larvas nauplii (350 ind./I) y los copépodos Cyclopoida (100 ind./l) en el año 1999. En dicho informe se observó que las especies ícticas capturadas en redes de 
enmalle estuvieron representadas por un $71,8 \%$ de dientudos (O. jenynsii), $14,66 \%$ de sabalitos (C. voga) y 10,53 de pejerrey (O. bonariensis).

Se trata de un ambiente con bajo impacto antropogénico, con moderada actividad agrícola-ganadera en campos linderos. La pesca deportiva es el principal uso de la laguna siendo el pejerrey (O. bonariensis) el objeto principal de la misma, sobre todo durante los meses fríos. Por su parte, la tararira (H. malabaricus) también fue un importante objetivo de la pesca deportiva hasta su casi desaparición del ambiente durante los meses fríos del año 2007.
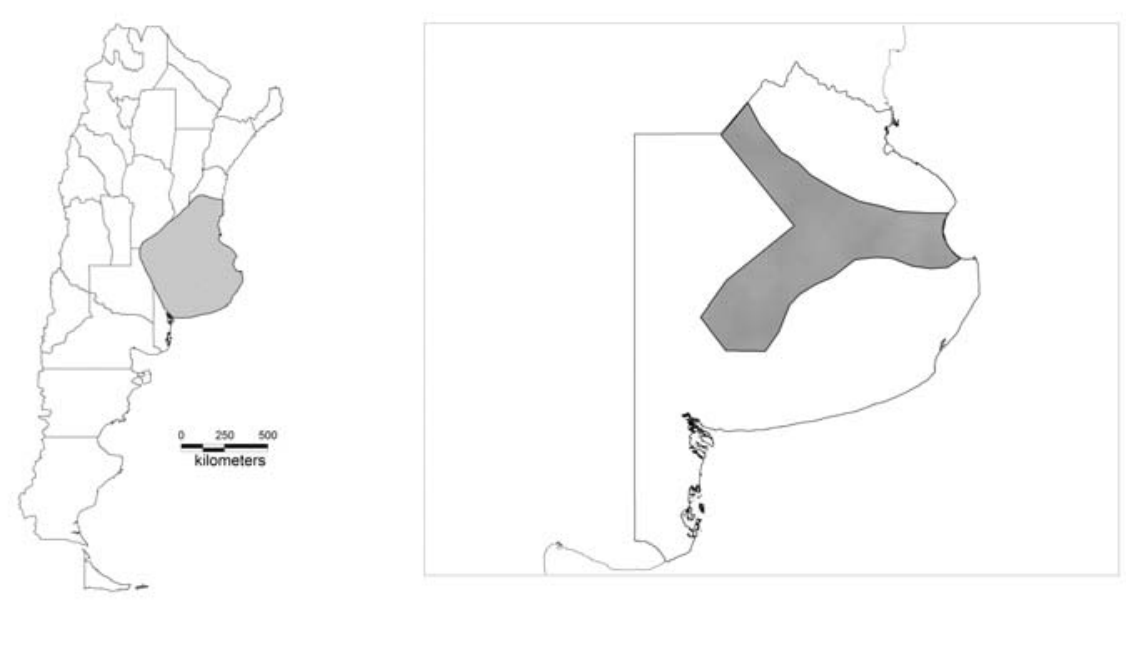

Figura II.1: Mapa de la República Argentina dónde se indica la región Pampeana y detalle de la provincia de Buenos Aires indicando la cuenca del Río Salado. 


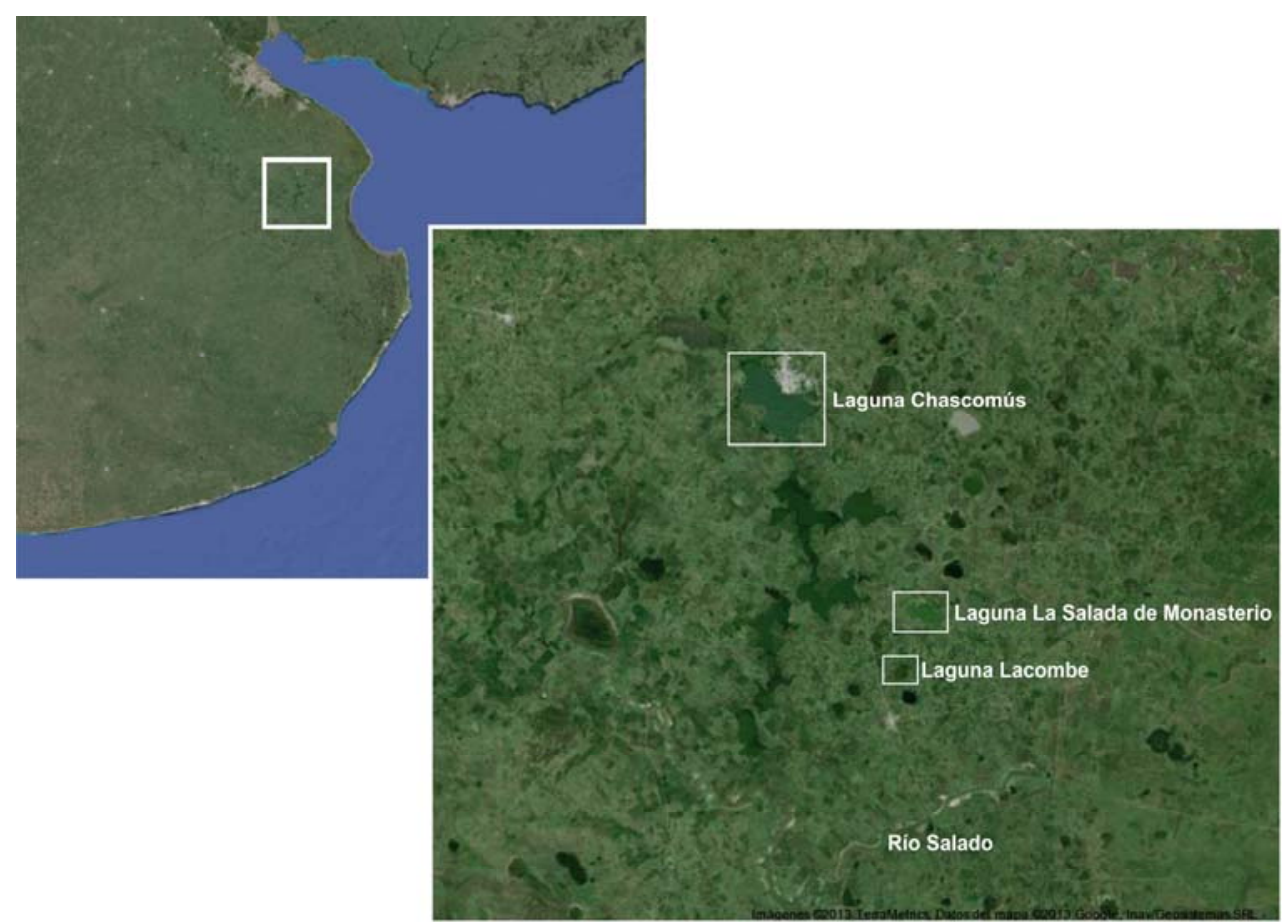

Figura II.2: Mapa del este de la Provincia de Buenos Aires y el detalle del área de estudio, donde se observa parte del Río Salado, la zona cercana a su desembocadura, y las lagunas en estudio.

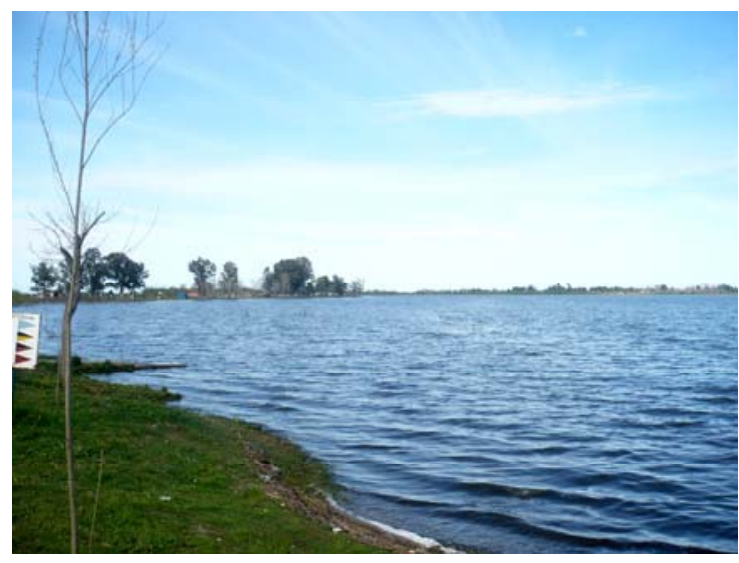

A

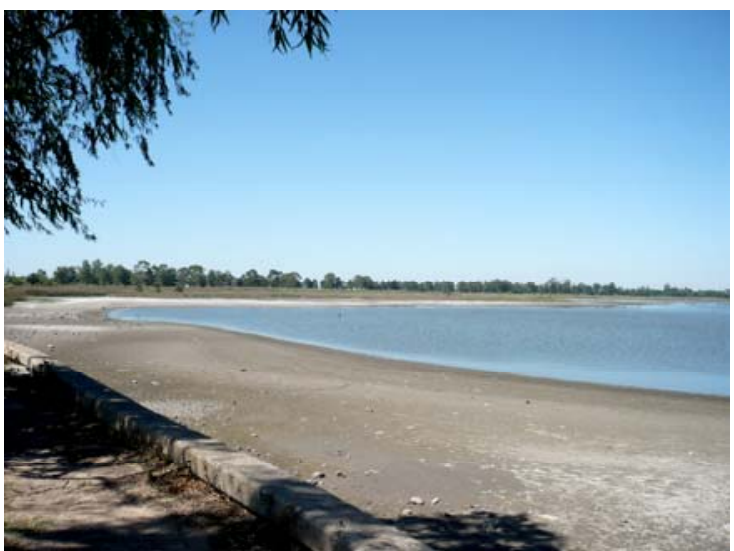

B

Figura II.3: A) Laguna de Chascomús vista desde una de sus costas. B) Laguna Chascomús durante el descenso de su nivel hidrométrico por sequía en el año 2007, donde se ven las murallas que rodean gran parte de sus costas. 


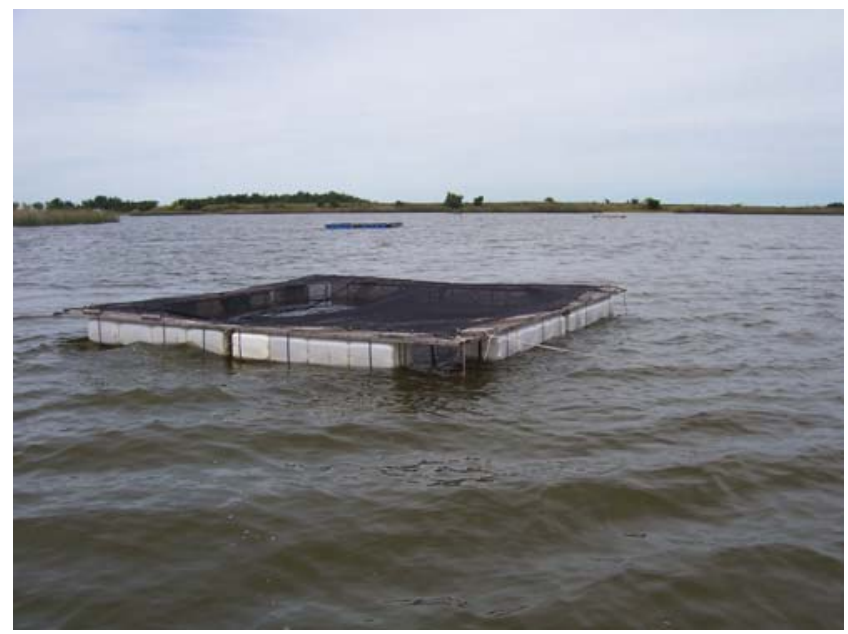

Figura II.4: Imagen de la laguna Lacombe en la zona libre de juncos donde se observa en primer plano una de las unidades experimentales (jaula flotante).

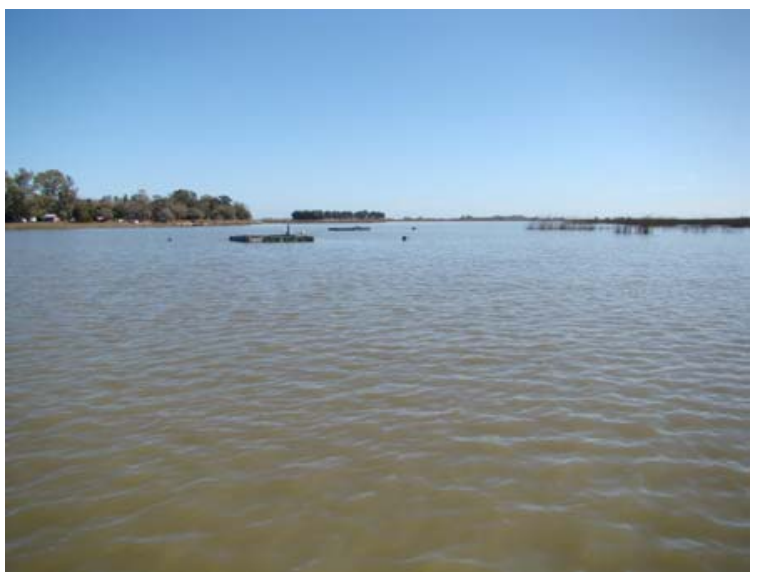

A

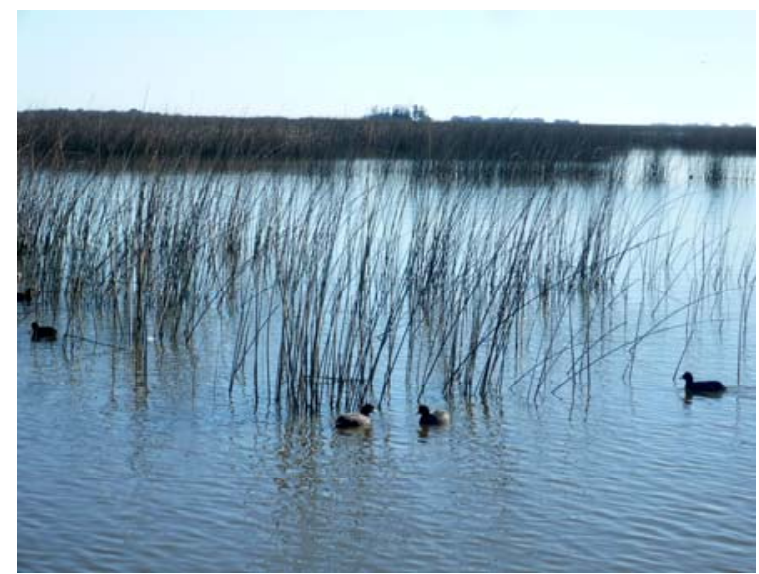

B

Figura II.5: A) Laguna La Salada de Monasterio, se observa la costa sudoeste y dos unidades experimentales (jaulas flotantes). B) Juncales y algunas aves que frecuentan la laguna La Salada de Monasterio

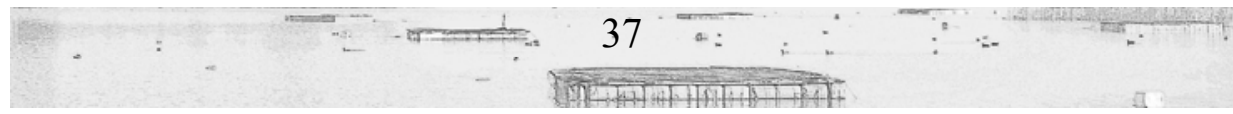




\section{III}

\section{MATERIALES Y MÉTODOS}
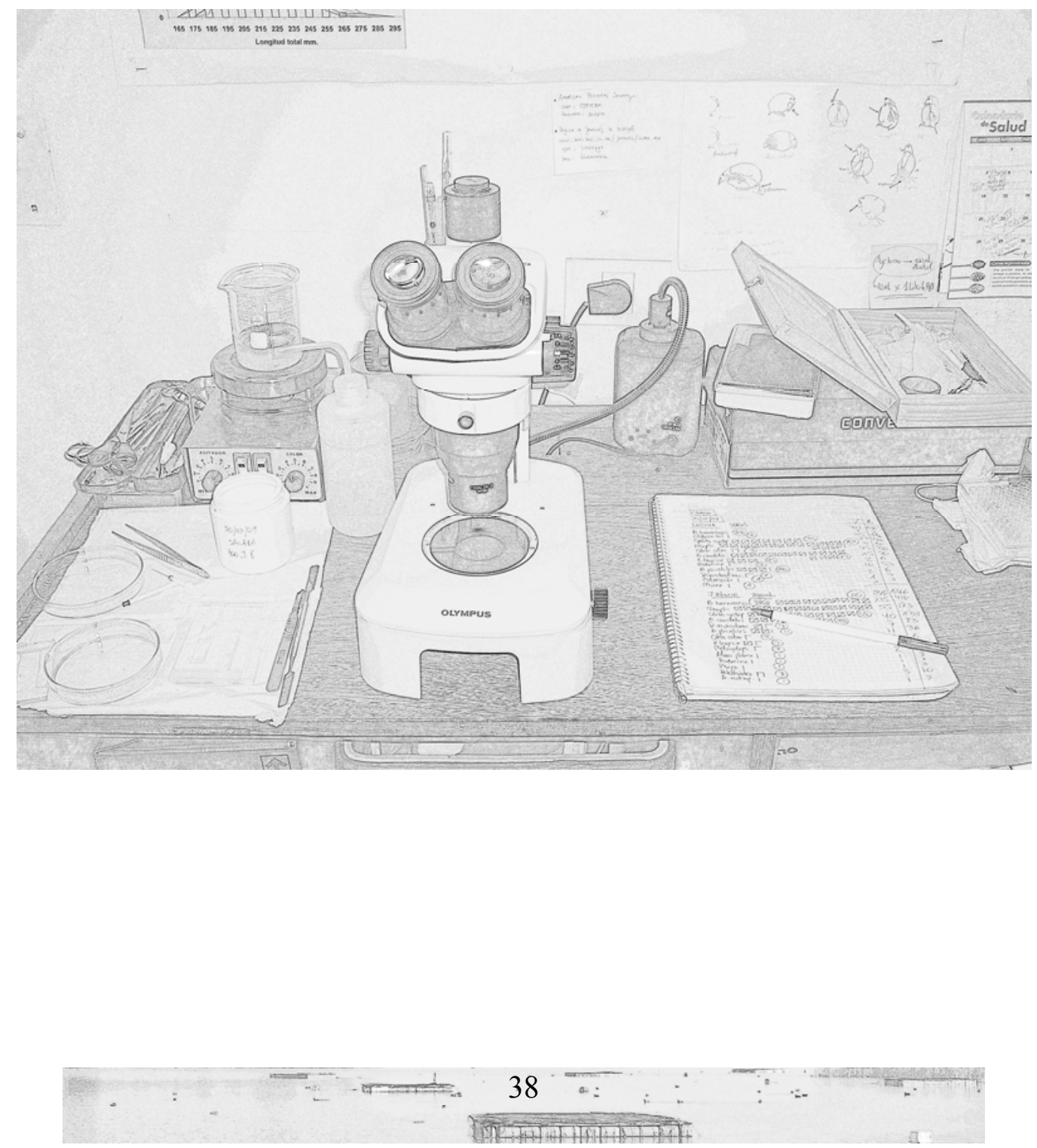


\section{Capítulo III: MATERIALES Y MÉTODOS}

Entre diciembre de 2006 y marzo de 2010 se realizaron experimentos de cría de postlarvas y juveniles de pejerrey en cavas experimentales que posee el Instituto Tecnológico de Chascomús (INTECH) y en unidades experimentales (jaulas flotantes) instaladas en las lagunas pampásicas detalladas ya en el capítulo II: Área de Estudio.

En función de las necesidades particulares de cada objetivo a cumplir, se siguieron diferentes diseños experimentales en los cuales se varió la cantidad de unidades experimentales, de lagunas donde se instalaron, el momento del año para realizar la siembra, la edad de los peces o la densidad de siembra. A su vez, teniendo en cuenta dichas variables de influencia sobre el cultivo extensivo de pejerrey en jaulas flotantes (ambiente, época del año y densidad de cría), los capítulos IV, V y VI de la presente tesis abordarán cada una de las variables en particular.

Las larvas recién eclosionadas utilizadas en los experimentos fueron obtenidas de la Estación Hidrobiológica de Chascomús. En determinados casos las postlarvas utilizadas en los experimentos realizados en jaulas fueron criadas previamente en las cavas experimentales, y en otros casos se criaron directamente en las lagunas, en jaulas tipo "nursery".

Durante los años de experimentación también se llevó a cabo un seguimiento de las lagunas estudiadas como parte de la caracterización del ambiente de cultivo, principalmente en cuanto a los parámetros limnológicos y la comunidad zooplanctónica. Por otra parte, en diversas ocasiones se tomaron muestras de pejerreyes "silvestres" con el fin de realizar comparaciones con aquellos criados en las cavas o las jaulas.

El detalle de los materiales y técnicas de cría utilizados y del seguimiento y análisis de los datos de los cultivos/experimentos se expondrán en los siguientes apartados, mientras que el diseño de cada experimento será explayado junto con algunas particularidades metodológicas, sus resultados y su discusión en cada capítulo específico. 


\subsection{Materiales y técnicas de cría de pejerrey implementadas}

\subsubsection{Obtención de postlarvas de pejerrey en cavas experimentales}

EI INTECH posee en su predio cavas experimentales de 30 metros de largo y 10 metros de ancho, impermeabilizadas con plástico negro de 300 micras, que reciben provisión de agua a una salinidad de $15 \mathrm{~g} / \mathrm{l}$ (Figura III.1).
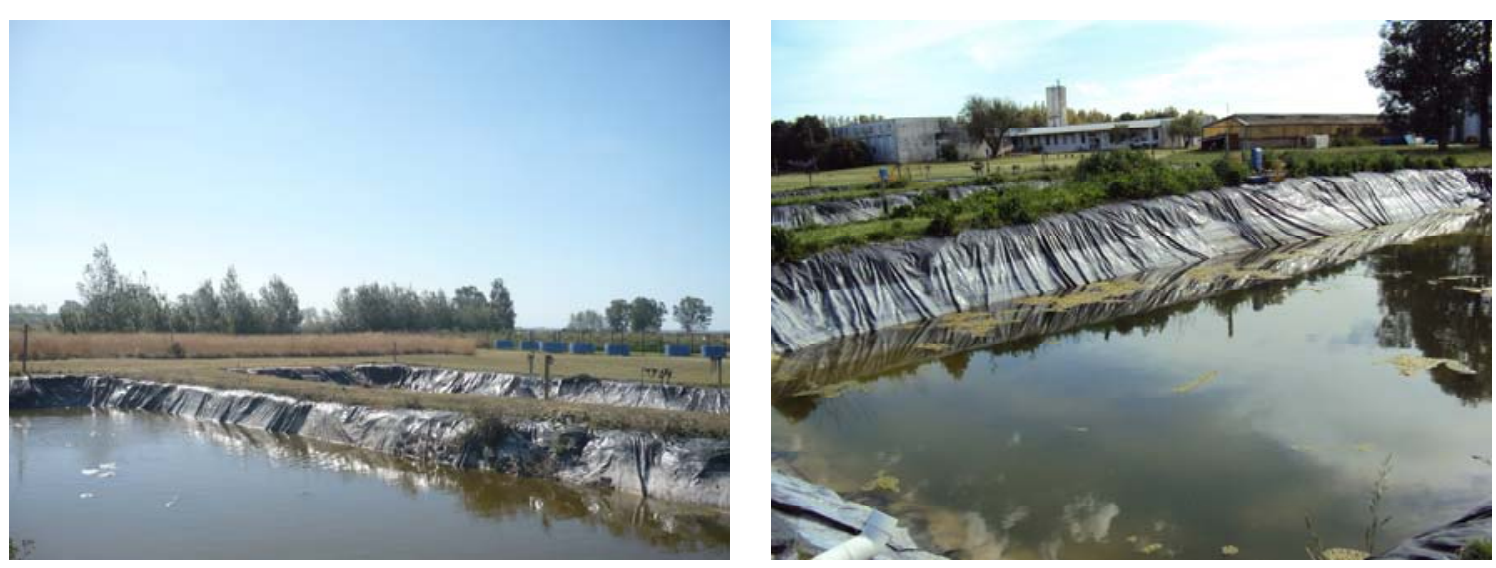

Figura III.1: Cavas experimentales ubicadas en el predio del Instituto Tecnológico de Chascomús (INTECH)

Dichas cavas fueron utilizadas para la obtención de postlarvas de pejerrey en: verano 2007-2008, primavera 2008, verano 2008-2009, otoño 2009 y primavera 2009. En todos los casos se siguió el mismo procedimiento (Figura III.2), con la excepción del verano 2007-2008 (cuando no se realizó un seguimiento). El proceso incluyó un monitoreo permanente de parámetros limnológicos y de la comunidad zooplanctónica, tomando como punto de partida el día de llenado de las cavas. De esta manera se apuntó a caracterizar el ambiente de cultivo y a identificar las condiciones que podrían ser las más apropiadas para la siembra de las larvas de pejerrey recién eclosionadas. Dichas condiciones en el caso de las larvas de otras especies (Morris \& Mischke 1999) estarían vinculadas con una cierta estabilidad limnológica relacionada a una densidad zooplanctónica mayor a los 1000 ind./l. 


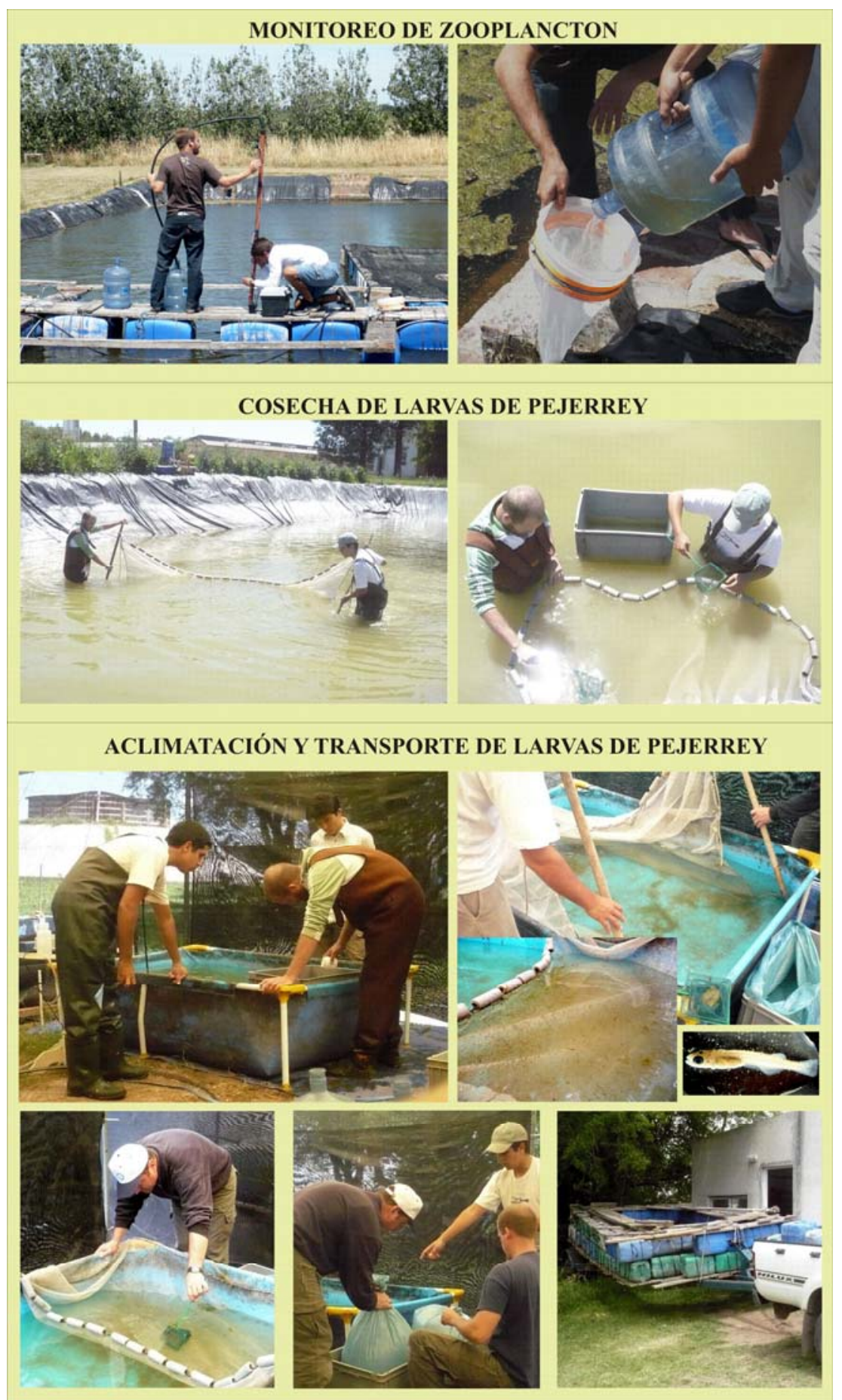

Figura III.2: Proceso de obtención de postlarvas de pejerrey en cavas experimentales: seguimiento del zooplancton, muestreo y cosecha de las larvas de pejerrey y aclimatación y transporte en bolsas con oxígeno

Después de aproximadamente 25 días (en primavera y verano) o de 45 días (en el otoño) se obtuvieron las postlarvas de pejerrey de talla apta para ser destinadas a los experimentos en jaulas. Utilizando una red de arrastre de 1,5 $\mathrm{m}$ de alto por $5 \mathrm{~m}$ de largo con un tamaño de poro de $1 \times 1 \mathrm{~mm}$ se capturaron los pejerreyes de las cavas, para luego ser contados y colocados en piletas de $2 \mathrm{~m}$ de largo por $1,40 \mathrm{~m}$ de ancho y $50 \mathrm{~cm}$ de

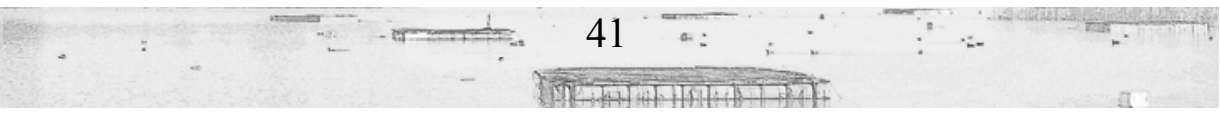


profundidad, previamente llenadas con agua de la misma cava. Allí se realizó el proceso de aclimatación realizando un intercambio lento y continuo de agua para reducir la salinidad desde los $15 \mathrm{~g} / \mathrm{l}$ hasta $4 \mathrm{~g} / \mathrm{l}$ durante 24hs, ya que ante un eventual transporte está comprobado que hacerlo a una salinidad cercana a los $5 \mathrm{~g} / \mathrm{l}$ disminuye notablemente la mortalidad (Tsuzuki et al. 2000). Por último, para su traslado a las lagunas, se dividieron en bolsas con $1 / 3$ de agua de las piletas y el resto de oxígeno, para minimizar el "stress" (Beveridge 2004) (Figura III.2).

\subsubsection{Obtención de postlarvas y cría de juveniles de pejerrey en jaulas flotantes}

Las jaulas flotantes utilizadas (volumen de $12 \mathrm{~m}^{3}$ ) constan de un marco de madera de $4 \mathrm{~m}$ de ancho por $4 \mathrm{~m}$ de largo (perímetro externo de $16 \mathrm{~m}^{3}$ ) con bidones de flotación, al cual se le añade alrededor de su perímetro interno una bolsa de red de una profundidad de 1,3 m (dejando $1 \mathrm{~m}$ efectivamente sumergido). El marco se conforma por cuatro tablones largos de 3,96 cm que van por fuera, y cuatro tablones un poco más cortos que van por dentro y que encastran con los anteriores en forma de "dientes". Además, otros ocho tablones más pequeños van en los ángulos, cuatro de ellos más cortos en las esquinas y cuatro más largos más adentro del cuadrado, vinculando a los cuatro tablones que conforman cada esquina (Figura III.3). 


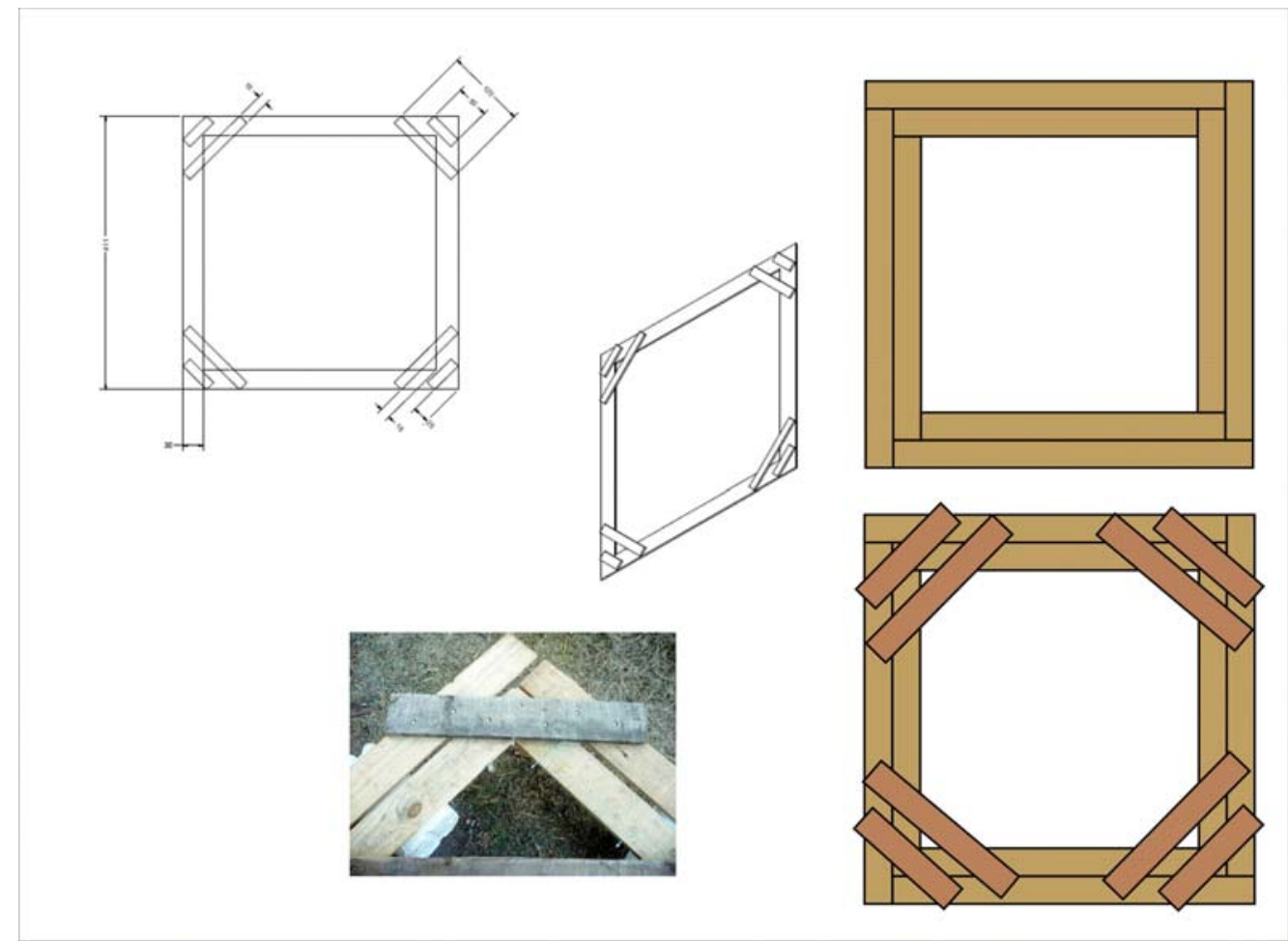

Figura III.3: Esquema que representa el plano de construcción del marco de las jaulas flotantes y el detalle de uno de sus ángulos fotografiado.

El marco lleva además pitones cerrados distribuidos a intervalos regulares en todo su perímetro interno (de donde cuelga la bolsa de red), y en todo su perímetro externo a intervalos más amplios para el amarre de la tapa. Para la flotación el marco cuenta con hileras de bidones por debajo. Cada bidón lleva dos aros de soga que lo sujetan a la madera (Figura III.4).
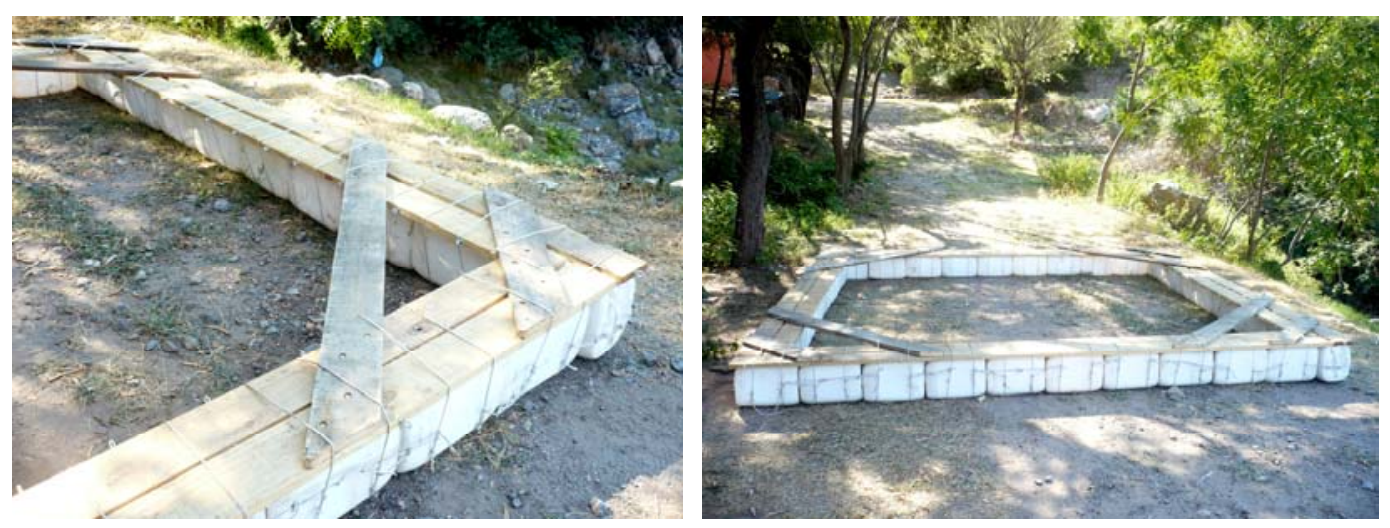

Figura III.4: Marco de las jaulas completo, con su estructura de madera y los bidones de flotación instalados.

Para la instalación y el anclaje de las jaulas en los cuerpos de agua se utilizan "muertos" (cubiertas de auto rellenas de hormigón) que se atan en dos esquinas opuestas de las jaulas, con una sogas cuya longitud es tres veces mayor (como mínimo) a la profundidad

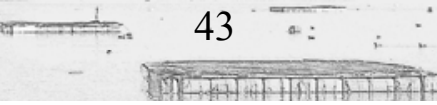


del sitio de instalación. En el trayecto del cabo de anclaje se instala un bidón (igual a los de flotación del marco) a una distancia dependiente del largo de la soga y de la profundidad, que funciona de "amortiguador" ante eventuales movimientos, usualmente provocados por tormentas. También se agrega una soga desde el muerto a la superficie, con una boya que marca su posición (Figura III.5).

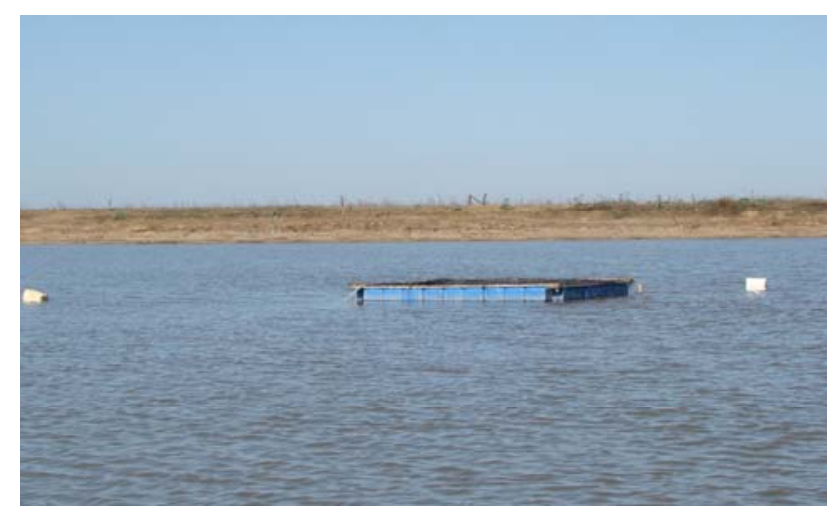

Figura III.5: Jaula flotante instalada en la laguna La Salada de Monasterio en julio del año 2009.

En el caso de las jaulas tipo "nursery", la red de la jaula consta de una malla de 0,5 $\times$ 0,5 mm. Para el caso de la cría de juveniles la malla en principio es de tipo "mosquitero" de $1,5 \times 1,5 \mathrm{~mm}$ y luego es cambiada por una tipo "anti-granizo" de $10 \times 2,5 \mathrm{~mm}$ de abertura de malla. Siempre se tiende a utilizar el tamaño de malla mayor que permita retener a los peces maximizando el intercambio de agua y zooplancton con el ambiente.

En el caso de los experimentos de cría de juveniles en jaulas, antes del inicio de cada experimento la totalidad de las postlarvas de pejerrey a utilizarse fueron sembradas en una jaula (jaula común) para realizar su aclimatación a la laguna. Luego de una semana fueron separadas en distintas jaulas conforme el diseño del experimento. A partir de dicho momento se realizó el seguimiento periódico de los ejemplares, de los parámetros limnológicos y la comunidad zooplanctónica en cada jaula y cuerpo de agua, siguiendo protocolos específicos.

\subsection{Seguimiento de parámetros limnológicos y comunidad zooplanctónica}

En todos los casos se realizó un monitoreo permanente de parámetros limnológicos (conductividad, $\mathrm{pH}$, oxígeno disuelto, temperatura, transparencia y profundidad) tanto de las cavas (cada dos días) como de las lagunas en estudio (semanalmente). La profundidad se midió utilizando un caño graduado, la transparencia mediante el disco de Secchi, la conductividad, el pH y el oxígeno disuelto mediante medidores automáticos (Hanna HI 
98130, Rhode Island, USA). El oxímetro también se utilizó para medir la temperatura en las cavas, en cambio la temperatura del agua de las lagunas se midió de manera continua mediante medidores automáticos programables instalados por fuera de alguna de las jaulas (Thermochron iButton, Sunnyvale, CA, USA). Se calculó el porcentaje de saturación del oxígeno, utilizando los valores de oxígeno y temperatura medidos, mediante el método gráfico publicado en Wetzel \& Likens (1991).

La comunidad zooplanctónica se muestreó cada tres días en las cavas y quincenalmente en las lagunas, tanto dentro como fuera de las unidades experimentales (jaulas). Se utilizó una bomba sumergible, ubicada en el extremo de un dispositivo especialmente diseñado, conformado por una barra graduada con una manguera en su interior (Figura III.6). En las cavas se tomaron $40 \mathrm{~L}$ de agua en dos niveles de profundidad, integrados en una muestra que represente toda la columna de agua. En las lagunas, en cada sitio de muestreo se tomaron $60 \mathrm{~L}$ de agua de la siguiente manera: $20 \mathrm{~L}$ cerca del fondo, $20 \mathrm{~L}$ en una profundidad intermedia y $20 \mathrm{~L}$ cerca de la superficie, integrando las tres profundidades también en una muestra representativa de la columna de agua. En ambos casos el agua fue filtrada con una red de plancton de $50 \mu \mathrm{m}$ de abertura de poro. Las muestras fueron fijadas con formalina al $4 \%$ para su posterior análisis cuali-cuantitativo (Figura III.7).

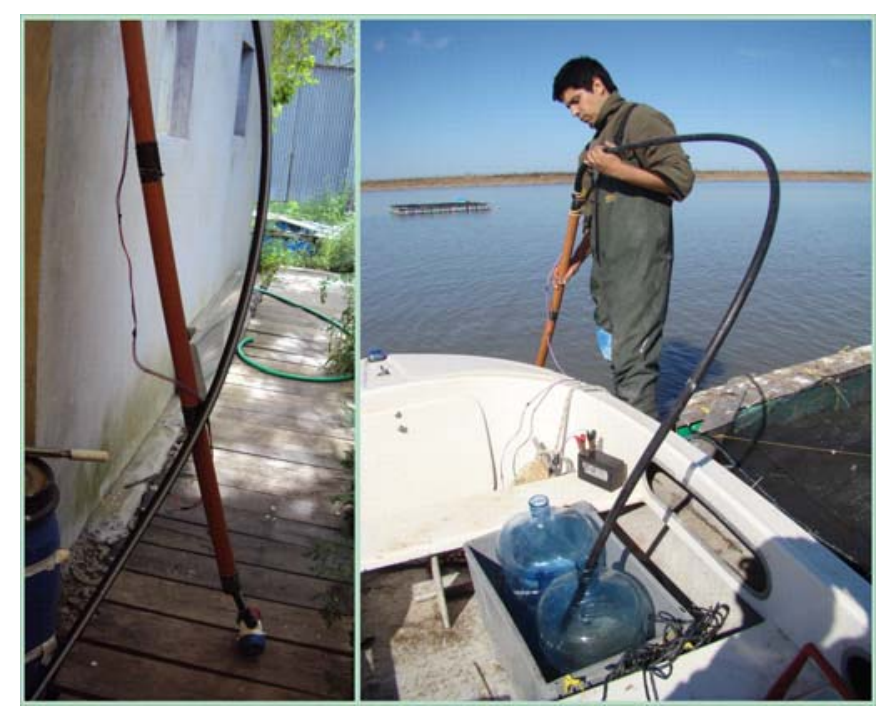

Figura III.6: Dispositivo especialmente diseñado para la toma de muestras de zooplancton y de su modo de uso. La bomba centrífuga es ubicada en el extremo de una manguera que se ubica en el interior de una barra graduada. 


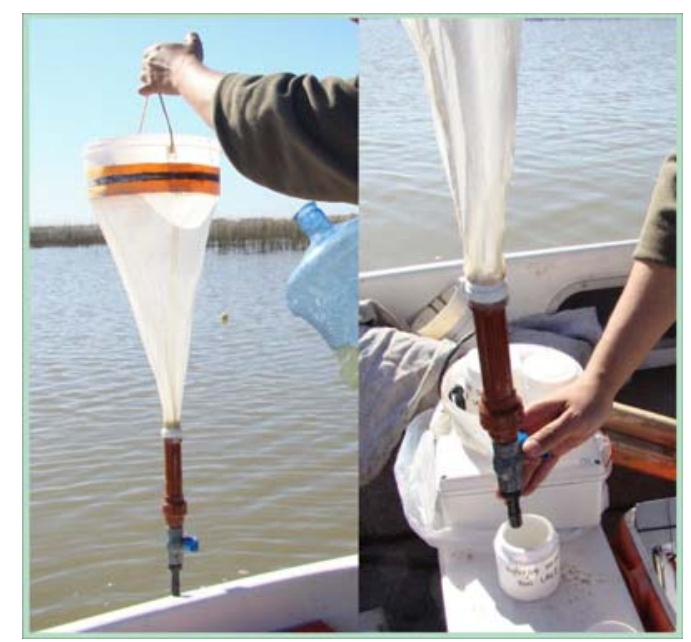

Figura III.7: Red de zooplancton y detalle del vertido de la muestra en un recipiente colector.

En laboratorio, las muestras obtenidas fueron llevadas a volumen entero conocido para facilitar los cálculos y luego agitadas mediante agitador magnético para obtener submuestras representativas. Estas alícuotas fueron analizadas en cámaras de conteo Sedgwick-Rafter (1 ml) (APHA 1995) y Bogorov (10 ml) (Gannon 1971) en microscópico óptico y estereoscópico (lupa), respectivamente. Dicho análisis incluyó:

Determinación taxonómica utilizando bibliografía específica para cada grupo (Ringuelet 1958, Koste 1978, Reid 1985, De Melo \& Hebbert 1994, Paggi 1995, Nogrady \& Segers 2005, en pos de conocer la composición de la comunidad (en lo posible a nivel de especie) (Anexo 1).

- Recuento de individuos para conocer la abundancia zooplanctónica (AZ, en ind./l).

- Medición de un número elevado de individuos por especie y por muestra (30 en aquellas abundantes), para la obtención de tallas medias a utilizarse en el cálculo del peso seco (ps) y así obtener la biomasa zooplanctónica por litro ( $B Z$, en $\mu \mathrm{g}$ ps/l). Las abreviaturas se pueden encontrar en el anexo 2.

Para dicha medición de los individuos se utilizaron fotos capturadas mediante cámara digital instalada en lupa, mediante el software Infinity (C) (Lumenera Corporation 2013) (Figura III.8). La biomasa de los rotíferos se estimó a partir de las mediciones volumétricas utilizando aproximaciones geométricas (Ruttner Kolisko 1977, Mc Cauley 1984). El ps de las larvas nauplii de copépodos, de los copépodos juveniles y adultos y de los cladóceros fue estimado a partir de fórmulas descritas por Bottrell et al. (1976), Dumont et al. (1975) y 
Lawrence et al. (1987) mediante regresiones largo-peso disponibles para las especies encontradas o para otras morfológicamente similares.
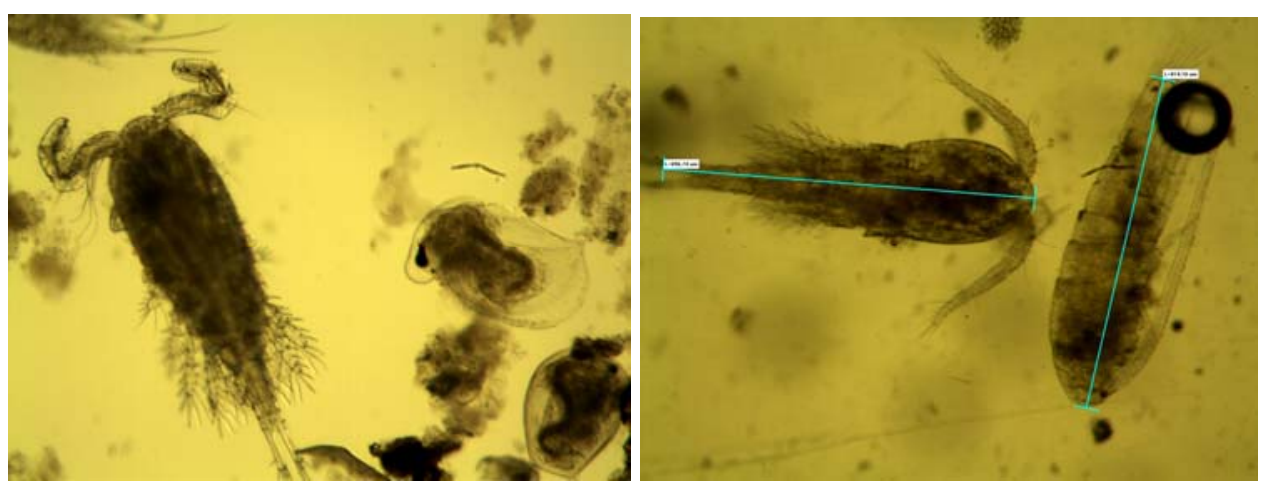

Figura III.8: Imágenes tomadas con el software Infinity ( C. En la segunda se observa la toma de mediciones.

Por otro lado, utilizando las tallas medias, las especies zooplanctónicas se clasificaron en tres clases de tamaño:

I: hasta 0,3 $\mathrm{mm}$ (rotíferos y larvas nauplii de copépodos)

II: 0,3-0,7 mm (copépodos y cladóceros pequeños)

III: más de 0,7 mm (copépodos y cladóceros grandes)

También se calculó el tamaño medio del zooplancton (TMZ) en cada fecha de muestreo y para cada tratamiento, como el promedio de los valores medios de cada clase de tamaño ponderados por sus respectivas abundancias registradas.

\subsection{Seguimiento del crecimiento del pejerrey bajo cultivo}

Los peces cultivados en las cavas fueron muestreados cada 4-7 días utilizando un copo de mano. Se sacrificaron entre 5 y 10 individuos por muestreo para la obtención de sus longitudes totales y standar (LT y LSt, en $\mathrm{mm}$ ) y los pesos (W, en g). Luego fueron fijados en formol al $10 \%$ para su posterior análisis de la dieta.

En el caso de los criados en jaulas en las lagunas se muestrearon mensualmente utilizando la misma red de arrastre descripta para la pesca de las postlarvas obtenidas en las cavas (1,5 m de alto por $4 \mathrm{~m}$ de largo con un tamaño de malla de $1,5 \times 1,5 \mathrm{~mm}$ ). Se anestesiaron 15 individuos por jaula y por fecha de muestreo (con $10 \mathrm{ml}$ de una solución de benzocaína diluida en alcohol (1gr: $100 \mathrm{ml}$ ) en $1000 \mathrm{ml}$ de agua). Se midieron in situ, 
obteniéndose su LT y LSt (en cm) (Figura III.9) y se sacrificaron en frío otros 5 individuos por jaula y por fecha, los cuales en laboratorio también fueron medidos (LT y LSt) y además pesados (W). Para el análisis de la dieta, estos individuos sacrificados fueron fijados en formol al $10 \%$.
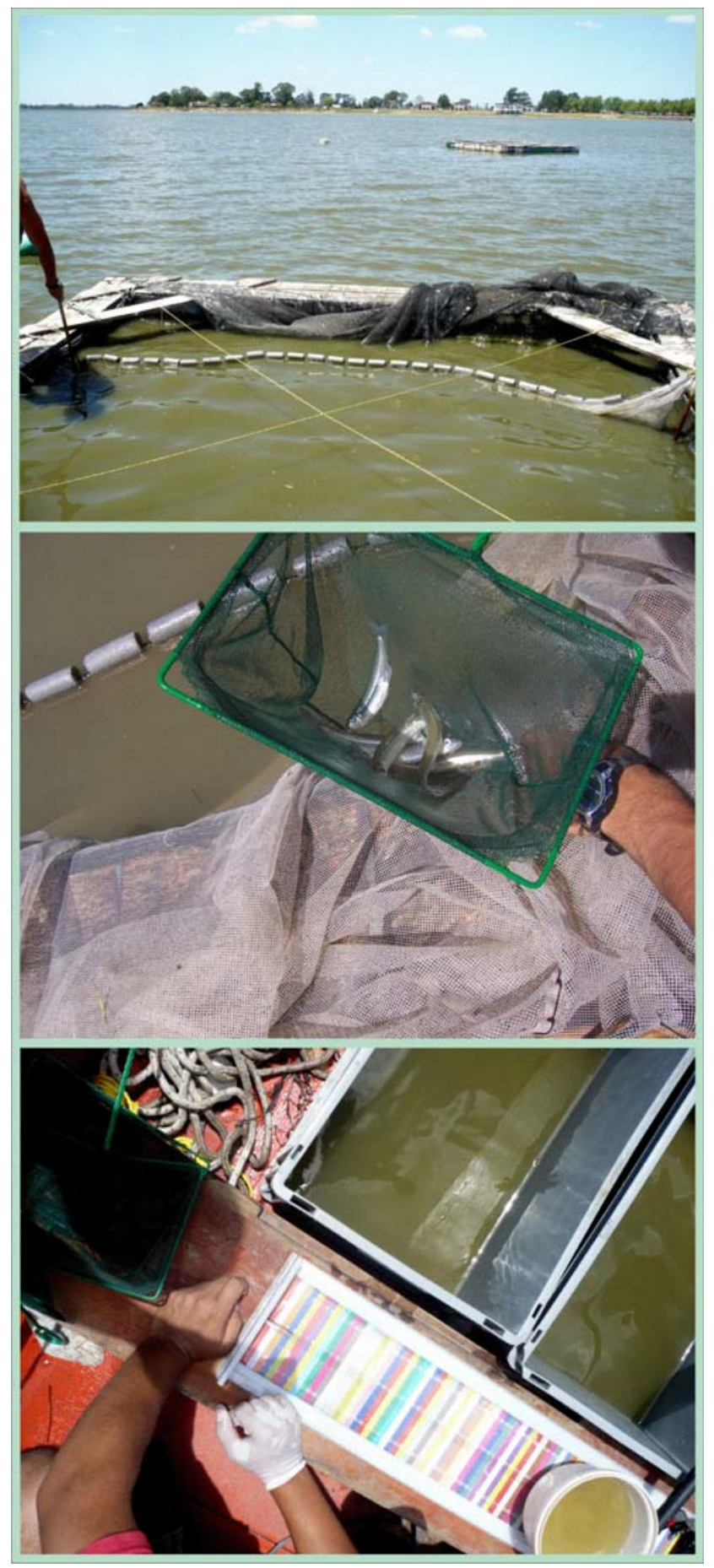

Figura III.9: Proceso de muestreo de los pejerreyes criados en jaulas flotantes, y medición de tallas in situ.

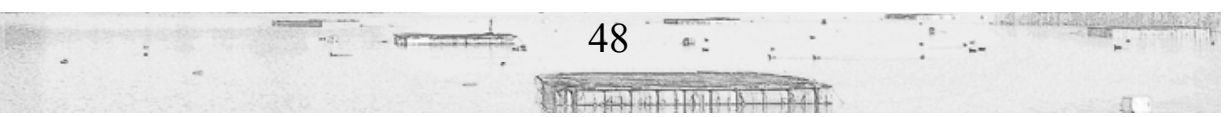


Al final de cada ciclo de cultivo se obtuvo el número final ( $\mathrm{N}$ final) de pejerreyes cultivados mediante repetidas pasadas utilizando la red de arrastre descripta para la técnica en cavas hasta obtener cero individuos.

\subsection{Seguimiento de la dieta de los pejerreyes cultivados}

Se extirpó cada tubo digestivo bajo lupa y su contenido fue analizado totalmente en el caso de las postlarvas. En el caso de los juveniles, en aquellos individuos donde fue posible debido a su talla (aproximadamente $\mathrm{LT}>3 \mathrm{~cm}$ ), el tubo digestivo se seccionó en tres partes (Figura III.10), y en los que no, se analizó el contenido completo.

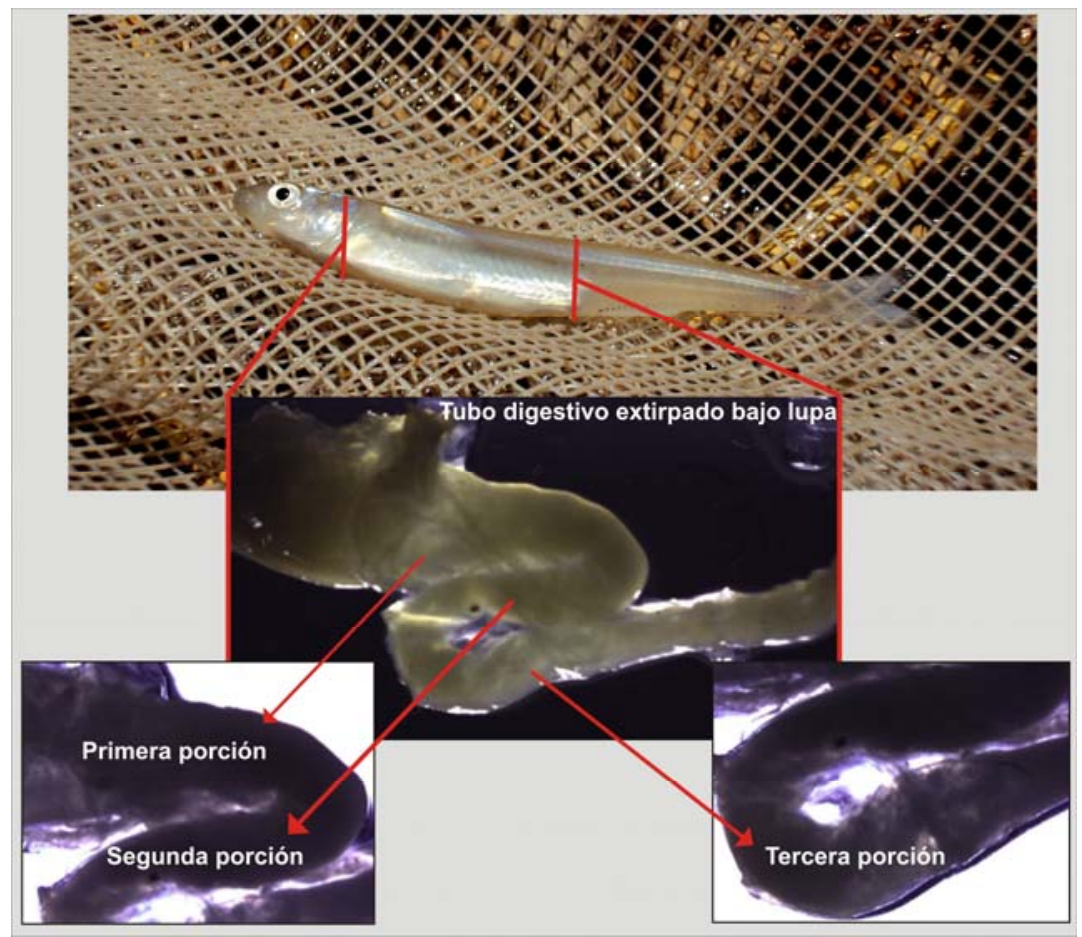

Figura III.10: Juvenil de pejerrey y tubo digestivo extirpado bajo lupa donde se observan las tres porciones consideradas en el presente trabajo.

El contenido de las dos primeras porciones (o el total, dependiendo del caso) fue transferido a vasos de precipitado, llevados a un volumen $50 \mathrm{~mL}$ (Rahman et al. 2010), y agitados mediante agitador magnético para la obtención de submuestras. Dichas muestras y submuestras fueron transferidas a cámaras de conteo (Sedgwick-Rafter y Bogorov) y analizadas del mismo modo que las muestras de zooplancton para identificar y cuantificar los componentes alimentarios (Hyslop 1980, Cortés 1997, Cortés 1999). 


\subsection{Los pejerreyes silvestres}

Se realizaron tres tipos de muestreos ictiológicos en las lagunas en estudio, clasificados en este caso como arrastres (A1, A2 y A3):

1) A1: Utilizando la misma red de arrastre descripta para la técnica de obtención de larvas en cavas, se realizaron arrastres paralelos a la costa entre dos personas.

2) A2: Utilizando una red de arrastre de $15 \mathrm{~m}$ de longitud y 1,2 $\mathrm{m}$ de altura, con una abertura de malla de $1 \mathrm{~cm}(0,5 \mathrm{~cm}$ en el copo central), se realizaron arrastres del mismo modo que A1 (Figura III.11).

3) A3: Utilizando una red de ictioplancton desarrollada artesanalmente para este fin, se realizaron transectas superficiales desde embarcación, en sectores cercanos a las jaulas. La red constó de un cono de red de 1 metro de alto, con $50 \mathrm{~cm}$ de diámetro de base (con un aro rígido), $10 \mathrm{~cm}$ de diámetro en su extremo (con la parte superior de un recipiente cortado para retener la captura), y abertura de malla de 0,5 $\mathrm{mm}$.

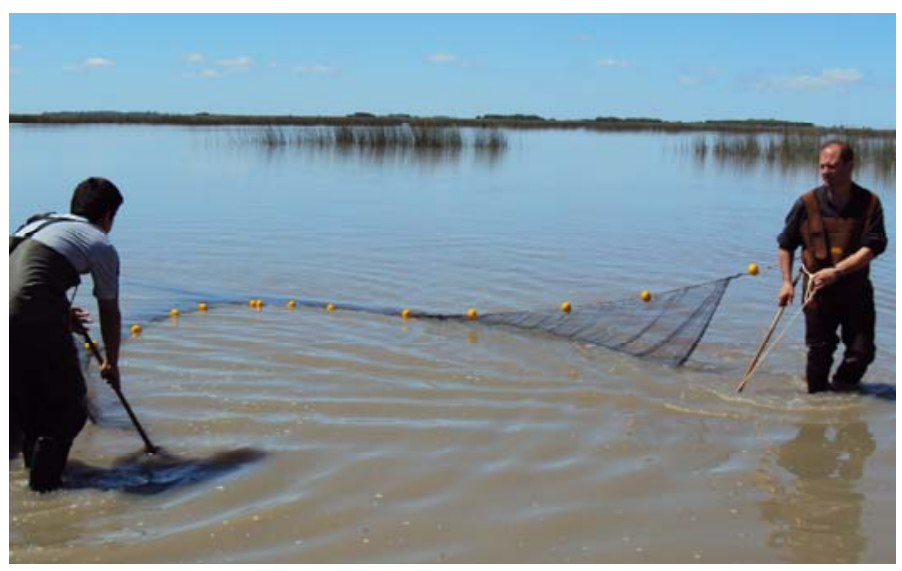

Figura III.11: Maniobra de pesca de arrastre de costa utilizando la red de arrastre descripta como "arrastre 2" en la laguna La Salada de Monasterio.

En todos los casos, una vez obtenida la captura se seleccionó sólo aquellos pejerreyes de tamaño comparable con los criados; se fijaron en formol al $10 \%$ para la posterior obtención en laboratorio de LT, LSt y W, y para el análisis de su dieta. 


\subsection{Análisis de datos}

\subsubsection{Parámetros limnológicos y comunidad zooplanctónica}

Con los datos obtenidos de los parámetros limnológicos se realizaron tablas y gráficos. Los gráficos fueron realizados para algunos parámetros por separado o combinados con otros en pos de observar las tendencias y las relaciones entre ellos.

Utilizando los valores de AZ y su frecuencia relativa se realizaron gráficos de Olmstead-Tukey (Sokal \& Rholf 1995) con el fin de jerarquizar la participación de las especies dentro de la comunidad zooplanctónica. Se trata de diagramas en dos ejes, con la variable independiente (eje de las abscisas $x$ ) representada por la frecuencia relativa y la variable dependiente (eje de las ordenadas y) correspondiente a la abundancia (en algunos casos es preciso utilizar el logaritmo de la misma). Además forman parte del diagrama dos líneas perpendiculares entre sí que cortan los ejes a la altura de los promedios de ambas variables. Quedan así cuatro cuadrantes correspondientes a las especies: dominantes (el cuadrante superior derecho, con las especies que presentan valores superiores al promedio para ambas variables), comunes (en el cuadrante inferior derecho, con las especies con valores de frecuencia relativa superior al valor medio pero abundancia inferior al promedio), ocasionales (en el cuadrante superior izquierdo, con las especies con valores de abundancia superior al valor medio pero frecuencia relativa inferior) y raras (en el cuadrante inferior izquierdo, con las especies que presentan valores inferiores para las medias de ambas variables). Cabe aclarar que las definiciones de abundante, rara y demás categorías son relativas y no absolutas ya que dependen de la escala de la investigación (Magurran 2004).

Los valores de $A Z$ y $B Z$ fueron analizados mediante métodos multivariados utilizando el programa PRIMER (Clarke \& Warwick 2001). Previo a dichos análisis los valores fueron transformados a log $(x+1)$ para reducir la contribución de las especies muy abundantes en relación a las menos abundantes. Para evaluar si los tratamientos se agrupan de manera diferencial de acuerdo a la composición de la comunidad zooplanctónica se utilizaron dos métodos estadísticos (gráficos): análisis Cluster y MDS (ordenamiento multidimensional no paramétrico), los cuales utilizan índices de similitud (Bray-Curtis). Para evaluar si existieron diferencias entre tratamientos (dentro de las jaulas) y en la laguna, se aplicó un análisis de similitud (ANOSIM) no paramétrico, de una vía, basado en permutaciones. A través del 
procedimiento de porcentajes de similitud (SIMPER), se identificaron y ordenaron las especies que, en promedio, contribuyeron más fuertemente a las diferencias. Dicho método utiliza matrices de similitud de Bray-Curtis derivadas de la composición de especies registradas, comparando cada muestra de un grupo con cada una de otro, e identifica las "especies discriminantes" (aquellas que aportan con más del 10\% a la disimilitud entre tratamientos) (Clarke \& Warwick 2001, Bulleri et al. 2005).

\subsubsection{El pejerrey}

Para evaluar el crecimiento de los pejerreyes cultivados y las posibles diferencias entre tratamientos, se aplicaron análisis de la varianza (ANOVA) que serán detallados de acuerdo a cada diseño experimental en los sucesivos capítulos.

Previo a todos los análisis estadísticos univariados, se comprobó el cumplimiento de los supuestos de normalidad y homogeneidad de varianzas (requeridos por el ANOVA) mediante los test de Kolmogorov-Smirnov y de Levene, respectivamente (Zar 1999). En algunos casos la homogeneidad de varianzas se testeó mediante el test de Cochram (Underwood 1997). Cuando no se cumplieron los supuestos, los datos fueron transformados siguiendo a Underwood (1997).

Se calcularon las tasas de crecimiento específicas (TCE) (Weatherley \& Gill 1987, Hopkins 1992) (utilizando los valores de LT (TCEL) y W (TCEW), de la siguiente manera:

$\operatorname{TCEL}(\mathrm{cm} / \mathrm{dí} a)=\left(\ln \mathrm{LT}_{2^{-}} \ln \mathrm{LT}_{1}\right) /\left(\mathrm{t}_{2}-\mathrm{t}_{1}\right)$

Donde $\mathrm{LT}_{2}$ y $L T_{1}$ son las $L T$ medias en el tiempo $2\left(t_{2}\right)$ y en el tiempo $1\left(t_{1}\right)$, respectivamente.

$$
\left.\operatorname{TCEW}(g / \text { día })=\ln W_{2}-\ln W_{1}\right) /\left(t_{2}-t_{1}\right)
$$

Donde $W_{2}$ y $W_{1}$ son los $W$ medios en el tiempo $2\left(t_{2}\right)$ y en el tiempo $1\left(t_{1}\right)$, respectivamente.

Estas TCE fueron también comparadas entre tratamientos utilizando ANOVA de una vía, y se indagó acerca de su relación con diversas variables de cada cultivo, mediante regresiones múltiples. Tanto las variables dependientes (TCE) como las independientes ( $A Z$, BZ, parámetros físico-químicos, tratamientos de densidad, etc.) fueron estandarizadas antes de llevar a cabo las regresiones, las cuales serán descriptas en los capítulos correspondientes.

En este trabajo los muestreos de zooplancton se realizaron con mayor frecuencia que los muestreos de peces con el fin de tener una idea lo más aproximada posible de la oferta 
de alimento a la cual estuvieron sujetos los peces. Con este objeto los datos de AZ y BZ fueron normalizados para cada período de muestreo de peces a fin de relacionar este valor con las tasas de crecimiento. La normalización se llevó a cabo ponderando los valores de AZ y BZ correspondientes a cada fecha de muestreo de zooplancton por la mitad de días transcurridos desde el muestreo previo o hasta el muestreo siguiente. La sumatoria de AZ y BZ ponderados se dividió por el número total de días transcurridos entre los muestreos de peces en cuestión para obtener las AZ y BZ normalizadas (AZN y BZN).

Con el fin de evaluar el estado nutricional de los peces se calculó el índice de condición por "stanzas" de crecimiento (Solimano 2013). Los índices de condición son indicadores del bienestar de los individuos (Gutreuter \& Childress 1990, Baigún et al. 2009), y permiten suponer que los peces estarán en "mejor" condición si son más pesados que otros peces de la misma talla (Richter et al. 2000). Como los peces no crecen del mismo modo a lo largo de toda su vida (Ricker 1979, Charnov et al. 2001, Shuter et al. 2005), presentando diferentes patrones de crecimiento ("stanzas" de crecimiento, Vasnetsov 1953), se decidió para la presente tesis utilizar el índice desarrollado por Solimano (2013), ya que la mayoría de los ejemplares medidos se ubican dentro del rango de tallas que utilizó el autor para su desarrollo (Colautti et al. 2009a, Garcia de Souza et al. 2009, Solimano et al. 2009, Colautti et al. 2010, Solimano et al. 2011, Garcia de Souza et al. 2013).

Índice de condición por "stanzas", WrS = Wobs/Wesp

siendo el Wobs (g), el peso obtenido en los muestreos, y el Wesp (g), el peso calculado para los intervalos de crecimiento, de la siguiente manera:

De 1,3 a $3 \mathrm{~cm}(\mathrm{Lst}): \mathrm{W}=0,008^{\star} \mathrm{Lst}^{3,18}$

De 3 a $8,5 \mathrm{~cm}(\mathrm{Lst}): \mathrm{W}=0,011^{*} \mathrm{Lst}^{2,86}$

De 8,5 a $12 \mathrm{~cm}: \mathrm{W}=0,003 * \mathrm{Lst}^{3,46}$

De esta manera, los individuos que presentaron un valor de WrS cercano o superior a 1 se consideraron en buena condición, mientras los valores por debajo de 1 indicaron baja condición de los individuos. 
Se calculó la tasa de supervivencia porcentual media (S \%) de cada tratamiento, siguiendo la fórmula de O'conell \& Raymond (Fex de Santis 1991):

$$
\mathbf{S} \%=\{[(\mathrm{Lc} / \mathrm{K})+\mathrm{Sf}] / \mathrm{Ls}\} \times 100
$$

Donde Lc es el número de peces sacrificados en cada muestreo, $\mathrm{Sf}$ es el $\mathrm{N}$ final (al final del experimento), Ls es el N inicial (la densidad de "stock") y K es una constante igual a Sf/100.

A su vez se calculó la producción media final $(P)$ de cada tratamiento, de la siguiente manera:

$$
\mathbf{P}(\mathrm{g})=\mathrm{W}_{\mathrm{mf}} \times \mathrm{N}_{\mathrm{f}}
$$

Donde $\mathrm{W}_{\mathrm{mf}} \mathrm{y} \mathrm{N}_{\mathrm{f}}$ son el peso medio final y el $\mathrm{N}$ final, respectivamente.

Como primera aproximación al estudio cuantitativo de los contenidos digestivos (CD), el aporte porcentual de cada clase de tamaño de zooplancton por cada tratamiento, cada edad de pez y cada talla de pez registrada, fue expresada en gráficos de columnas $100 \%$ apiladas.

Mediante métodos multivariados (CLUSTER, MDS, ANOSIM y SIMPER) se comparó la dieta de los pejerreyes criados bajo diferentes tratamientos. A su vez, se calcularon los tamaños medios de presa (TMP) por cada réplica, tratamiento y fecha de muestreo. Los CD fueron además comparados con los valores de AZ obtenidos para cada tratamiento, evaluando de esta manera las diferencias entre la "oferta" (zooplancton registrado en las jaulas) y la "demanda" (lo consumido por los peces). Dicha comparación también se realizó mediante gráficos, análisis multivariados e índices de selectividad.

La representatividad de los ítems alimentarios también se evaluó mediante el cálculo de las frecuencias de ocurrencia (FO) para cada ítem encontrado, la composición porcentual por número (CPN) y la composición porcentual por peso (CPP), y con estos parámetros combinados se calculó el:

Índice de importancia relativa (IRI) (Pinkas et al. 1971, Hyslop 1980, Bowen 1996):

$$
\mathbf{I R I}=(\mathrm{CPN}+\mathrm{CPP}) \times(\mathrm{FO} \%)
$$

Siendo: $\mathrm{FO}=$ Proporción de tubos digestivos que contienen un determinado ítem alimenticio, CPN = Número de ítems de un determinado tipo, expresado como porcentaje del número total de ítems encontrados en un tubo digestivo. CPP = Peso de ítems de un 
determinado tipo, expresado como porcentaje del peso total del alimento ingerido por un determinado pez.

Para evaluar la amplitud de nicho trófico y la selectividad alimentaria de los peces criados en cada edad, tamaño y tratamiento, se aplicaron los siguientes índices:

\section{Índice de amplitud trófica de Levins}

$$
\mathbf{H}^{\prime}=\left(\sum \mathrm{p}_{\mathrm{i}}^{2}\right)^{-1}
$$

Donde $p_{i}$ es la proporción de cada ítem en la dieta (Levins 1968).

El índice otorga valores entre $1 \mathrm{y}+\infty$. Un valor de $\mathrm{H}^{\prime}=1$ significa que el individuo es monófago y valores más altos que 1 significan que la dieta es diversa.

\section{Índice de selectividad de forrajeo óptimo}

$$
\mathbf{F R}=\mathrm{pC}_{\mathrm{i}} / \mathrm{pO}_{\mathrm{i}}
$$

Donde $\mathrm{pC}_{\mathrm{i}}$ es la proporción de cada ítem consumido, y $\mathrm{pO}_{\mathrm{i}}$ es la proporción de cada ítem "ofrecido" por el ambiente.

Este índice puede tomar valores entre 0 y $+\infty$. Si FR $=0$, significa que dicho ítem no forma parte de la dieta, $0>\mathrm{FR}<1=$ representa una selectividad negativa, $\mathrm{FR}=1$ significa indiferencia y FR $>1$ = indica selectividad positiva.

Índice de selectividad de Strauss (Strauss 1979, Bowen 1996)

$$
\mathbf{L}=\mathrm{r}_{\mathrm{i}}-\mathrm{p}_{\mathrm{i}}
$$

Donde $r_{i}$ es la abundancia relativa de la presa i en la dieta (como proporción del número total de presas en la dieta) y $\mathrm{p}_{\mathrm{i}}$ es la abundancia relativa de la presa i en el ambiente.

El índice puede tomar valores entre $+1=$ indica una selección perfecta por un tipo de presa, y $-1=$ que indica una selección perfecta en contra de ella.

Se realizaron comparaciones entre los CD de los pejerreyes silvestres con los criados en jaula de tallas similares, mediante métodos multivariados e índices de amplitud trófica y selectividad alimentaria (Capítulo VII). 


\section{IV}

INFLUENCIA DEL AMBIENTE

EN LA CRÍA EXTENSIVA DE PEJERREY:

Especial atención a la comunidad zooplanctónica
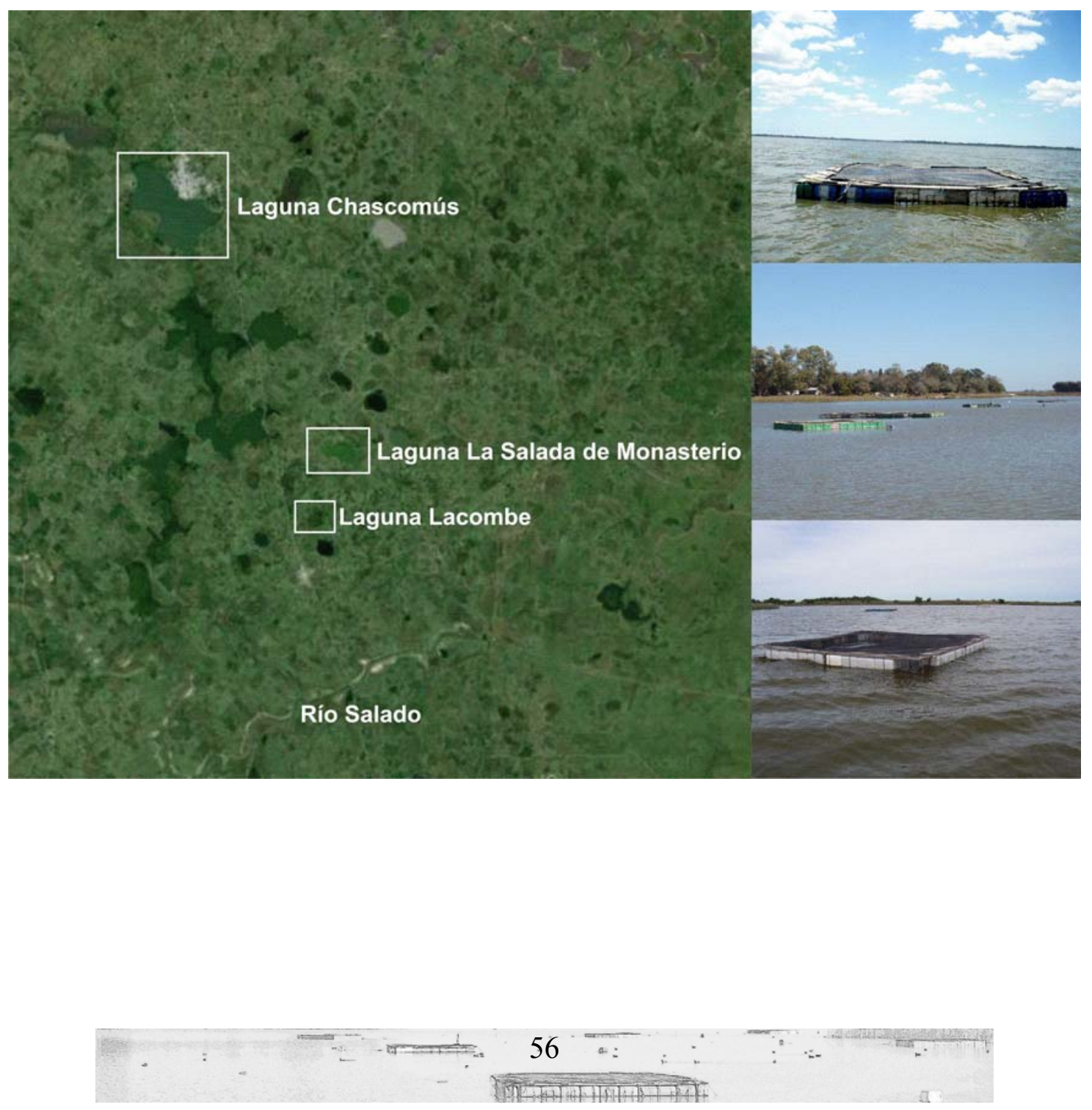


\section{Capítulo IV: INFLUENCIA DEL AMBIENTE EN LA CRÍA EXTENSIVA DE PEJERREY: especial atención a la comunidad zooplanctónica}

\subsection{Introducción}

El éxito del cultivo de peces en jaulas depende en gran medida de las características del cuerpo de agua en el cual se instalen las jaulas (Masser 2012). La elección del sitio de instalación del sistema resulta de gran importancia, ya que afecta la viabilidad del mismo (por ejemplo en términos económicos), la producción y la mortalidad (Beveridge 2004). Una ubicación apropiada de las unidades de cría en el ambiente es esencial para su correcto funcionamiento, particularmente en relación con la calidad del agua dentro de las jaulas y la reducción de los impactos ambientales en sus proximidades (Masser 2012). Según Beveridge (2004), existen tres criterios a tener en cuenta en la selección del sitio de instalación de un sistema de cría en jaulas flotantes:

- 1) Los factores ambientales necesarios para que una especie pueda prosperar (temperatura, salinidad, oxígeno, movimiento del agua, etc.).

- 2) Los factores ambientales necesarios para una instalación exitosa del sistema de jaulas flotantes (características climatológicas, resguardo, profundidad, sustrato).

- 3) Los factores vinculados con el establecimiento y la rentabilidad (aspectos legales, accesos, servicios, seguridad, consideraciones económicas y sociales).

En particular para el pejerrey criado de manera extensiva en jaulas emergen dos variables importantes a tener en cuenta, ambas vinculadas a la calidad del agua que ingresa en las unidades de cría: las características de las jaulas, sobre todo en términos de su permeabilidad, y las características de la comunidad zooplanctónica (como alimento natural de la especie) presente en el ambiente (Colautti et al. 2009b, Colautti et al. 2010). Este alimento natural "ofrecido" por el ambiente (zooplancton) resulta ser un factor importante que podría ser incorporado en el primero de los criterios definidos por Beveridge (2004) mencionados precedentemente. Además, resulta importante destacar que dichos factores 
ambientales a tener en cuenta también emergen como influyentes en el uso de otros sistemas de cría extensiva, como las cavas experimentales (Garcia de Souza et al. 2009).

Teniendo en cuenta los criterios influyentes se desarrolló la siguiente hipótesis de trabajo: "Entre los factores ambientales que afectan el crecimiento y la producción del pejerrey bajo cultivo extensivo en cavas experimentales y en jaulas flotantes, la disponibilidad del alimento natural es la que presenta mayor influencia".

Para comprobar la hipótesis, en el presente capítulo se estudia la influencia de los parámetros físico-químicos y de la disponibilidad de zooplancton (y sus características) de los tres ambientes lagunares estudiados: Chascomús, Lacombe y La Salada de Monasterio (ya descriptos en el capítulo II) sobre la cría extensiva de pejerrey. De esta manera se busca testear si entre dichas "características del ambiente de cultivo" es realmente la disponibilidad de zooplancton la variable que más afecta el crecimiento y la producción de pejerrey criado extensivamente en jaulas flotantes.

Para el caso de las cavas experimentales que posee el INTECH (descriptas en el capítulo III), se apunta a caracterizar el ambiente de cultivo y a identificar las condiciones que podrían ser las más apropiadas para la siembra de las larvas de pejerrey recién eclosionadas.

\subsection{Metodología particular}

Se realizaron dos etapas de trabajo de campo conformadas por cuatro experimentos en tres lagunas de la provincia de Buenos Aires:

* Parte 1 ("estudio preliminar"): Conformada por los experimentos 1 y 2 que se realizaron en Chascomús y Lacombe con dos objetivos particulares:

* Evaluar la relación entre las variables limnológicas y las características del zooplancton con el crecimiento del pejerrey criado en jaulas instaladas en dichos ambientes.

* Continuar con la puesta a punto del sistema de cría, ya implementado previamente en Lacombe (Colautti et al. 2010). 
* Parte 2: Conformada por los experimentos 3 y 4, realizados en Chascomús y La Salada de Monasterio. En esta parte además de evaluar la influencia del zooplancton en el crecimiento de los pejerreyes criados en jaulas, se observa su efecto sobre la supervivencia y producción.

Cada experimento contó a su vez de dos etapas: etapa "nursery" (EN) y etapa "experimental" (EE). Los diseños experimentales serán detallados para cada ensayo junto con los respectivos resultados. La EN del estudio preliminar se llevó a cabo en jaulas instaladas en las lagunas, por lo que los resultados serán tratados en conjunto con la $\mathrm{EE}$, mientras que en la parte 2 dicha EN se realizó en cavas, por lo cual los resultados serán tratados separadamente, en el caso que dicha etapa haya sido monitoreada (experimento 4). En todos los casos la EE fue llevada a cabo en jaulas flotantes instaladas en las lagunas, utilizando en un principio malla de tipo "mosquitero" y hacia el final de los experimentos mallas de tipo "anti-granizo".

Desde el inicio de las EN hasta el final de cada experimento se realizó un monitoreo de parámetros físico-químicos y de la abundancia y biomasa zooplanctónica (AZ y BZ), en las cavas y en las lagunas, tanto dentro como fuera de las jaulas.

Los parámetros físico-químicos evaluados durante cada experimento serán mencionados en los apartados de "metodología específica". Para evaluar similitudes y diferencias en la comunidad zooplanctónica de las lagunas se utilizaron los métodos multivariados descriptos en el capítulo III. En el caso del análisis Cluster, éstos fueron superpuestos a los gráficos MDS para evaluar si las lagunas se agruparon de manera diferencial de acuerdo a la composición de la comunidad zooplanctónica. En el experimento 4 además se realizaron comparaciones entre las jaulas con y sin peces.

Teniendo en cuenta que el diseño de los experimentos fue de dos factores y de tipo mixto, con un factor intra-sujetos (el tiempo) y un factor inter-sujetos (las lagunas), las medidas de longitud y peso de los peces se evaluaron estadísticamente mediante RM ANOVA (ANOVA de dos vías, para medidas repetidas). Mediante este análisis se pudo testear el efecto del tiempo, de las lagunas, y de la interacción entre ambos, sobre el crecimiento de los individuos criados. Dichas comparaciones se hicieron primero entre las jaulas de una misma laguna, para luego hacerse entre lagunas. En los casos en que no se hallaron diferencias entre jaulas se utilizó todo el "pool" de mediciones tomadas por fecha por laguna para la comparación entre lagunas, mientras que cuando existieron diferencias entre jaulas se utilizó el promedio por jaula. A su vez seguido de cada RM ANOVA se llevaron a cabo test 
"post hoc" de Bonferroni, para evaluar las diferencias en cuanto al crecimiento en cada fecha de muestreo.

Utilizando las variables físico-químicas obtenidas, las abundancias y biomasas zooplanctónicas y las tasas de crecimiento específicas (TCE) de los pejerreyes se realizaron regresiones múltiples (Sokal \& Rohlf 1995) con el objeto de identificar aquellas variables significativas en cuanto a su efecto sobre la tasa de crecimiento. Las AZ y BZ utilizadas para dicho análisis fueron ponderadas "entre fechas", calculando los promedios a partir de los intervalos de tiempo correspondientes con sus respectivas tasas de crecimiento (explicado en el capítulo III). 


\subsection{Diseños experimentales y Resultados}

\subsection{1 $\underline{\text { Parte } 1}$}

\section{Experimento 1}

Diseño experimental

\# EN: Dos jaulas "nursery" en Chascomús y dos en Lacombe sembradas con pejerreyes de 3 días de vida.

- Densidad de siembra: 117 ind./ $\mathrm{m}^{3}$ (1400 ind./ jaula)

- Fecha de siembra: $24 / 11 / 2006$

\# EE: Jaulas (mosquitero), dos en Chascomús y dos en Lacombe, sembradas con pejerreyes de 23 días de vida.

- Fecha de siembra: 14/12/2006

- Duración del experimento: 27 días en Chascomús (50 días de edad) y 110 días en Lacombe (133 días de edad).

Metodología específica: Los parámetros evaluados durante el experimento 1 fueron $\mathrm{pH}$, salinidad y temperatura del agua (la cual pudo ser registrada de manera automatizada y continua únicamente para la laguna Chascomús, ya que los medidores instalados en Lacombe presentaron problemas técnicos que impidieron contar con el registro continuo).

\section{Resultados}

\section{Parámetros físico-químicos}

No se encontraron grandes diferencias entre las lagunas en las variables físicoquímicas medidas: el pH promedio fue de 8,65 en Chascomús y de 9,5 en Lacombe. La salinidad promedio fue de 0,3 $\mathrm{g} / \mathrm{l}$ en Chascomús y $0,45 \mathrm{~g} / \mathrm{l}$ en Lacombe. La temperatura promedio del agua fue de $26,3{ }^{\circ} \mathrm{C}$ en Chascomús (Figura IV.1). Las jaulas de la laguna Chascomús fueron objeto de vandalismo y el experimento tuvo que darse por finalizado en esa laguna a los 50 días de vida de los peces. En el caso de Lacombe, el experimento duró hasta los 113 días de vida de los peces, y en ese momento (febrero de 2007) se registró en dicha laguna una notoria bajante del nivel hidrométrico y un crecimiento importante de macrófitas sumergidas (Myriophyllum sp.) que cubrieron el 70\% del cuerpo de agua. 


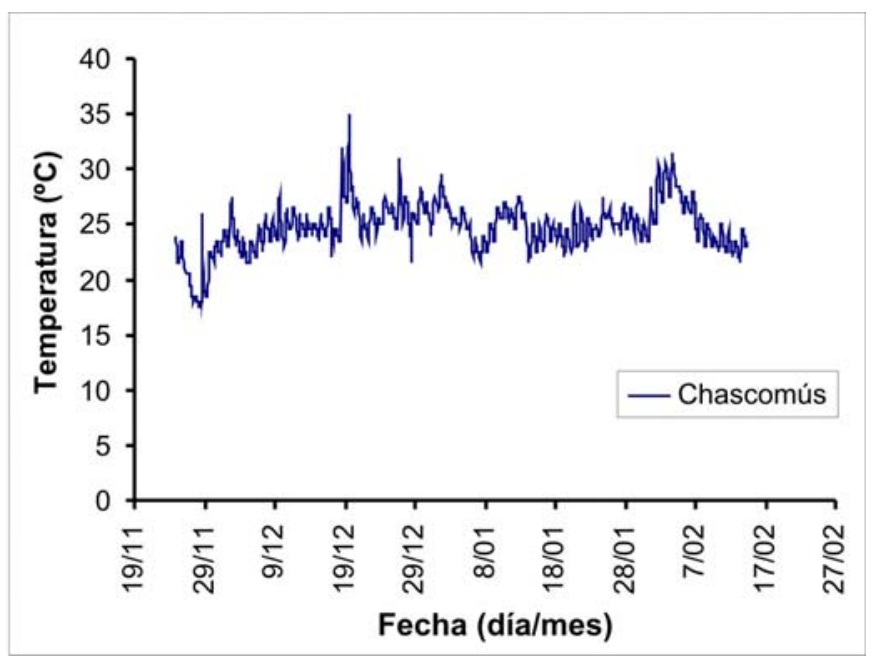

Figura IV.1: Temperaturas registradas en la laguna de Chascomús a lo largo del experimento 1.

\section{Comunidad zooplanctónica}

La composición taxonómica del zooplancton de la laguna Chascomús fue de 8 especies de rotíferos, 5 especies de copépodos (3 Cyclopoida, 1 Calanoida y 1 Harpacticoida) y 2 especies de cladóceros, y en Lacombe se encontraron 11 especies de rotíferos, 5 copépodos (3 Cyclopoida, 1 Calanoida y 1 Harpacticoida) y 3 cladóceros (Anexo 1).

En cuanto a la abundancia total zooplanctónica (AZ) de las lagunas (promedio de las muestras tomadas fuera de las jaulas), el pico máximo del período de estudio ocurrió en ambos ambientes en el mes de enero (Figura IV.2). Dicho valor máximo fue marcadamente más elevado en la laguna Lacombe, con 3500 ind./l, representados casi exclusivamente por rotíferos, principalmente Brachionus havanaensis (2669 ind./l). En la laguna de Chascomús la AZ no tuvo grandes variaciones a lo largo del período de estudio, aunque el momento de mayor AZ coincidió con el de Lacombe. 


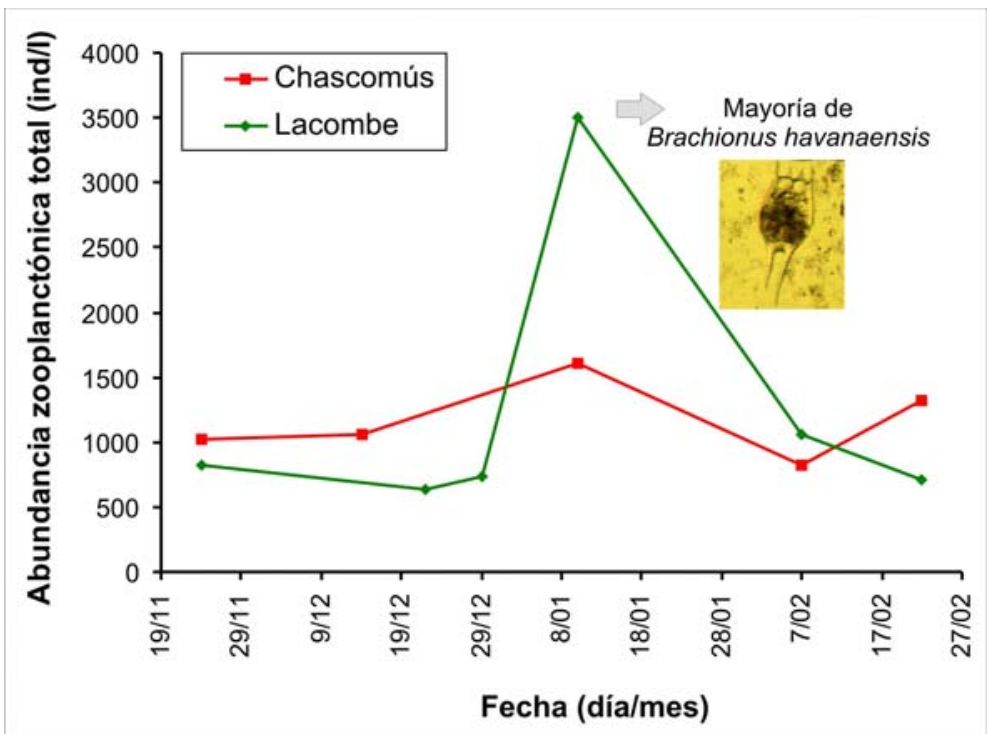

Figura IV.2: Abundancia zooplanctónica total promedio registrada fuera de las jaulas en Chascomús y Lacombe (experimento 1). Se indica el rotífero Brachionus havanaensis, mayoritario durante el máximo de AZ en Lacombe.

Los rotíferos fueron el grupo dominante durante todo el período en la laguna de Chascomús, mientras que en Lacombe lo fueron sólo para la segunda mitad, desde la fecha donde se observó el pico máximo en adelante. En las primeras fechas las larvas nauplii de copépodos fueron dominantes en Lacombe, aunque con bajos valores de AZ (Figura IV.3). El zooplancton de tamaño pequeño (Categoría I, conformada por ítems de hasta 0,3 mm) dominó en abundancia durante todo el período de estudio en ambas lagunas (Figura IV.4).

Al comparar la comunidad zooplanctónica de ambas lagunas en términos de AZ por especies, se encontraron diferencias (ANOSIM de una vía, $R=0,632 ; p<0,05$ ). Dicha diferencia (SIMPER, 51\% de disimilitud entre lagunas) tuvo como "especies discriminantes" a los rotíferos Keratella tropica y Brachionus caudatus, notablemente más abundantes en Chascomús durante todo el experimento (Figura IV.5). Otro rotífero que tuvo diferencias en su $A Z$ fue $B$. havanaensis, con mayores $A Z$ en Chascomús durante la primera parte del experimento, pero no fue identificada como "discriminante" ya que en el verano tuvo valores altos de $A Z$ en ambas lagunas. 


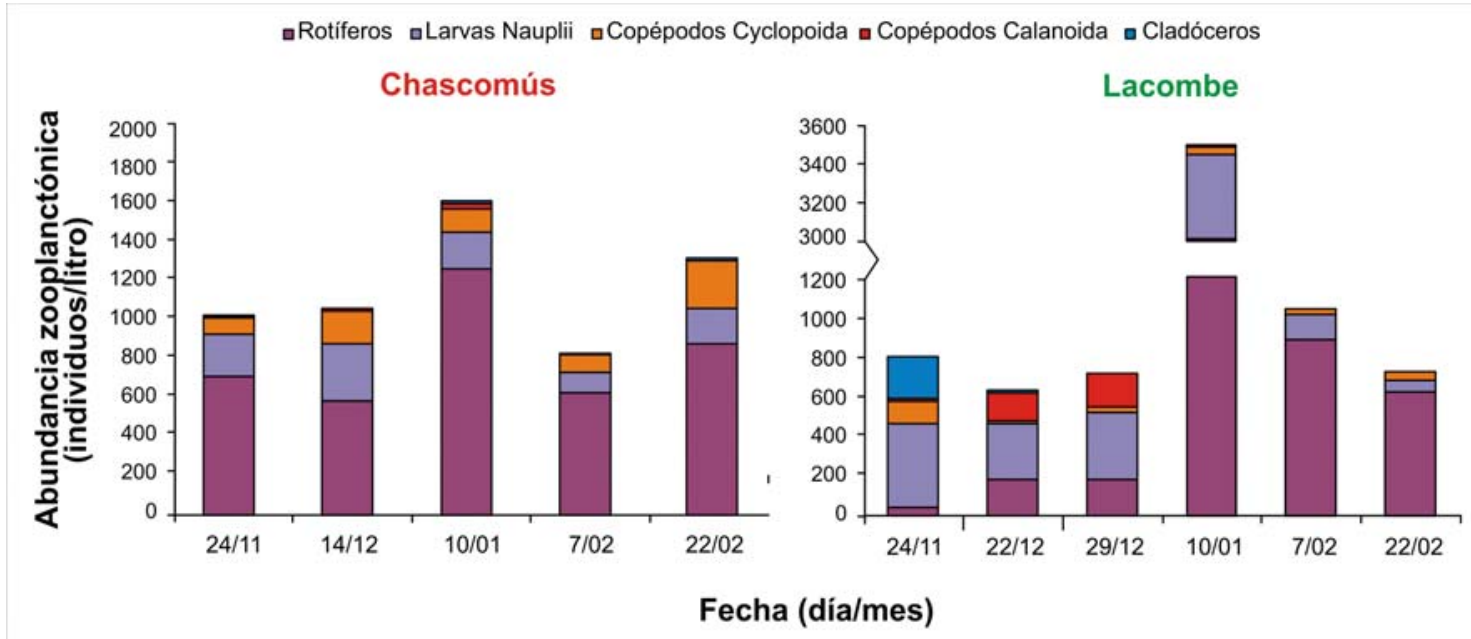

Figura IV.3: Abundancia zooplanctónica registrada en las lagunas, discriminada por grupos taxonómicos

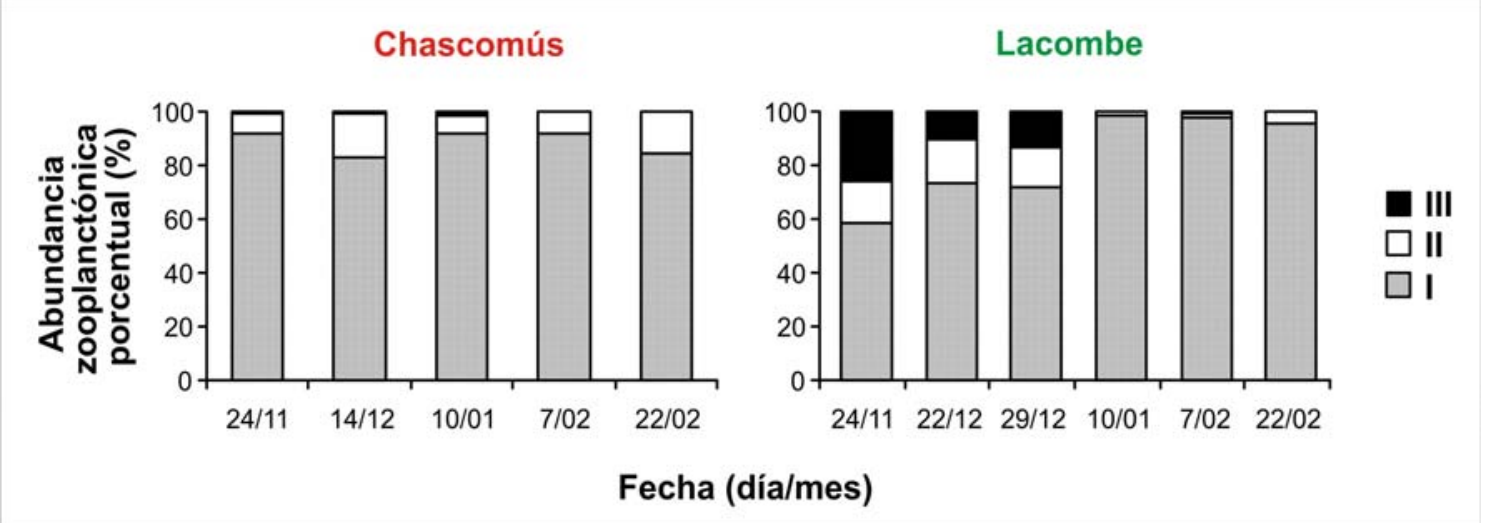

Figura IV.4: Abundancia zooplanctónica registrada en las lagunas, discriminada por categorías de tamaño (I = hasta 0,3 mm, II = 0,3-0,7 $\mathrm{mm}$ y III = más de 0,7 mm).

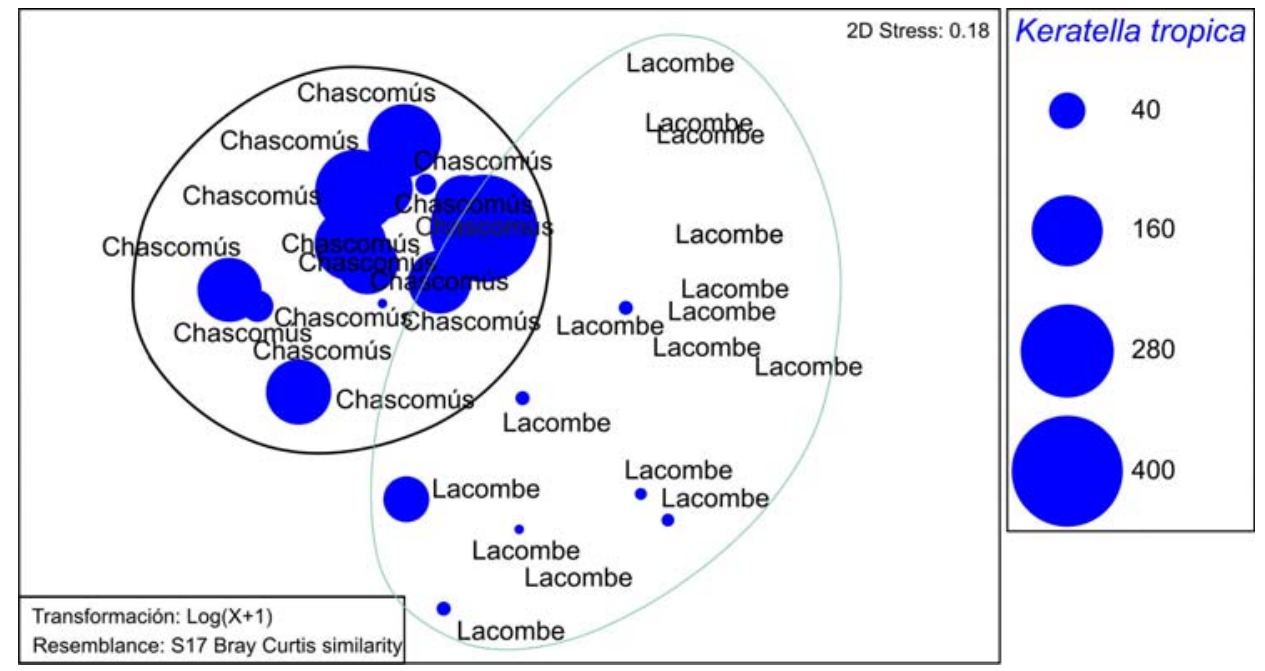

Figura IV.5: MDS comparando ambas lagunas donde se indican con líneas verdes los análisis cluster superpuestos y con burbujas azules la dominancia de la especie discriminante: Keratella tropica 
Respecto de la biomasa total zooplanctónica por litro (BZ), los patrones seguidos en ambos ambientes fueron opuestos (Figura IV.6). En Lacombe la BZ fue alta al principio del experimento (valores cercanos a los $1000 \mu \mathrm{g}$ ps/l) y descendió hasta ser muy baja al final en el mes de febrero. En Chascomús dicho valor fue aumentando a lo largo del experimento, aunque sin alcanzar valores muy elevados en ningún momento del ciclo (el pico fue de 643 $\mu \mathrm{g}$ ps/l en el muestreo de fines de febrero).

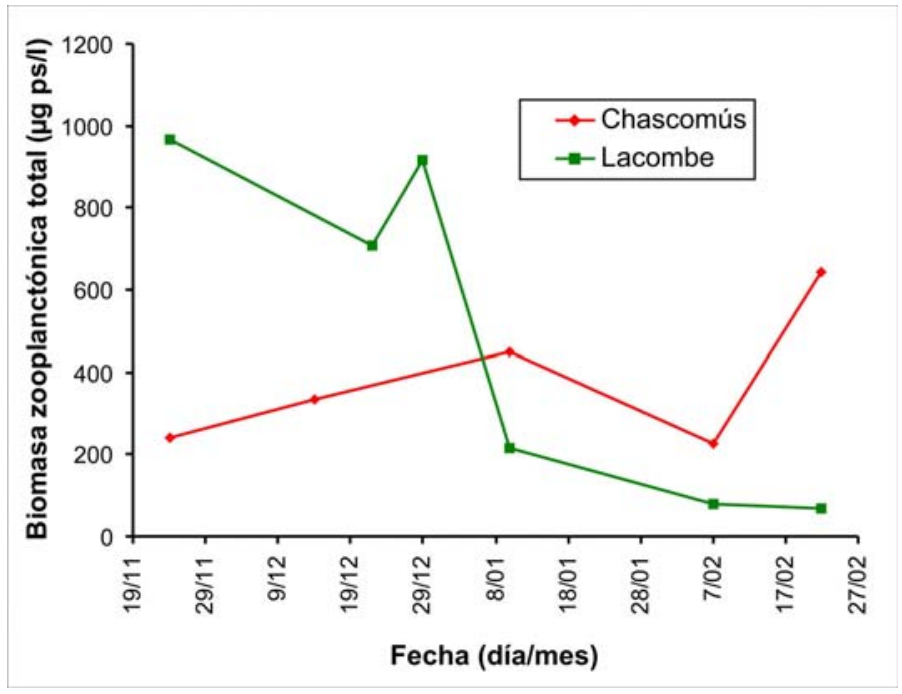

Figura IV.6: Biomasa zooplanctónica total promedio, registrada fuera de las jaulas en Chascomús y Lacombe

Los individuos de tamaño intermedio (categoría II, entre 0,3 y 0,7 mm) y grande (categoría III, más de 0,7 mm) fueron los que más aportaron a la BZ en todo el experimento en Chascomús y en la primera mitad del mismo en Lacombe. Durante la segunda mitad (enero y febrero) los de menor talla (I) fueron los dominantes en biomasa (Figura IV.7) en Lacombe.

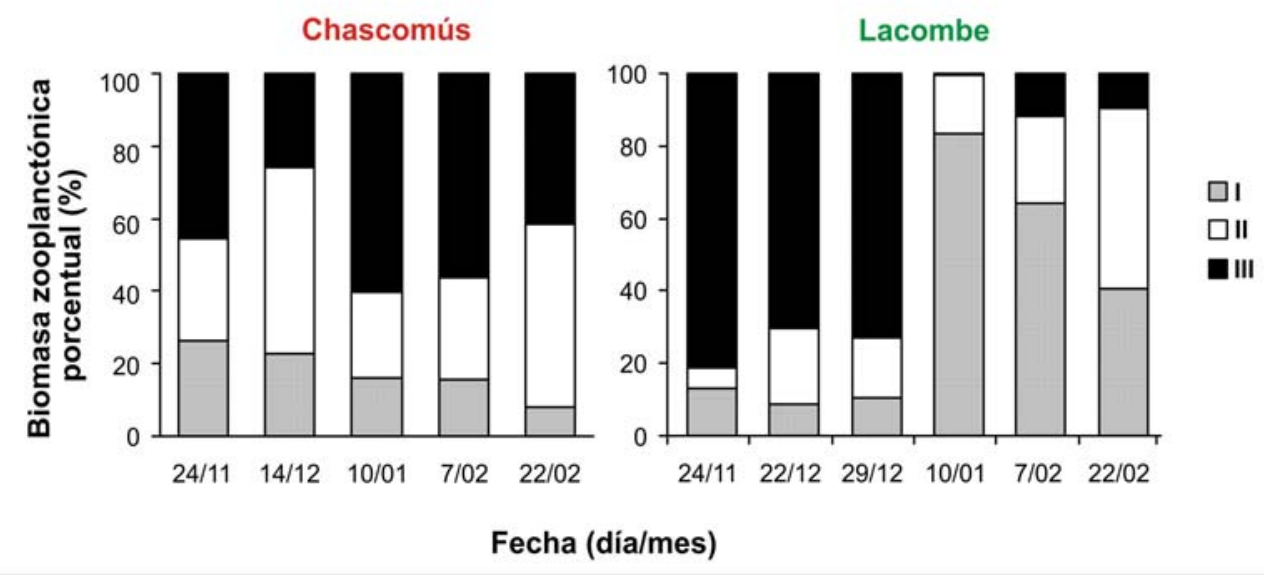

Figura IV.7: Biomasa zooplanctónica porcentual registrada en las lagunas, por categorías de tamaño ( $\mathrm{I}=$ hasta 0,3 $\mathrm{mm}, \mathrm{II}=0,3-0,7 \mathrm{~mm}$ y III $=$ más de $0,7 \mathrm{~mm}$ ). 
En términos de BZ por especies se encontraron diferencias entre lagunas (ANOSIM de una vía, $R=0,467 ; p<0,05$ ), y se identificaron como especies discriminantes (SIMPER, 49,4\% de disimilitud) a los copépodos Cyclopoida: Metacyclops mendocinus y A. robustus (estadío de copepodito), por presentar mayor BZ en Chascomús (94,8 y 115,5 $\mathrm{mg}$ ps/l en promedio, respectivamente) y al copépodo Calanoida Notodiaptomus incompositus con mayor BZ en Lacombe durante los meses de noviembre y diciembre (574,2 $\mu \mathrm{g}$ ps/l promedio) y en Chascomús durante enero y febrero (49,1 $\mu \mathrm{g}$ ps/l promedio) (Figura IV.8).

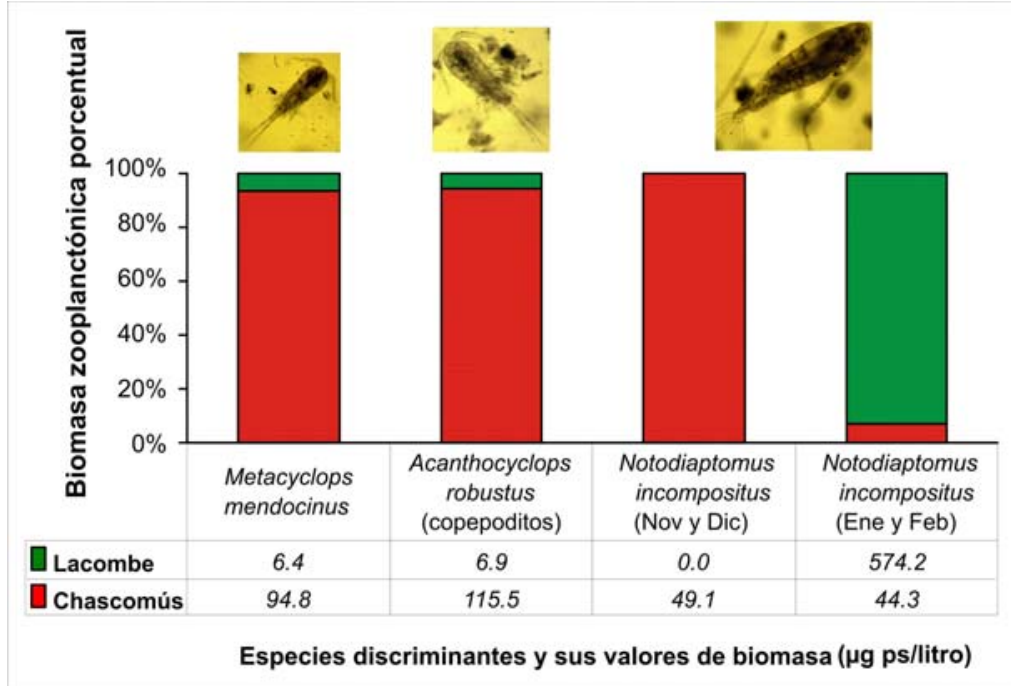

Figura IV.8: Biomasa zooplanctónica ( $\mu \mathrm{g}$ ps/l) de las especies discriminantes identificadas por el SIMPER y su correspondiente contribución porcentual al comparar los valores entre ambas lagunas.

\section{Crecimiento del pejerrey cultivado}

No se observaron diferencias entre las jaulas instaladas en Chascomús en cuanto a la longitud (RM ANOVA, $\left.F_{(1,20)}=3,32 ; p=0,08\right)$ y al peso (RM ANOVA, $F_{(1,21)}=0,37 ; p=0,55$ ). Tampoco fueron diferentes los valores de crecimiento en Lacombe, tanto en largo (RM ANOVA, $\left.F_{(1,18)}=0,62 ; p=0,44\right)$ como en peso (RM ANOVA, $\left.F_{(1,16)}=2,41 ; p=0,14\right)$. Teniendo en cuenta las dos fechas de muestreo comparables (a los 23 y 50 días de edad), al comparar el crecimiento entre lagunas (Figura IV.9), mediante ANOVA de medidas repetidas, se observó que la interacción entre el factor "tiempo" y el factor "laguna" fue significativa, tanto para los valores de longitud ( $R M$ ANOVA, $\left.F_{(1,42)}=73,24 ; p<0,05\right)$ como para el peso (RM ANOVA, $\left.F_{(1,42)}=142,3 ; p<0,05\right)$. En las dos fechas el mayor crecimiento se observó en los peces criados en la laguna Chascomús (Test de Bonferroni, $p<0,05$ ). La longitud total (LT) 
promedio alcanzada en Chascomús $(5,3 \mathrm{~cm})$ a los 50 días, se pudo alcanzar en Lacombe recién en el doble de tiempo $(5,7 \mathrm{~cm}$ los 93 días).

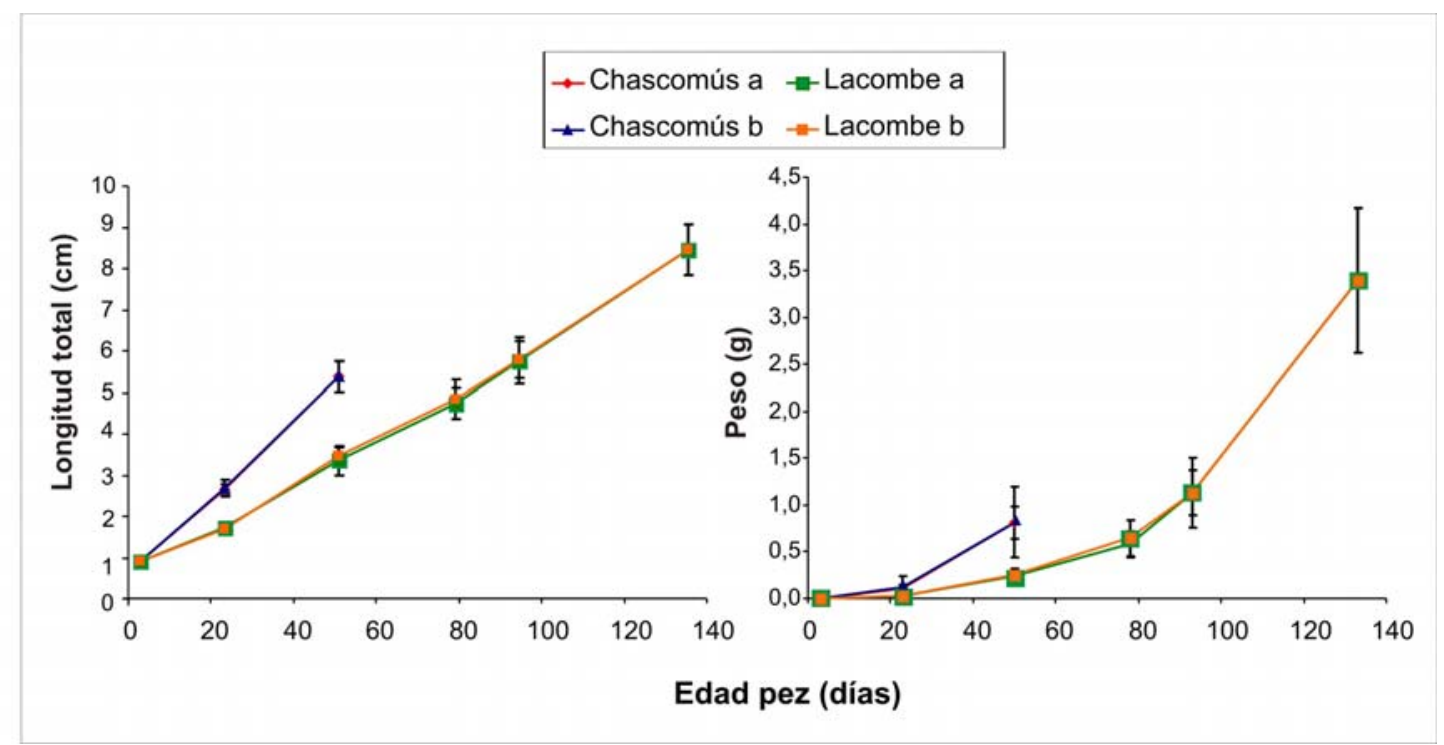

Figura IV.9: Crecimiento en longitud y en peso (LT y W promedio por jaula y sus desvíos) de los pejerreyes criados en las jaulas instaladas en Chascomús ( $\mathrm{a}$ y b) y Lacombe (a y b) durante el experimento 1.

Las regresiones múltiples pudieron realizarse únicamente para Lacombe, por falta de datos en Chascomús, utilizando las tasas de crecimiento en largo y peso como variables dependientes y la salinidad, el pH y las AZ y BZ (de la laguna) normalizadas por período (AZN y BZN), como variables independientes (previamente estandarizadas). Globalmente se obtuvieron valores de $R^{2}$ elevados y significativos, tanto al utilizar las tasas en largo $\left(R^{2}=\right.$ 0,$\left.999 ; F_{(4,1)}=3593,4 ; p<0,05\right)$ como al utilizar las tasas en peso $\left(R^{2}=0,999 ; F_{(4,1)}=328,9\right.$; $p<0,05)$. Ambas regresiones identificaron las $A Z N$ y $B Z N$ de la laguna como variables significativas, indicadoras de la TCE en longitud y en peso, AZN con valor negativo y BZN con valor positivo, siendo los modelos ajustados:

$T C E=a+x 1 A Z N+x 2 B Z N$

Donde, para el largo: $a=-0,020 ; x 1=-0,0003 ; x 2=0,0006(p<0,05)$ y para el peso: $a=-0,265$; $x 1=-0,002 ; x 2=0,002(p<0,05)$. 


\section{Experimento 2}

Diseño experimental

\# EN: Dos jaulas en la laguna Chascomús y dos en Lacombe sembradas con
pejerreyes de 3 días de vida.
Densidad de siembra: $42 \mathrm{ind} . / \mathrm{m}^{3}$ ( 500 ind./ jaula)
Fecha de siembra: $10 / 03 / 2007$
\# EE: Jaulas (mosquitero), dos en la laguna Chascomús y dos en Lacombe, sembradas
con pejerreyes de 24 días de vida.
Fecha de siembra: $03 / 04 / 2007$
Duración del experimento: 77 días en jaulas (101 días de edad)
Metodología específica: Los parámetros evaluados fueron pH, salinidad, temperatura del
agua, profundidad, transparencia, conductividad y oxígeno disuelto, sólo para la etapa N.

Resultados

\section{Parámetros físico-químicos}

Las lagunas fueron similares en cuanto a las variables físico-químicas medidas durante la etapa nursery del experimento 2 (Tabla IV.1).

Tabla IV.1: Parámetros físico-químicos registrados en Chascomús y Lacombe, etapa "nursery", experimento 2.

\begin{tabular}{lccccccc}
\multicolumn{1}{c}{ Laguna } & Fecha & $\begin{array}{c}\text { Profundidad } \\
(\mathbf{m})\end{array}$ & $\begin{array}{c}\text { Transparencia } \\
(\mathbf{m} \text { de Secchi) }\end{array}$ & $\begin{array}{c}\text { Conductividad } \\
(\mathbf{m S / c m})\end{array}$ & $\mathbf{p H}$ & $\begin{array}{c}\text { Oxígeno } \\
\text { Disuelto } \\
(\mathbf{m g} / \mathbf{L})\end{array}$ & $\begin{array}{c}\text { Temperatura } \\
\left({ }^{\circ} \mathbf{C}\right)\end{array}$ \\
\hline Chascomús & $19 / 03 / 2007$ & 1,18 & 0,13 & 2,3 & 9 & 11,2 & 23,7 \\
Lacombe & $19 / 03 / 2007$ & 1,13 & 0,60 & 2,9 & 10,1 & 9,5 & 20,8 \\
Chascomús & $3 / 04 / 2007$ & 1,16 & 0,17 & 2,2 & 8,8 & 10,6 & 21,3 \\
Lacombe & $3 / 04 / 2007$ & 1,39 & 0,80 & 2,6 & 9,7 & 12,4 & 21,9 \\
\hline
\end{tabular}

\section{Comunidad zooplanctónica}

La composición taxonómica resultó similar a la del experimento 1 (Anexo 1). La AZ total registró un marcado descenso desde el inicio del experimento hasta el final en la laguna de Chascomús, mientras que en Lacombe tuvo valores bajos durante todo el mismo, salvo en un muestreo donde se registró un pico de 1185 ind./I (Figura IV.10), que de todos modos fue menor al registrado al comienzo del experimento en Chascomús (1422 ind./l). 


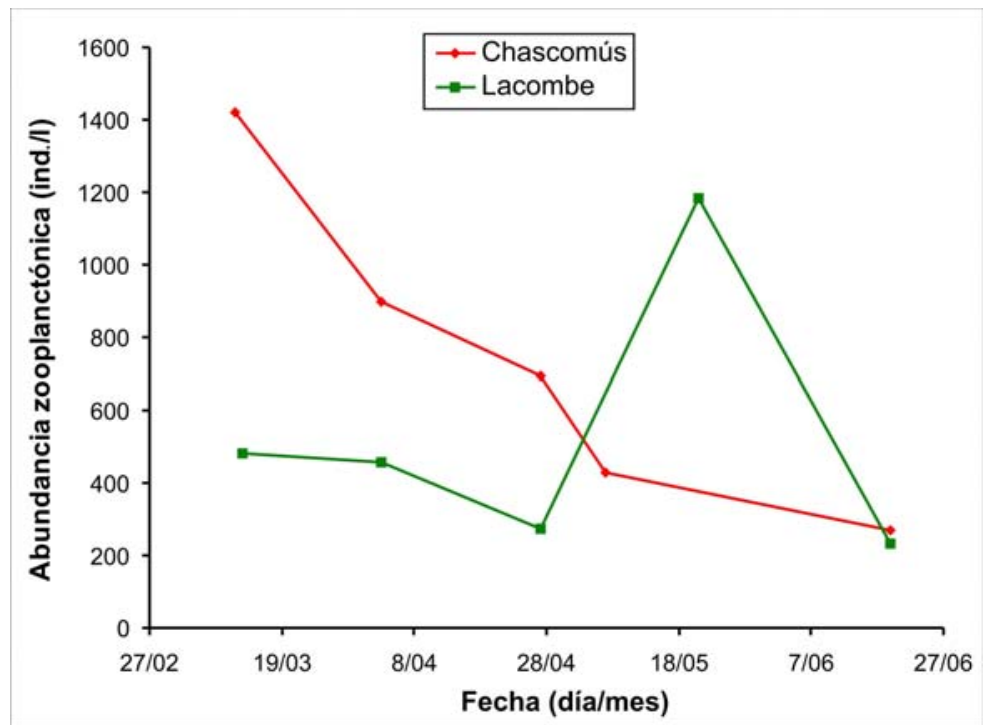

Figura IV.10: Abundancia total zooplanctónica promedio por fecha, registrada fuera de las jaulas en Chascomús y Lacombe durante el experimento 2.

Durante todo el experimento dominaron en abundancia las larvas nauplii de copépodos y los rotíferos, principalmente las especies: Brachionus caudatus, B. havanaensis y Keratella tropica en Chascomús y B. plicatilis y Lecane luna en Lacombe (Figura IV.11). Por ende, en términos de tamaño los dominantes fueron los integrantes del zooplancton de clase I (Figura IV.12).

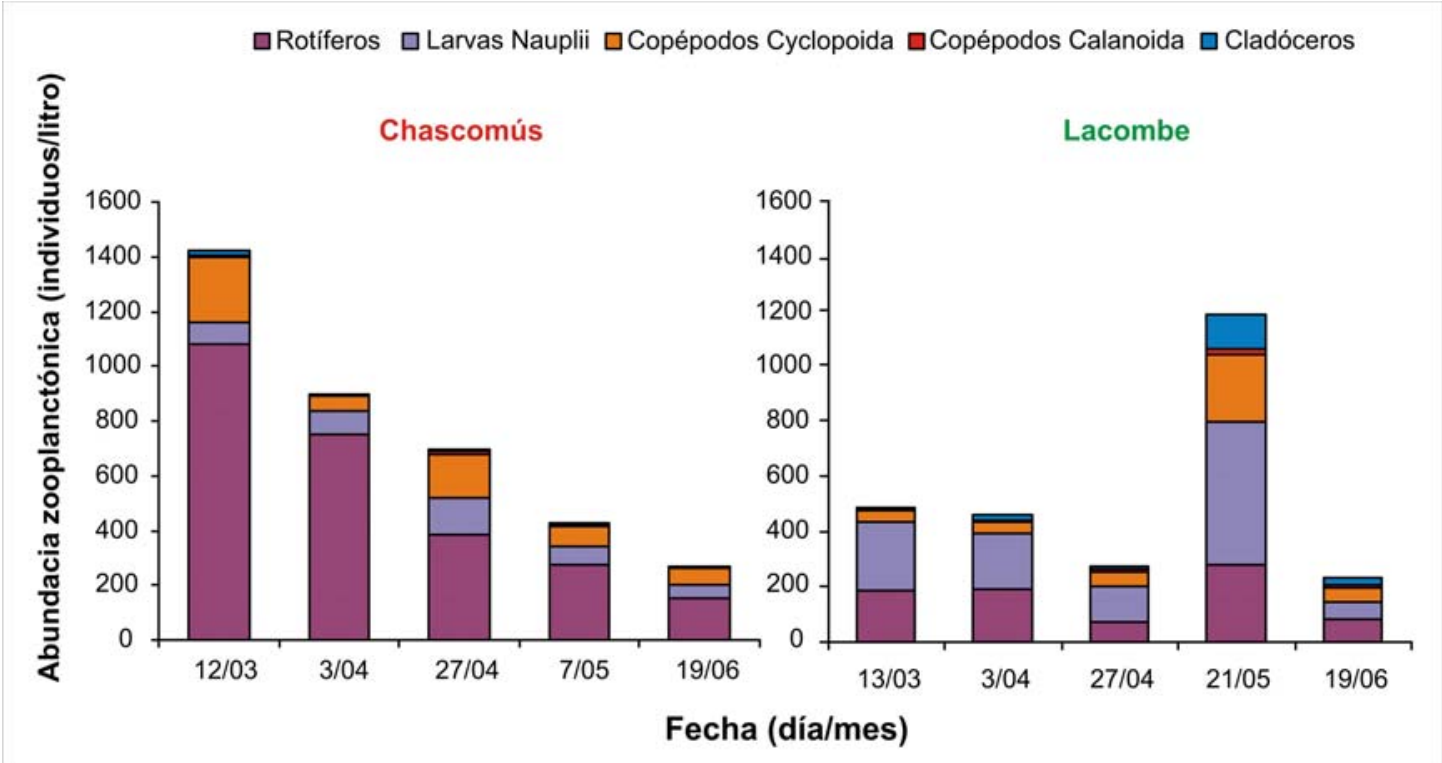

Figura IV.11: Abundancia zooplanctónica registrada en las lagunas, discriminada por grupos taxonómicos 


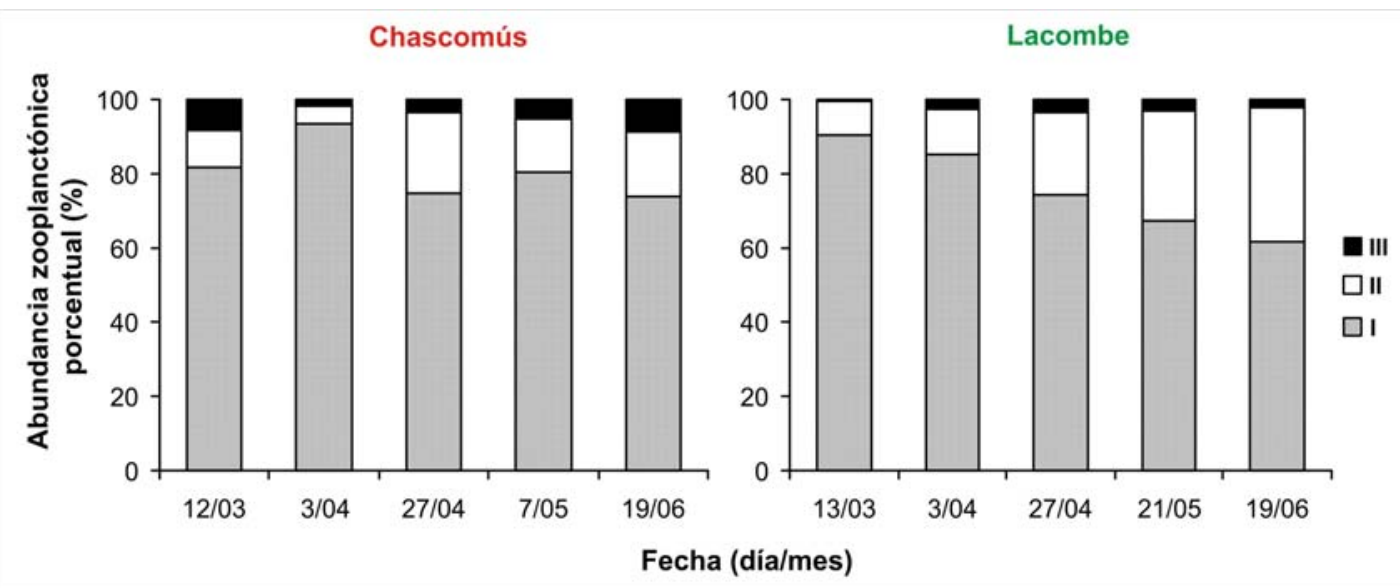

Figura IV.12: Abundancia zooplanctónica registrada en las lagunas, discriminada por categorías de tamaño (I = hasta $0,3 \mathrm{~mm}$, II = 0,3-0,7 $\mathrm{mm}$ y III = más de 0,7 mm).

Se observaron diferencias entre las lagunas en términos de AZ por especies (ANOSIM, $R=0,84 ; p<0,05)$, identificándose como "especies discriminantes" (SIMPER) al copepodito de A. robustus (presente exclusivamente en Chascomús durante todo el experimento) y a $K$. tropica (más abundante en Chascomús) y B. plicatilis (presente casi exclusivamente en Lacombe) (Figura IV.13).

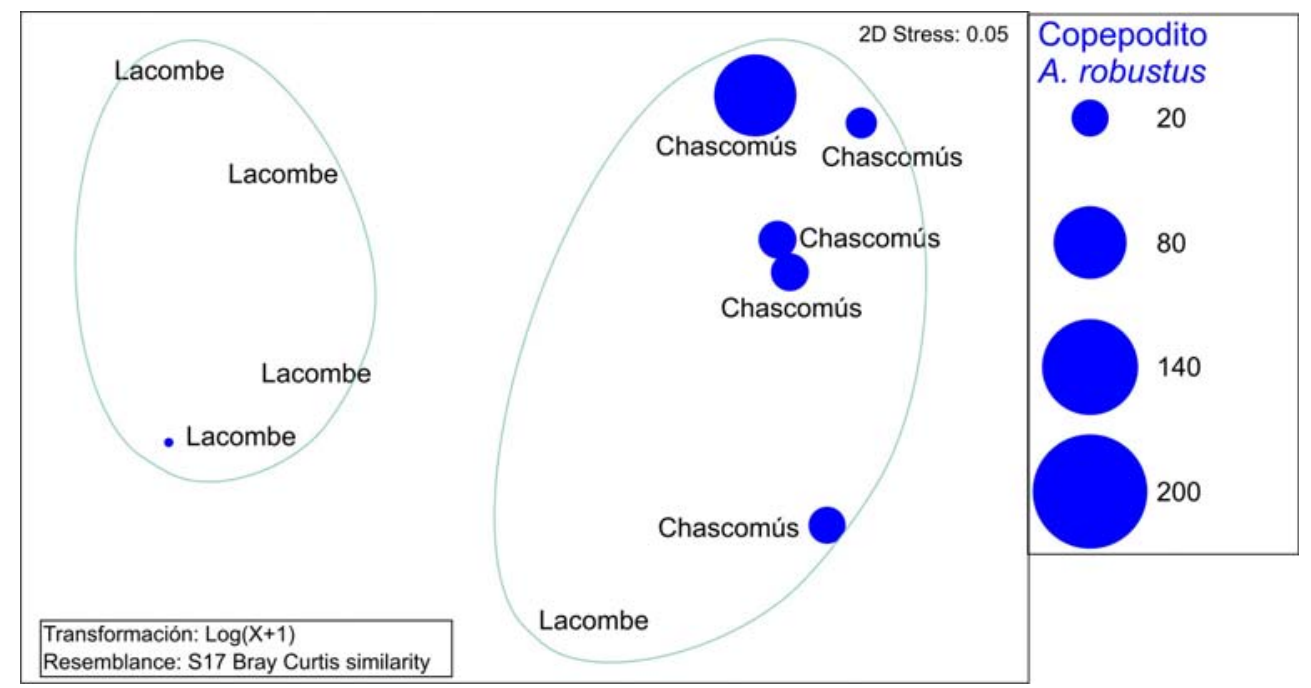

Figura IV.13: MDS comparando ambas lagunas donde se indican con líneas verdes los análisis cluster superpuestos y con burbujas azules la dominancia de la especie discriminante: Acanthocyclops robustus (copepodito).

En términos de $B Z$, el comportamiento de las lagunas fue similar a lo acontecido con AZ (Figura IV.14), con un pico máximo para la laguna Chascomús en el primer muestreo (debido principalmente al copepodito de A. robustus). 


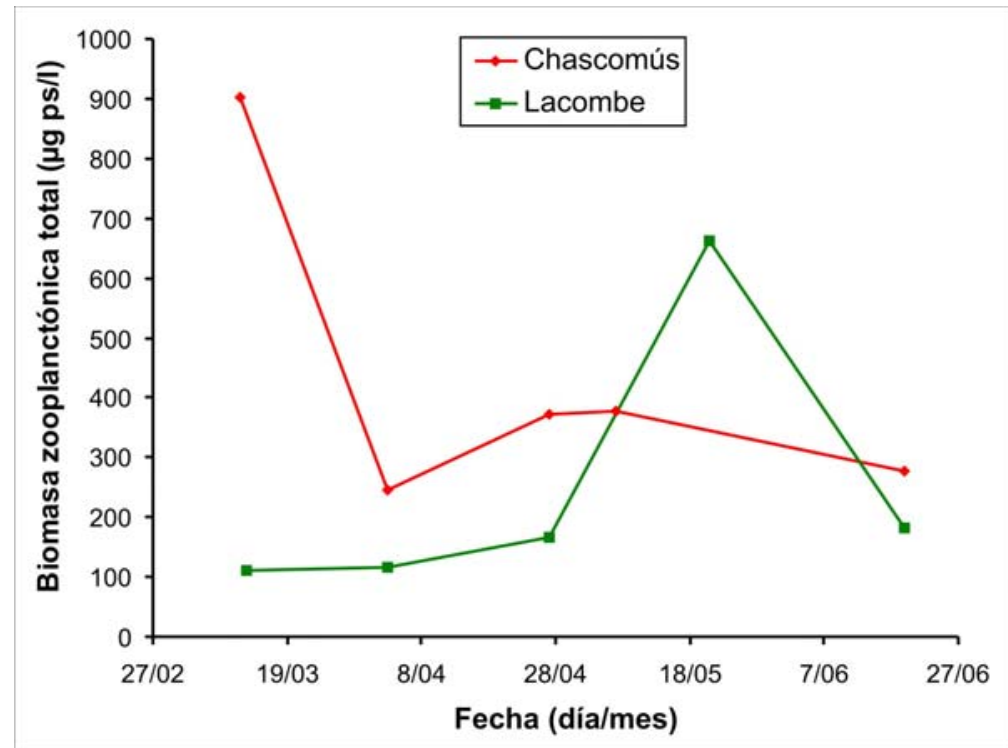

Figura IV.14: Biomasa total zooplanctónica promedio por fecha, registrada fuera de las jaulas en Chascomús y Lacombe, durante el experimento 2.

En la laguna de Chascomús los individuos de mayor tamaño fueron los dominantes en términos de biomasa en casi todos los muestreos, mientras que en Lacombe lo hicieron los de tamaño intermedio (Figura IV.15).

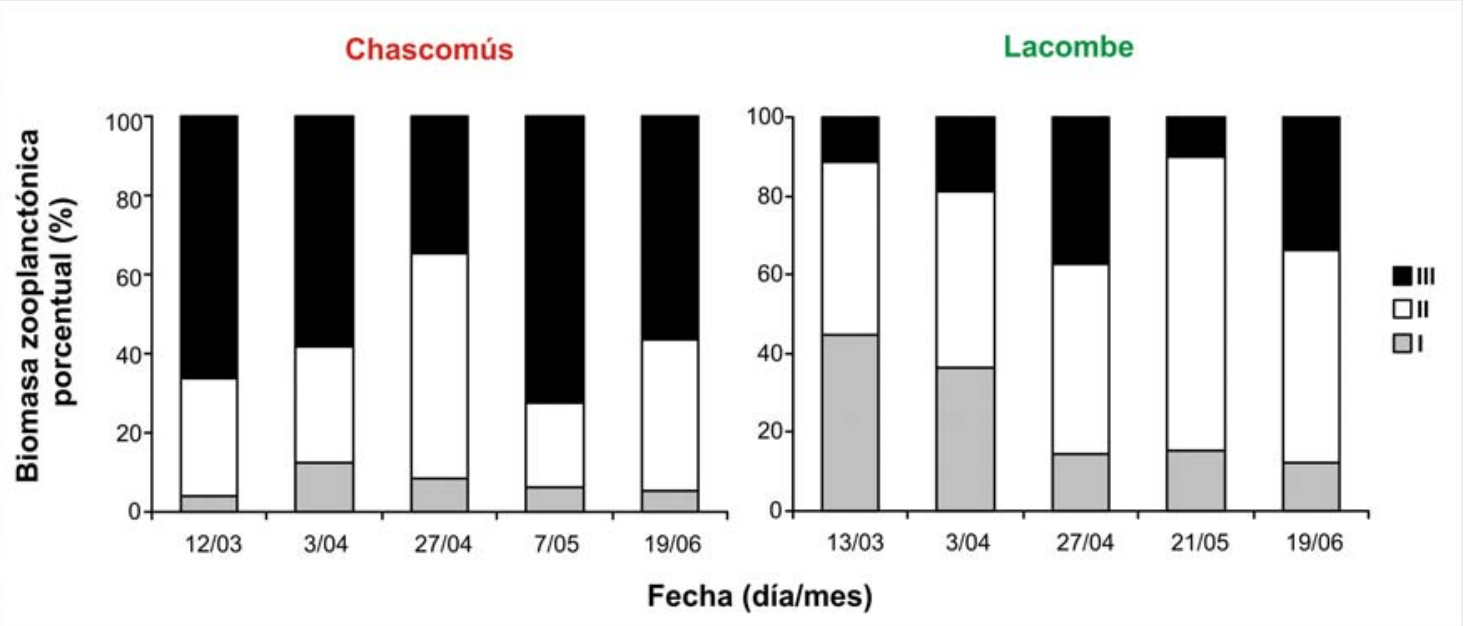

Figura IV.15: Biomasa zooplanctónica porcentual registrada en las lagunas, por categorías de tamaño(I = hasta 0,3 mm, II = 0,3-0,7 mm y III = más de 0,7 mm).

Las lagunas presentaron diferencias en términos de BZ por especies (ANOSIM, R = $0,824 ; p<0,05)$ y la especie que más aportó a dichas diferencias (SIMPER) fue $A$. robustus con mayores biomasas registradas para Chascomús (promedio de 130,7 $\mu \mathrm{g}$ ps/l de copepoditos de la especie y de $105,85 \mu \mathrm{g}$ ps/l de adultos). 


\section{Crecimiento del pejerrey cultivado}

No se observaron diferencias entre las jaulas instaladas en Chascomús en cuanto a la longitud (RM ANOVA, $\left.F_{(1,14)}=0,04 ; p=0,84\right)$ y al peso (RM ANOVA, $F_{(1,14)}=0,27 ; p=0,61$ ). Tampoco fueron diferentes los valores de crecimiento en Lacombe en cuanto al largo (RM ANOVA, $\left.F_{(1,18)}=3,83 ; p=0,06\right)$, mientras que sí hubo diferencias entre las jaulas al comparar el crecimiento en peso (RM ANOVA, $\left.F_{(1,18)}=7,82 ; p<0,05\right)$.

Al comparar el crecimiento en largo entre lagunas (Figura IV.16), se observó que la interacción entre el factor "tiempo" y el factor "laguna" fue significativa (RM ANOVA, $F_{(2,68)}=$ 8,8; $p<0,05)$. En el caso del peso, las lagunas fueron diferentes entre sí (RM ANOVA, $F_{(1,2)}=$ $55,5 ; p<0,05)$. El crecimiento fue mayor en largo y en peso en los peces criados en la Laguna Chascomús en todas las fechas (test de Bonferroni: $p<0,05$ ). La única excepción a este patrón se encontró para el peso en la primera fecha de muestreo. Los valores promedio obtenidos al final del experimento (101 días de edad) fueron 4,8 y 3,8 cm, y 0,6 y 0,25 g, en Chascomús y Lacombe, respectivamente.

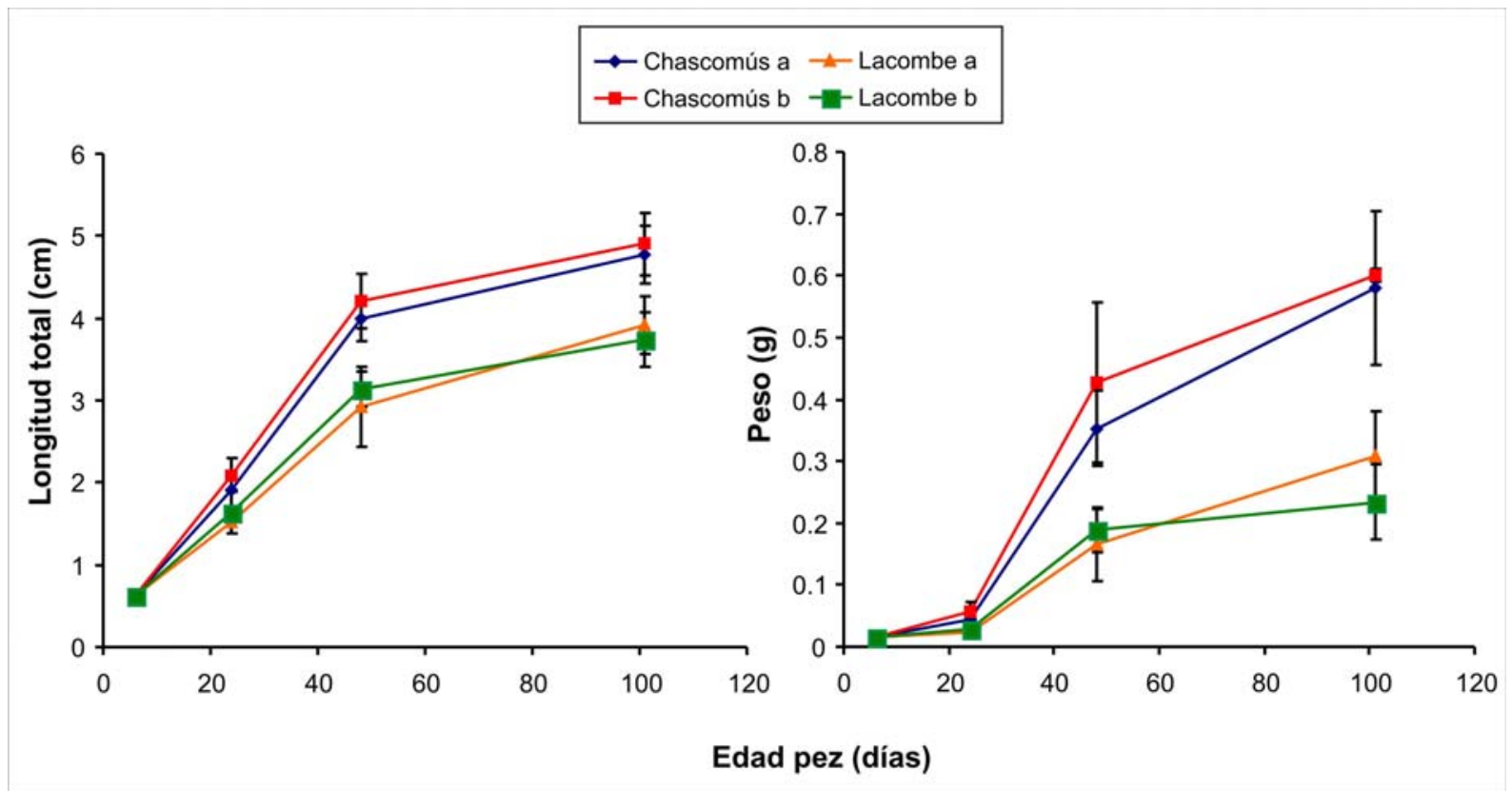

Figura IV.16: Crecimiento en longitud y peso (LT y W promedio por jaula y sus desvíos) de los pejerreyes criados en las jaulas instaladas en Chascomús ( $\mathrm{a}$ y b) y Lacombe (a y b) durante el experimento 2.

Ante la falta de datos de variables ambientales no pudo realizarse la regresión, y al comparar las TCE (LT y W) con AZN y BZN no se observó ninguna correlación significativa. 


\subsection{2 $\quad$ Parte 2}

\section{Experimento 3}

Diseño experimental

\# EN: Obtención de postlarvas en cavas (sin seguimiento).

\# EE: Jaulas (mosquitero), cuatro en la laguna de Chascomús y cuatro en La Salada de Monasterio sembradas con pejerreyes de 25 días de vida.

- Densidad de siembra: 67 ind./ $/ \mathrm{m}^{3}$ (800 ind./jaula).

- Fecha de siembra: $21 / 12 / 2007$.

- Duración del experimento: 206 días en jaulas (231 días de edad).

- Estuvieron en jaulas común antes de ser divididos en las cuatro jaulas por laguna. A los 37 días de edad (02/01/2008) fue la división.

Metodología específica: Los parámetros físico-químicos evaluados fueron $\mathrm{pH}$, salinidad, temperatura del agua, profundidad, transparencia, conductividad y oxígeno disuelto, sólo para la etapa experimental. Durante el mes de abril se detectaron problemas en los medidores automáticos de temperatura en La Salada por lo cual no hay datos para ese momento del experimento.

\section{Resultados (EE)}

\section{Parámetros físico-químicos}

Las lagunas fueron similares en cuanto a las variables físico-químicas medidas (Tabla IV.2 y Figura IV.17), aunque se observaron algunas diferencias en cuanto a la transparencia (mayor en La Salada, con un promedio de $50 \mathrm{~cm}$ ) y en cuanto a la conductividad (mayor en Chascomús, con un promedio de $1,9 \mathrm{mS} / \mathrm{cm}$ ).

Tabla IV.2: Parámetros físico-químicos registrados en las lagunas Chascomús y La Salada de Monasterio durante el experimento 3.

\begin{tabular}{lccccccc}
\multicolumn{1}{c}{ Laguna } & Fecha & $\begin{array}{c}\text { Profundidad } \\
(\mathbf{m})\end{array}$ & $\begin{array}{c}\text { Transparencia } \\
(\mathbf{m} \text { de Secchi) }\end{array}$ & $\begin{array}{c}\text { Conductividad } \\
(\mathbf{m S} / \mathbf{c m})\end{array}$ & $\mathbf{p H}$ & $\begin{array}{c}\text { Oxígeno } \\
\text { Disuelto } \\
(\mathbf{m g} / \mathbf{L})\end{array}$ & $\begin{array}{c}\text { Temperatura } \\
\left({ }^{\circ} \mathbf{C}\right)\end{array}$ \\
\hline Chascomús & $21 / 12 / 2007$ & 1,7 & 0,15 & 1,9 & 8,7 & 6,9 & 27,4 \\
La Salada & $21 / 12 / 2007$ & 2 & 0,61 & 1,2 & 8,8 & 6,7 & 25,7 \\
Chascomús & $30 / 01 / 2008$ & 1,48 & 0,14 & 2,5 & 8,6 & 6,5 & 23,8 \\
La Salada & $30 / 01 / 2008$ & 1,88 & 0,38 & 1,9 & 8,6 & 7,7 & 24,1 \\
Chascomús & $14 / 03 / 2008$ & 1,58 & & 0,3 & 9,1 & 9,6 & 21,0 \\
La Salada & $14 / 03 / 2008$ & 1,9 & & 1,4 & 8,9 & 6,8 & 21,5 \\
Chascomús & $5 / 05 / 2008$ & 1,55 & 0,21 & 3,1 & 9,1 & 9,4 & 13,7 \\
La Salada & $5 / 05 / 2008$ & 1,8 & 0,50 & 2,0 & 8,9 & 9,8 & 13,9 \\
\hline
\end{tabular}




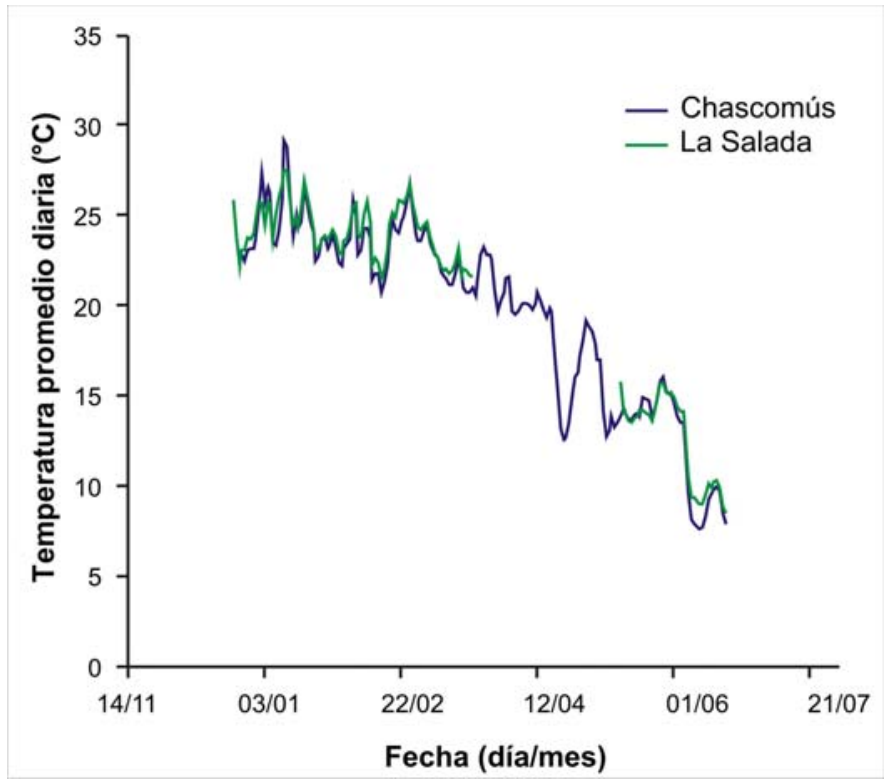

Figura IV.17: Temperaturas promedio diarias registradas en el experimento 3 en Chascomús y La Salada.

\section{Comunidad zooplanctónica}

Se encontraron 8 especies de rotíferos, 3 copépodos Cyclopoida, 1 copépodo Calanoida y 6 especies de cladóceros en Chascomús, y 12 rotíferos, 2 copépodos Cyclopoida y 2 especies de cladóceros (en muy baja abundancia) en La Salada de Monasterio (ausencia de copépodos Calanoida) (Anexo 1). Es de destacar la presencia del cladócera Daphnia spinulata en la laguna La Salada de Monasterio, aunque sólo en el primer muestreo (21/12/2007).

Las lagunas presentaron diferencias en su AZ (Figuras IV.18 y IV.19), al analizarlas por especies (ANOSIM, $R=0,574 ; p<0,05$ ). Se observó que los representantes de la clase I fueron más abundantes en La Salada, mientras que las clases II y III fueron más abundantes en Chascomús (Figura IV.20). Las especies discriminantes (SIMPER) fueron el cladócero Moina micrura y el copépodo $N$. incompositus, presentes sólo en Chascomús, con elevadas abundancias sobre todo al principio del experimento (137,8 ind./I de M. micrura y 70 ind./I de $N$. incompositus, en promedio, durante diciembre y enero), y el rotífero $K$. tropica, con mayores abundancias en La Salada (112,7 ind./I en promedio durante los primeros 3 meses del experimento) (Figura IV.21). 


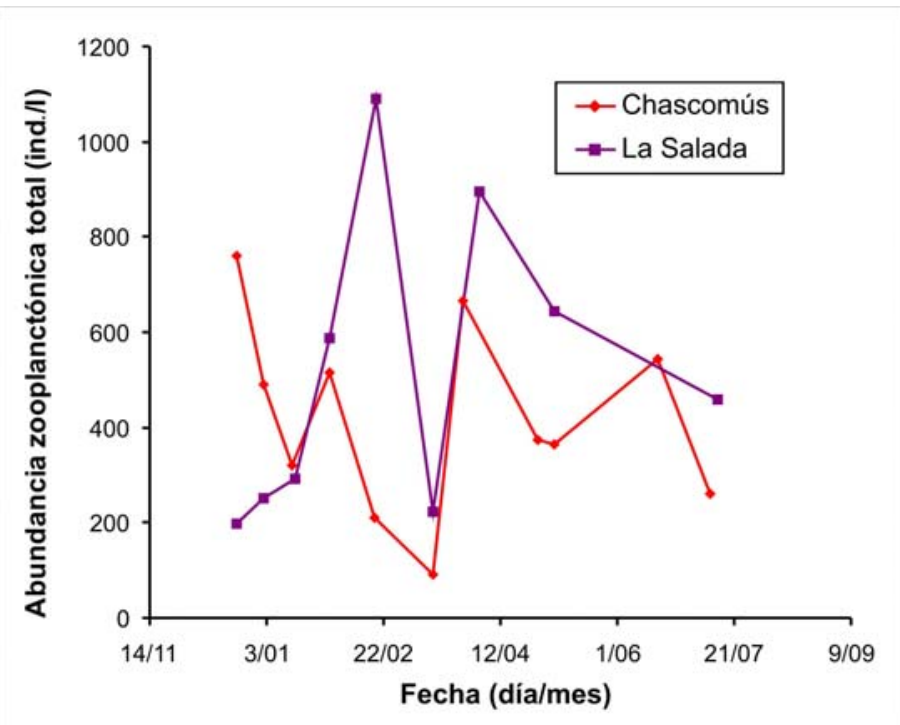

Figura IV.18: Abundancia total zooplanctónica promedio registrada fuera de las jaulas en Chascomús y La Salada en el experimento 3.

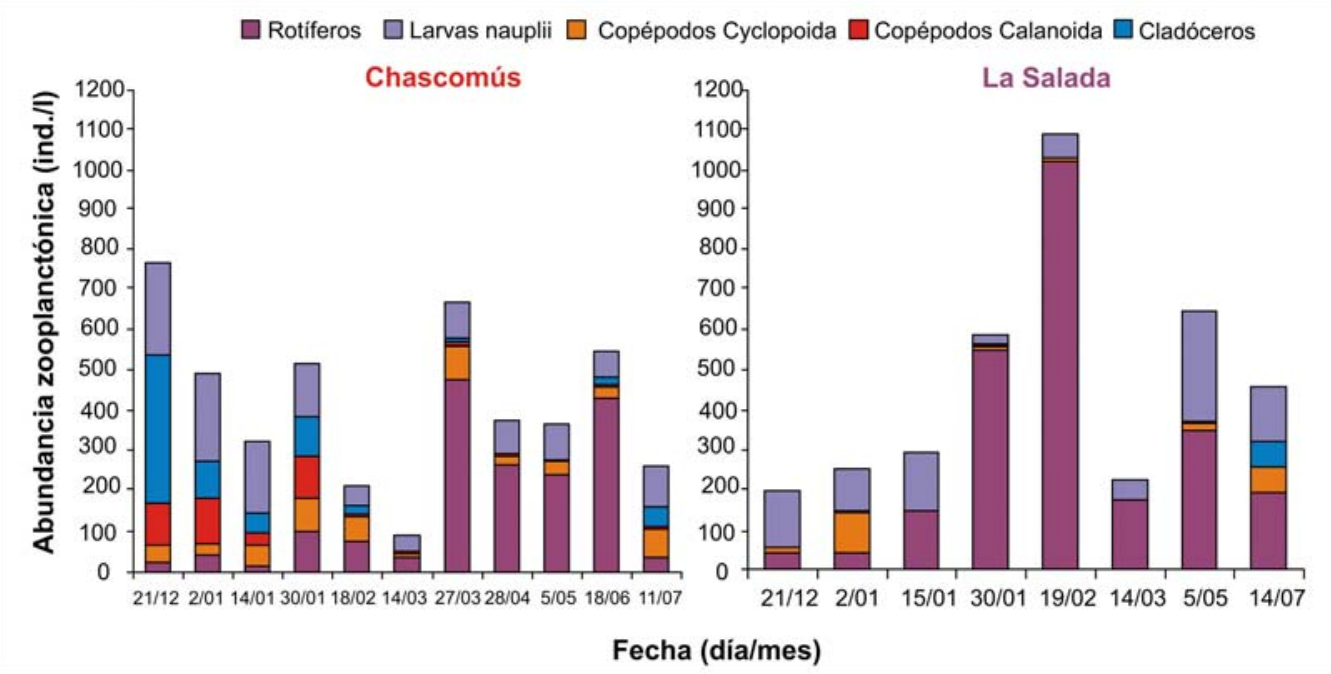

Figura IV.19: Abundancia zooplanctónica registrada en las lagunas, discriminada por grupos taxonómicos

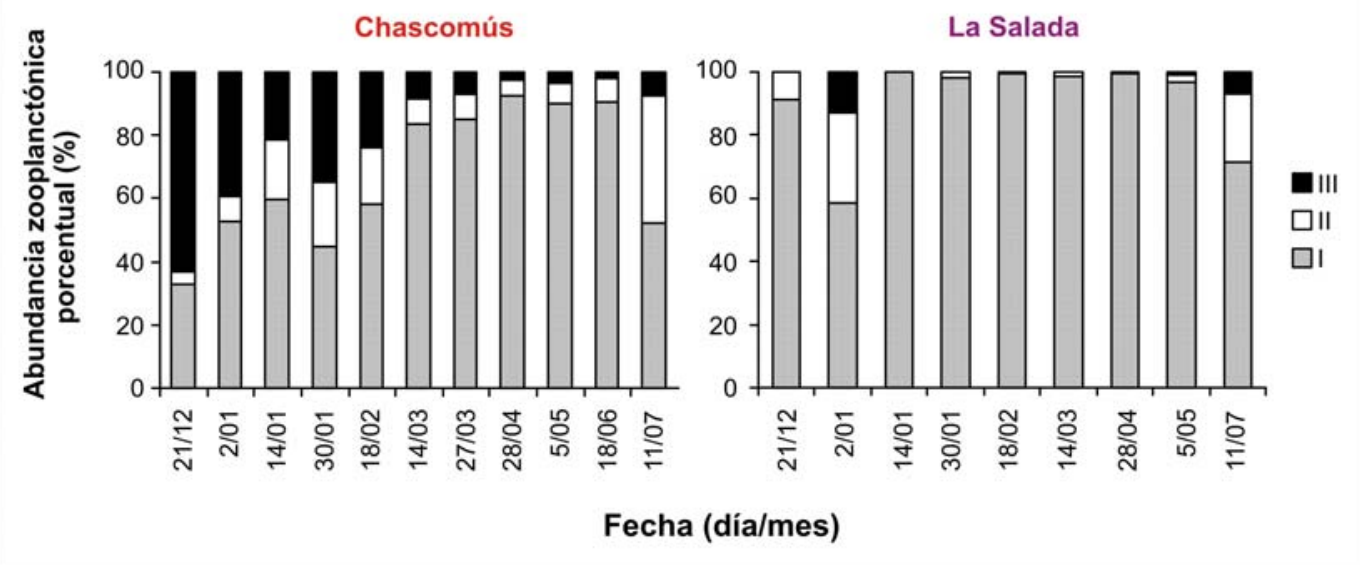

Figura IV.20: Abundancia zooplanctónica porcentual discriminada por categorías de tamaño ( $\mathrm{I}=$ hasta 0,3 mm, II = 0,3-0,7 mm y III = más de 0,7 mm). 


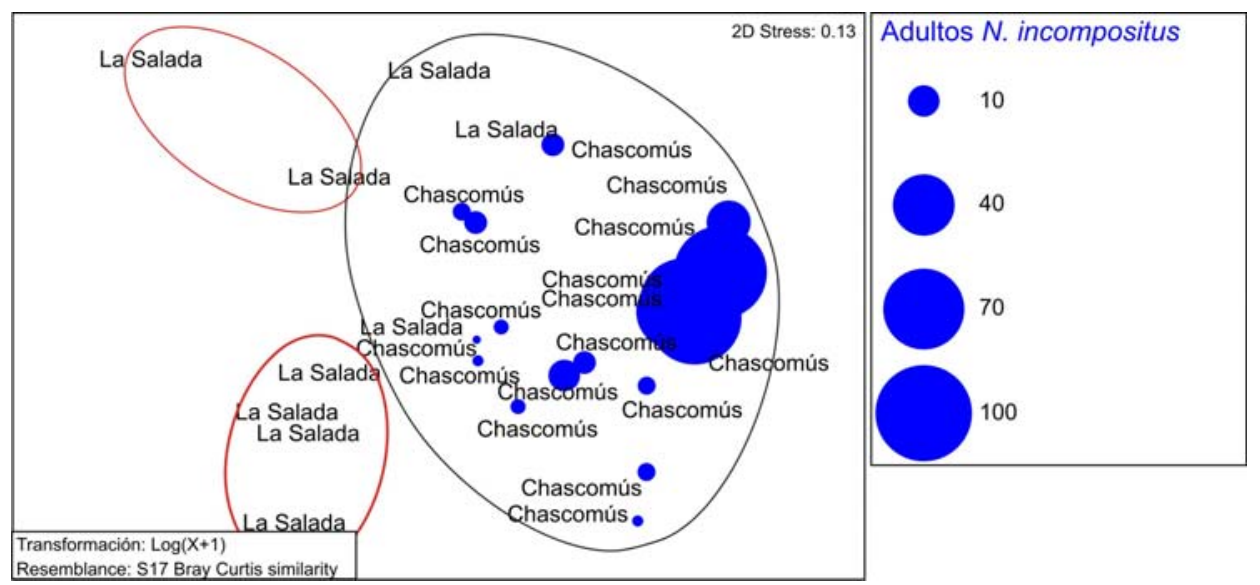

Figura IV.21: MDS comparando ambas lagunas donde se indican con líneas verdes los análisis cluster superpuestos y con burbujas azules la dominancia de la especie discriminante: Notodiaptomus incompositus

La BZL total promedio (Figura IV.22) registró un valor elevado al principio del experimento en Chascomús (2022,5 $\mathrm{mg}$ ps/l) para luego ir descendiendo a lo largo del mismo. En la Salada su valor nunca superó los 250 mg ps/l. Dicha biomasa, analizada por especies, resultó ser diferente entre lagunas (ANOSIM, $R=0,689 ; p<0,05)$. Las especies que más aportaron a dichas diferencias (SIMPER) y sus respectivas BZ promedio fueron: $N$. incompositus (234,8 $\mu \mathrm{g}$ ps/l), M. micrura (97,3 $\mu \mathrm{g}$ ps/l) (ambas presentes sólo en Chascomús) у $A$. robustus $(40,4 \mu \mathrm{g} \mathrm{ps} / \mathrm{l})$, con mayores abundancias en Chascomús. Los valores que permiten ver el grado de contribución destacada de estas especies de modo más claro son los máximos registrados: 988,8 (N. incompositus), 115,3 (A. robustus) y 879,6 (M. micrura) $\mu \mathrm{g}$ $\mathrm{ps} / \mathrm{l}$.

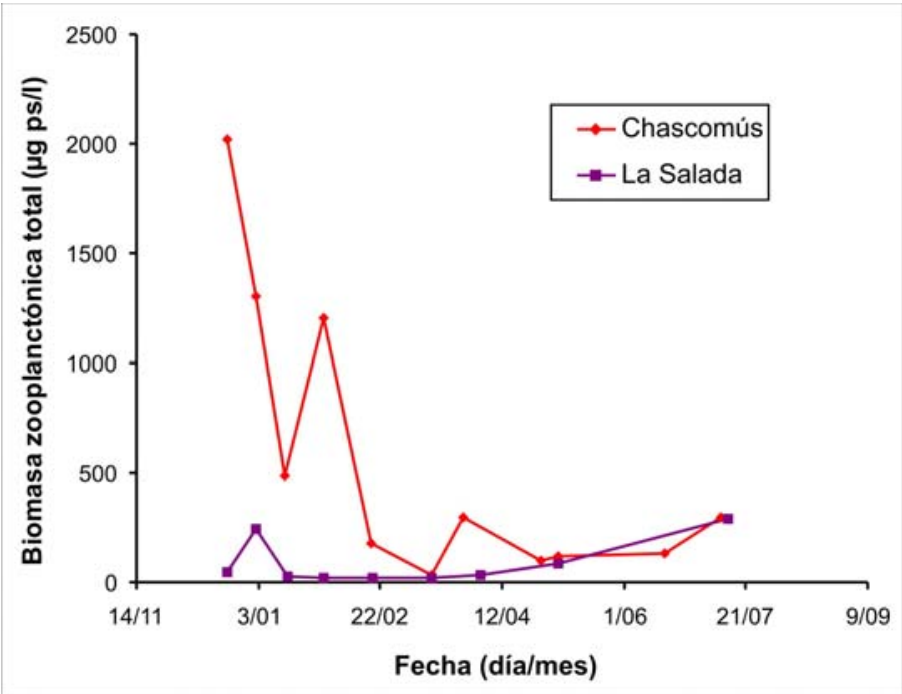

Figura IV.22: Biomasa total zooplanctónica promedio registrada en las lagunas en estudio. 
En términos de BZ por tallas dominó siempre la III en Chascomús, mientras que en La Salada fue variable, dominó la mayoría de las veces el zooplancton clase I (Figura IV.23).

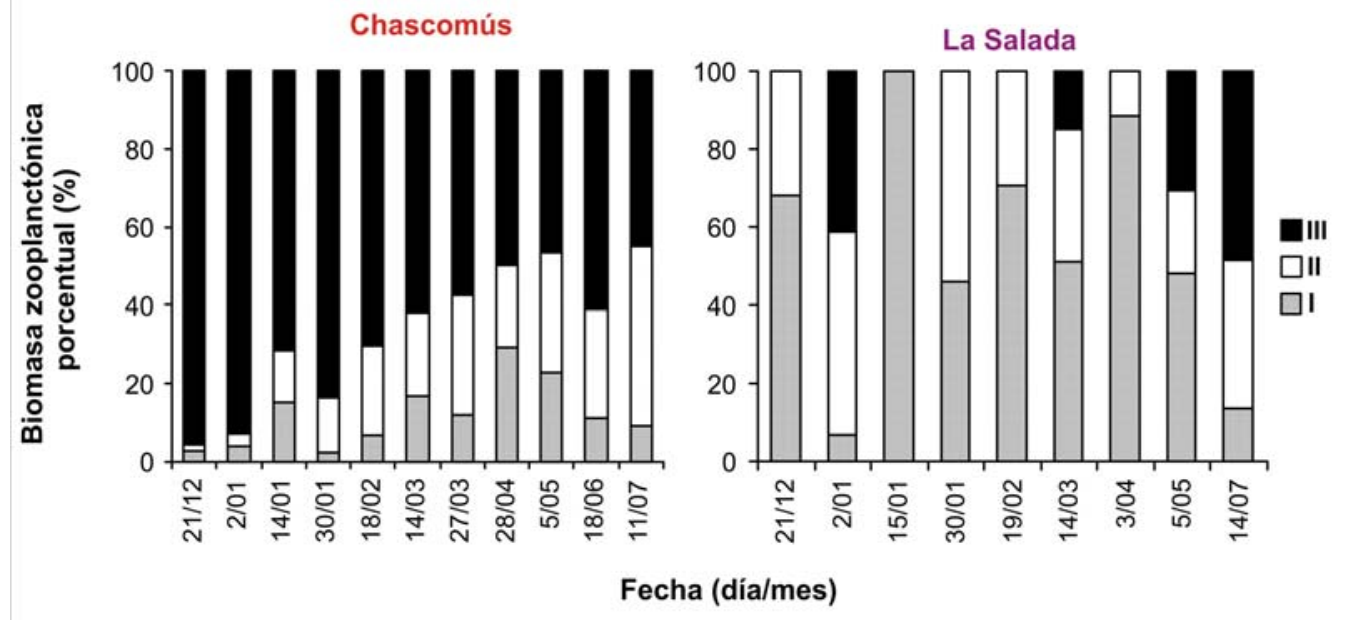

Figura IV.23: Biomasa zooplanctónica porcentual registrada en las lagunas, por categorías de tamaño (I = hasta $0,3 \mathrm{~mm}, \mathrm{II}=0,3-0,7 \mathrm{~mm}$ y III = más de 0,7 mm).

\section{Crecimiento, supervivencia y producción del pejerrey cultivado}

Al comparar el crecimiento en largo entre jaulas se encontró una interacción significativa entre los factores "tiempo" y "jaulas" en Chascomús (RM ANOVA, $F_{(9,84)}=2,81$; $p<0,05)$, con diferencias sólo significativas al comparar la jaula "a" con la "c" y la "d", a los 159 días de edad (Bonferroni test, $\mathrm{p}<0,05$ ), pero no se encontraron diferencias entre las jaulas en La Salada (RM ANOVA, $\left.\mathrm{F}_{(3,28)}=3,33 ; \mathrm{p}=0,06\right)$ en ninguna comparación de a pares en ningún momento del experimento (Bonferroni test, $p>0,05$ ) (Figuras IV.24). En cuanto al peso de los individuos, no se encontraron diferencias entre las jaulas en Chascomús (RM ANOVA, $F_{(3,28)}=$ 2,$43 ; p=0,09$ ) y sí en La Salada (RM ANOVA, $\left.F_{(3,28)}=3,5 ; p<0,05\right)$, aunque las diferencias no fueron significativas en ninguna de las comparaciones de a pares para cada fecha de muestreo (Bonferroni test, $p>0,05$ ). Por otra parte, al comparar las lagunas entre sí, se observó una interacción significativa entre el tiempo y las lagunas en cuanto a la longitud de los pejerreyes criados (RM ANOVA, $\left.F_{(3,186)}=52,9 ; p<0,05\right)$, con un LT promedio final de 10,50 cm en Chascomús y 6,99 cm en La Salada, a los 231 días de vida, y también en cuanto al peso (RM ANOVA, $F_{(3,186)}=46,8 ; p<0,05$ ), con un peso individual promedio final de $6,2 \mathrm{~g}$ en Chascomús, siendo 3,3 veces superior al registrado en La Salada (1,86 g). 


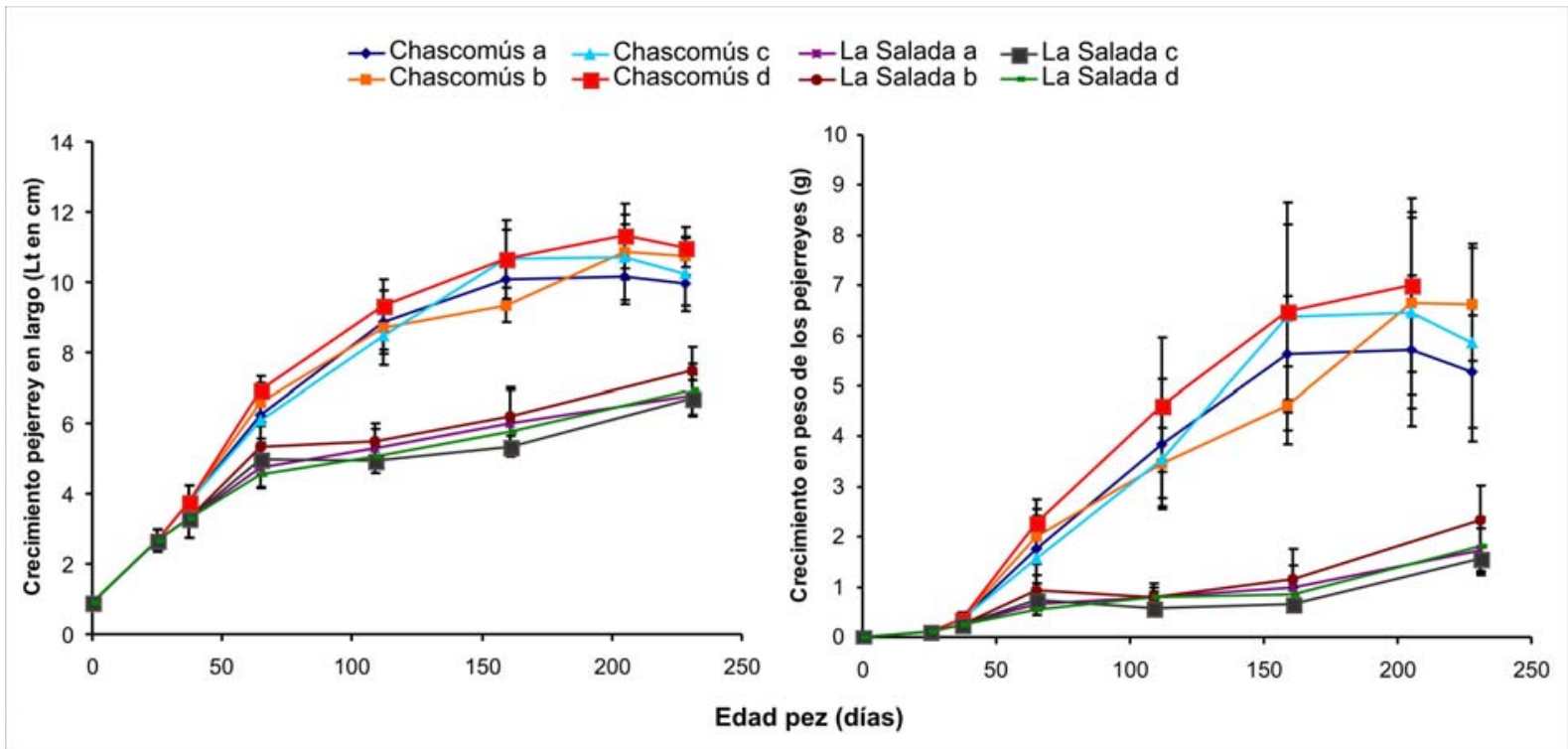

Figura IV.24: Crecimiento en longitud y peso (LT y W promedio por jaula y sus desvíos) de los pejerreyes criados en las jaulas instaladas en Chascomús ( $a, b, c$ y d) y La Salada de Monasterio ( $a, b$, c y d).

Mediante el análisis de regresión múltiple utilizando la tasa de crecimiento en largo como variable dependiente y el $\mathrm{pH}$, la temperatura y las $\mathrm{AZ}$ y $\mathrm{BZ}$ (de la laguna) normalizadas por período (AZN y BZN), como variables independientes (previamente estandarizadas), se identificó a la BZN como la variable explicatoria de la variación en las TCEL en Chascomús $\left(\mathrm{R}^{2}\right.$ $\left.=0,999 ; F_{(3,1)}=5831,8 ; p<0,05\right)$, mientras que el modelo testeado no resultó significativo al intentar explicar dicha variación en La Salada, ni tampoco al realizar el análisis con las tasas en peso (TCEW) en ambas lagunas. Por eso, el único modelo ajustado resultante fue:

$\mathrm{TCEL}=\mathrm{a}+\mathrm{x} 1 \mathrm{BZN}$

donde $a=-0,097 ; x 1=0,00061(p<0,05)$.

La biomasa final de peces contenidos por jaula resultó variable, obteniéndose los mejores resultados para dos jaulas de la laguna de Chascomús (Figura IV.25), donde se obtuvo un orden de magnitud mayor que en las jaulas de La Salada de Monasterio. Al comparar estas observaciones mediante un test de " $\mathrm{t}$ " de Student no se encontraron diferencias en cuanto a las medias $\left(t_{(6)}=0,91 ; p=0,4\right)$, pero sí en cuanto a las varianzas $(p<0,05)$. La supervivencia fue baja en todas las jaulas, con valores entre el 15 y el $46 \%$. 


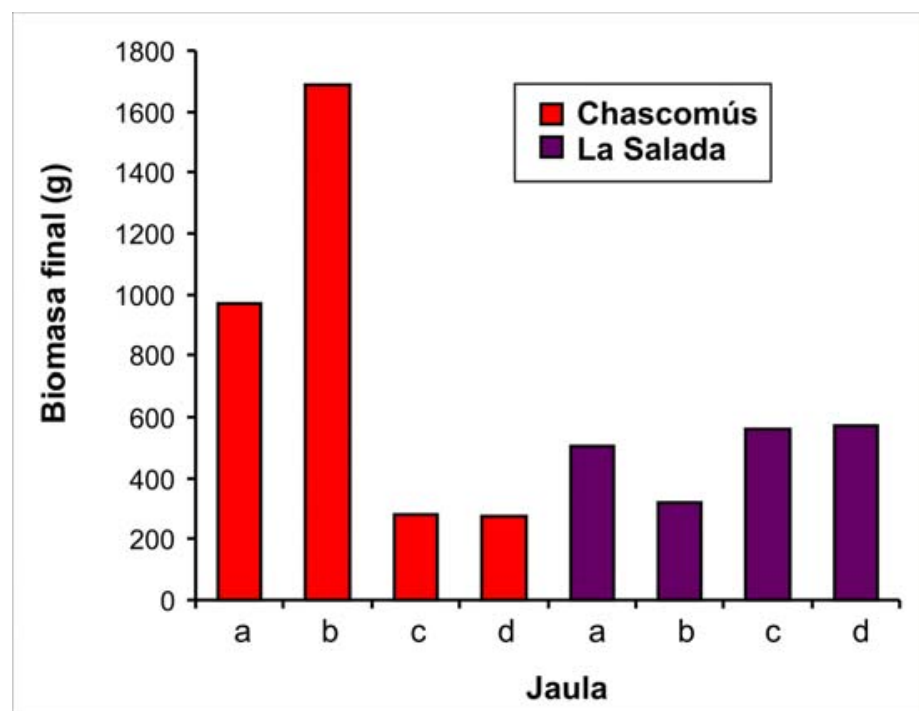

Figura IV.25: Biomasa final por jaula (g) obtenida al final del experimento 3.

\section{Alimentación del pejerrey cultivado}

La dieta de los pejerreyes criados en este experimento se evaluó sólo al final del mismo, analizando los CD de 20 ejemplares, 10 de Chascomús y 10 de La Salada. Los resultados del índice de importancia relativa IRI se expresan en la figura IV.26, dónde se observa que en Chascomús los pejerreyes consumieron mayoritariamente $N$. incompositus, seguido de Bosmina huaronensis y en La Salada el consumo estuvo dirigido casi por completo hacia B. huaronensis.

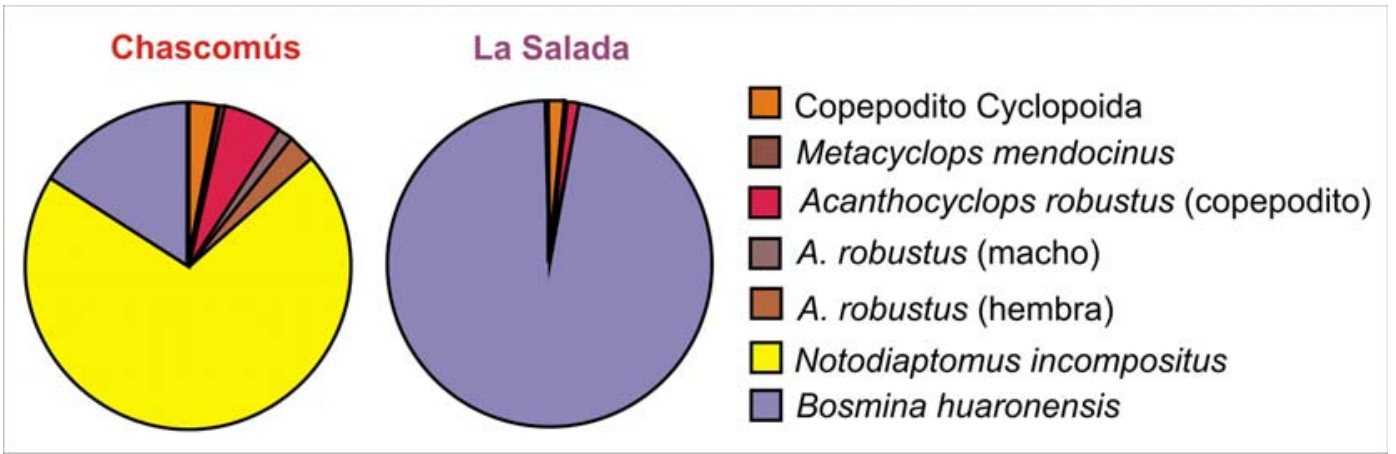

Figura IV.26: Índice de importancia relativa (IRI\%) de los ítems alimentarios encontrados en los contenidos digestivos de los pejerreyes criados en el experimento 3. 


\section{Experimento 4}

Diseño experimental

\# EN: Obtención de postlarvas en cavas.

\# EE: Jaulas (mosquitero), dos en la laguna de Chascomús y dos en La Salada de Monasterio sembradas con pejerreyes de 26 días de vida.

- Densidad de siembra: 42 ind./ $/ \mathrm{m}^{3}$ (500 ind./jaula).

- Fecha de siembra: 22/10/2008.

- Duración del experimento: 78 días en jaulas (104 días de edad).

- Una jaula "blanco" por laguna (jaulas sin peces).

Metodología específica: Los parámetros evaluados fueron $\mathrm{pH}$, salinidad, temperatura del agua, profundidad, transparencia, conductividad y oxígeno disuelto, tanto en las cavas como en las lagunas. También se analizó en este caso la dieta de los ejemplares criados.

\section{Resultados}

Etapa "nursery"

\section{Parámetros físico-químicos}

La profundidad de la cava se mantuvo en 1 metro. Los valores obtenidos para el resto de los parámetros físico-químicos fueron promediados por semana (Tabla IV.3).

Tabla IV.3: Parámetros físico-químicos registrados en la cava, valores promedio por semana.

\begin{tabular}{cccccc} 
Semana & $\begin{array}{c}\text { Transparencia } \\
\text { (m de Secchi) }\end{array}$ & $\mathbf{p H}$ & $\begin{array}{c}\text { Salinidad } \\
(\mathbf{m S / c m})\end{array}$ & $\begin{array}{c}\text { Oxígeno Disuelto } \\
(\mathbf{m g} / \text { Litro) }\end{array}$ & $\begin{array}{c}\text { Temperatura } \\
\left({ }^{\circ} \mathbf{C}\right)\end{array}$ \\
\hline $\mathbf{1}$ & 0,80 & 8,0 & 1,8 & 18,8 & 15,7 \\
$\mathbf{2}$ & 0,40 & 7,8 & 1,5 & 16,1 & 16,5 \\
$\mathbf{3}$ & 0,52 & 7,8 & 1,6 & 14,4 & 15,7 \\
$\mathbf{4}$ & 0,48 & 7,7 & 1,5 & 14,0 & 16,0 \\
$\mathbf{5}$ & 0,75 & 7,7 & 1,6 & 13,3 & 16,6 \\
$\mathbf{6}$ & 1,00 & 8,1 & 1,5 & 10,8 & 17,8 \\
$\mathbf{7}$ & 1,00 & 8,2 & 1,5 & 10,9 & 18,8 \\
$\mathbf{8}$ & 1,00 & 8,3 & 1,5 & 12,3 & 19,5 \\
$\mathbf{9}$ & 0,74 & 8,4 & 1,5 & 13,3 & 21,0 \\
\hline
\end{tabular}

\section{Comunidad zooplanctónica}

Se encontraron como taxa dominantes a los rotíferos $B$. plicatilis, a larvas nauplii de copépodos Cyclopoida y a Ostrácodos (Heterocypris incongruens) (Figura IV.27). B. plicatilis tuvo su pico de AZ a los 35 días desde el llenado de las cavas (más de 2500 ind./I), momento en que se decidió sembrar las larvas de pejerrey recién eclosionadas. 


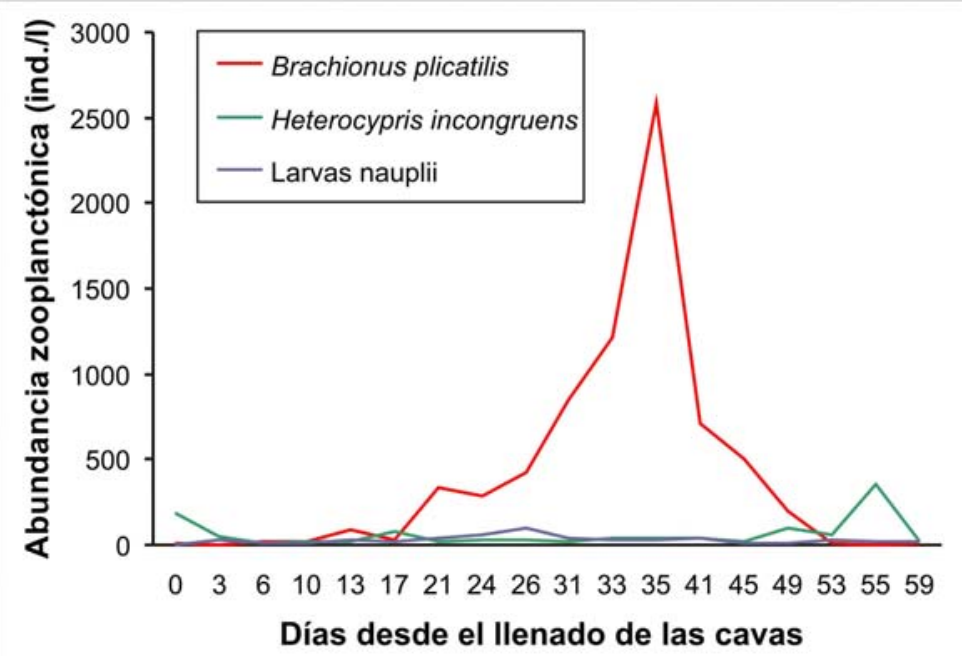

Figura IV.27: Abundancia zooplanctónica registrada en las cavas, discriminada por los grupos más abundantes.

\section{Crecimiento del pejerrey cultivado}

El seguimiento del crecimiento de las larvas se realizó para una de las cavas utilizadas y sus longitudes y pesos pueden observarse en las figuras IV.28. De las 10000 larvas de pejerrey sembradas en la cava con una longitud total promedio de 7,3 $\mathrm{mm}$, fueron retiradas 6000 con un promedio de $20 \mathrm{~mm}$ de longitud total, lo cual representa un $60 \%$ de supervivencia.

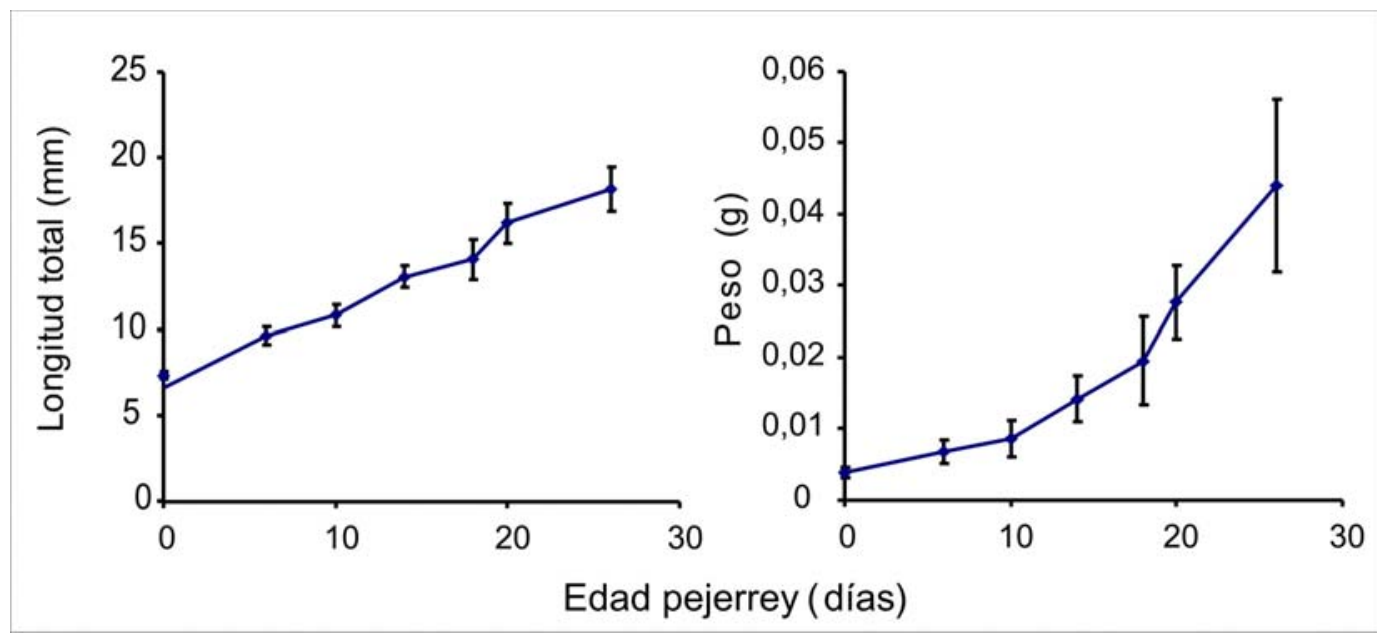

Figura IV.28: Crecimiento en longitud y peso (LT y W promedio y sus desvíos) de los pejerreyes criados en la cava, en función de la edad de los peces.

Alimentación del pejerrey cultivado 
El análisis de la dieta de postlarvas criadas en cavas será desarrollado en el capítulo V.

\section{Etapa Experimental}

\section{Parámetros físico-químicos}

Las lagunas fueron similares en cuanto a las variables físico-químicas medidas (tabla IV.4), con alguna diferencia aparente, por ejemplo en cuanto a la conductividad (mayor en Chascomús, con un promedio de $2 \mathrm{mS} / \mathrm{cm}$ ).

Tabla IV.4: Parámetros físico-químicos registrados en cada fecha de muestreo en ambas lagunas.

\begin{tabular}{lccccccc}
\multicolumn{1}{c}{ Laguna } & Fecha & $\begin{array}{c}\text { Profundidad } \\
(\mathbf{m})\end{array}$ & $\begin{array}{c}\text { Transparencia } \\
(\mathbf{m} \text { de Secchi) }\end{array}$ & $\begin{array}{c}\text { Conductividad } \\
(\mathbf{m S / c m})\end{array}$ & pH & $\begin{array}{c}\text { Oxígeno } \\
\text { Disuelto } \\
(\mathbf{m g} / \mathrm{L})\end{array}$ & $\begin{array}{c}\text { Temperatura } \\
\left({ }^{\circ} \mathbf{C}\right)\end{array}$ \\
\hline Chascomús & $24 / 10 / 2008$ & & & 1,9 & 9,0 & 10,3 & 21,4 \\
La Salada & $24 / 10 / 2008$ & & & 1,3 & 8,4 & 10,4 & 23,5 \\
Chascomús & $10 / 11 / 2008$ & 1,4 & 0,12 & 2,1 & 8,9 & 7,8 & 22,8 \\
La Salada & $11 / 11 / 2008$ & 1,7 & 0,22 & 1,1 & 8,6 & 8,8 & 25,4 \\
Chascomús & $2 / 12 / 2008$ & 1,2 & 0,80 & 1,8 & 8,3 & 10 & 19,2 \\
La Salada & $2 / 12 / 2008$ & 1,4 & 0,42 & 1,3 & 8,4 & 8,4 & 18,3 \\
Chascomús & $15 / 12 / 2008$ & 1,2 & 0,10 & 1,9 & 9,1 & 7,6 & 26 \\
La Salada & $17 / 12 / 2008$ & & 0,35 & 1,2 & 8,4 & 7,8 & 27,8 \\
Chascomús & $7 / 01 / 2009$ & 0,9 & 0,10 & 2,3 & 8,8 & 10,4 & 27,1 \\
La Salada & $8 / 01 / 2009$ & 1,3 & 0,35 & 1,3 & 8,8 & 9,7 & 24,7 \\
\hline
\end{tabular}

\section{Comunidad zooplanctónica}

Se encontraron 6 especies de rotíferos, 4 copépodos y 5 cladóceros en Chascomús, mientras que en La Salada se registraron 8 rotíferos, 3 copépodos y 4 cladóceros (Anexo 1). La AZ total fue diferente entre lagunas (ANOSIM, $R=0,982 ; p<0,05$ ) siendo mayor en Chascomús (Figura IV.29), debido principalmente a la presencia de una elevada AZ de rotíferos, especialmente en noviembre (Figura IV.30). Las especies que más aportaron a las diferencias entre lagunas (SIMPER de 75,42\%) fueron B. havanaensis y B. caudatus con elevadas AZ en Chascomús (AZ promedio de 842,22 ind./I y 531,83 ind./l, respectivamente), donde hubo bajas abundancias de microcrustáceos (Figura IV.31). 


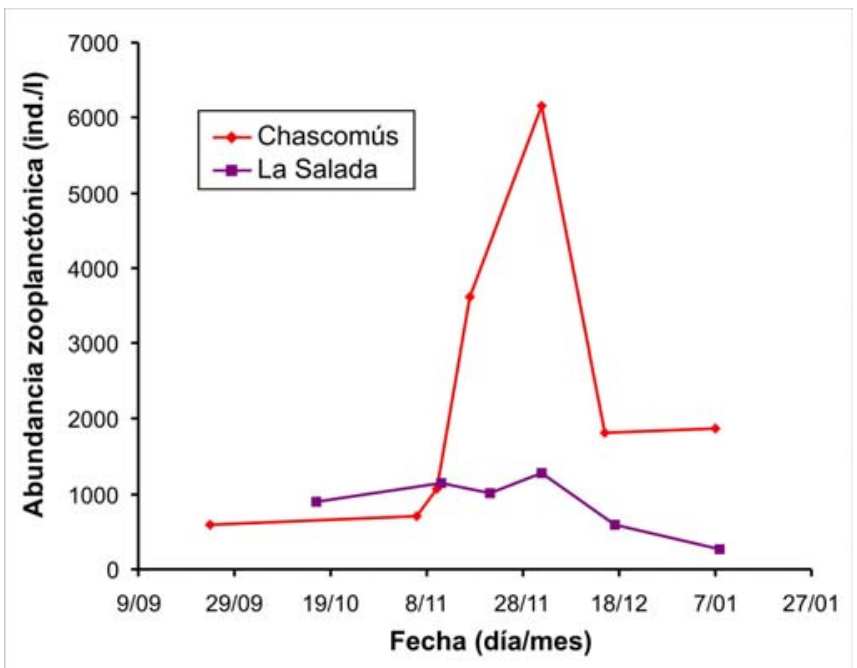

Figura IV.29: Abundancia total zooplanctónica registrada en ambas lagunas.

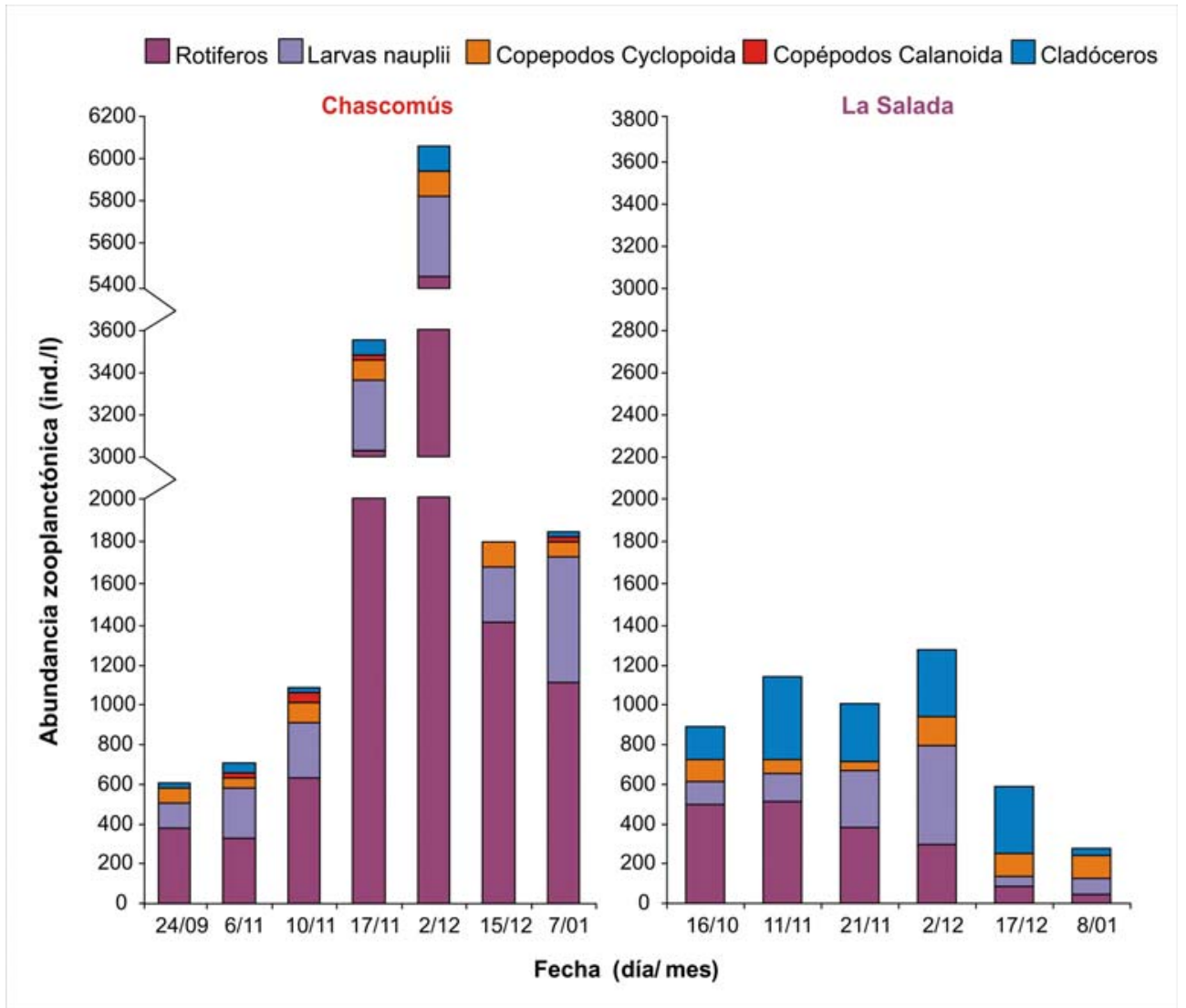

Figura IV.30: Abundancia zooplanctónica (ind./litro) discriminada por grupos taxonómicos. 


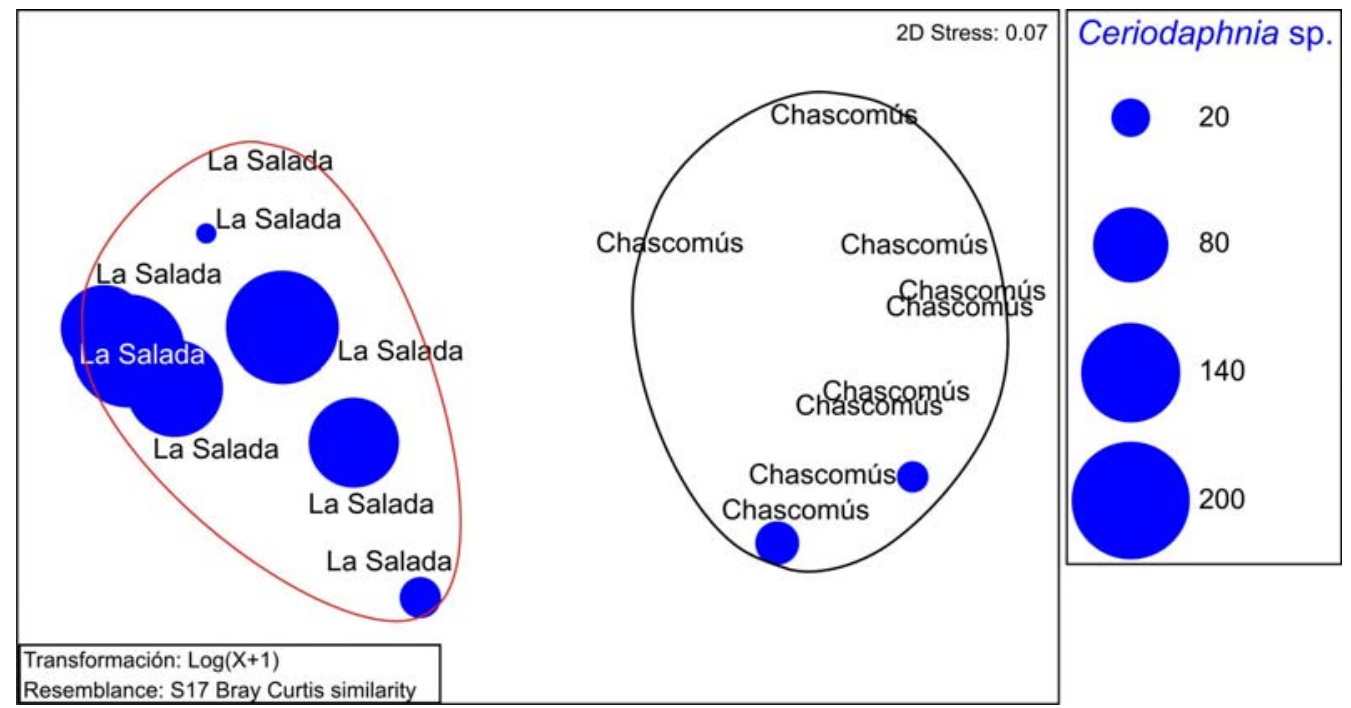

Figura IV.31: MDS comparando ambas lagunas donde se indican con líneas verdes los análisis cluster superpuestos y con burbujas azules la dominancia de la especie discriminante: Ceriodaphnia dubia

En La Salada de Monasterio predominaron los rotíferos al comienzo de la experiencia (alrededor de 500 ind./l), luego predominaron las larvas nauplii y los cladóceros, principalmente $B$. huaronensis y Ceriodaphnia dubia. También se registró en La Salada Daphnia spinulata (Cladocera) en baja abundancia, sólo en noviembre. Al final del experimento en enero la AZ de la laguna la Salada descendió notablemente (Figura IV.29).

Durante el período de experimentación los representantes de la clase I fueron más abundantes en Chascomús, mientras que los de las clases II y III lo fueron en La Salada (Figura IV.32).

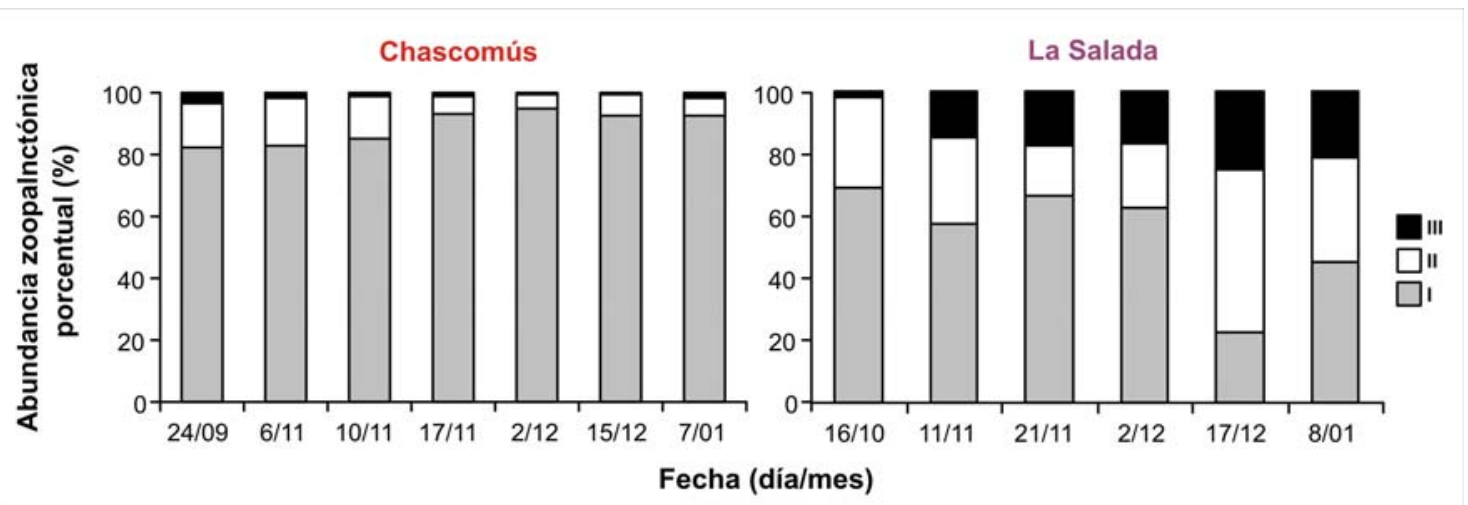

Figura IV.32: Abundancia zooplanctónica porcentual, discriminada por categorías de tamaño ( $\mathrm{I}=$ hasta 0,3 mm, II = 0,3-0,7 $\mathrm{mm}$ y III = más de 0,7 mm).

En las jaulas blanco (JB) y las jaulas con peces (JP) las AZ por clases se dieron de un modo similar a las lagunas (Figura IV.33). No se observaron diferencias entre tratamientos (JB, JP y Laguna) en ninguna de las dos lagunas estudiadas (ANOSIM, $p>0,05$ ). 


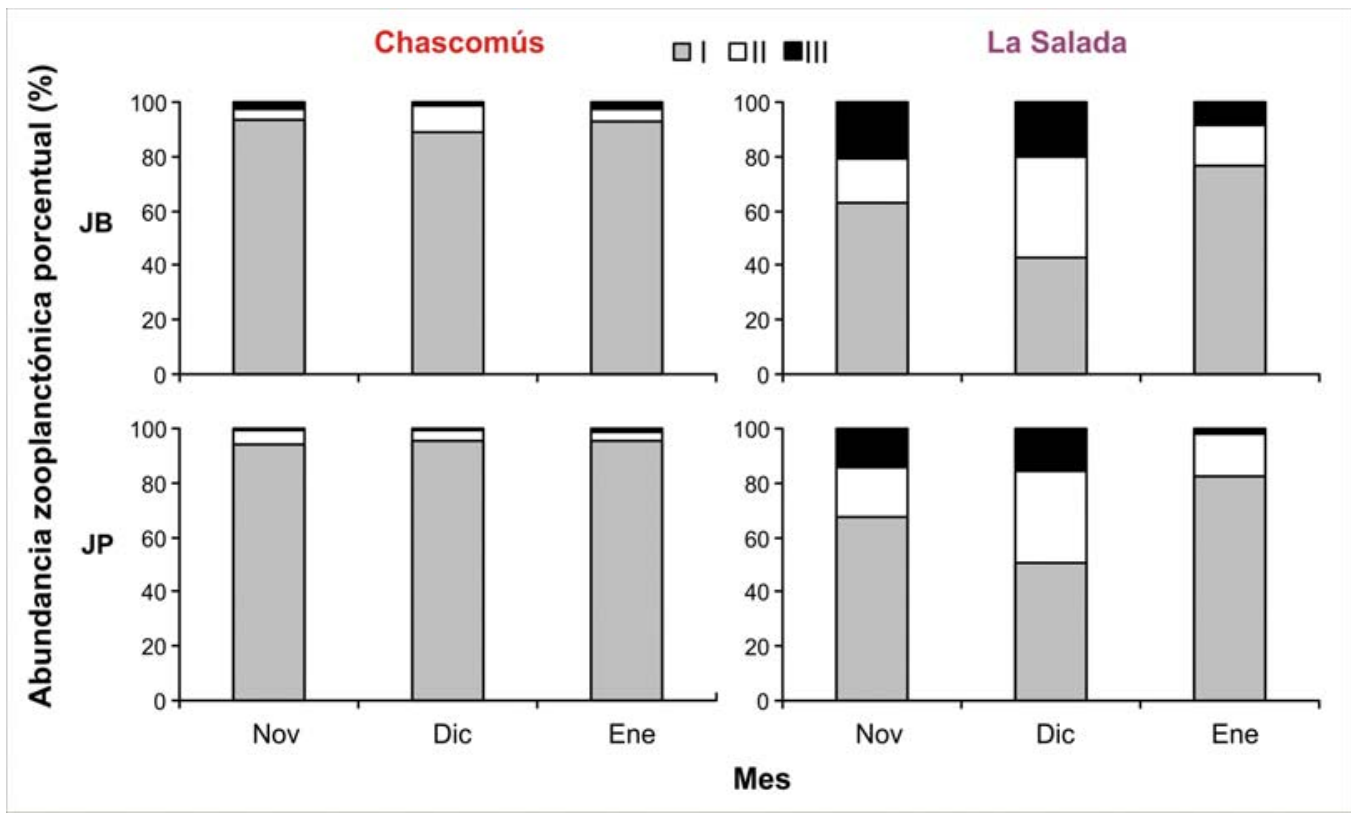

Figura IV.33: Abundancia zooplanctónica porcentual, discriminada por el aporte de cada categoría de tamaño al total observado en las jaulas blanco (JB) y jaulas con peces (JP) (I = hasta 0,3 mm, II =0,3-0,7 mm y III = más de $0,7 \mathrm{~mm})$.

La BZ total fue diferente entre lagunas (ANOSIM, $R=0,94 ; p<0,05$ ), con mayor BZ en La Salada (Figura IV.34), siendo las especies que más contribuyeron a la diferencia (SIMPER de 67,4\%) B. huaronensis y C. dubia, con mayores BZ en La Salada de Monasterio (156,1 y 153,2 $\mu \mathrm{g}$ ps/l promedio, respectivamente).

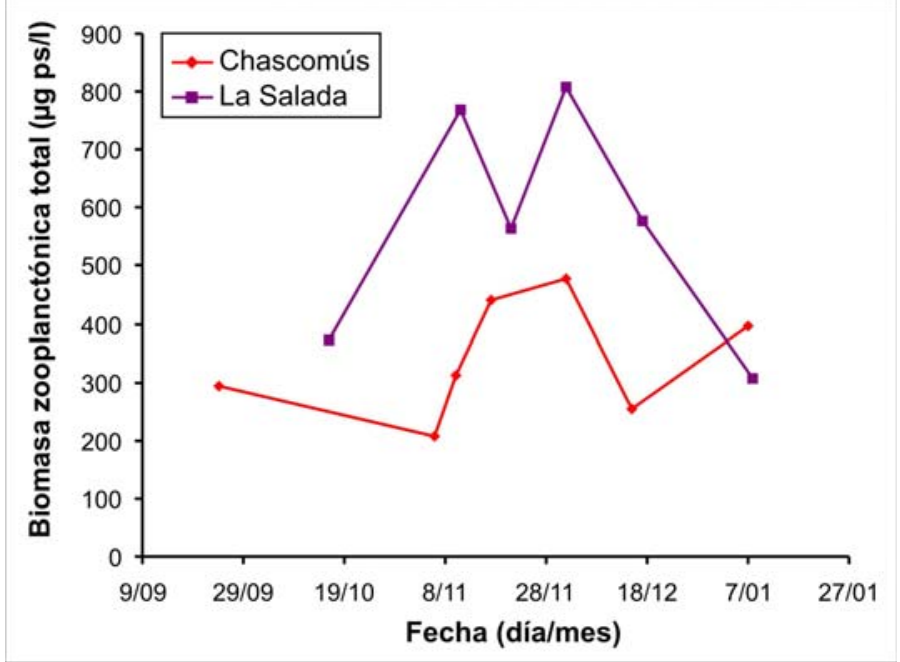

Figura IV.34: Biomasa zooplanctónica total registrada en Chascomús y La Salada durante el experimento 4.

En términos de la composición de la BZ por categorías de tamaño, la dominancia fue variable y repartida en Chascomús, pero fueron dominantes los individuos de tamaño medio y grande en La Salada (Figura IV.35). 


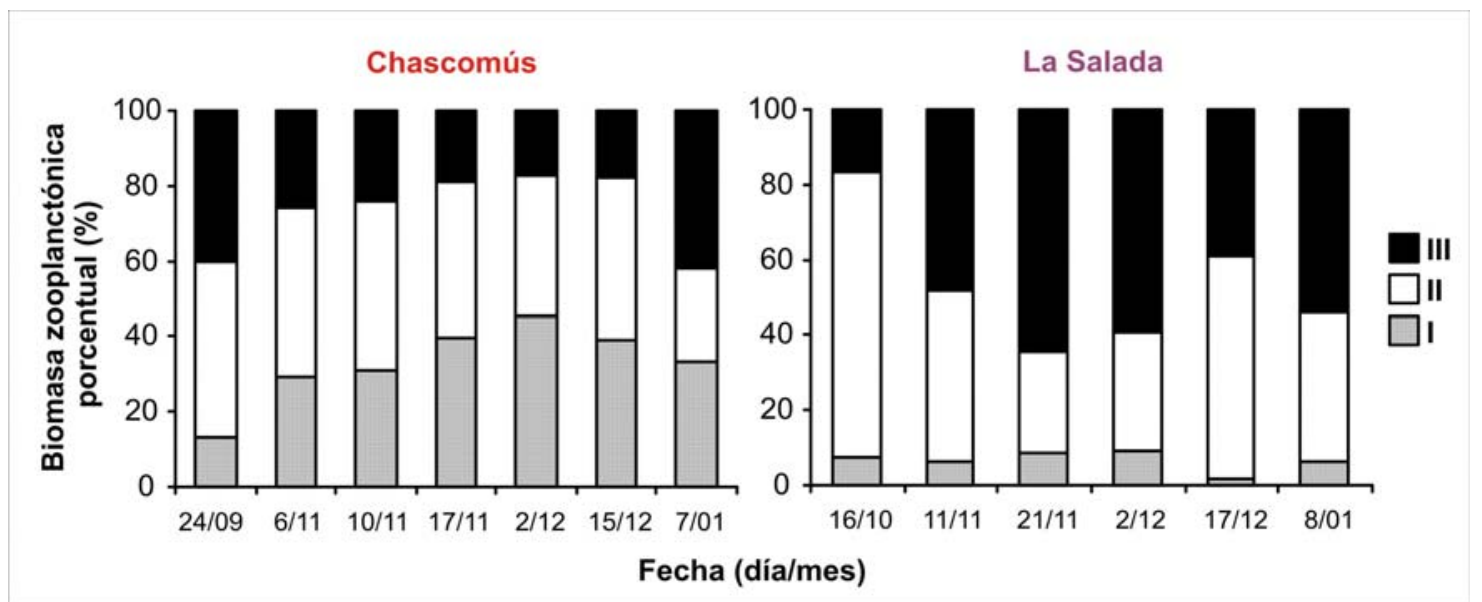

Figura IV.35: Biomasa zooplanctónica porcentual por categorías de tamaño registrada en cada fecha de muestreo en Chascomús y La Salada durante el experimento 4 ( $\mathrm{I}=$ hasta 0,3 mm, II =0,3-0,7 $\mathrm{mm}$ y III = más de 0,7 mm).

\section{Crecimiento, supervivencia y producción del pejerrey cultivado}

El crecimiento de los peces cultivados no presentó diferencias entre réplicas (RM ANOVA`s: para la longitud, $F_{(1,58)}=0,09 ; p=0,77$ y $F_{(1,58)}=0,25 ; p=0,62$, en Chascomús y La Salada, respectivamente; para el peso, $F_{(1,18)}=0,47 ; p=0,5$ y $F_{(1,18)}=0,57 ; p=0,46$, en Chascomús y La Salada, respectivamente), pero sí entre lagunas. La interacción entre el tiempo y el factor "lagunas" fue significativa (RM ANOVA, $F_{(2,196)}=20,8 ; p<0,05$ y $F_{(2,76)}=24,2$; $p<0,05$, para la longitud y el peso, respectivamente). La longitud total individual final promedio fue de 10,4 cm en La Salada y $7,7 \mathrm{~cm}$ en Chascomús, mientras que en La Salada el peso individual promedio final $(6,9 \mathrm{~g})$ fue 2,3 veces superior al de Chascomús ( $3 \mathrm{~g}$ ) (Figura IV.36), a los 104 días de edad de los peces. 


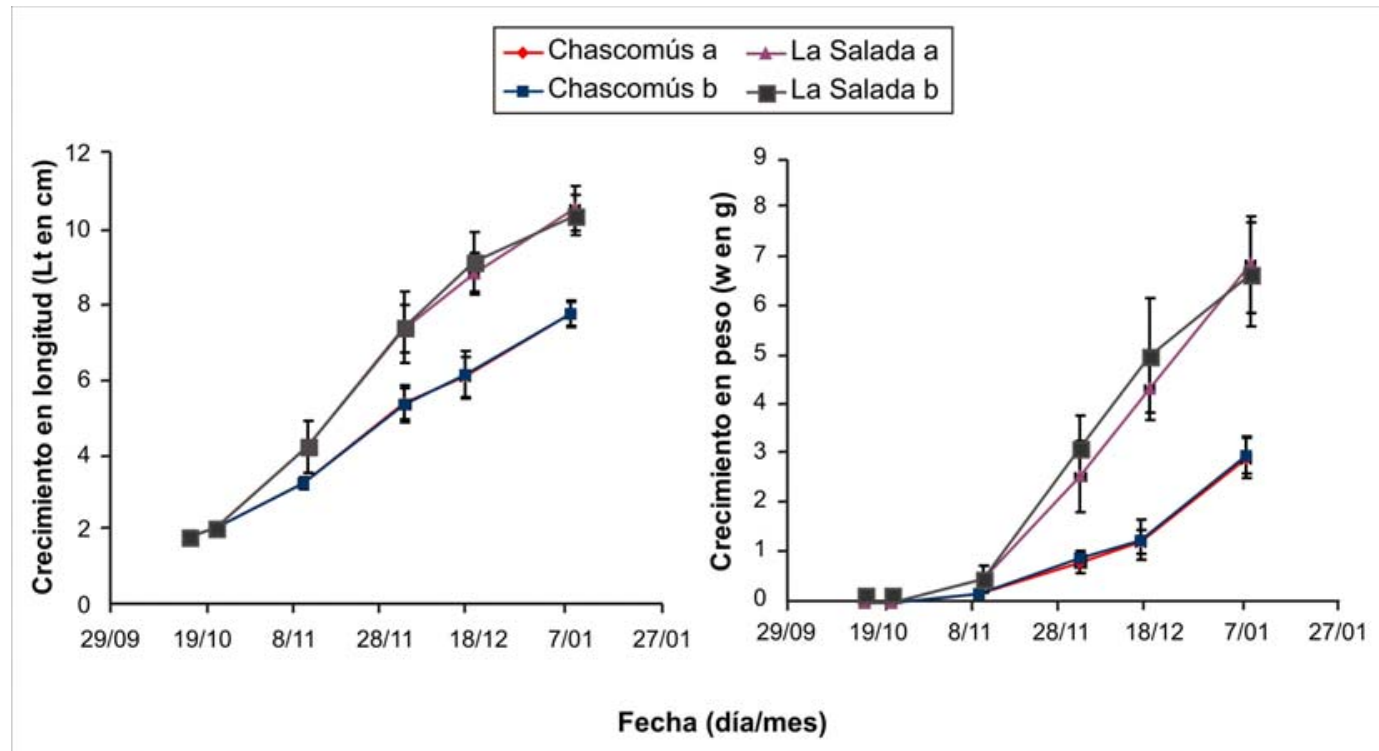

Figura IV.36: Crecimiento en longitud y peso (LT y W promedio por jaula y sus desvíos) de los pejerreyes criados en las jaulas instaladas en Chascomús $(a, b)$ y La Salada de Monasterio $(a, b)$.

Las regresiones múltiples se realizaron utilizando las tasas de crecimiento en largo y peso como variables dependientes y la profundidad, transparencia, conductividad, $\mathrm{pH}$, oxígeno disuelto, temperatura, AZ y BZ (de la laguna) normalizadas por período (AZN y BZN), como variables independientes (previamente estandarizadas). En particular se obtuvieron coeficientes de regresión elevados, tanto al utilizar las tasas en largo $\left(R^{2}=0,998 ; F_{(3,4)}=885,3\right.$; $p<0,05$ y $R^{2}=0,99 ; F_{(3,1)}=477,3 ; p<0,05$, en Chascomús y La Salada, respectivamente), como al utilizar las tasas en peso $\left(R^{2}=0,999 ; F_{(2,2)}=1865,7 ; p<0,05\right.$ y $R^{2}=0,95 ; F_{(1,3)}=51,3 ; p<0,05$, en Chascomús y La Salada, respectivamente). Se identificaron diferentes variables indicadoras de las tasas de crecimiento, siendo los modelos ajustados:

TCEL (Chascomús) $=\mathrm{a}+\mathrm{x} 1$ Temperatura $+x 2 \mathrm{AZN}+\mathrm{x} 3$ BZN

Donde, $a=0,081 ; x 1=-0,005 ; x 2=0,0008 ; x 3=0,0004(p<0,05)$.

TCEL (La Salada) $=a+x 1$ AZN

Donde, $a=-0,282 ; x 1=-0,002(p<0,05)$.

TCEW (Chascomús) $=\mathrm{a}+\mathrm{x} 1 \mathrm{BZN}+\mathrm{x} 2$ Conductividad

Donde, $a=0,009 ; x 1=0,002 ; x 2=-0,0006(p<0,05)$.

TCEW $($ La Salada $)=a+x 1$ AZN

Donde, $a=0,112 ; x 1=-0,004(p<0,05)$. 
La biomasa final fue marcadamente mayor en La Salada, y la supervivencia fue mayor al $80 \%$ en todos los casos, excepto en una réplica de Chascomús (tabla IV.5).

Tabla IV.5: Biomasa final (g) y supervivencia (\%) obtenida en cada jaula durante el experimento 4.

\begin{tabular}{lccc}
\multicolumn{1}{c}{ Lagunas } & Jaulas & Biomasa final $\mathbf{( g )}$ & Supervivencia (\%) \\
\hline Chascomús & CH a & 1269,8 & 85,3 \\
Chascomús & CH b & 956,8 & 64,9 \\
La Salada & SAL a & 2764,0 & 82,0 \\
La Salada & SAL b & 2893,7 & 85,7 \\
\hline
\end{tabular}

\section{Alimentación del pejerrey cultivado}

En base al análisis de 46 contenidos digestivos (CD) de pejerreyes cultivados en Chascomús y La Salada (23 de cada laguna, 5 en la jaula común y luego 3 por jaula por fecha de muestreo) se vio que la composición y la cantidad de zooplancton ingerido cambiaron temporalmente. A 19 días de haber sido sembrados en las jaulas (10/11/2008) se observó en ambas lagunas una variabilidad en las clases de tamaño del zooplancton ingerido, siendo encontrados individuos de las tres clases, con mayor proporción de clases II y III (Figura IV.37). El consumo total aumentó hacia fines de la primavera (Figura IV.38), de modo más marcado en La Salada, donde los pejerreyes ingirieron grandes cantidades de cladóceros ( $B$. huaronensis y C. dubia) y sobre todo de copépodos Cyclopoida (M. mendocinus y A. robustus (copepoditos en su mayoría)). La clase III fue siempre dominante en los CD y la clase I estuvo escasamente representada al principio del experimento y ausente al final del mismo. Esta representatividad de la clase I en la dieta fue un poco mayor en Chascomús, donde aún en la fecha de muestreo del 02/12/2008, con 67 días de edad y 5,4 cm de LT promedio, consumieron un $15 \%$ de clase I en promedio. Al final del experimento, con pejerreyes de más de 100 días de vida, se observó una clara predilección por $A$. robustus en ambas lagunas. 


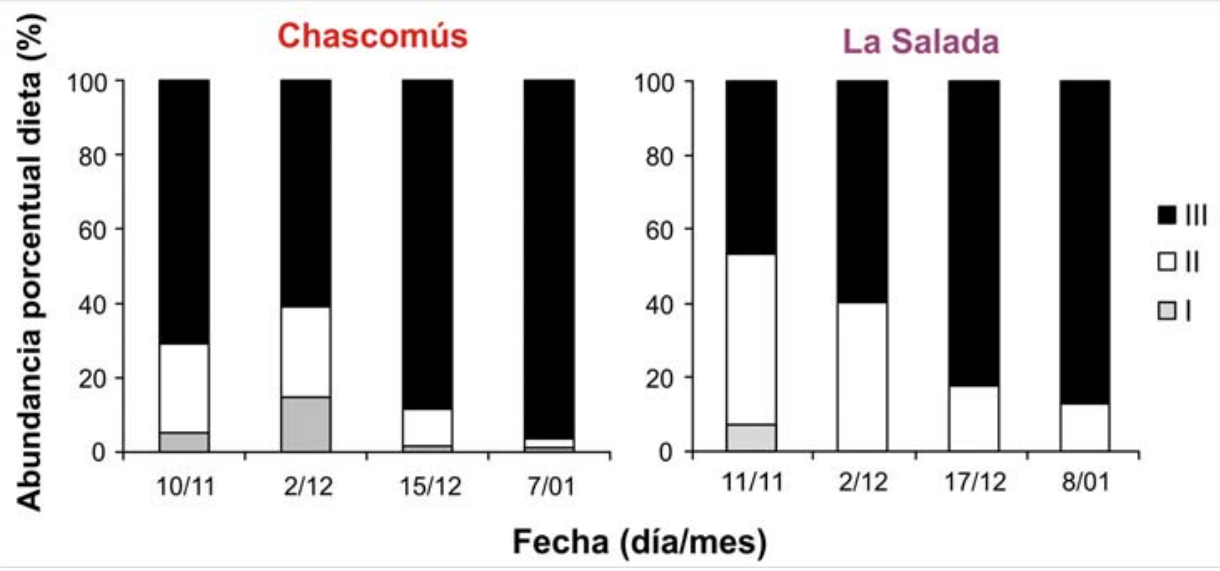

Figura IV.37: Abundancia porcentual de los ítems alimentarios, discriminados por categorías de tamaño, registrados en la dieta de los pejerreyes criados en la etapa en jaulas del experimento 4 ( $\mathrm{I}=$ hasta 0,3 $\mathrm{mm}$, II = 0,3-0,7 mm y III = más de 0,7 mm).

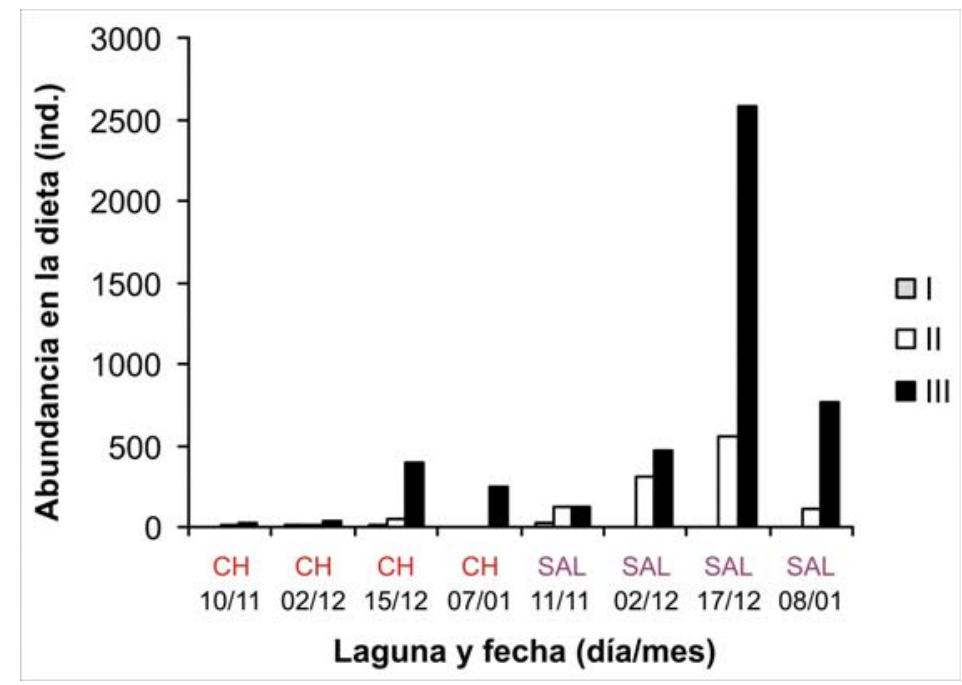

Figura IV.38: Abundancia promedio por fecha y por laguna de las tres clases de tamaño de zooplancton, en la dieta de los pejerreyes criados en el experimento 4 ( $\mathrm{I}=$ hasta $0,3 \mathrm{~mm}$, II = 0,3-0,7 mm y III = más de 0,7 mm).

En cuanto a la importancia relativa de los ítems (Figura IV.39), se observó que en Chascomús el más importante en la dieta fue $A$. robustus, salvo en el primer muestreo (45 días de vida, principio de la primavera) donde fue $N$. incompositus. En La Salada fueron más importantes los cladóceros (B. huaronensis y C. dubia) hasta los 67 días de vida y luego fue $A$. robustus. Hubo ítems que estuvieron presentes, pero con bajos IRI, como otros clacóceros ( $C$. rectangula) y algunos macroinvertebrados (quironómidos, anfípodos y partes de insectos). 


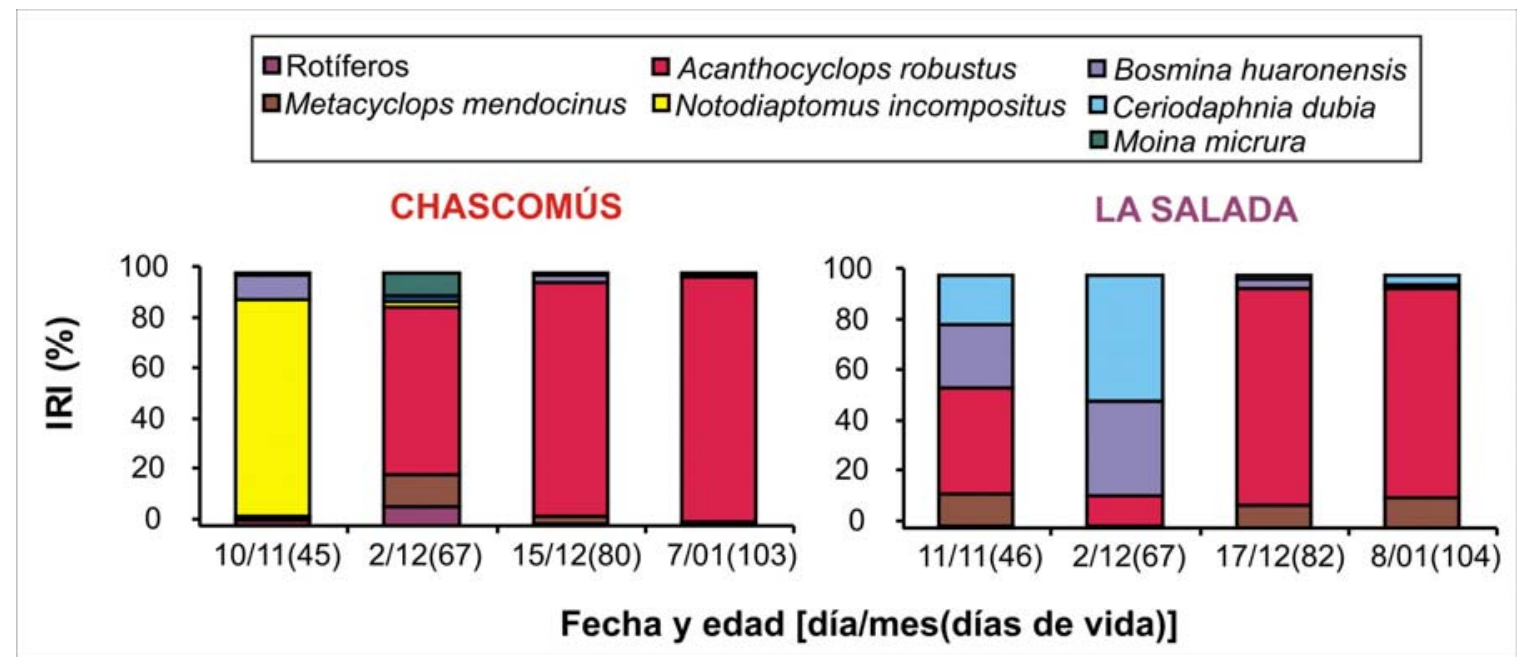

Figura IV.39: Índice de importancia relativa porcentual por fecha de muestreo (y edad de los peces) en ambas lagunas, teniendo en cuenta los ítems mayoritarios. Los rotíferos encontrados fueron Brachionus plicatilis, $B$. caudatus, B. havanaensis y K. tropica. 


\subsection{Discusión}

Los resultados del análisis de la comunidad zooplanctónica desarrollada en las cavas (sólo para la etapa "nursery" del experimento 4) demuestran que, realizando un seguimiento exhaustivo de dicha comunidad, es factible la identificación del momento ideal de siembra de larvas de pejerrey recién eclosionadas para un mejor aprovechamiento de los recursos. También fue demostrado que mediante dicho método de cría es posible la obtención de un número alto de postlarvas de pejerrey y una baja mortalidad. Además, en el caso de pretender utilizar dichas postlarvas para la cría de juveniles en jaulas en lagunas, con un adecuado manejo de la calidad del agua durante el transporte, es posible no sólo mantener la mortalidad baja, sino lograr traslados exitosos y siembras eficientes. También pudo observarse una clara dominancia del rotífero $B$. plicatilis en las cavas, lo cual resulta coincidente con las preferencias de dicha especie hacia las aguas con elevada salinidad (Fukusho 1989). Otros trabajos comprueban esta preferencia ya que muestran picos de abundancia de este rotífero en los momentos que el ambiente exhibe mayor salinidad (Olivier 1961, Gabellone et al. 2001, Ardohain 2008).

Los peces planctívoros criados de modo extensivo en jaulas tendrían sus máximos crecimientos y producciones en ambientes eutróficos (Bayne te al 1991, Rai 2000), siempre y cuando las condiciones ambientales sean apropiadas (temperatura, oxígeno disuelto, etc.) y la fuente de alimento abundante. Sin embargo, ante la casi ausencia de estudios sistemáticos que permitan determinar las densidades óptimas de cultivo de peces (Beveridge 2004), emerge la importancia de realizar una evaluación inédita hasta el momento: el estudio exhaustivo del ambiente natural donde se instalan las unidades de cría, en términos de los parámetros limnológicos y de la disponibilidad de zooplancton.

Los resultados de los análisis multivariados aplicados a las abundancias y biomasas zooplanctónicas registradas en las etapas experimentales muestran que las especies que conforman la comunidad zooplanctónica definen y diferencian a las lagunas pampásicas estudiadas. En los cuatro experimentos (E1, E2, E3 y E4) existieron diferencias en AZ y BZ (discriminada por especies) entre las lagunas, mientras que se observaron ciertas similitudes y diferencias en cuanto a las especies discriminantes (Tabla IV.6) y en cuanto a las especies que se identifican como dominantes, comunes, ocasionales y raras (Gráficos de Olmstead-Tukey, 
Figura IV.40). Estas similitudes en cuanto a la importancia relativa de las especies, aunque aparentemente contradictoria con la sentencia de que las especies zooplanctónicas definen y diferencian las lagunas estudiadas, resulta importante en el hecho de poder identificar ciertas combinaciones típicas de las lagunas pampásicas. Por ejemplo, en cuanto a la AZ relativa de los grupos taxonómicos y las categorías de tamaño, se observó, como es típico en las lagunas de la región Pampeana, la dominancia de los rotíferos y las larvas nauplii frente a los copépodos (juveniles y adultos) y cladóceros, es decir la categoría I frente a las II y la III.

Las diferencias halladas entre las lagunas (Tabla IV.6) permiten destacar que existe una relación entre el zooplancton de las lagunas y el crecimiento de los pejerreyes de las jaulas. En los cuatro experimentos, de los cuales se puede observar un resumen en la figura IV.41, las mayores LT y W individuales finales promedio se dieron en las jaulas instaladas en las lagunas con mayores AZ y BZ. No sólo se obtuvieron los mayores crecimientos de los peces en las lagunas con mayores $B Z$, sino que también se observó que en esas lagunas los ítems zooplanctónicos de mayor tamaño (categorías de tamaño II y III) fueron los que estuvieron mejor representados. Fue así que en Chascomús en E1, E2 y E3 y en La Salada de Monasterio en E4, las especies discriminantes de las diferencias entre lagunas en cuanto a su BZ fueron de copépodos y cladóceros medianos y grandes (Tabla IV.6). 
Tabla IV.6: Resumen de los resultados de los análisis multivariados aplicados al zooplancton y de los parámetros finales de crecimiento de los pejerreyes de cada experimento.

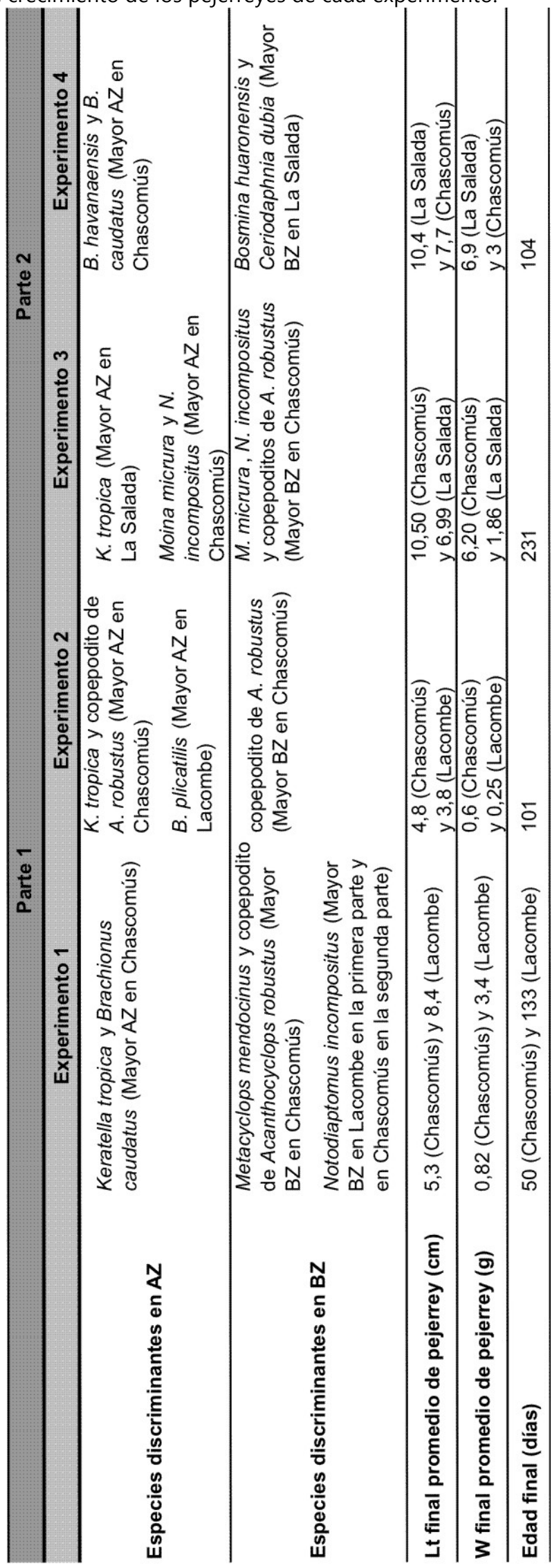




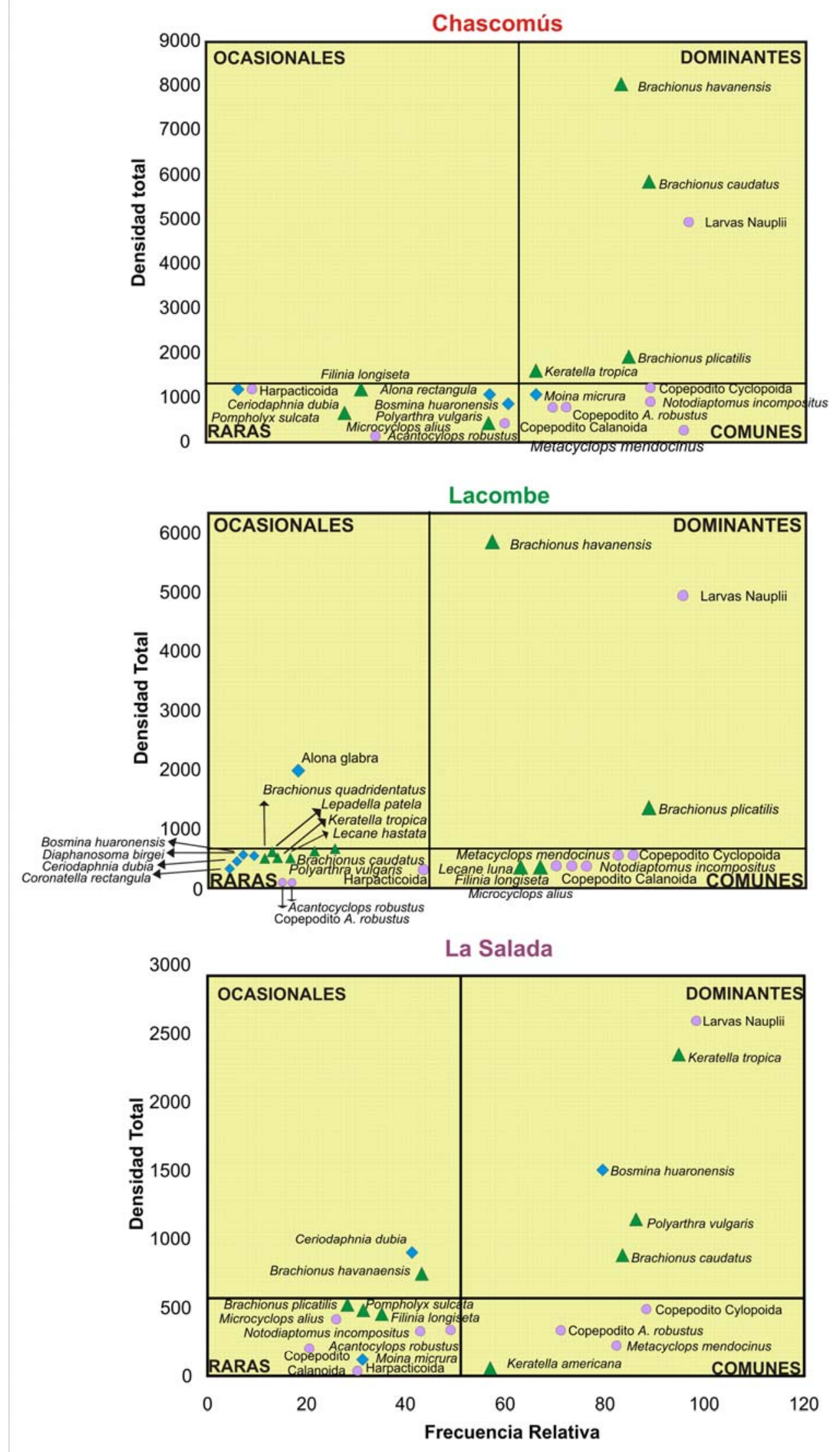

Figura IV.40: Gráficos de Olmstead-Tukey que indican las especies dominantes, ocasionales, comunes y raras en las lagunas Chascomús, Lacombe y La Salada.

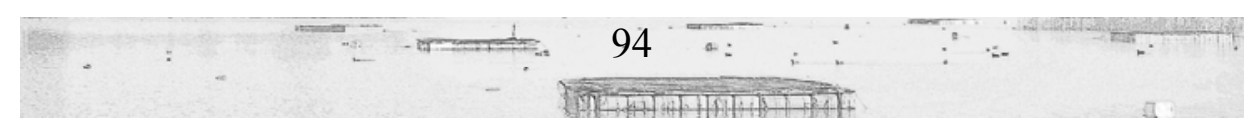




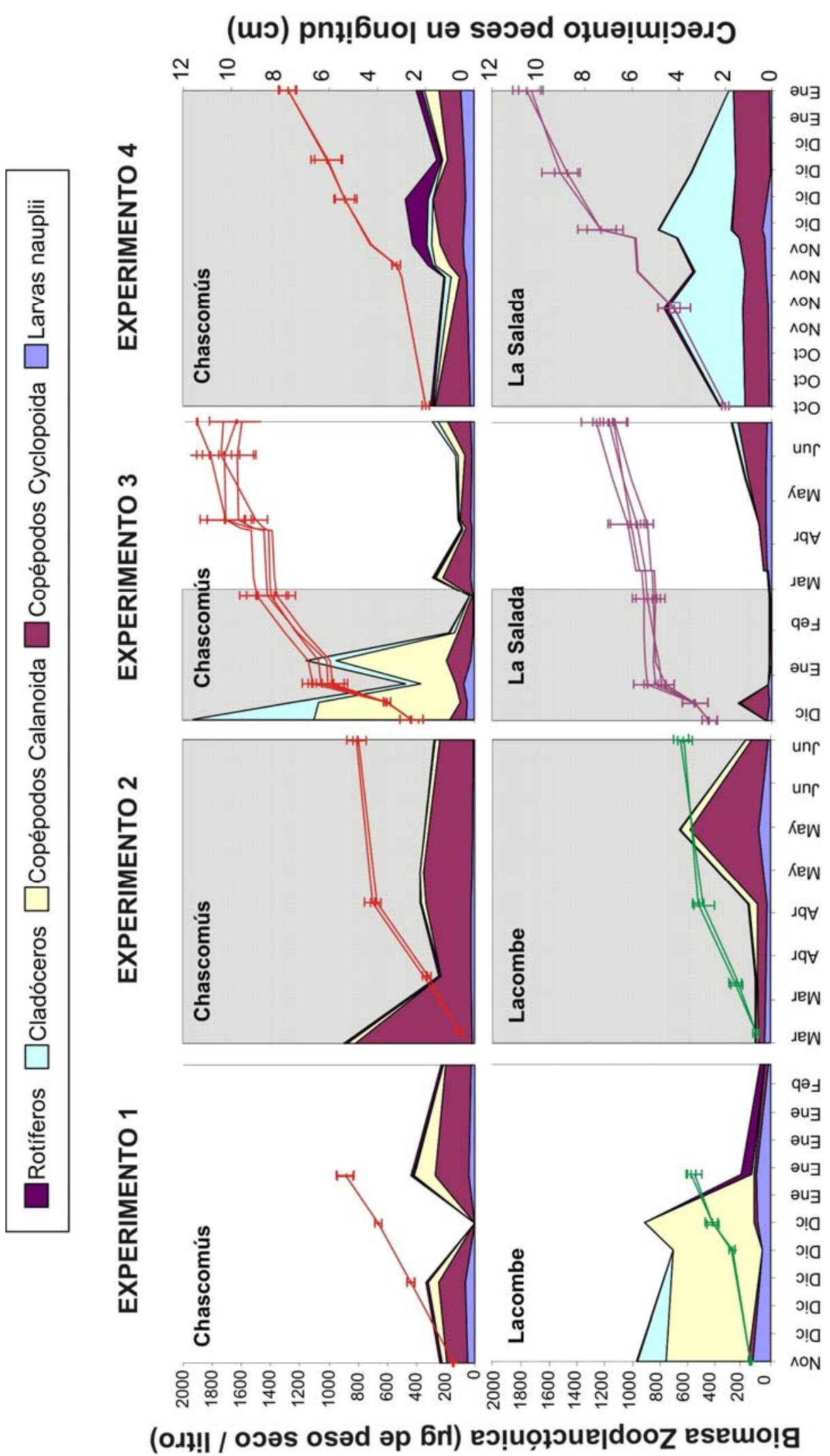

Figura IV.41: Biomasa zooplanctónica ( $\mu \mathrm{g}$ de peso seco/litro), discriminada por grupos taxonómicos, registrada en las lagunas en los cuatro experimentos (áreas apiladas) y curvas de crecimiento en longitud (con promedios por jaula y sus desvíos, por fecha de muestreo, en $\mathrm{cm}$ ) de los pejerreyes criados en los cuatro experimentos. Las áreas coloreadas de gris representan 100 días de experimentación. 
Resulta interesante observar que las especies discriminantes tuvieron valores de BZ verdaderamente elevados en algunos casos, y en los que no, su selección como especies contribuyentes a las diferencias pudo deberse a la comparación con los otros ítems en un contexto de escasa biomasa. Por ejemplo, se registraron valores elevados de BZ promedio de $N$. incompositus en Lacombe al principio de $\mathrm{E} 1$ y picos de BZ de N. incompositus y M. micrura en Chascomús al principio de E3, y hubo valores bajos de BZ promedio de M. mendocinus y N. incompositus en Chascomús en el E1 (Figura IV.41).

Cabe aclarar en este punto que por la naturaleza de los diseños experimentales, al utilizar las medidas individuales para testear las diferencias en el crecimiento entre las lagunas (RM ANOVA), se cometió pseudoreplicación (Hurlbert 1984), y que se deberían tener en cuenta las implicancias de ésto al analizar los resultados.

Los experimentos realizados demuestran que el crecimiento del pejerrey (aplicando la técnica de cultivo extensivo en jaulas flotantes dentro de lagunas) está fuertemente condicionado por la composición cuali-cuantitativa de la comunidad zooplanctónica presente en el ambiente. Dicha sentencia coincide, al menos en parte, con lo establecido por Jensen (1985), quien asegura que las principales variables que afectan el crecimiento de los peces son las fluctuaciones de la temperatura y la disponibilidad de alimento. Al observar que el crecimiento de los pejerreyes fue diferente dependiendo de la laguna en dónde se instalaron las jaulas y analizando los modelos obtenidos al realizar las regresiones múltiples, es posible aseverar que la disponibilidad de alimento, sobre todo en términos de biomasa (normalizada por período entre fechas de muestreo de peces, para obtener mayor fidelidad en cuanto a lo realmente disponible como alimento) es la variable que mejor explica las diferencias en las tasas de crecimiento de los peces. En todos los modelos obtenidos apareció alguno de los dos atributos del zooplancton (AZ y BZ) como significativos, y es de destacar que la AZ lo hizo siempre de manera negativa y la BZ de manera positiva, lo cual indica la importancia de la composición del zooplancton que define la biomasa. BZ aparece como el principal regulador del crecimiento del pejerrey en jaulas flotantes (resultó significativa o con valores muy cercanos a la significancia en todos los casos), mientras que otras variables ambientales como la temperatura, que según la literatura podría haber tenido su influencia, no serían tan influyentes (se incorporó como variable significativa sólo en el modelo de regresión múltiple de la TCEL para Chascomús, en E4). El hecho de que los integrantes de la familia Atherinidae presenten una gran adaptación a ambientes nuevos y cambiantes (de ahí su elevada 
abundancia en las áreas templadas del mundo, donde las fluctuaciones ambientales son comunes) (Bamber \& Henderson 1988) sostiene también esta idea de "relación proporcional" entre la biomasa zooplanctónica (aportada principalmente por copépodos y cladóceros) y el crecimiento (y la producción) del pejerrey.

En el caso del E4 resulta importante destacar que entre las lagunas comparadas, La Salada de Monasterio resultó tener una composición zooplanctónica de mayor biomasa y, a su vez, fue donde se registró el mayor crecimiento de los pejerreyes criados, contrario a lo que ocurrió en E3 donde al comparar las mismas lagunas, Chascomús tuvo mayores BZ y mayor crecimiento del pejerrey (Figura IV.41). Esta comparación entre dos experimentos realizados en las mismas lagunas pero en distintos años y momentos del año también permite observar que en E4 los pejerreyes llegaron a la talla máxima experimental en menos tiempo que en E3 (áreas coloreadas en gris en la figura IV.41). Esto sugiere que la época (estación por ejemplo) de siembra de los alevines en jaulas influye de manera significativa en el crecimiento de dicho lote, lo cual promueve la realización de experimentos para testearlo (capítulo V). Además, estos hechos permiten asegurar que a mayores BZ totales, y mayor representatividad de especies zooplanctónicas grandes, se obtienen mejores TCE en la cría extensiva de pejerrey en jaulas, lo cual se vincula con un concepto que será denominado aquí "calidad", haciendo referencia a determinados ítems del zooplancton como alimento óptimo del pejerrey. Esta calidad está vinculada con la relación entre el carbono, el nitrógeno y el fósforo: C:N:P (Hessen 2008), de dichas presas, la cual es variable, incluso estacionalmente, en el zooplancton, más que nada por la variabilidad que poseen los diferentes ítems de la comunidad en cuanto al contenido de $\mathrm{P}$, ya que el $\mathrm{C}$ y el $\mathrm{N}$ serían más estables, al menos en comparación con el ambiente marino (Anderson \& Hessen 1991). El P es un elemento cuyo interés ecológico radica en su importancia en el crecimiento de los organismos y su relativa baja disponibilidad en el medio (Wetzel 2001). Es así que unas presas se vuelven más convenientes que otras en cuanto al equilibrio entre el esfuerzo de captura y el aporte nutricional, por ejemplo al incorporar microcrustáceos a la dieta, los cuales por más que sean escasos presentan una gran ventaja en comparación con los rotíferos, que por más cantidad que ingieran su aporte nutricional será menor. Esto se debe al contenido proteico necesario en todo organismo, sobre todo en aquellos de crecimiento rápido. Es decir no sólo importa la $B Z$ presente en el ambiente, sino cómo está compuesta esta BZ y el aporte nutricional en $C$, $\mathrm{N}$ y $\mathrm{P}$ que realicen las presas. De hecho, para la misma laguna, por ejemplo Chascomús, el 
crecimiento no fue siempre el mismo, los mayores valores se obtuvieron en E3, donde dominan la biomasa los copépodos Calanoida y los cladóceros (Figura IV.41).

Profundizando un poco más entonces se puede decir que las diferencias en el crecimiento de los peces se vinculan con las diferencias en cuanto al aporte nutricional de los diferentes ítems zooplanctónicos. Si bien los copépodos se caracterizan por poseer altos niveles proteicos y buenos perfiles de aminoácidos su composición de ácidos grasos varía considerablemente de acuerdo a su dieta (Prieto Guevara \& Atencio-Garcia 2008). Los cladóceros en cambio poseen un elevado contenido de ácidos grasos cuando están bien alimentados y presentan un amplio espectro de enzimas importantes (proteinasas, peptidasas, amilasas, lipasas y celulasas) que sirven como exoenzimas en el intestino de las larvas (Prieto et al. 2006), y además presentan mayor contenido de $\mathrm{P}$ que los copépodos (Andersen \& Hessen 1991, Hessen et al. 2013).

A las diferencias estequiométricas se suman otras como el hecho de que los copépodos presentan movimientos rápidos, por saltos (Pasternak et al. 2006), y por ende altas probabilidades de escape y los cladóceros en cambio poseen movimientos más lentos (Geiger \& Turner 1990). Además, las poblaciones de cladóceros suelen declinar rápidamente ante la depredación por peces (Geiger 1983, Geiger et al. 1985) e incluso ser más vulnerables a la depredación por copépodos que por peces (Brandl 1998, Chang \& Hanazato 2005, Blumenshine \& Hambright 2003). Otras características de las presas que pueden influir en la selección son: morfología, palatabilidad, facilidad de manejo, digestión y abundancia, así como el futuro riesgo de predación (Hart 1986, Reiriz et al. 1998).

Por otro lado, la gran variabilidad registrada en las biomasas finales de peces contenidos por jaula, en E3 en Chascomús, enmascara las diferencias encontradas (Figura IV.25). Dicha variabilidad pudo deberse a la mortalidad y/o a los escapes que pueden haber ocurrido. Las características de la laguna Chascomús han generado algunos problemas a lo largo de los experimentos, como por ejemplo el hecho de que por su gran extensión y su morfología está muy expuesta al viento, el cual genera mucho movimiento del agua. Además por su ubicación lindante a una ciudad con gran afluencia de turismo, el vandalismo se convierte en un importante factor que afecta las unidades de cría. Esta observación indica que la clara dependencia hacia las variables ambientales no es sólo un atributo del sistema de cría en jaulas sino que puede verse además como un tema a resolver. Esto se debería tener en cuenta para futuros experimentos, ya que el mejoramiento de las unidades de cría 
permitirá en algún momento poder establecer cultivos en lagunas más grandes donde se puedan destinar sectores específicos de las mismas para la instalación de jaulas flotantes.

Por último, los resultados alcanzados en cuanto a la dieta de los peces criados promovió un estudio más detallado de la misma en experimentos subsiguientes que permitieran realizar más comparaciones e incluso perseguir el objetivo de estudiar el desarrollo ontogenético de la alimentación del pejerrey al estudiar su dieta en las etapas "nursery", experimentales y en los silvestres (Capítulos V, VI y VII). 


\section{V}

\section{INFLUENCIA DE LA ESTACIONALIDAD}

\section{EN EL CULTIVO EXTENSIVO DE PEJERREY}
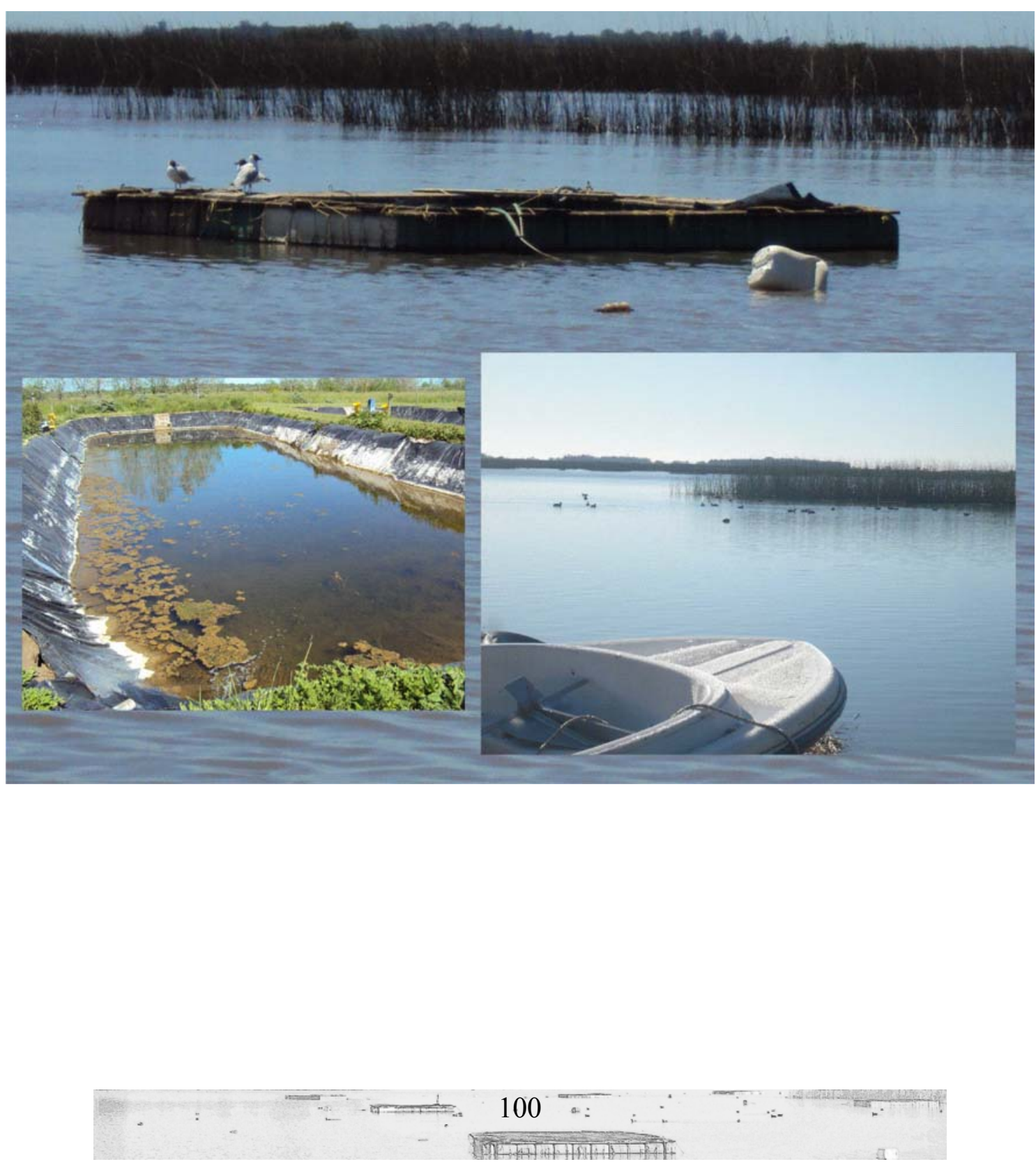


\section{Capítulo V: INFLUENCIA DE LA ESTACIONALIDAD EN EL CULTIVO EXTENSIVO DE PEJERREY}

\subsection{Introducción}

La sincronización que existe entre el desove de los peces y los eventos bióticos y abióticos (en inglés: "timing") ha sido estudiada en el ambiente marino por Cushing (1972, 1990), desarrollando una hipótesis conocida con el nombre de "match-mismatch". Dicha hipótesis postula que el desove de los peces está coordinado con la dinámica ecosistémica, ya que el nacimiento de las larvas se solapa con la época de floración del plancton (Bollens et al. 1992). Implícita en esta hipótesis está la idea de que las larvas representan una etapa particularmente sensible del desarrollo ontogenético de los peces en términos de su alimentación, sobre todo en el estadío de postlarva. El estadío ontogenético de larva es un "período crítico" (sensu Hjort 1914) en el que la supervivencia es muy variable y se determina el éxito posterior del reclutamiento (Cushing 1972). La hipótesis "match-mismatch" reinterpretada de un modo más específico establece: "La coincidencia entre la abundancia de postlarvas de peces y la disponibilidad de presas de zooplancton de tamaño medio (TMZ) adecuado" (Sherman et al. 1981, Frank \& Leggett 1982, Sinclair \& Tremblay 1984), que según algunos autores, dicho TMZ sería de entre 50 y 200 um (Arthur 1976, Sumida \& Moser 1980, Kane 1984).

Otro campo donde resulta esencial tener en cuenta esta sensibilidad característica de los estadíos tempranos de vida es en la acuicultura, sobre todo de especies que atraviesan estadíos larval, postlarval y juvenil, como el pejerrey, el cual presenta un período reproductivo que cuenta con desoves desde fines del invierno hasta el comienzo del otoño, con dos picos de desoves, uno mayor en la primavera y otro de menor magnitud en el verano tardío (Calvo \& Morriconi 1972, Strüssmann 1989, Berasain et al. 2008, Rosso \& Quirós 2010).

El éxito de la larvicultura depende en gran medida del manejo de la primera alimentación (Atencio-Garcia et al. 2003, Prieto Guevara et al. 2006). Se ha dicho que son los desaciertos en cuanto a la alimentación y la nutrición de las postlarvas, la cual se compone en 
la mayoría de los casos de zooplancton, los que constituyen el cuello de botella que impide la expansión de la actividad (Prieto Guevara \& Atencio-Garcia 2008).

Por otro lado, para la comunidad zooplanctónica, la temperatura y la disponibilidad de recursos son dos factores ambientales que regulan su estructura en general (Gyllström et al. 2005). Las respuestas del zooplancton a los cambios ambientales que ocurren en el transcurso del ciclo anual son rápidas y evidentes, y en las regiones templadas y frías, las pronunciadas variaciones anuales de temperatura y la duración del fotoperíodo figuran entre los factores que más influyen sobre la tasa de producción planctónica (González de Infante 1988). Para algunos autores, la temperatura además de regular la estructura del zooplancton influye sobre las interacciones entre los diferentes componentes del mismo, mientras que otros autores vinculan dichos procesos con la depredación.

Los trabajos que vinculan la estructuración del zooplancton con la temperatura, han destacado que los zooplanctontes de pequeño tamaño son dominantes frente a los de mayor tamaño en los lagos tropicales y subtropicales (Fernando et al. 1987, Dumont 1994, Meerhoff et al. 2007a, Havens et al. 2009). Por su parte, Gillooly \& Dodson (2000) han demostrado que el tamaño medio de los cladóceros planctónicos disminuye desde las regiones templado-frías hacia las tropicales, tanto en el hemisferio Norte como en el Sur. Relacionado con esto, Moore et al. (1996) consideran a los cladóceros pequeños como "competidores superiores" bajo la influencia de la temperatura, argumentando que a mayores temperaturas los individuos de tallas menores son más eficientes debido al menor incremento de las necesidades energéticas.

Más recientemente se ha argumentado que la intensa depredación por peces, en lugar de la temperatura, es la responsable de la reducción del tamaño medio observado en el zooplancton hacia los trópicos (Sarma et al. 2005, Jones \& Jeppesen 2007, Meerhoff et al. 2007b, Havens et al. 2009, Lacerot 2010, Sosnovsky et al. 2010, Iglesias et al. 2011). Vinculado con esta postura se encuentra la hipótesis de eficiencia por tamaños ( $\mathrm{SEH}$, desarrollada en el capítulo I) (Brooks \& Dodson 1965), la cual permite deducir además, que en ausencia de depredación por peces, el zooplancton de gran tamaño es competitivamente superior al de pequeño tamaño.

De todos modos, basándose en uno u otro estamento (estructuración por la temperatura o por la depredación), aparentemente contradictorios, es posible asegurar que la dominancia de determinada talla de zooplancton es dependiente de las condiciones 
ambientales (Feniova et al. 2013). Además, la temperatura ambiental influye estacionalmente de una manera crítica sobre las demandas metabólicas de los organismos, regulando por ejemplo la energía destinada al crecimiento en los peces, y afectando los procesos ecosistémicos en general (Wootton 1990), entre ellos, el de la depredación.

En el caso del paisaje pampeano, existe una elevada variabilidad anual e interanual que se ve reflejada en el comportamiento estacional de los ecosistemas lagunares (Quirós et al. 2002a). Estos autores aseguran que gran parte de las lagunas pasa por una fase estacional de aguas claras caracterizada por una elevada abundancia de cladóceros de gran tamaño que finaliza cuando alcanzan su pico de abundancia las postlarvas y juveniles de los peces planctívoros más abundantes, como el pejerrey (O. bonariensis) y el porteño ( $P$. valenciennis) y de detritívoros-planctívoros como el sabalito (C. voga). Esto ocurriría en la primavera tardía y principios del verano, mientras que los cladóceros además poseerían su propia estacionalidad en la composición de especies, con un predominio de especies de menor tamaño en invierno (géneros Bosmina, Ceriodaphnia, Alona y Leydigia) y de mayor tamaño en la época estival (géneros Daphnia y Moina).

Teniendo en cuenta la inestabilidad y estacionalidad de los ambientes lagunares pampeanos y considerando la sincronización entre el nacimiento de los peces y la abundancia de sus presas, se propuso un experimento con el objetivo de testear la influencia que posee dicha estacionalidad ambiental sobre la comunidad zooplanctónica y sobre el cultivo de larvas y juveniles de pejerrey. 


\subsection{Diseño experimental}

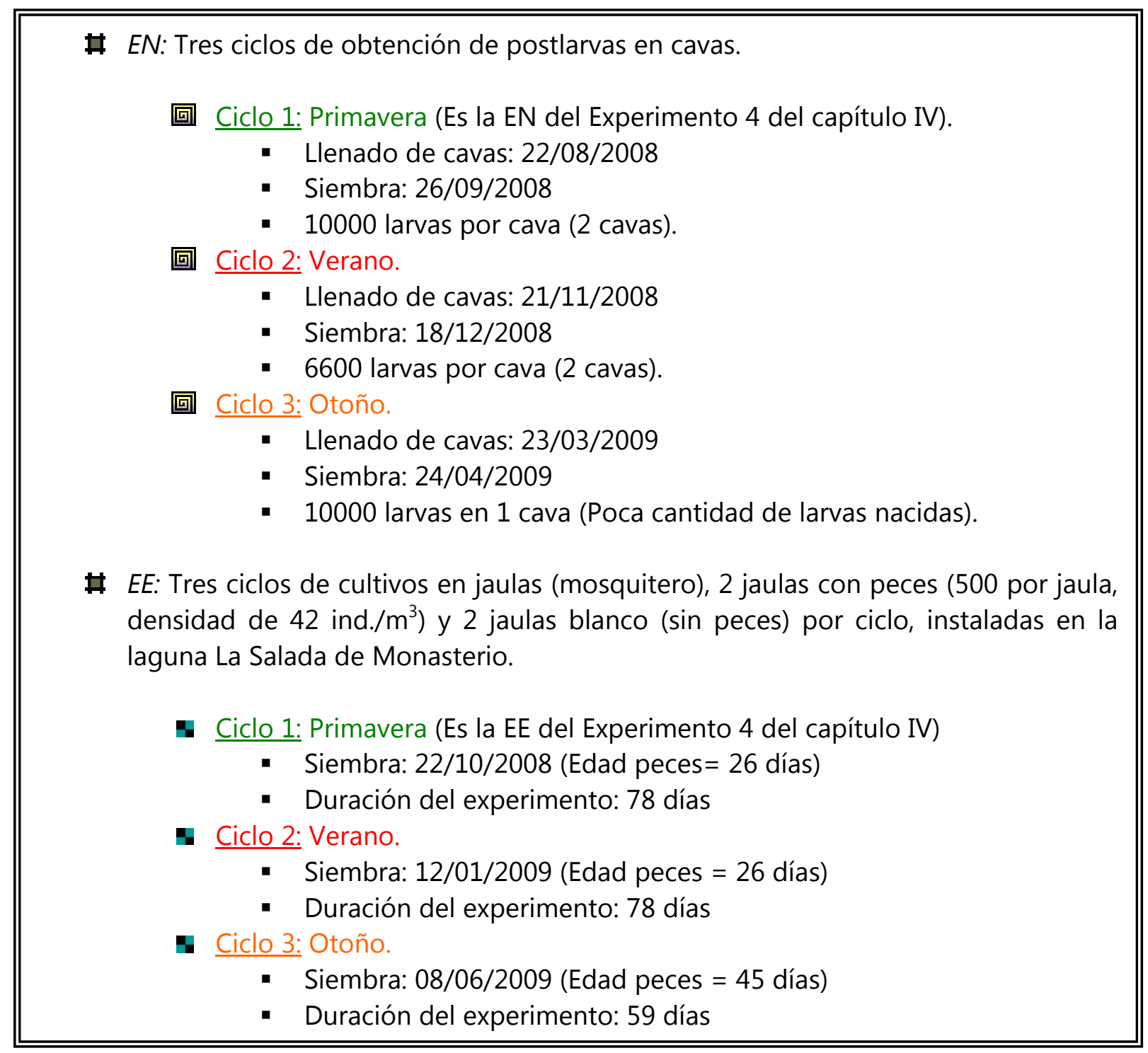

\subsection{Metodología particular}

Las abundancias y biomasas zooplanctónicas ( $A Z$ y $B Z$ ) registradas en las cavas y dentro y fuera de las jaulas, fueron comparadas entre ciclos y entre jaulas con y sin peces mediante métodos multivariados (ANOSIM, SIMPER, etc.), mientras que el crecimiento de los peces fue comparado mediante ANOVA de medidas repetidas (RM ANOVA) seguidos de SNK test para comparar entre pares. En los gráficos y tablas se indicó con colores cada ciclo. Ciclo 1 (primavera): color verde, ciclo 2 (verano): color rojo y ciclo 3 (otoño) color anaranjado claro. 


\subsection{Resultados}

\subsubsection{Etapa "nursery"}

\section{Parámetros físico-químicos}

Las variables medidas en las cavas registraron valores similares en cada ciclo (Tabla V.1), con la excepción de la temperatura que siguió un patrón estacional (Figura V.1) y la transparencia que varío de manera inversamente proporcional a la temperatura (Menor transparencia promedio en verano, cuando fueron las temperaturas más altas).

Tabla V.1: Valores medios y desvíos estándar de parámetros físico-químicos registrados en los tres ciclos de cultivo en cavas (Oxígeno disuelto, temperatura, salinidad, $\mathrm{pH}$ y transparencia).

\begin{tabular}{ccccccc} 
& $\begin{array}{c}\text { Transparencia } \\
(\mathbf{c m} \text { de Secchi) }\end{array}$ & $\begin{array}{c}\text { Salinidad } \\
(\mathbf{g} / \mathbf{L})\end{array}$ & $\mathbf{p H}$ & $\begin{array}{c}\text { Oxígeno Disuelto } \\
(\mathbf{m g} / \mathbf{L})\end{array}$ & $\begin{array}{c}\text { Porcentaje de saturación } \\
\text { del oxígeno promedio (\%) }\end{array}$ & $\begin{array}{c}\text { Temperatura } \\
\left({ }^{\circ} \mathbf{C}\right)\end{array}$ \\
\hline Ciclo 1 & $72,83 \pm 25,5$ & $15,3 \pm 0,8$ & $8,02 \pm 0,32$ & $13,47 \pm 2,41$ & 158 & $17,84 \pm 2,24$ \\
\hline Ciclo 2 & $46,83 \pm 8,44$ & $15,1 \pm 0,9$ & $8,14 \pm 0,14$ & $14,03 \pm 2,56$ & 190 & $26,18 \pm 4,43$ \\
\hline Ciclo 3 & $65,4 \pm 25,49$ & $14,9 \pm 0,6$ & $8,09 \pm 0,38$ & $13,74 \pm 2,72$ & 165 & $19,52 \pm 4,54$ \\
\hline
\end{tabular}

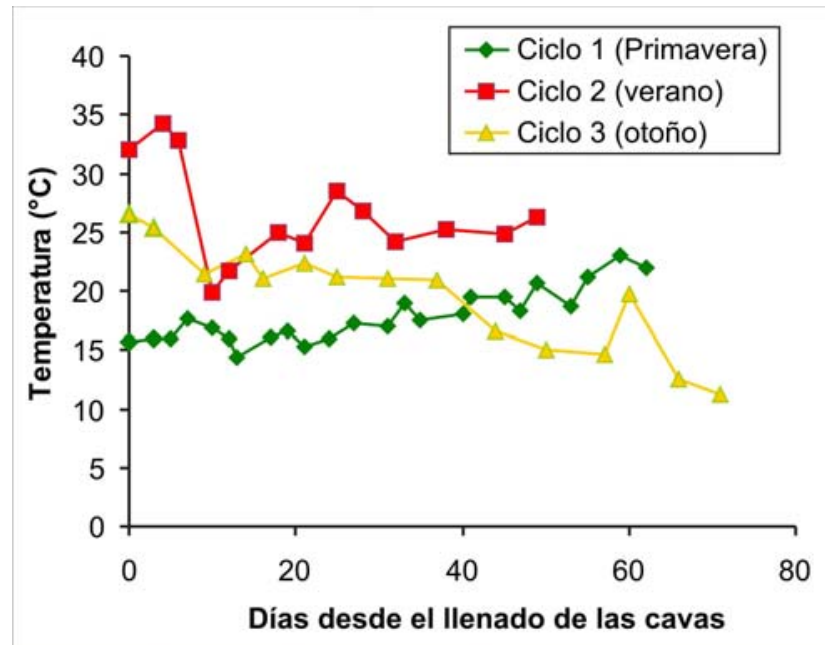

Figura V.1: Temperatura promedio registrada durante los tres ciclos de cultivo en cavas. 


\section{Comunidad zooplanctónica}

Analizando la composición de la comunidad zooplanctónica encontrada en las cavas se vio que $B$. plicatilis fue la especie dominante en todos los casos. Con menor representación se encontraron otros rotíferos del mismo género: $B$. havanaensis y $B$. caudatus, del género Keratella: K. tropica, K. americana y $K$. lenzi y larvas nauplii de copépodos y adultos de copépodos Cyclopoida (Microcyclops alius) y Ostrácodos (Heterocypris incongruens).

La AZ encontrada en las cavas fue variable a lo largo del tiempo en cada ciclo, y con ciertas diferencias entre los ciclos (Figura V.2). En el ciclo de otoño se registró la menor AZ (ciclo 1). Los momentos elegidos para sembrar las larvas de pejerrey en función de la AZ fueron similares en cuanto al tiempo desde el llenado de las cavas pero diferentes en cuanto a la AZ registrada (indicados con flechas negras en la Figura V.2).

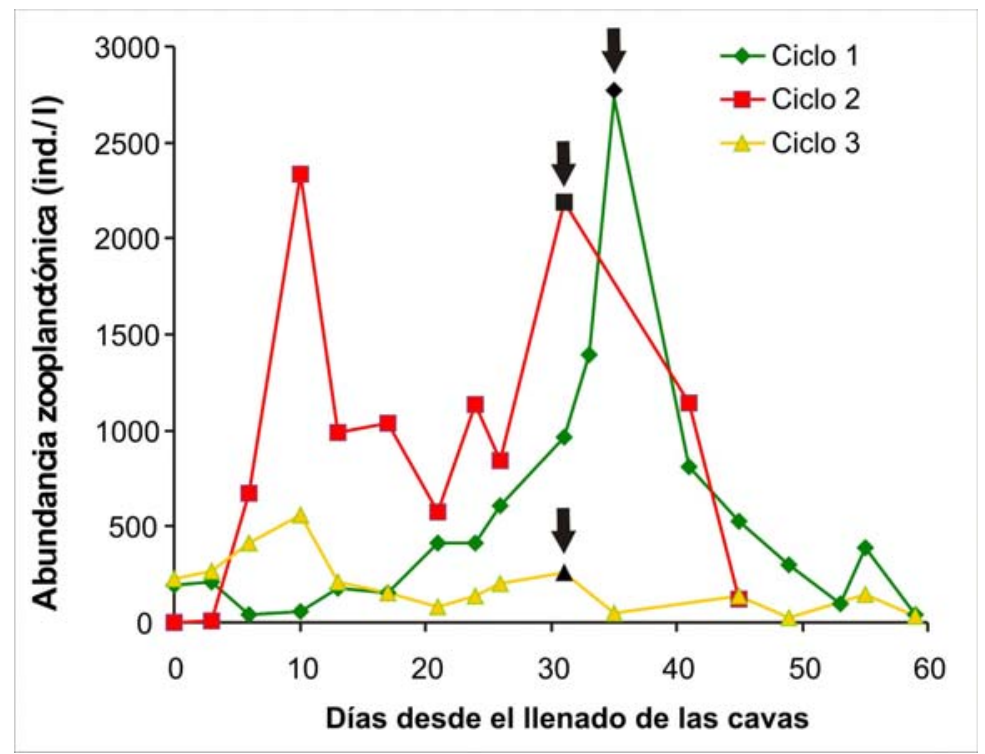

Figura V.2: Abundancia zooplanctónica total promedio, registrada en las cavas en los tres ciclos de cultivo. Los puntos negros indican la fecha de muestreo en la cual se decidió sembrar las larvas de pejerrey.

El rotífero $B$. plicatilis fue dominante en AZ durante la mayor parte de los ciclos, aunque se pudieron separar los ciclos en tres momentos (de 0 a 17 días, de 18 a 45 días y más de 45 días, desde el llenado de las cavas) de acuerdo a los diferentes ítems dominantes en la primavera y el otoño (en verano domina siempre B. plicatilis) (Tabla V.2). Las dominancias en AZ por ítems también pueden observarse en la figura V.3 de acuerdo a las categorías de tamaño, donde se observa una marcada dominancia de zooplancton de pequeño tamaño (categoría I). 
Tabla V.2: Ítems dominantes en abundancia zooplanctónica para cada ciclo dividido en tres momentos.

\begin{tabular}{clll} 
Días desde el llenado & \multicolumn{1}{c}{ Ciclo 1} & \multicolumn{1}{c}{ Ciclo 2 } & \multicolumn{1}{c}{ Ciclo 3} \\
\hline $\mathbf{0 - 1 7}$ & Ostrácodos & Brachionus plicatilis & B. plicatilis \\
\hline $\mathbf{1 8 - 4 5}$ & B. plicatilis & B. plicatilis & B. plicatilis \\
\hline & & & B. plicatilis, B. caudatus, B. \\
45-final & Ostrácodos & B. plicatilis & tropica, Ke americana, K. \\
& & & lenzi y ostrácodos \\
\hline
\end{tabular}

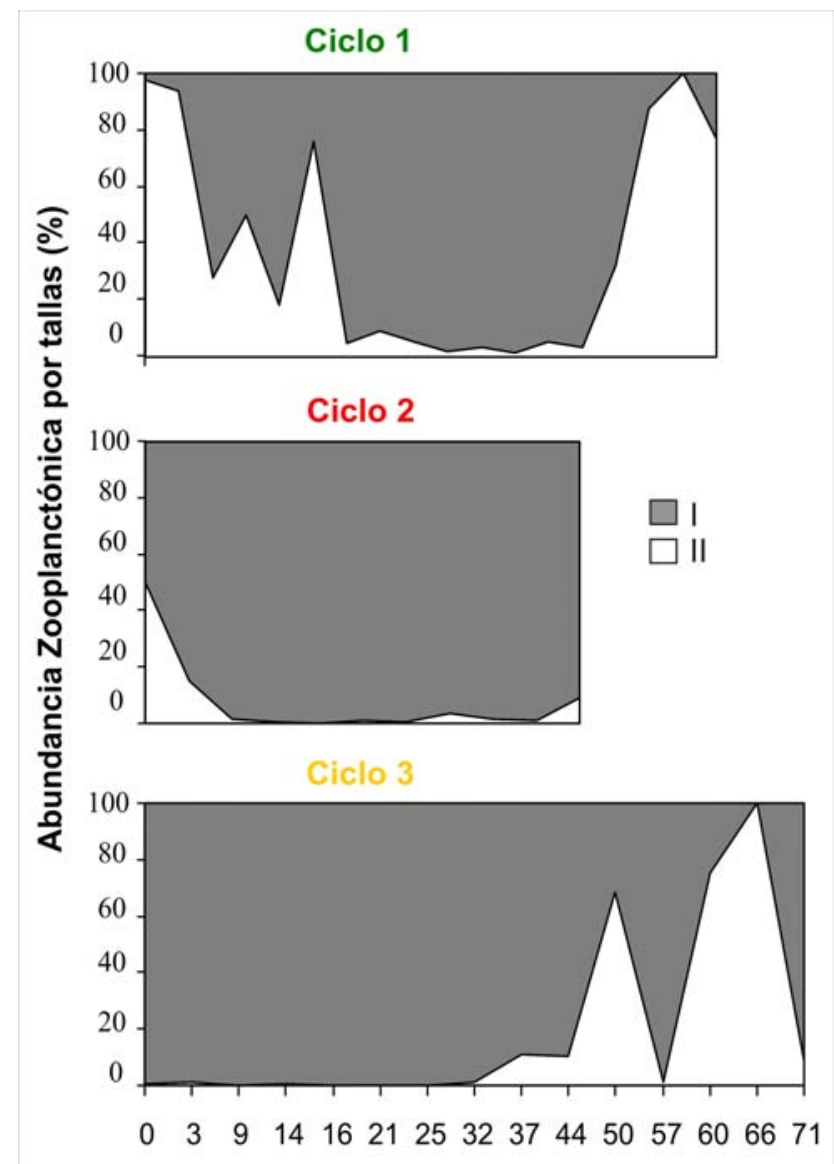

Días desde el llenado de las cavas

Figura V.3: Abundancia zooplanctónica porcentual por ciclo y por categorías de tamaño

$$
(\mathrm{I}=\text { gris y } \mathrm{II}=\text { blanco }) \text {. }
$$

La biomasa total zooplanctónica (BZ) mostró valores bajos (Figura V.4) con una marcada dominancia de grupos pequeños como los rotíferos. Las diferencias observadas entre los ciclos en cuanto a su BZ, permiten decir que fue mayor en el ciclo 2 (primavera). 


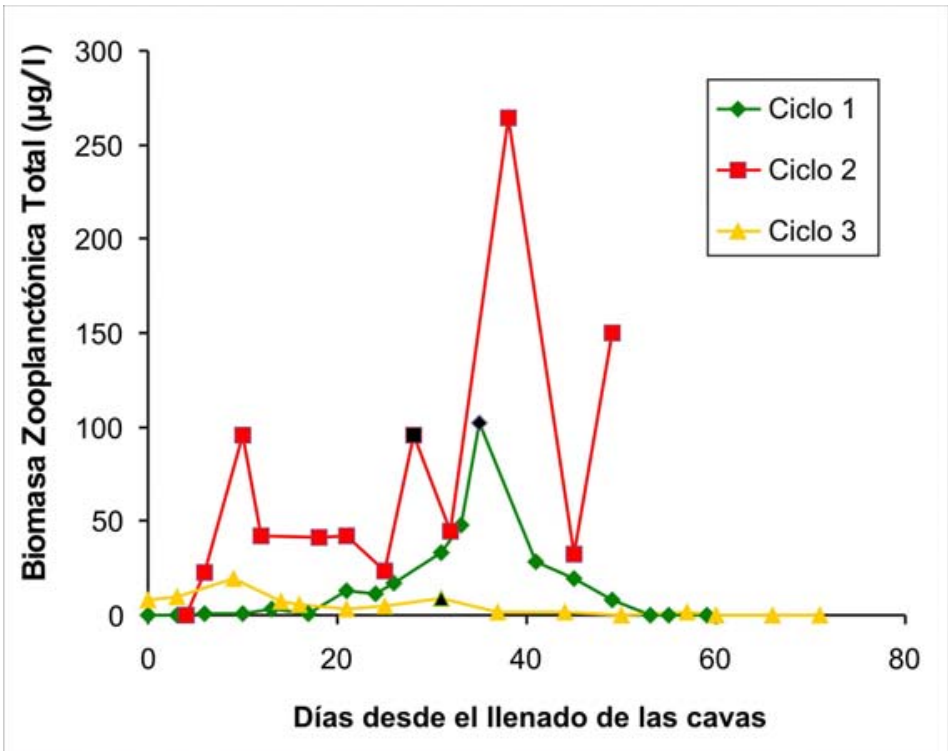

Figura V.4: Biomasa total zooplanctónica promedio por fecha de muestreo, por ciclo de cultivo.

\section{Crecimiento del pejerrey cultivado}

Se observaron diferencias entre ciclos en el crecimiento de las postlarvas (Figura V.5), siendo significativa la interacción entre los factores "edad" y "ciclo" (RM ANOVA, $F_{(8,48)}=27,2$; $p<0,05$, para la longitud y $F_{(8,48)}=4,64 ; p<0,05$, para el peso).

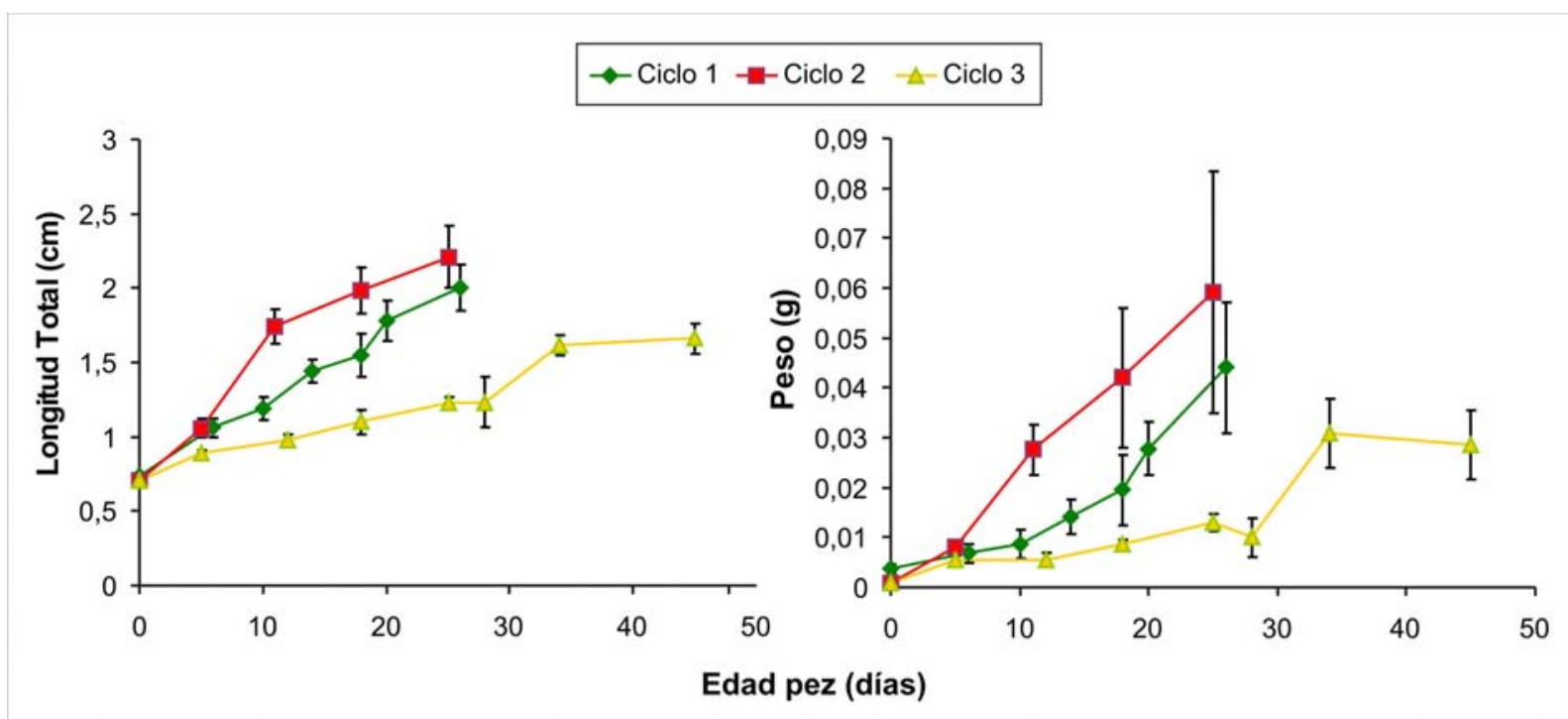

Figura V.5: Crecimiento de las postlarvas en los tres ciclos. Valores promedios por muestreo en largo y peso, con sus desvíos estándar, en función de la edad de los peces.

En el otoño los peces crecieron significativamente menos que en primavera, y ambos menos que en verano (Bonferroni test, $p<0,05$ ), salvo en las primeras dos edades muestreadas (0 y 5 días) (Tabla V.3). 
Tabla V.3: Resultados de las comparaciones de a pares (Bonferroni test), donde se indica para cada edad de pez comparada la significancia de la diferencia en longitud y peso (ns: no significativa, ${ }^{*} p<0,05,{ }^{* * *} p<0,001$ ).

\begin{tabular}{cccc}
\hline Edad (días) & Ciclo 1 vs. Ciclo 2 & Ciclo 1 vs. Ciclo 3 & Ciclo 2 vs Ciclo 3 \\
\hline 0 & $\mathrm{~ns}$ & $\mathrm{~ns}$ & $\mathrm{~ns}$ \\
5 & $\mathrm{~ns}$ & $\mathrm{~ns}$ & $\mathrm{~ns}$ \\
12 & $* * *$ & $*$ & $* * *$ \\
18 & $* * *$ & $* * *$ & $* * *$ \\
25 & $*$ & $* * *$ & $* * *$ \\
\hline
\end{tabular}

Las tasas de crecimiento variaron estacionalmente, siendo muy bajas en el otoño. Por esta razón durante la etapa "nursery" del ciclo 3 se alcanzó un tamaño comparable con el obtenido al final en el resto de los ciclos (1,6 cm de longitud total individual promedio) recién a los 45 días de vida. Se observó una correlación significativa entre las tasas de crecimiento en longitud de los peces criados en las cavas y la $A Z$ sólo para el ciclo $2\left(R^{2}=0,73\right)$.

La supervivencia de las larvas fue variable, $60 \%$ en el ciclo 1, $30 \%$ en el ciclo 2 y 7,3\% en el ciclo 3. Dicha supervivencia estuvo correlacionada positivamente con la AZ registrada en el momento de la siembra de las larvas $\left(R^{2}=0,92\right)$ en todos los ciclos.

\section{Alimentación del pejerrey cultivado}

Se analizaron $70 \mathrm{CD}$ de postlarvas de pejerrey criadas en cavas, y su composición cuali-cuantitativa evaluó de dos maneras diferentes: en función de la edad de las mismas y en función de su talla; además se graficó de acuerdo a las categorías de tamaño del zooplancton.

Según la edad de los peces (Figura V.6), en el ciclo 1 existió un predominio de larvas nauplii de copépodos y el rotífero $B$. plicatilis hasta alrededor de los 15 días, para luego incorporar ostrácodos en la dieta. En el ciclo 2 consumieron exclusivamente rotíferos (huevos y adultos de $B$. plicatilis) hasta los 18 días de edad, para luego pasar a un predominio de copépodos Cyclopoida, Harpacticoida y ostrácodos. En el ciclo 3 a los primeros 5 días se alimentaron exclusivamente de huevos de rotíferos, de los 10 a los 25 días predominaron los copépodos Harpacticoida y luego de los 25 días la dieta incorporó a los ostrácodos.

Según la talla de los peces (Figura V.7), se observó en el conjunto de los datos de los tres ciclos, que a medida que los peces crecieron su dieta se hizo más diversa. Los rotíferos 
fueron muy importantes hasta una LT de pez de 1,5 cm, y disminuyeron en su contribución a la dieta a partir de los $2 \mathrm{~cm}$ de LT, donde además se incorporaron los copépodos y los ostrácodos.

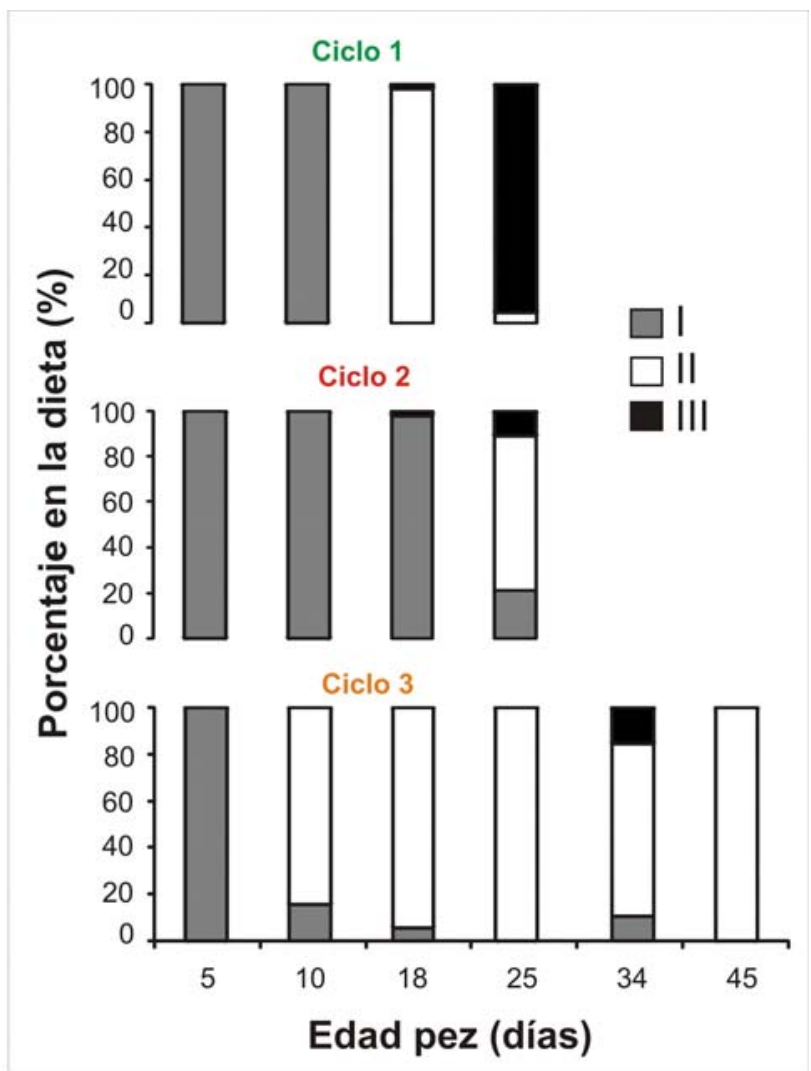

Figura V.6: Contribución porcentual en la dieta de las tres categorías de tamaño de presa en función de la edad de los peces, para los tres ciclos del experimento.

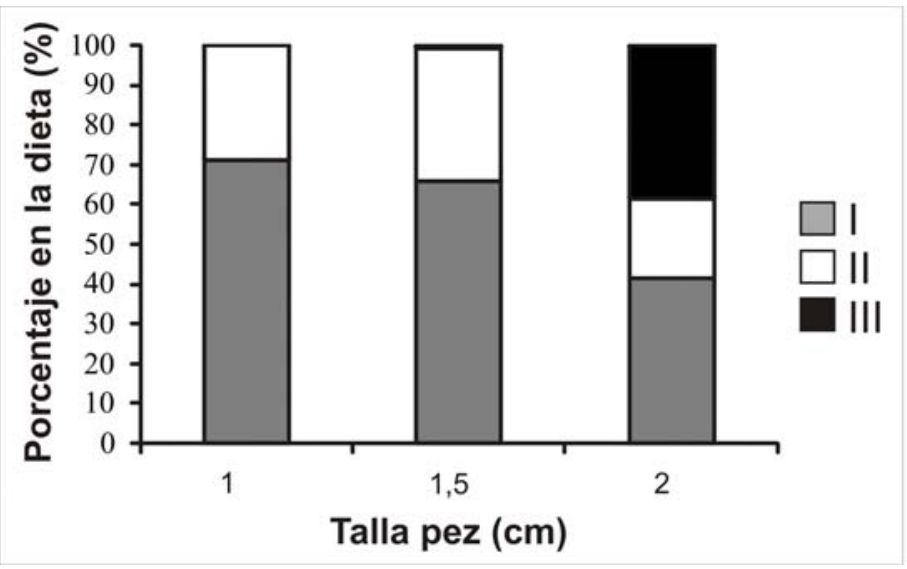

Figura V.7: Contribución porcentual en la dieta de las tres categorías de tamaño de presa en función de la talla de los peces (promedio de los tres ciclos del experimento).

Al comparar mediante métodos multivariados las proporciones de la oferta de zooplancton del ambiente y de lo consumido por las postlarvas criadas, se encontraron 
diferencias en los tres ciclos de cultivo (ANOSIM, $p<0,05$ ) con diferentes especies discriminantes de dichas diferencias (SIMPER), siendo a veces discriminantes por estar en mayor abundancia en el ambiente que en lo consumido, y otras veces de modo inverso (Tabla V.4).

Tabla V.4: Resultado del análisis SIMPER comparando la abundancia zooplanctónica de las cavas (AZC) y los contenidos digestivos (CD) de las postlarvas de pejerrey criadas en los tres ciclos.

\begin{tabular}{llll}
\hline & \multicolumn{1}{c}{ Ciclo 1 } & \multicolumn{1}{c}{ Ciclo 2 } & \multicolumn{1}{c}{ Ciclo 3} \\
\hline \% de disimilitud & 82,4 & 83,2 & 98,8 \\
Ítems discriminantes* & Brachionus plicatilis, & B. plicatilis (> en AZ) y & Acanthocyclops robustus \\
& ostrácodos y larvas Nauplii & huevos de rotíferos y & (copepoditos) (> en CD) y \\
& (> en AZ) & Microcyclops alius & ostrácodos y B. plicatilis (> \\
& & $(>$ en CD) & en AZ) \\
\hline
\end{tabular}

*Aportan más del $10 \%$ a la disimilitud entre tratamientos

Los índices de amplitud trófica y de selectividad alimentaria aplicados ( $\mathrm{H}^{\prime}$ de Levins, y FR de forrajeo óptimo) fueron también evaluados de acuerdo a la edad (Tabla V.5) y la talla de las larvas (Tabla V.6). La dieta fue monofágica $\left(H^{\prime}=1\right)$ en los primeros días de vida (a tallas menores) y fue diversa de los 18 días en adelante en los ciclos 1 y 2 y de los 10 días en adelante en el ciclo 3, siendo más diversa en el ciclo 3 en comparación con los otros. Los ítems medianos y grandes (categorías II y III) no formaron parte de la dieta en los primeros días. Luego la talla II fue seleccionada positivamente a partir de los 18 días en el ciclo 1 y a partir de los 10 días en los ciclos 2 y 3. 
Tabla V.5: Índices de amplitud trófica de Levins $\left(\mathrm{H}^{\prime}\right)$ y de selectividad alimentaria de forrajeo óptimo (FR) en función de la edad de los peces para los tres ciclos de la etapa "nursery".

\begin{tabular}{|c|c|c|c|c|c|}
\hline \multirow{2}{*}{ Ciclo } & \multirow{2}{*}{$\begin{array}{l}\text { Edad } \\
\text { (días) }\end{array}$} & \multirow{2}{*}{$\mathbf{H}^{\prime}$} & \multicolumn{3}{|c|}{ FR } \\
\hline & & & I & II & III \\
\hline \multirow{4}{*}{1} & 6 & 1,00 & 1,07 & 0,00 & 0,00 \\
\hline & 10 & 1,00 & 1,03 & 0,00 & 0,00 \\
\hline & 18 & 1,55 & 0,00 & 621,32 & 0,20 \\
\hline & 25 & 1,07 & 0,00 & 55,67 & 25,52 \\
\hline \multirow{4}{*}{2} & 6 & 1,00 & 1,02 & 0,00 & 0,00 \\
\hline & 10 & 1,00 & 1,00 & 21,44 & 0,00 \\
\hline & 18 & 1,04 & 1,07 & 2,36 & 0,04 \\
\hline & 25 & 1,78 & 0,10 & 332,51 & 0,59 \\
\hline \multirow{6}{*}{3} & 6 & 1,00 & 1,11 & 0,00 & 0,00 \\
\hline & 10 & 1,74 & 0,18 & 37,96 & 0,00 \\
\hline & 18 & 1,11 & 0,11 & 18,61 & 0,00 \\
\hline & 25 & 1,00 & 0,00 & 8,33 & 0,00 \\
\hline & 34 & 2,88 & 0,21 & 89,16 & 0,32 \\
\hline & 45 & 2,35 & 0,38 & 3,24 & 1,34 \\
\hline
\end{tabular}

Tabla V.6: Índices de amplitud trófica de Levins $\left(\mathrm{H}^{\prime}\right)$ y de selectividad alimentaria de forrajeo óptimo (FR) en función de la talla de los peces para los tres ciclos de la etapa "nursery".

\begin{tabular}{|c|c|c|c|c|c|}
\hline \multirow{2}{*}{ Ciclo } & \multirow{2}{*}{$\begin{array}{c}\text { Talla pez } \\
(\mathrm{cm})\end{array}$} & \multirow{2}{*}{$\mathbf{H}^{\prime}$} & \multicolumn{3}{|c|}{ FR } \\
\hline & & & I & II & III \\
\hline \multirow{3}{*}{1} & 1 & 1,0 & 1,0 & 0,0 & 0,0 \\
\hline & 1,5 & 1,6 & 0,6 & 310,7 & 0,1 \\
\hline & 2 & 1,1 & 0,0 & 31,0 & 14,4 \\
\hline \multirow{3}{*}{2} & 1 & 1,0 & 1,0 & 0,0 & 0,0 \\
\hline & 1,5 & 1,0 & 1,0 & 21,4 & 0,0 \\
\hline & 2 & 1,4 & 0,6 & 167,4 & 0,3 \\
\hline \multirow{2}{*}{3} & 1 & 1,2 & 0,3 & 16,2 & 0,0 \\
\hline & 1,5 & 2,9 & 0,3 & 46,2 & 0,8 \\
\hline
\end{tabular}

\subsubsection{Etapa Experimental}

\section{Parámetros físico-químicos}

Los parámetros físico-químicos medidos mostraron variaciones estacionales (Tabla V.7). El nivel hidrométrico de La laguna La Salada fue descendiendo a medida que avanzaron los ciclos, pasando de un promedio de $154 \mathrm{~cm}$ en primavera a $95 \mathrm{~cm}$ en otoño. La temperatura se modificó del mismo modo, observándose el mayor valor promedio en el ciclo 1 y el menor en el ciclo 3, mientras que la conductividad y el pH variaron de manera inversa. La transparencia fue mayor en el ciclo de verano (ciclo 2), mientras que el oxígeno disuelto presentó el menor valor en el ciclo de verano. 
Tabla V.7: Parámetros físico-químicos registrados durante el experimento, medidos en cada fecha de muestreo.

\begin{tabular}{|c|c|c|c|c|c|c|c|c|}
\hline & Fecha & $\begin{array}{l}\text { Profundidad } \\
\text { (cm) }\end{array}$ & $\begin{array}{l}\text { Transparencia } \\
\text { (cm de Secchi) }\end{array}$ & $\begin{array}{l}\text { Conductividad } \\
(\mathrm{mS} / \mathrm{cm})\end{array}$ & pH & $\begin{array}{c}\text { Oxígeno } \\
\text { Disuelto } \\
\text { (mg/L) }\end{array}$ & $\begin{array}{c}\text { Porcentaje de } \\
\text { saturación del } \\
\text { oxígeno (\%) }\end{array}$ & $\begin{array}{c}\text { Temperatura } \\
\left({ }^{\circ} \mathrm{C}\right)\end{array}$ \\
\hline \multirow{6}{*}{$\begin{array}{l}\text { Ciclo 1: } \\
\text { Primavera }\end{array}$} & $24 / 10 / 2008$ & 170 & 20 & 1,35 & 8,4 & 10,4 & 125 & 23,5 \\
\hline & $11 / 11 / 2008$ & 170 & 22 & 1,06 & 8,6 & 8,8 & 105 & 25,4 \\
\hline & $21 / 11 / 2008$ & 170 & 30 & 1,12 & 8,4 & 9,2 & 112 & 23,3 \\
\hline & 2/12/2008 & 140 & 42 & 1,26 & 8,4 & 8,4 & 95 & 18,3 \\
\hline & $17 / 12 / 2008$ & 140 & 35 & 1,24 & 8,4 & 7,8 & 96 & 27,8 \\
\hline & 8/01/2009 & 135 & 35 & 1,34 & 8,8 & 9,7 & 117 & 24,7 \\
\hline \multirow{7}{*}{$\begin{array}{l}\text { Ciclo 2: } \\
\text { Verano }\end{array}$} & $5 / 02 / 2009$ & 120 & 43 & 1,43 & 8,9 & 8,0 & 95 & 23,5 \\
\hline & $13 / 02 / 2009$ & 120 & 40 & 1,36 & 8,2 & 9,1 & 101 & 24,4 \\
\hline & 8/01/2009 & 135 & 35 & 1,34 & 8,8 & 9,7 & 117 & 24,7 \\
\hline & 5/02/2009 & 120 & 43 & 1,43 & 8,9 & 8,0 & 95 & 23,5 \\
\hline & $13 / 02 / 2009$ & 120 & 40 & 1,36 & 8,2 & 9,1 & 101 & 24,4 \\
\hline & $11 / 03 / 2009$ & 120 & 32 & 1,71 & 8,9 & 8,0 & 95 & 23,4 \\
\hline & 30/03/2009 & 105 & 31 & 1,76 & 9,1 & 8,3 & 95 & 22,1 \\
\hline \multirow{9}{*}{$\begin{array}{c}\text { Ciclo 3: } \\
\text { Otoño }\end{array}$} & $4 / 05 / 2009$ & 95 & 30 & 1,80 & 9,1 & 10,0 & 103 & 17,3 \\
\hline & $18 / 05 / 2009$ & 90 & 23 & 1,80 & 9,3 & 9,5 & 100 & 12,9 \\
\hline & 28/05/2009 & 90 & 27 & 1,80 & 9,1 & 11,5 & 118 & 12,1 \\
\hline & 8/06/2009 & 90 & 25 & 1,78 & 9,0 & 10,4 & 110 & 11,4 \\
\hline & $17 / 06 / 2009$ & 90 & 24 & 1,79 & 9,0 & 9,4 & 96 & 10,1 \\
\hline & 2/07/2009 & 90 & 20 & 1,80 & 9,3 & 10,2 & 100 & 8,4 \\
\hline & $17 / 07 / 2009$ & 100 & 21 & 1,79 & 9,1 & 13,3 & 140 & 10,2 \\
\hline & $30 / 07 / 2009$ & 105 & 15 & 1,69 & 9,0 & 10,5 & 98 & 7,2 \\
\hline & 6/08/2009 & 105 & 15 & 1,69 & 9,0 & 10,8 & 110 & 10,5 \\
\hline
\end{tabular}

\section{Comunidad zooplanctónica}

La AZ total de la laguna registró variaciones estacionales (Figura V.8) con un marcado pico durante el verano, ciclo donde se registró la mayor AZ en promedio.

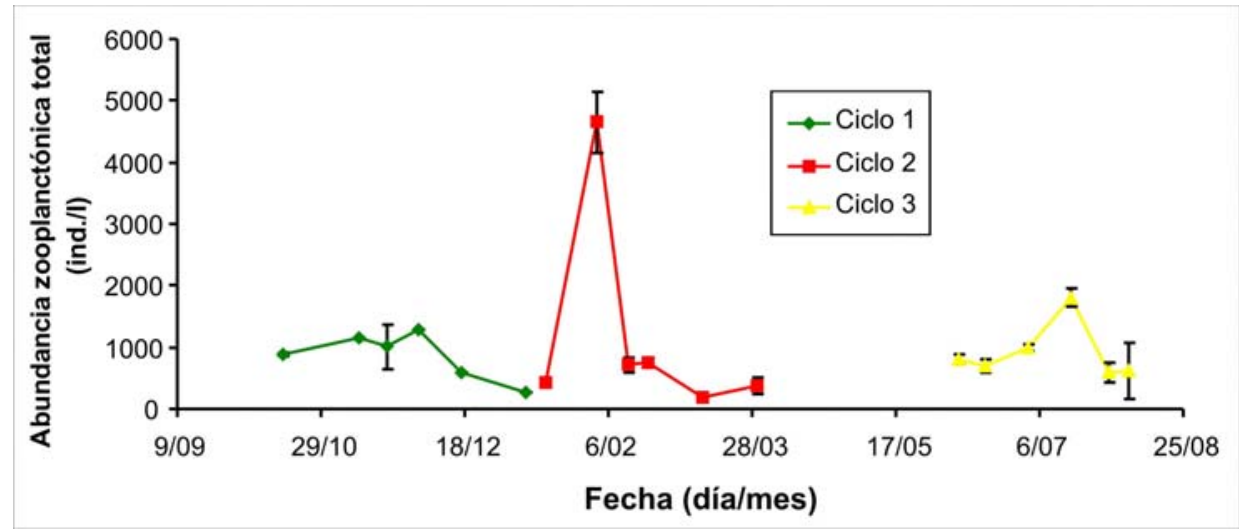

Figura V.8: Abundancia total zooplanctónica promedio por fecha en cada ciclo del experimento.

La composición por grupos de la comunidad zooplanctónica de la laguna presentó algunas diferencias entre las tres estaciones testeadas, como por ejemplo la importante contribución de cladóceros en la primavera, y casi ausencia de ellos en los otros dos ciclos. En 
términos de AZ por grupos, los rotíferos y las larvas nauplii fueron dominantes en casi todos los casos (Figura V.9). No se encontraron copépodos Calanoida, con la excepción de una fecha de muestreo en el ciclo 3 (otoño), pero en muy baja abundancia.

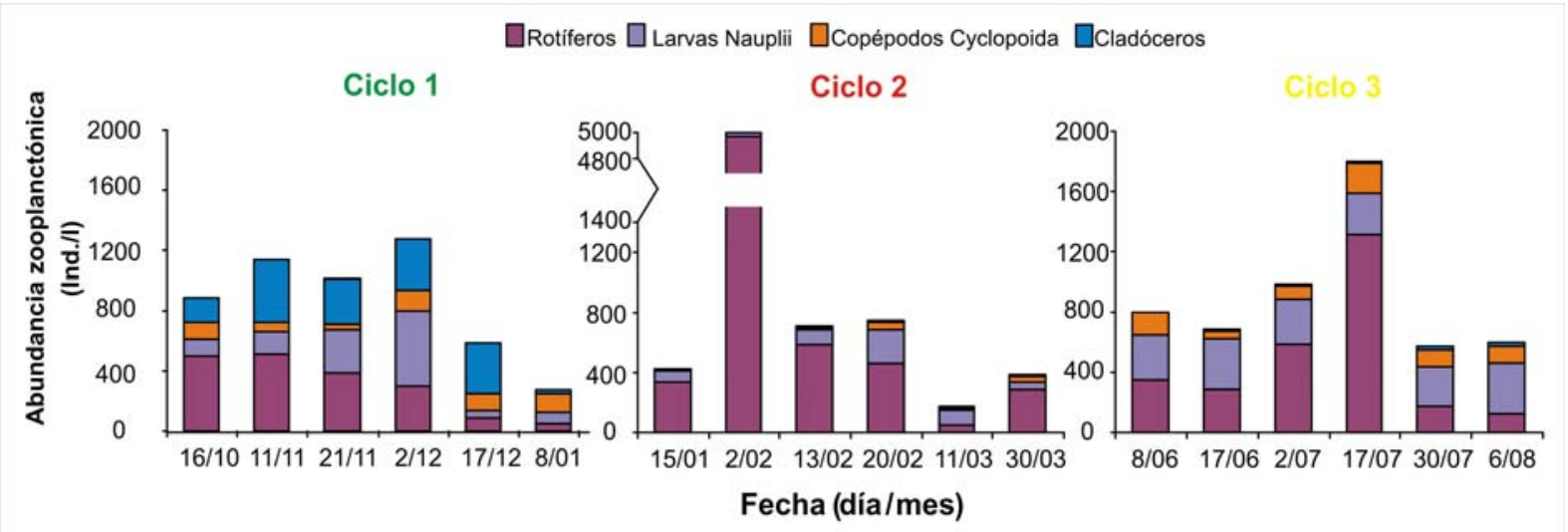

Figura V.9: Abundancia total zooplanctónica (ind./l) registrada en la laguna discriminada por grupos taxonómicos, considerando en el grupo de copépodos Cyclopoida al conjunto de los estadíos juveniles (copepoditos) y adultos.

En cuanto a la AZ por especies, ésta resultó ser diferente entre ciclos (ANOSIM, $p<0,05)$ con diferentes especies discriminantes identificadas por el SIMPER de acuerdo a los ciclos comparados (Tabla V.8).

Tabla V.8: Comparación de la abundancia zooplanctónica de la laguna en los tres ciclos de cultivo (SIMPER).

\begin{tabular}{llll}
\hline & \multicolumn{1}{c}{ Ciclo 1 vs Ciclo 2 } & Ciclo 1 vs Ciclo 3 & \multicolumn{1}{c}{ Ciclo 2 vs Ciclo 3 } \\
\hline \% de disimilitud & 49,04 & 42,8 & 54,2 \\
Ítems discriminantes* & Ceriodaphnia dubia (> en & Ceriodaphnia dubia y & Brachionus havanaensis ( \\
& Ciclo 1) y Brachionus & Polyarthra vulgaris ( $>$ & en Ciclo 2) y Keratella \\
& havanaensis (> en Ciclo 2) & en Ciclo 1) & tropica (> en Ciclo 3) \\
\hline
\end{tabular}

*Aportan más del $10 \%$ a la disimilitud entre tratamientos

Al comparar la AZ total de las jaulas con peces (AZJP) y las jaulas blanco (AZJB) (Figura V.10), se pudo observar que en promedio la AZJB fue mayor a la AZJP en la mayoría de las fechas de muestreo. Al evaluar dichas diferencias estadísticamente se encontró que la interacción entre los factores "tiempo" y "tipo de jaula" (JP ó JB) fue significativa en dos ciclos $\left(\right.$ RM-ANOVA, $F_{(3,6)}=28,2 ; p<0,05$, en el ciclo 1 y $F_{(3,12)}=4,1 ; p<0,05$, en el ciclo 2), mientras que se observaron diferencias en el factor "tipo de jaula" para el ciclo 3 (RM ANOVA, $F_{(1,2)}=$ $29,8 ; p<0,05)$. Las comparaciones con el SNK test indicaron que las JB tuvieron $A Z$ significativamente mayor $(p<0,05)$ que las JP en todas las fechas de muestreo de primavera, 
la primera y última fecha del verano y la primer fecha del otoño. En el resto de los muestreos del verano y el otoño AZJB fue siempre mayor que AZJP pero sin diferenciarse según el SNK test. Mediante métodos multivariados no se observaron diferencias entre JB y JP (ANOSIM, $p>0,05)$ en cuanto a su composición cuali-cuantitativa de especies.

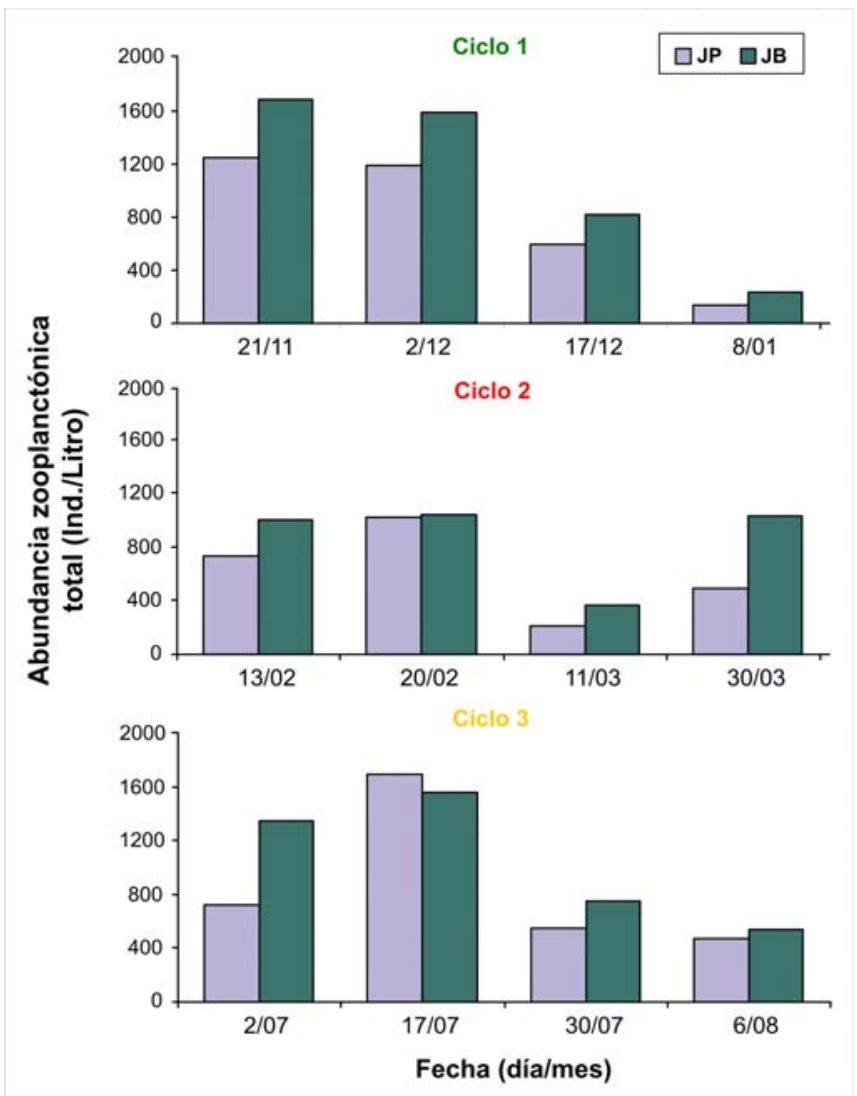

Figura V.10: Abundancia zooplanctónica total promedio encontrada en las jaulas con peces (JP) y las jaulas blanco (JB), en cada fecha de muestreo.

En términos de BZ de la laguna, se observaron diferencias entre estaciones (Figura V.11). La mayor BZ promedio se observó en primavera $(587,4 \pm 212 \mu \mathrm{g}$ peso seco/l) y la mínima en el verano $(50,65 \pm 24,25 \mu \mathrm{g}$ peso seco/l). 


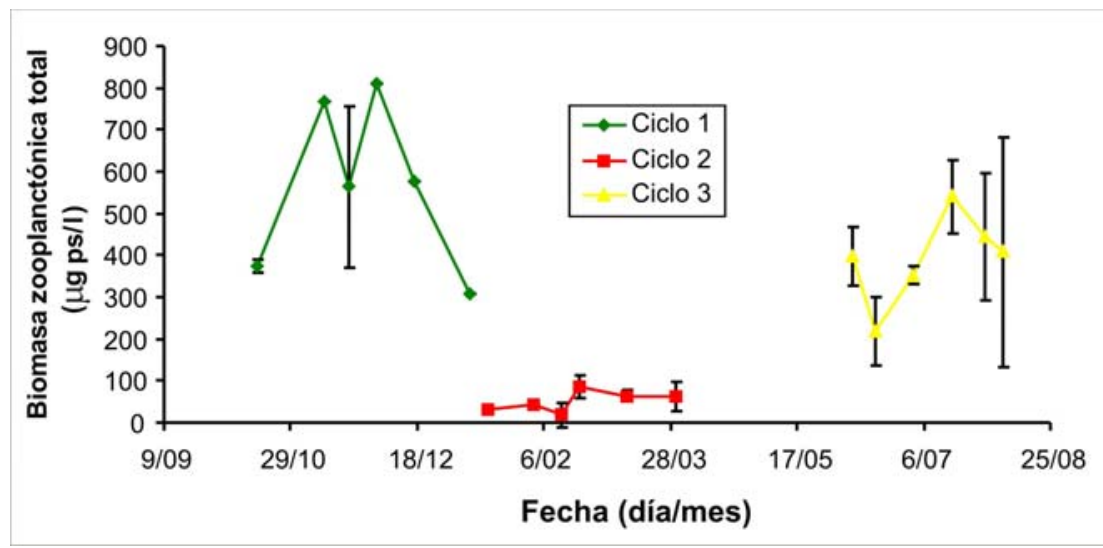

Figura V.11: Biomasa total zooplanctónica (promedios y desvíos), registrada en La Salada durante la etapa experimental de los tres ciclos de producción.

Analizando la BZ por especies, el ANOSIM arrojó diferencias entre los ciclos (ANOSIM, $p<0,05)$ y el SIMPER identificó como especies discriminantes a $C$. dubia y $B$. huaronensis (Mayor BZ en el ciclo 1 respecto del 2 y del 3) y a A. robustus (copepodito) y M. mendocinus (adultos) (Mayor BZ en el ciclo 3 respecto del 2).

\section{Crecimiento del pejerrey cultivado}

No se observaron diferencias entre las unidades experimentales, en cuanto al crecimiento en largo, en los ciclos de primavera (1) y otoño (3) (RM ANOVA, $F_{(1,58)}=0,21 ; p=$ 0,14 y $\left.\mathrm{F}_{(1,28)}=0,05 ; \mathrm{p}=0,82\right)$. En cuanto al peso de los individuos tampoco se hallaron diferencias entre las jaulas en estos dos ciclos (RM ANOVA, $F_{(1,18)}=2,07 ; p=0,17$ y $F_{(1,8)}=$ 0,$11 ; p=0,24$, respectivamente). En el ciclo 2 (verano), se halló una interacción significativa entre los factores "tiempo" y "jaula", tanto para el largo como para el peso de los individuos $\left(\right.$ RM ANOVA, $F_{(2,116)}=5,15 ; p<0,05$ y $F_{(2,36)}=5,0 ; p<0,05$, respectivamente), sin embargo según el Bonferroni test dicha diferencia fue significativa $(p<0,05)$ sólo al final del ciclo (104 días). Al comparar el crecimiento entre tratamientos (ciclos) se observaron diferencias, tanto en cuando al largo como al peso de los pejerreyes (RM ANOVA, $F_{(4,262)}=162,9 ; p<0,05$ y $F_{(4,94)}=$ 69,$9 ; p<0,05$, respectivamente). El menor crecimiento se dio en otoño (Ciclo 3), y el mayor en primavera, siendo el peso final de los peces criados en primavera ocho veces superior al estival y 50 veces al otoñal después de un período de 60 días de cultivo (Figura V.12). 


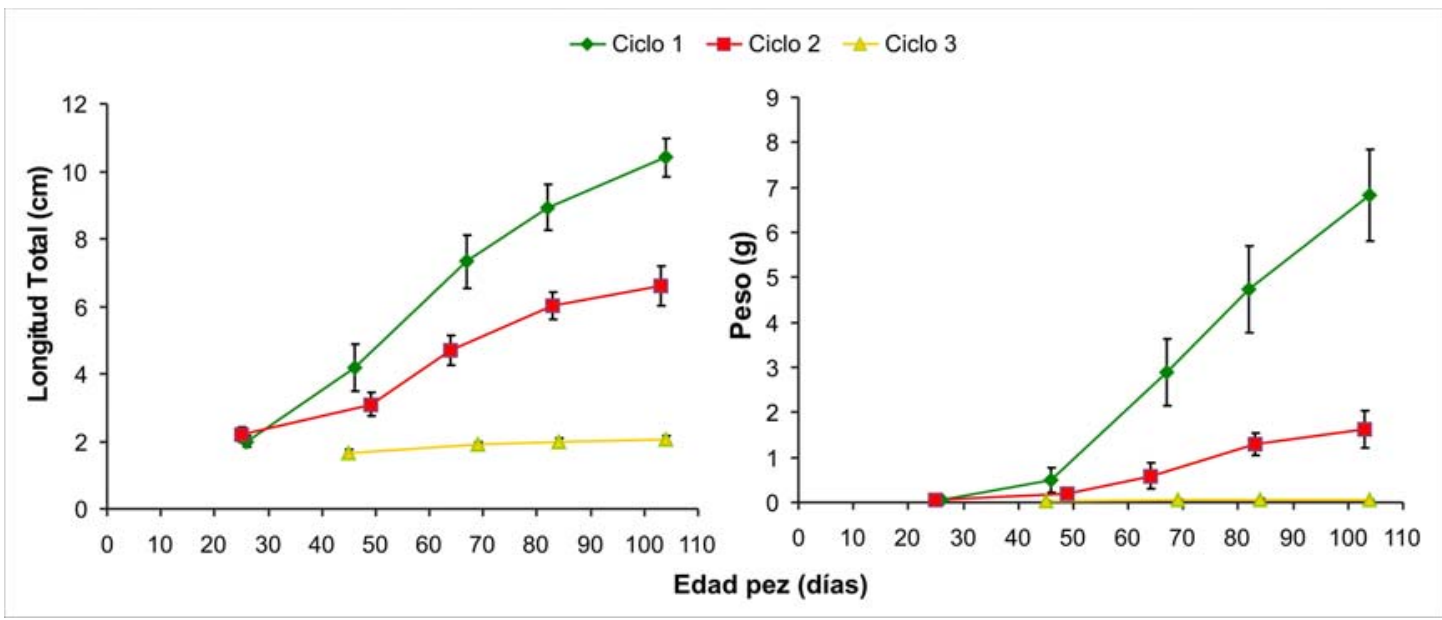

Figura V.12: Crecimiento de los pejerreyes criados en jaulas, en longitud y peso (LT en cm y W en g).

Se observó una correlación positiva significativa entre las tasas de crecimiento de los peces criados en jaulas y la $A Z$ en los ciclos de primavera y verano $\left(R^{2}=0,72\right.$ y 0,92 respectivamente) y no se observó correlación en el otoño.

Los peces mostraron una buena condición en todo el experimento, con valores de WrS cercanos a 1. Los valores más altos de WrS se encontraron entre los 64 y 84 días de vida de los pejerreyes en los ciclos de primavera y otoño, mientras que en el verano se registraron los valores más bajos, incluso por debajo de 1 a los 64-69 días de vida (Tabla V.9).

Tabla V.9: Índices de condición por stanzas (promedio y desvíos) para cada ciclo de cría y en cada fecha de muestreo comparable (expresada por intervalos de edades de los peces, en días)

\begin{tabular}{lcccc}
\hline \multicolumn{1}{c}{ Ciclo } & 45-49 días & 64-69 días & 82-84 días & 104 días \\
\hline Primavera & $1,12 \pm 0,14$ & $1,42 \pm 0,21$ & $1,46 \pm 0,23$ & $1,16 \pm 0,09$ \\
Verano & $1,08 \pm 0,11$ & $0,94 \pm 0,06$ & $1,15 \pm 0,08$ & $1,14 \pm 0,12$ \\
Otoño & $1,13 \pm 0,10$ & $1,37 \pm 0,16$ & $1,46 \pm 0,09$ & $1,09 \pm 0,08$ \\
\hline
\end{tabular}

La producción de primavera resultó uno y dos órdenes de magnitud superior a la del verano y otoño, respectivamente, mientras que la supervivencia fue mayor en una de las jaulas del ciclo 2, seguida de las dos jaulas de primavera (Tabla V.10). 
Tabla V.10: Biomasa final en gramos y supervivencia (\%) en cada jaula y en cada ciclo de producción.

\begin{tabular}{ccrr} 
Ciclo & Jaulas & Biomasa final (g) & Supervivencia (\%) \\
\hline 1 & a & 2764,0 & 82,0 \\
1 & b & 2893,7 & 85,7 \\
2 & a & 562,4 & 70,2 \\
2 & b & 805,2 & 99,6 \\
3 & a & 10,4 & 43,3 \\
3 & b & 10,4 & 43,3 \\
\hline
\end{tabular}

\section{Alimentación del pejerrey cultivado}

En términos generales, los juveniles de pejerrey se alimentaron mayoritariamente de zooplancton de clase III en primavera y verano, sobre todo a partir de los 69 días de vida. En el otoño la dieta estuvo constituida principalmente por zooplancton de talla II (Figura V.13). Al comparar la oferta zooplanctónica, en términos de proporciones de AZ por especie y por jaula, con las proporciones de lo consumido, se observaron diferencias en los tres ciclos (ANOSIM, $p<0,05)$, con diferentes especies discriminantes (SIMPER), siendo, como se dijo para la etapa "nursery", a veces discriminantes por mayor AZ en el ambiente que en lo consumido, y otras veces de modo inverso (Tabla V.11).

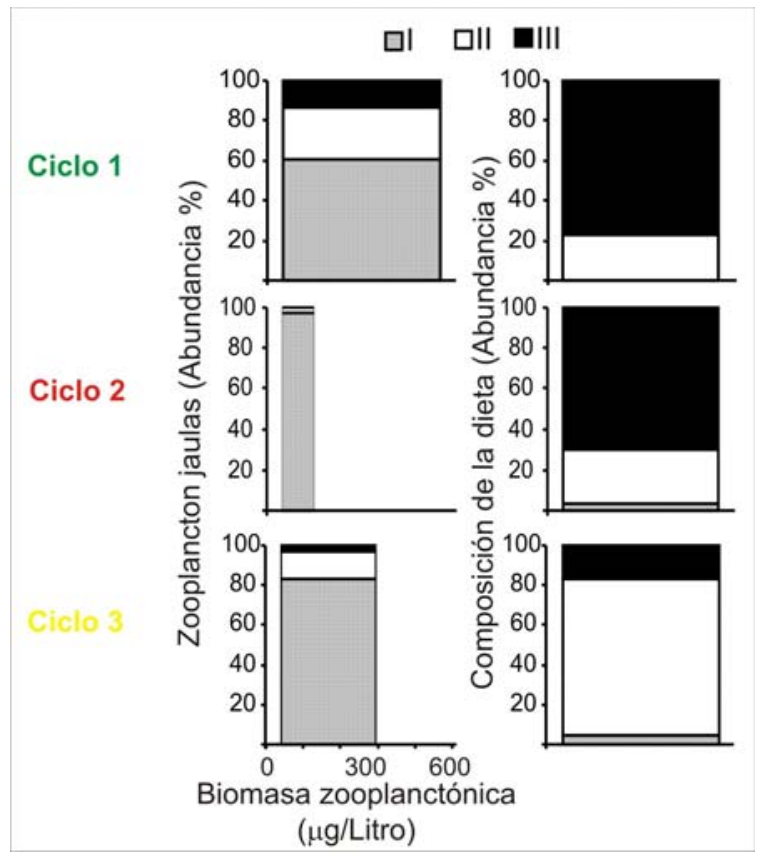

Figura V.13: Biomasa y abundancia zooplanctónica de las jaulas (ciclo 1: primavera, 2: verano, 3: otoño), por categorías taxonómicas (A la izquierda, ejes x e y respectivamente) y abundancia porcentual en la dieta (derecha). 
Tabla V.11: Resultado del análisis SIMPER comparando la abundancia zooplanctónica de las jaulas (AZJ) y los contenidos digestivos (CD) de los juveniles de pejerrey criados en los tres ciclos.

\begin{tabular}{llll}
\hline & \multicolumn{1}{c}{ Ciclo 1 } & \multicolumn{1}{c}{ Ciclo 2 } & \multicolumn{1}{c}{ Ciclo 3} \\
\hline \% de disimilitud & 75,9 & 93,5 & 84,6 \\
Ítems discriminantes* & Acanthocyclops robustus & Brachionus havanaensis & Larvas nauplii, Keratella \\
& (copepoditos y adultos) $>$ & y larvas nauplii $(>$ en & tropica y K. lenzi ( $>$ en AZ) \\
& en CD y larvas nauplii $(>$ & AZ) y A. robustus & y Metacyclops mendocinus y \\
& en AZ) & (copepoditos) $(>$ en CD) & Bosmina huaronensis ( $>$ en \\
& & CD) \\
\hline
\end{tabular}

*Aportan más del $10 \%$ a la disimilitud entre tratamientos

Analizando las variaciones en función de la edad y la talla se observó que la amplitud trófica de los peces fue descendiendo a medida que avanzaron los días (y que los peces crecieron), durante la etapa experimental, aunque dicho descenso no se observó en el ciclo 3, donde durante todo el ciclo el valor de H' fue bajo (Tabla V.12 y V.13). Los resultados del índice de forrajeo óptimo indicaron que los peces fueron selectivos hacia el zooplancton de tamaño medio al principio del ciclo 2 y 3 , pasando a seleccionar la talla mayor (III) al avanzar en edad y talla (tablas V.12 y V.13, y Figura V.13).

Tabla V.12: Índices de amplitud trófica de Levins $\left(\mathrm{H}^{\prime}\right)$ y de selectividad alimentaria de forrajeo óptimo (FR) en función de la edad de los peces para los tres ciclos de la etapa experimental.

\begin{tabular}{|c|c|c|c|c|c|}
\hline \multirow{2}{*}{ Ciclo } & \multirow{2}{*}{$\begin{array}{l}\text { Edad } \\
\text { (días) }\end{array}$} & \multirow{2}{*}{$\mathbf{H}^{\prime}$} & \multicolumn{3}{|c|}{ FR } \\
\hline & & & I & II & III \\
\hline \multirow{4}{*}{1} & 46 & 2,0 & 0,2 & 1,5 & 9,7 \\
\hline & 67 & 2,2 & 0,0 & 1,4 & 3,5 \\
\hline & 82 & 1,7 & 0,0 & 0,4 & 6,9 \\
\hline & 104 & 1,1 & 0,0 & 0,9 & 47,7 \\
\hline \multirow{4}{*}{2} & 49 & 2,1 & 0,5 & 372,7 & 27,6 \\
\hline & 64 & 2,0 & 0,0 & 3,9 & 11,2 \\
\hline & 83 & 1,5 & 0,0 & 1,0 & 46,8 \\
\hline & 102 & 1,3 & 0,1 & 1,9 & 295,2 \\
\hline \multirow{3}{*}{3} & 69 & 1,6 & 0,2 & 9,8 & 2,6 \\
\hline & 84 & 1,9 & 0,4 & 5,5 & 13,2 \\
\hline & 104 & 1,3 & 0,0 & 5,4 & 6,4 \\
\hline
\end{tabular}


Tabla V.13: Índices de amplitud trófica de Levins $\left(\mathrm{H}^{\prime}\right)$ y de selectividad alimentaria de forrajeo óptimo (FR) en función de la talla de los peces para los tres ciclos de la etapa experimental.

\begin{tabular}{|c|c|c|c|c|c|}
\hline \multirow{2}{*}{ Ciclo } & \multirow{2}{*}{$\begin{array}{c}\text { Talla pez } \\
\text { (cm) }\end{array}$} & \multirow{2}{*}{$\mathbf{H}^{\prime}$} & \multicolumn{3}{|c|}{ FR } \\
\hline & & & I & II & III \\
\hline \multirow{4}{*}{1} & 4 & 2,0 & 0,2 & 1,5 & 9,7 \\
\hline & 7 & 2,2 & 0,0 & 1,4 & 3,5 \\
\hline & 8 & 1,7 & 0,0 & 0,4 & 6,9 \\
\hline & 9 & 1,1 & 0,0 & 0,9 & 47,7 \\
\hline \multirow{3}{*}{2} & 3 & 2,1 & 0,5 & 372,7 & 27,6 \\
\hline & 4 & 2,0 & 0,0 & 3,9 & 11,2 \\
\hline & 6 & 1,4 & 0,1 & 1,45 & 171,0 \\
\hline 3 & 2 & 1,6 & 0,2 & 6,9 & 7,4 \\
\hline
\end{tabular}




\subsection{Discusión}

La comunidad zooplanctónica posee una posición estratégica en las tramas tróficas acuáticas, con gran influencia en el movimiento de la energía en los ecosistemas acuáticos y en la manera en que dichas tramas tróficas se organizan (Eskinazi-Sant`Anna et al. 2007). Los mismos autores comentan que la posición del zooplancton en la cadena alimentaria genera una gran conexión con los productores primarios, siendo extremadamente susceptible a los cambios estructurales que puedan ocurrir en el nivel trófico inferior. Además, de acuerdo a lo comentado en la bibliografía, posee una fuerte vinculación con los niveles tróficos superiores que lo hace responsable del flujo de energía que ocurre desde las algas a los peces. Esta característica de posicionamiento intermedio que tiene el zooplancton hace que su estudio sea de mucha utilidad para evaluar los cambios que ocurren en los ecosistemas. Estos cambios podrían ser aquellos eventos puntuales como de floraciones algales y eutrofización, o aquellos cíclicos y permanentes, como los vinculados con la estacionalidad de los ambientes acuáticos templados subtropicales.

El plancton de los ambientes acuáticos someros presenta variaciones estacionales que se ven representadas por marcados picos de abundancia y biomasa de los componentes en diferentes momentos del ciclo anual. En la primavera suele observarse un marcado pico de biomasa fitoplanctónica, siendo ésta la estación de máximo crecimiento de dicha comunidad. Por otra parte, en los lagos profundos que se estratifican ocurre un segundo pico anual de biomasa en el otoño, menos conspicuo que el de primavera, resultado de un nuevo aporte de nutrientes a la zona fótica (González de Infante 1988).

Durante la etapa "nursery" se registraron picos de abundancia y biomasa zooplanctónica en diferentes momentos en relación al llenado de las cavas en cada ciclo de cultivo. En la primavera el pico de AZ se dio cerca de 30 días desde el llenado, lo cual coincide con el solapamiento que suele observarse entre los ciclos del zooplancton y del fitoplancton en los ambientes naturales (Sommer 1989, Lampert \& Sommer 1997). Sin embargo, dicho solapamiento ocurre de forma clara en lagos del Hemisferio Norte, donde durante el ciclo anual, cuando la temperatura aumenta (en primavera), las formas zooplanctónicas de diapausa salen de dicha fase de latencia, crecen y se reproducen rápidamente a expensas del abundante alimento que encuentran en ese momento (González 
de Infante 1988). En el caso de los lagos someros de nuestra región dicha relación no es tan previsible ya que los nutrientes no constituyen un recurso limitante para el fitoplancton, mientras que sí se observan ocasionalmente problemas vinculados con la luz (Torremorel et al. 2007) y el movimiento de la columna de agua tan poco profunda.

La fertilización de las cavas aseguró una elevada abundancia fitoplanctónica, y aceleró los procesos en el verano, provocando que se diera un pico de AZ sólo a 10 días desde el llenado. Además en esta estación ocurrió un segundo pico alrededor de 30 días desde el llenado, y fue éste el momento elegido para la siembra de las larvas, teniendo en cuenta la comparación con la primavera. El vínculo de los procesos ecológicos de interacciones tróficas entre comunidades con las variables ambientales con ritmos marcadamente estacionales se evidencia de modo más claro aún cuando se observa lo ocurrido en otoño: en esa estación la temperatura fue descendiendo, el fotoperíodo cambió y no hubo ningún pico de AZ que alcanzara los 1000 ind./I (recomendado como la condición apropiada para una siembra exitosa de larvas de peces según Morris \& Mischke 1999). A pesar de esta situación, por una cuestión metodológica, se sembraron las larvas pasados los 30 días desde el llenado, con el objetivo de poder comparar los resultados de primavera y verano.

Las diferencias halladas en $A Z$ total entre ciclos ( $A Z$ representada principalmente por B. plicatilis) fueron acompañadas por diferencias en cuanto a la BZ, a pesar de los bajos valores registrados debido a la escasez de microcrustáceos. También fueron registradas diferencias en el crecimiento de las larvas (sin diferencias entre los ciclos 1 y 2, pero significativamente diferentes del 3). El menor crecimiento durante el ciclo 3 provocó que su duración fuera mayor a la del resto ya que resultaba necesario esperar a que las larvas crecieran a una longitud al menos similar al resto de los ciclos $(1,6 \mathrm{~cm}$ LT), no sólo por una cuestión comparativa sino porque dicha longitud resulta necesaria en el caso de que las postlarvas sean transferidas a jaulas flotantes (como ocurrió en este caso), debido a la abertura de malla inicial de las mismas. Estas diferencias en el crecimiento, junto con las diferencias notables observadas en la supervivencia de las post-larvas, pueden vincularse con la estacionalidad y su influencia sobre las comunidades planctónicas, lo cual pudo corroborarse también por el vínculo entre la supervivencia y la AZ registrada al momento de la siembra de las larvas.

Las postlarvas de pejerrey presentaron selectividad alimentaria desde el comienzo de la alimentación exógena, la cual fue dirigida al principio netamente sobre los rotíferos. La 
dieta de las postlarvas también mostró algunas diferencias entre ciclos. En la primavera y el verano, vinculado con la mayor oferta aliementaria, las postlarvas fueron monofágicas hasta los 10 días de vida, para pasar a una dieta más diversa recién a los 18 días, mientras que en el otoño esta ampliación del espectro trófico se dio antes, apenas a los 6 días de vida. Dichas diferencias se hacen nulas cuando se compara por tallas de pez. En los tres ciclos recién entre 1,5 y $2 \mathrm{~cm}$ de LT pasaron a consumir elementos mayores (categoría III), posiblemente por restricciones previas por el tamaño de la boca, como observó Zagarese (1991), y vinculado seguramente con la disponibilidad.

Las $A Z$ y $B Z$ registradas en la laguna durante la etapa experimental fueron diferentes entre estaciones, lo cual evidencia una diferencia importante en la calidad del zooplancton presente en cada ciclo. Dicha observación se puede vincular directamente con las diferencias registradas en el crecimiento de los pejerreyes, los cuales tuvieron su mejor rendimiento en la primavera, ciclo en el cual se registraron las mayores BZ. A su vez, fue en el ciclo de primavera donde se identificaron las especies que podrían considerarse más pesadas, lentas y nutritivas (Morris \& Mischke 1999), como determinantes de las diferencias en AZ y BZ entre ciclos (principalmente el cladócero C. dubia).

A mayores BZ (y mayor representatividad de especies grandes) se obtuvieron mejores tasas de crecimiento y producciones, situación que evidencia la posibilidad de calibrar un índice de calidad del zooplancton para cría de pejerrey. Al igual que en las cavas, en ambientes naturales marcadamente estacionales como las lagunas pampásicas, resulta crítico considerar el momento de inicio del cultivo, o la siembra de los peces, para aprovechar al máximo los recursos disponibles.

A su vez, en vista de los resultados es posible decir que la influencia de la temperatura sobre el crecimiento del pejerrey puede considerarse secundaria o indirecta, ya que como se dijo, es la disponibilidad de zooplancton (en cantidad y calidad) el principal factor de influencia sobre el crecimiento de la especie criada en jaulas. Este resultado coincide con los obtenidos en las regresiones múltiples realizadas en el capítulo IV, donde la temperatura no resultaba una variable significativa.

En cuanto a la alimentación de las larvas y juveniles, resulta interesante observarla en un continuo desde el comienzo de la alimentación exógena (Figura V.14). El aporte de las diferentes categorías de tamaño del zooplancton a la dieta de los pejerreyes fue cambiando a lo largo del tiempo, en función de la edad y la talla de los peces. Al analizar las diferencias 
halladas entre la oferta y el consumo se vio que aquellas especies o ítems zooplanctónicos que resultaron ser discriminantes lo hicieron por tener mayores valores de $A Z$ en el ambiente o en la dieta, lo cual se vinculó con la talla media de dichos ítems en el caso de la EE, pero no siguió un patrón claro en el caso de la EN (tablas V.4 y V.11). En el caso de la EE, las especies discriminantes pertenecientes a la categoría I, lo fueron por tener mayores AZ en el ambiente y aquellas pertenecientes a las clase II (en el ciclo de otoño: $M$. mendocinus y $B$. huaronensis) y III (en los ciclos de primavera y verano: copepoditos y adultos de $A$. robustus) por ser más abundantes en la dieta. Esta última observación refuerza el hecho de que durante el otoño las condiciones no resultaron propicias para la cría extensiva de pejerrey, en este caso para la obtención de postlarvas y juveniles, teniendo en cuenta la calidad del zooplancton ofrecido y consumido. Además, dichos resultados son coincidentes con los observados por otros autores acerca los cambios estacionales que pueden ocurrir en la dieta del pejerrey (Grosman 1995b, Colautti et al. 2003).

Lo mencionado también puede vincularse con la selectividad alimentaria del pejerrey, la cual al está presente desde el comienzo de la alimentación exógena, donde ante una determinada oferta el pez consume los ítems del mayor tamaño posible. A su vez, dicha selectividad alimentaria del pejerrey cultivado extensivamente (y por ende la amplitud trófica de la especie bajo cultivo) se vio además alterada de modo estacional: durante el ciclo 3, la amplitud trófica de las postlarvas aumentó al final de la EN y una vez que los peces fueron sembrados en las jaulas en la laguna dicha amplitud disminuyó, tornándose nuevamente (como así lo hicieran a mediados de la EN) hacia una mayor selectividad dirigida hacia el zooplancton de tamaño medio. Sin embargo en primavera y verano a partir de los 69 días de edad (entre 5 y $8 \mathrm{~cm}$ de LT) los pejerreyes se alimentaron mayoritariamente de zooplancton de clase III (tablas V.5, V.6, V.12 y V.13, figuras V.6, V.7, V.13 y V.14). Esta alteración de la amplitud trófica de la especie también se vio vinculada con la oferta en cada uno de los ciclos estudiados. Ante un descenso de la oferta alimentaria, que fue ocurriendo con el tiempo, el pejerrey diversificó su dieta de modo de compensar su falta ingeriendo ítems no zooplanctónicos (o de "reemplazo"), como el caso de los ostrácodos. Éstos últimos se volvieron fundamentales en el ciclo 3 donde la oferta zooplanctónica nunca fue elevada. 


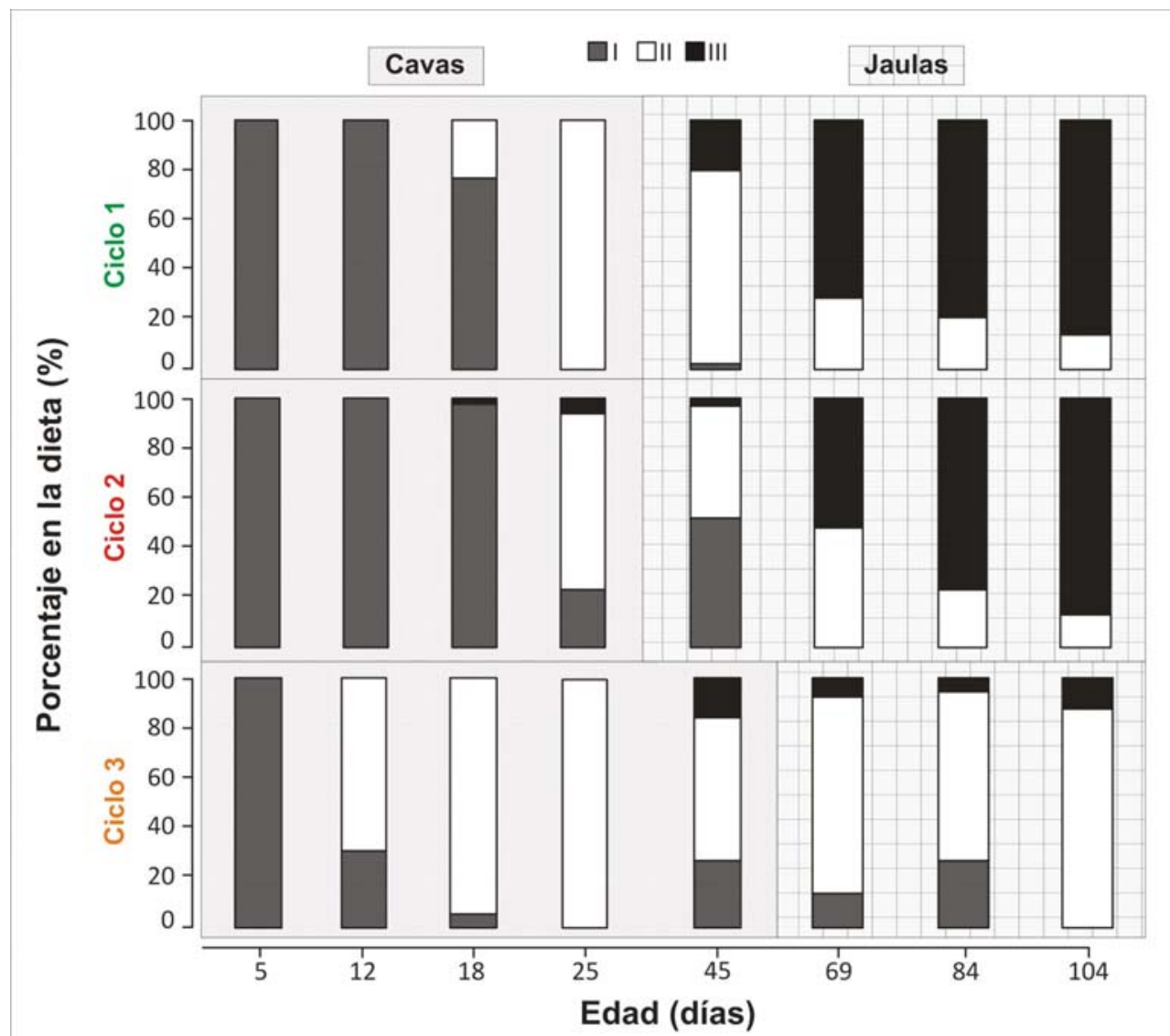

Figura V.14: Abundancia porcentual de las clases de tamaño del zooplancton en la dieta de larvas y juveniles de pejerrey criados en cavas y en jaulas, en función de la edad de los peces, en los 3 ciclos.

Los resultados obtenidos concuerdan con lo postulado acerca de la sensibilidad del estadío de postlarva, siendo que ante importantes cambios en cuanto a la disponibilidad de zooplancton en calidad y cantidad, las postlarvas de pejerrey presentaron significativos cambios en su crecimiento y supervivencia. Lo establecido por la teoría "match-mismatch" acerca del tamaño y cantidad de alimento ideal concuerda con lo observado en este experimento y con lo explorado por otros autores para otras especies: por sus características, los ítems zooplanctónicos más adecuados como primera alimentación de los peces son los rotíferos (Torrans 1986, Prieto Guevara \& Atencio-Garcia 2008), ya que presentan elevado valor nutricional (Watanabe et al. 1983) y son de fácil localización y captura por parte de los peces, debido a que su natación es lenta y no presentan importantes defensas contra sus predadores vertebrados (Stemberger \& Gilbert 1987). 


\section{VI}

INFLUENCIA DE LA DENSIDAD DE CRÍA Y LA

\section{CALIDAD DE ALIMENTO NATURAL}

(en el cultivo extensivo de pejerrey)

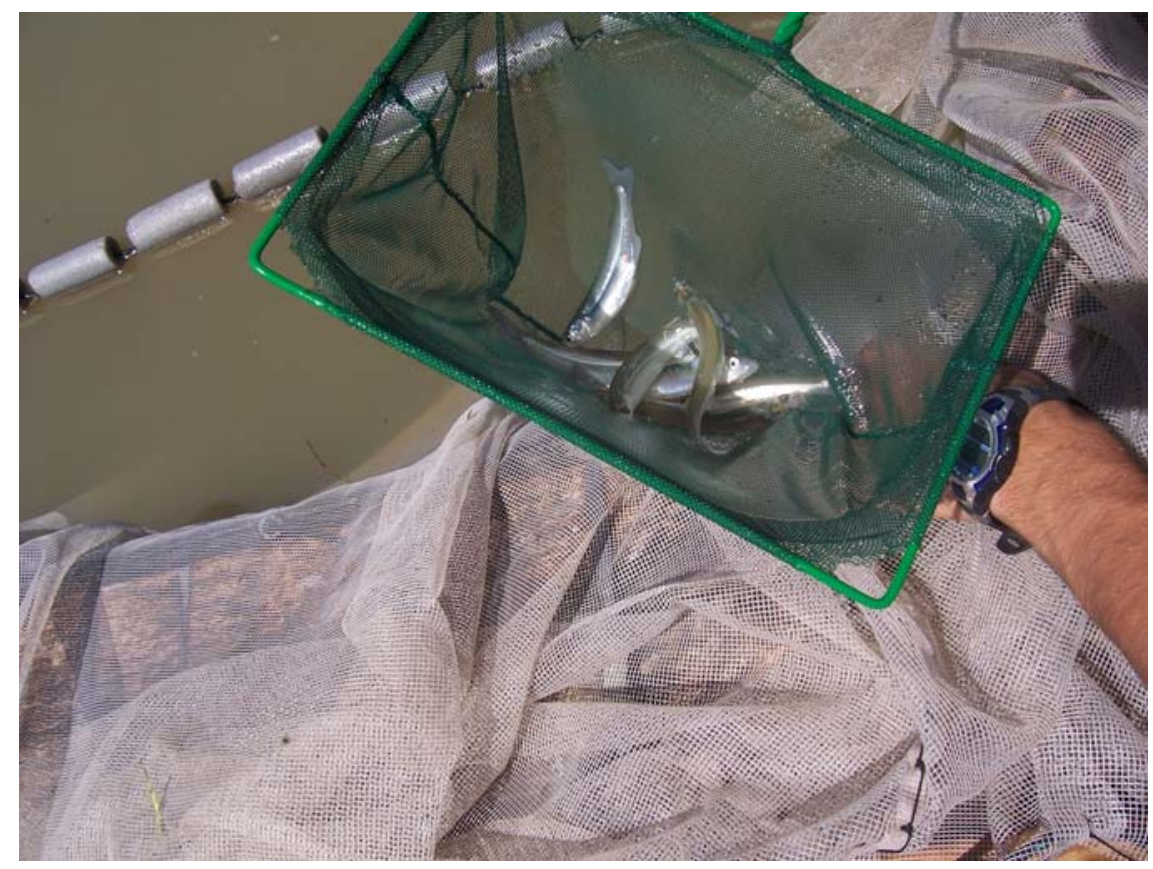




\section{Capítulo VI: INFLUENCIA DE LA DENSIDAD DE CRÍA Y LA CALIDAD DE ALIMENTO NATURAL en el cultivo extensivo de pejerrey}

\subsection{Introducción}

Como ya se ha desarrollado previamente, la depredación por parte de los peces juega un rol muy importante en el control de la estructura de tallas de la comunidad zooplanctónica (Stein et al. 1995). De acuerdo a la Hipótesis SEH el tamaño medio del zooplancton (TMZ) tiende a ser máximo cuando la densidad de sus depredadores vertebrados es baja, y por ende, si la densidad de los depredadores vertebrados aumenta, el TMZ disminuye. De acuerdo con esto, la densidad de cría emerge como un factor crítico a la hora de garantizar una disponibilidad de alimento óptima para los pejerreyes criados en jaulas bajo un régimen de tipo extensivo.

La densidad de cría es un factor significativo en la determinación de la producción en jaulas (Hengsawat et al. 1997), y tanto las altas como las bajas densidades tienen efectos sobre el cultivo. El contacto y la competencia entre individuos son más importantes a altas densidades, mientras que a bajas densidades el uso de los recursos es menos eficiente. Un aumento en esta densidad de "stock" resulta en un aumento del stress (Leatherland $\&$ Cho 1985), lo que implica mayores requerimientos energéticos. Diversos artículos han mostrado que el aumento en la densidad de cría produce el descenso de la tasa de crecimiento de los peces criados, mayor desvío estándar de los parámetros del crecimiento y mayor mortalidad (El-Sayed 2002, Coulibaly et al. 2007, Zeng et al. 2010, Yi et al. 1996). Por otra parte, se ha demostrado en varios casos que la densidad de cría óptima es específica para cada especie, por ejemplo para Colosoma macropomum (Gomes et al. 2006), Clarias gariepinus (Hengsawat et al. 1997, Islam et al. 2006, Barcellos et al. 2004), Dicentrarchus labrax (Papoutsogou et al. 1998), Lates calcarifer (Fermin et al. 1996), Oncorhynchus mykiss (North et al. 2006) y Oreochromis niloticus (Ouattara et al. 2003, Gibtan et al. 2008), entre otros.

Por su parte, un aspecto fundamental a tener en cuenta en el caso del pejerrey, es que no se encuentran desarrollados los criterios para definir las densidades de cultivo óptimas. Y dado este escenario, donde la producción del pejerrey podría depender de la densidad de 
cría y de la capacidad de carga del ambiente, resulta importante desarrollar estos criterios, y hacerlo teniendo en cuenta las condiciones ambientales, en particular lo vinculado con su alimento principal: el zooplancton. Por ello, el objetivo del presente capítulo es evaluar por primera vez el efecto de la densidad de cría y de la calidad del alimento natural disponible sobre la producción de juveniles de pejerrey cultivado extensivamente en jaulas, y de esta manera proveer de criterios al desarrollo y al manejo de este sistema de cultivo.

Este capítulo fue publicado parcialmente en: Garcia de Souza J.R., Solimano P.J., Maiztegui T., Baigún C.R.M. \& Colautti D. C. 2013. Effects of stocking density and natural food availability on the extensive cage culture of pejerrey (Odontesthes bonariensis) in a shallow Pampean lake in Argentina. Aquaculture Research, doi:10.1111/are.12286. 


\subsection{Diseño experimental}

\# EN: Dos jaulas "'nursery"" en la laguna La Salada de Monasterio, sembradas con larvas de 1 día de vida.

- Densidad de siembra: 833,3 individuos $/ \mathrm{m}^{3}$ (10000 ind./jaula)

- Fecha de siembra: 03/12/2009

\# EE: Jaulas (mosquitero) en la laguna La Salada de Monasterio (Figura VI.1), sembradas con pejerreyes de 33 días de vida, bajo tres tratamientos de diferente densidad de cría (individuos $/ \mathrm{m}^{3}$ ):

- T1 (25), T2 (50) y T3 (75) (Figura VI.2).

- Fecha de siembra: 04/01/2010

- Duración del experimento: 80 días (113 días de edad).

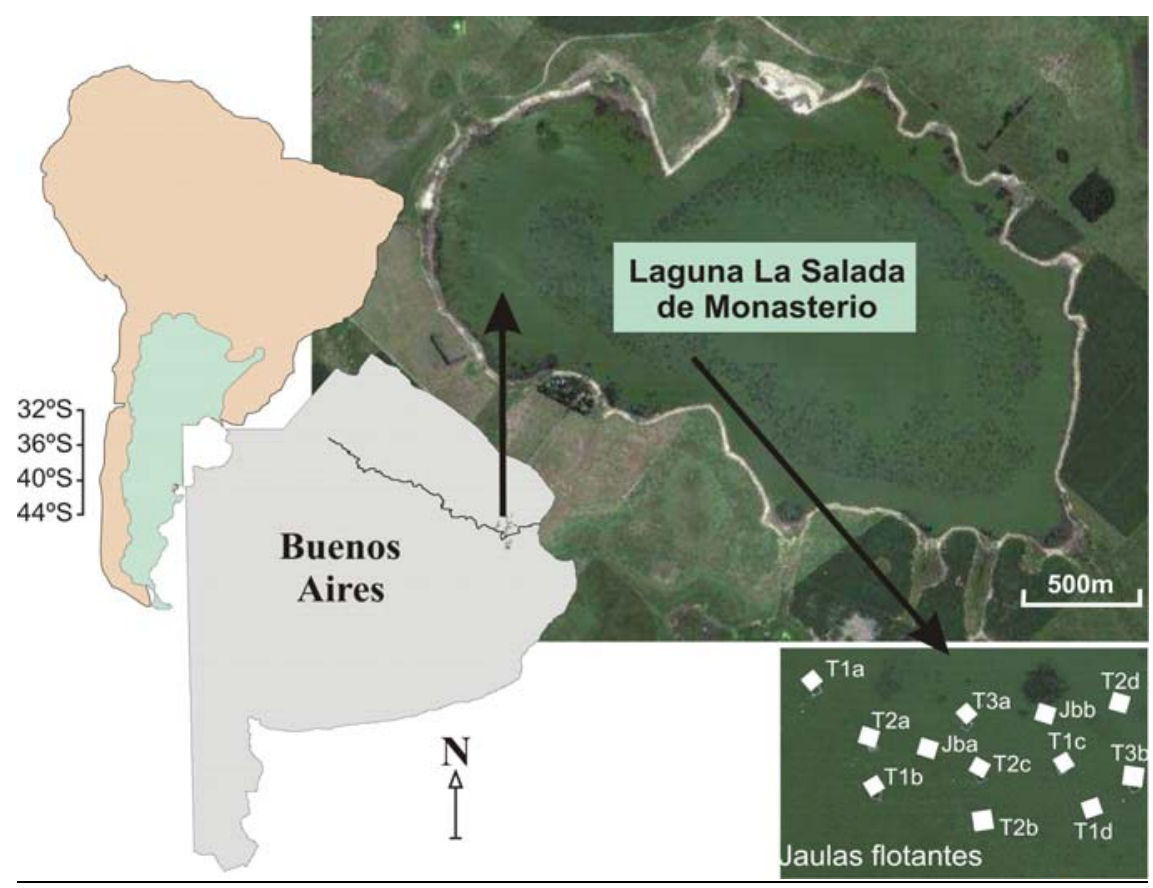

Figura VI.1: Ubicación de las jaulas en La Salada de Monasterio.

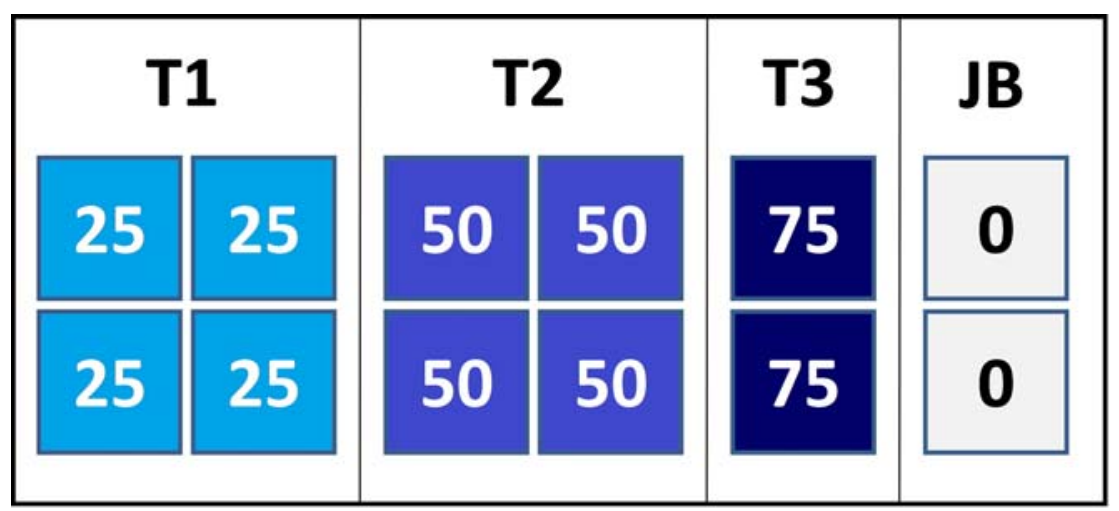

Figura VI.2: Diseño experimental, tres tratamientos de jaulas con peces (JP) a diferentes densidades de "stock" $\left(\mathrm{T} 1, \mathrm{~T} 2\right.$ y $\mathrm{T} 3$ en individuos $/ \mathrm{m}^{3}$ ) y un tratamiento sin peces (JB). 


\subsection{Metodología particular}

La medición de parámetros físico químicos, la toma de muestras y las comparaciones en $A Z$ y $B Z$ entre tratamientos, tanto para $E N$ como $E E$, se hicieron del modo descrito en la metodología general de la tesis.

Las jaulas utilizadas durante EN fueron instaladas previamente a la siembra de las larvas con la intención de aprovechar el desarrollo del zooplancton en ausencia de depredadores y favorecer la primera alimentación de las larvas. En relación con esto se compararon las AZ dentro y fuera de las jaulas (ANOSIM) y se realizó un cálculo de un coeficiente de correlación entre el tiempo de instalación de las jaulas y el valor de $\mathrm{R}$ del ANOSIM (como expresión del grado de similitud o diferencia entre AZL y AZJ) con el fin de evaluar la permeabilidad de las jaulas.

Particularmente para este experimento el crecimiento de los pejerreyes durante la EE se analizó estadísticamente mediante un ANOVA anidado de dos factores (Sokal \& Rohlf 1995, Ruohonen 1998, Quinn \& Keough 2002), siendo el tratamiento de densidad el factor principal, las jaulas el factor anidado (anidadas en cada tratamiento) y los individuos muestreados en cada jaula los residuales. Seguido del análisis se llevó a cabo un SNK (test post hoc) (Underwood 1997) para evaluar el detalle de las diferencias.

Las tasas de crecimiento específicas (TCE), se compararon entre tratamientos mediante ANOVA de medidas repetidas (RM ANOVA), seguido de test de Bonferroni. Además se llevó a cabo una regresión múltiple (Sokal \& Rohlf 1995) para evaluar las relaciones entre las TCE y las diferentes densidades de siembra y las BZ encontradas en la laguna y en las jaulas (BZL y BZJ) para cada categoría de tamaño de zooplancton (I, II y III) por separadas y combinadas. Las BZ utilizadas para dicho análisis fueron las normalizadas, calculadas como fue descrito en el capítulo III, a partir de los intervalos de tiempo correspondientes con sus respectivas TCE ((BZLN I, BZLN II, BZLN III, BZLN II+III, BZJN I, BZJN II, BZJN III y BZJN II+III)). Además las TCE fueron analizadas junto con los porcentajes de las diferentes categorías de tamaño encontradas en los contenidos digestivos (CD) por separado y combinadas (CD I, CD II, CD III y CD II+III), por medio de modelos lineales y no lineales. 


\section{$6.4 \quad$ Resultados}

\subsubsection{Etapa "nursery"}

\section{Parámetros físico químicos}

Los resultados de las variables físico químicas medidas se expresan en la figura VI.3 (Promedio, máximos y mínimos de temperatura diaria) y en la tabla VI.1 (Profundidad, transparencia, conductividad y $\mathrm{pH}$ ).

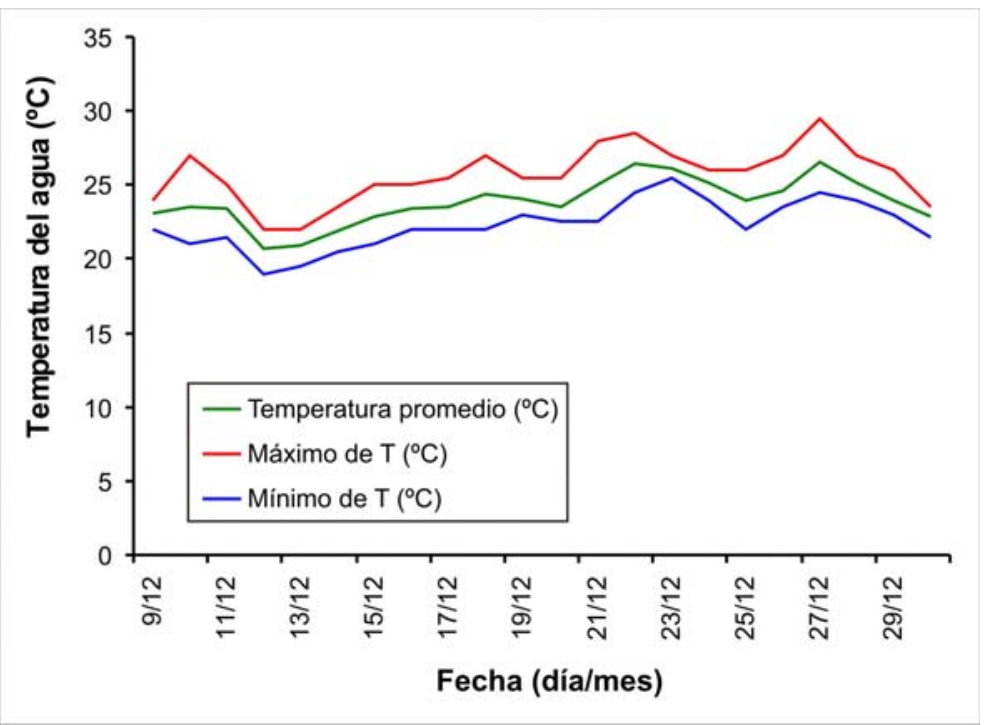

Figura VI.3: Temperaturas registradas durante la etapa "nursery" (valores diarios medios, máximos y mínimos).

Tabla VI.1: Parámetros limnológicos medidos durante la etapa "nursery"

\begin{tabular}{rcccc}
$\begin{array}{c}\text { Fecha de } \\
\text { muestreo }\end{array}$ & Profundidad (m) & $\begin{array}{c}\text { Transparencia (m } \\
\text { de Sechi) }\end{array}$ & $\begin{array}{c}\text { Conductividad } \\
\text { (mS/cm) }\end{array}$ & pH \\
\hline $3 / 12 / 2009$ & 1,10 & 0,45 & 1,86 & 9,42 \\
$9 / 12 / 2009$ & 1,10 & 0,20 & 1,76 & 9,17 \\
$16 / 12 / 2009$ & 1,15 & 0,35 & 1,91 & 8,29 \\
$23 / 12 / 2009$ & 1,10 & 0,35 & 1,87 & 9,07 \\
$30 / 12 / 2009$ & 1,15 & 0,35 & 1,86 & 8,91 \\
\hline
\end{tabular}




\section{Comunidad zooplanctónica}

La comunidad zooplanctónica dentro y fuera de las jaulas estuvo dominada en AZ por ítems de pequeño tamaño (I) durante toda esta etapa (Figura VI.4). La BZ estuvo dominada por zooplancton de tamaño medio al principio (Más BZII en las jaulas que en la laguna) y por zooplancton de tamaño mayor en la última fecha (Más BZIII en la laguna que en las jaulas) (Figura VI.5). En términos de AZ y BZ por especies, la laguna no fue diferente de las jaulas en las dos primeras fechas de muestreo desde la instalación de las mismas (9 y 16/12/2009, 7 y 14 días de vida de las larvas respectivamente), pero sí se observaron diferencias en la tercer y cuarta fecha (23 y 30/12/2009, 21 y 28 días de vida) (ANOSIM, p<0,05). El coeficiente de correlación entre el tiempo desde la instalación de las jaulas y el valor de $\mathrm{R}$ del ANOSIM arrojó un valor de 0,93 indicando que a medida que pasó el tiempo se acrecentaron las diferencias entre el zooplancton de dentro y fuera de las jaulas.

Las especies discriminantes (SIMPER) de dichas diferencias en términos de AZ fueron los juveniles y adultos de M. mendocinus y A. robustus, que fueron en la tercer y cuarta fecha más abundantes en la laguna y el rotífero Polyarthra vulgaris que fue más abundante en las jaulas en el muestreo del 23/12/2009. En términos de BZ, las especies discriminantes fueron los mismos copépodos y M. micrura, con mayor BZ en la laguna.

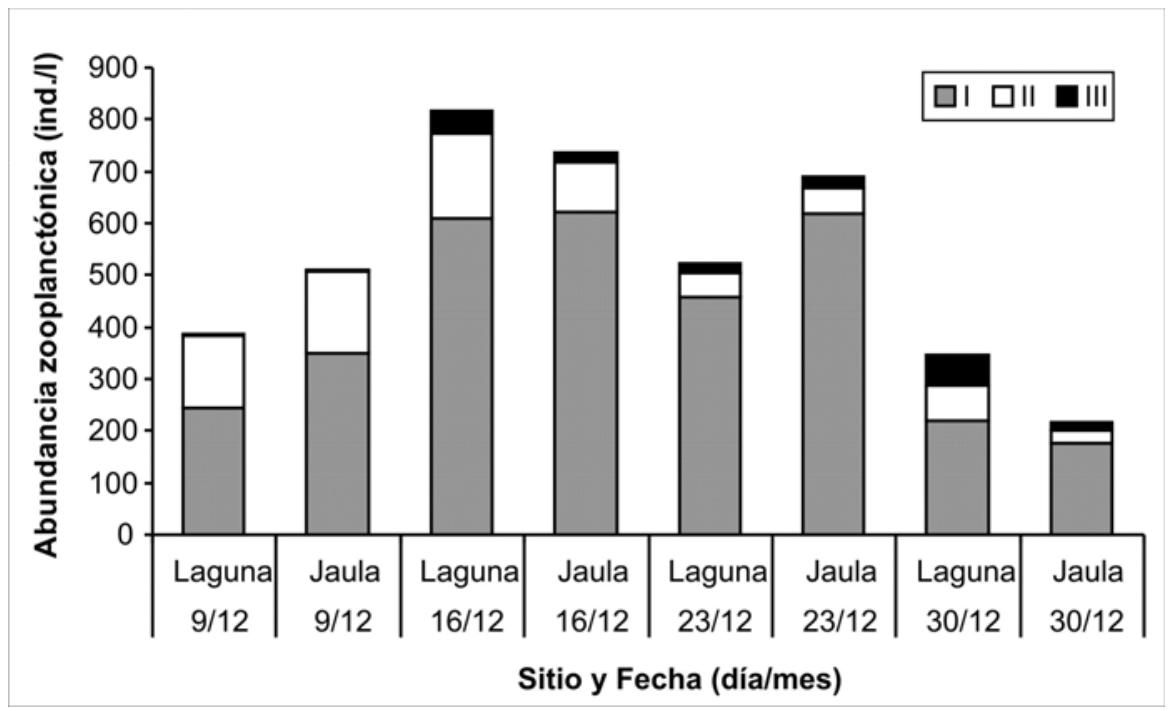

Figura VI.4: Abundancia zooplanctónica por fecha (promedio de jaulas y laguna), y por categorías de tamaño. 


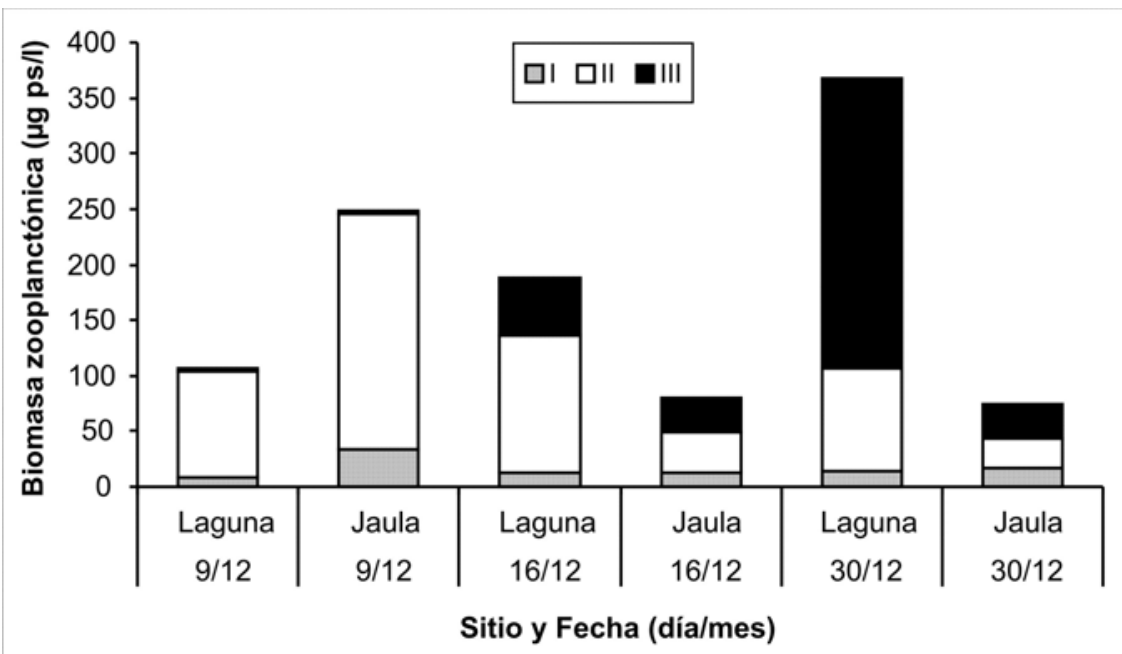

Figura VI.5: Biomasa zooplanctónica por fecha (promedio de jaulas y de la laguna), y por categorías de tamaño.

\section{$\underline{\text { Crecimiento del pejerrey cultivado }}$}

El crecimiento en longitud y peso durante esta etapa de cría de postlarvas en jaulas "nursery" se observa en la figura VI.6.

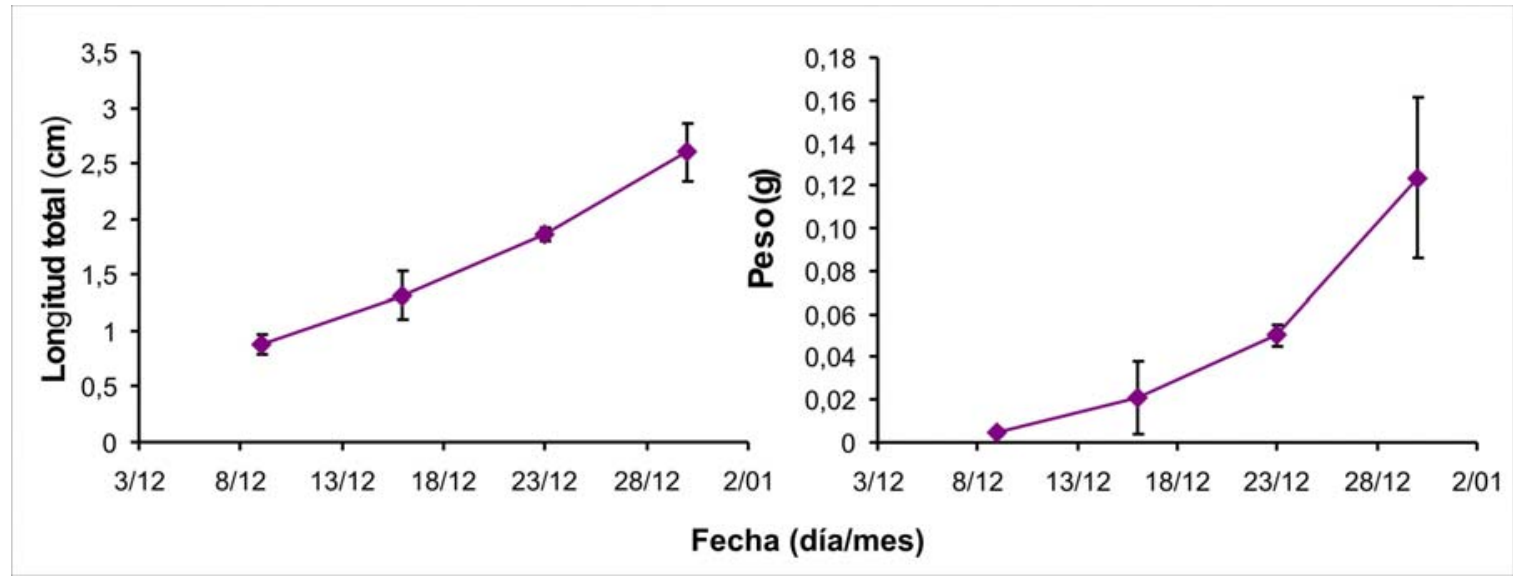

Figura VI.6: Crecimiento en longitud y peso (LT en cm y W en g) de postlarvas criadas en las jaulas "nursery".

\section{Alimentación del pejerrey cultivado}

La dieta de las postlarvas de pejerrey criadas en la EN fue evaluada sólo analizando los CD de 5 ejemplares al final de la etapa.

Así se observó que pejerreyes de talla promedio de $3 \mathrm{~cm}$ de LT y 28 días de edad consumieron un $70 \%$ de zooplancton de talla III (Figura VI.7). 


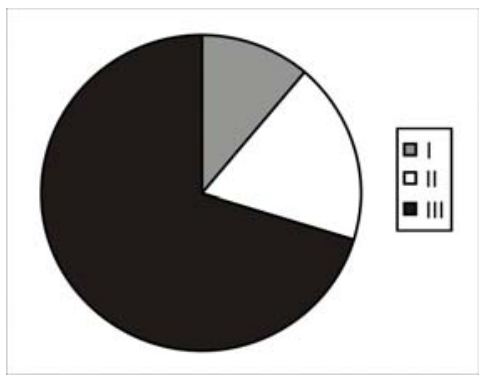

Figura VI.7: Contribución porcentual promedio de las tres categorías de tamaño del zooplancton en los CD de pejerreyes obtenidos de la etapa "nursery"

\subsubsection{Etapa Experimental}

\section{Parámetros físico químicos}

La temperatura media registrada a lo largo del experimento fue de $23,9{ }^{\circ} \mathrm{C}$ (desvío estándar de $3,1^{\circ} \mathrm{C}$ ) (Figura VI.8). El promedio y el desvío del rango de temperatura diario fue $3,81 \pm 2,37^{\circ} \mathrm{C}$, con valores máximos y mínimos de 12,5 y $0,5^{\circ} \mathrm{C}$, respectivamente. Los valores de otras variables físico-químicas registradas se expresan en la tabla VI.2.

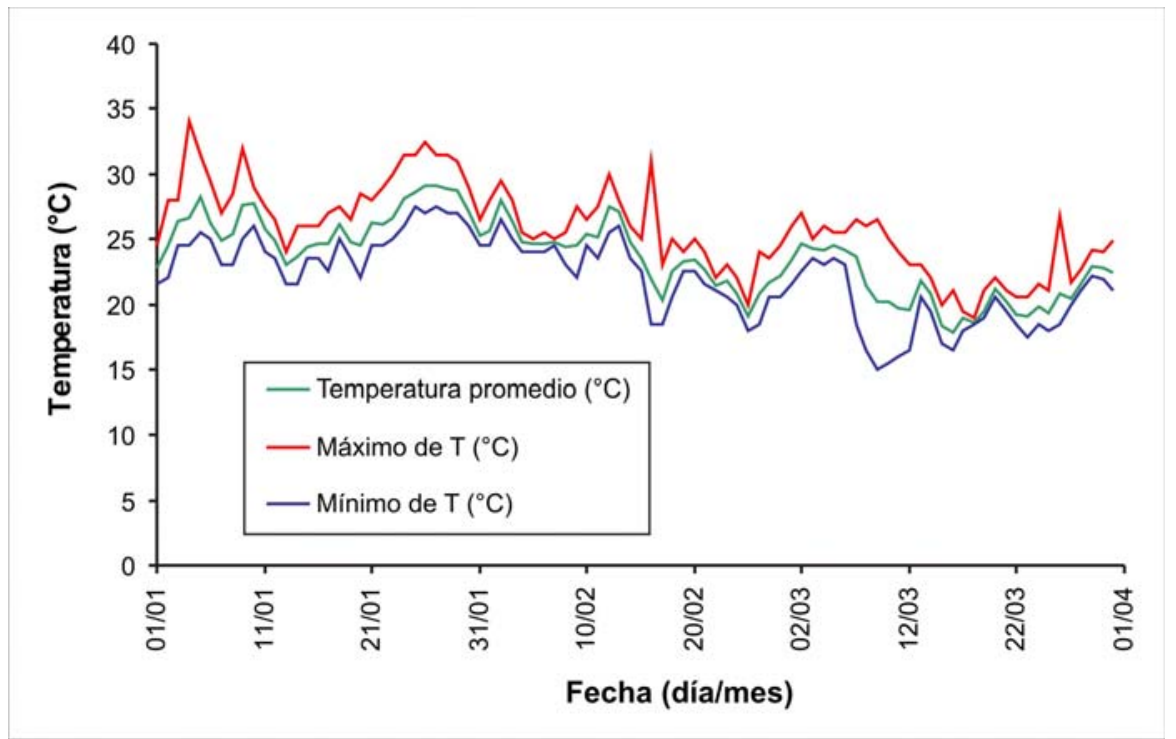

Figura VI.8: Temperaturas registradas durante la etapa experimental (valores medios, máximos y mínimos). 
Tabla VI.2: Parámetros limnológicos medidos durante la etapa experimental

\begin{tabular}{rcccc}
$\begin{array}{c}\text { Fecha de } \\
\text { muestreo }\end{array}$ & $\begin{array}{c}\text { Profundidad } \\
(\mathbf{m})\end{array}$ & $\begin{array}{c}\text { Transparencia } \\
\text { (m de Sechi) }\end{array}$ & $\begin{array}{c}\text { Conductividad } \\
(\mathbf{m S} / \mathbf{c m})\end{array}$ & $\mathbf{p H}$ \\
\hline $4 / 01 / 2010$ & 1,10 & 0,28 & 1,89 & 9,05 \\
$13 / 01 / 2010$ & 1,05 & 0,20 & 1,92 & 9,78 \\
$21 / 01 / 2010$ & 1,03 & 0,22 & 2,00 & 9,80 \\
$28 / 01 / 2010$ & 1,00 & 0,20 & 1,98 & 9,30 \\
$15 / 02 / 2010$ & 1,00 & 0,25 & 2,00 & 9,30 \\
$9 / 03 / 2010$ & 1,05 & 0,24 & 2,71 & 9,56 \\
$25 / 03 / 2010$ & 1,05 & 0,16 & 2,76 & 9,65 \\
\hline
\end{tabular}

\section{Comunidad zooplanctónica}

La comunidad zooplanctónica de la laguna y de las jaulas estuvo dominada por los rotíferos, en términos de $A Z$, durante todo el experimento (Laguna: 1278, T1: 751, T2: 1055 y T3: 1025 individuos/litro en promedio), con su valor máximo registrado en marzo (5237 ind./litro) (Figura VI.9). La abundancia de microcrustáceos (Copepoda y Cladocera) nunca superó los 230 ind./litro durante el experimento.

Existieron diferencias en AZ por especies entre tratamientos en todas las fechas de muestreo, excepto en la primera de ellas (ANOSIM, p<0,05). B. havanaensis (Clase I) y $A$. robustus (Clase III) fueron las especies identificadas como discriminantes (SIMPER) de acuerdo a su $A Z$.

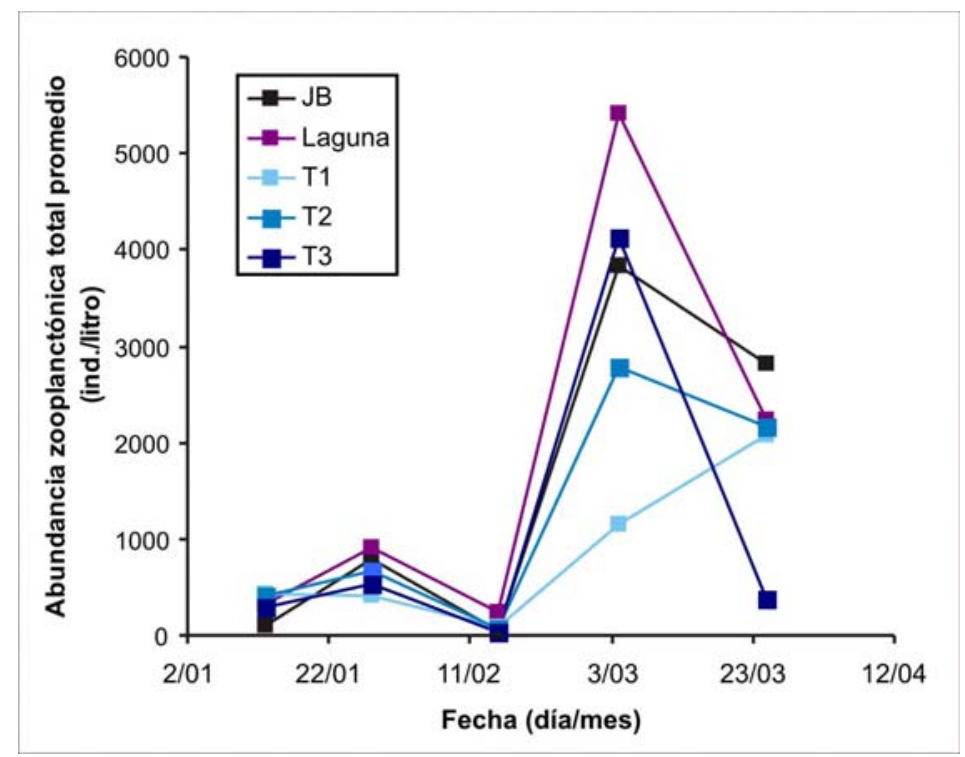

Figura VI.9: Abundancia zooplanctónica registrada en la laguna y en los diferentes tratamientos durante el experimento 
La BZ total siguió un patrón de variación similar en la laguna y en las JP durante todo el experimento (Figura VI.10). Se observaron dos picos de biomasa, uno en enero (222 $\mu \mathrm{g}$ ps/l en promedio, principalmente debido a los copépodos, en la laguna y en T1) y otro en marzo (258 $\mathrm{\mu g}$ ps/l en promedio, principalmente por los rotíferos en la laguna y en T3).

Al evaluar en conjunto la laguna, las JP y las JB se observaron diferencias en términos de BZ entre tratamientos para cada edad de pez (ANOSIM, $p<0,05$ ), registrándose las mayores diferencias entre las JB y las JP, con valores entre 48,9 y $51,8 \%$ de disimilitud (BZ total inicial y final expresadas en la figura VI.11 y resultados SIMPER resumidos en las tablas VI.3 y VI.4).

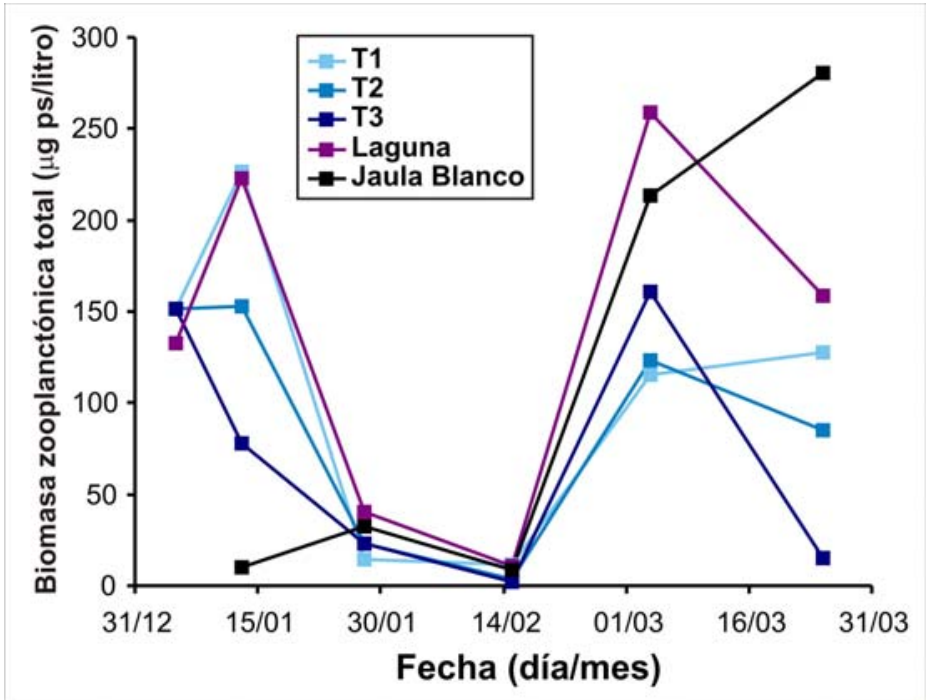

Figura VI.10: Biomasa zooplanctónica promedio (peso seco $\mu \mathrm{g} / \mathrm{l}$ ) de muestras tomadas dentro y fuera de las jaulas (de todos los tratamientos, T1, T2, T3 y Jaulas Blanco), a lo largo del período de estudio.

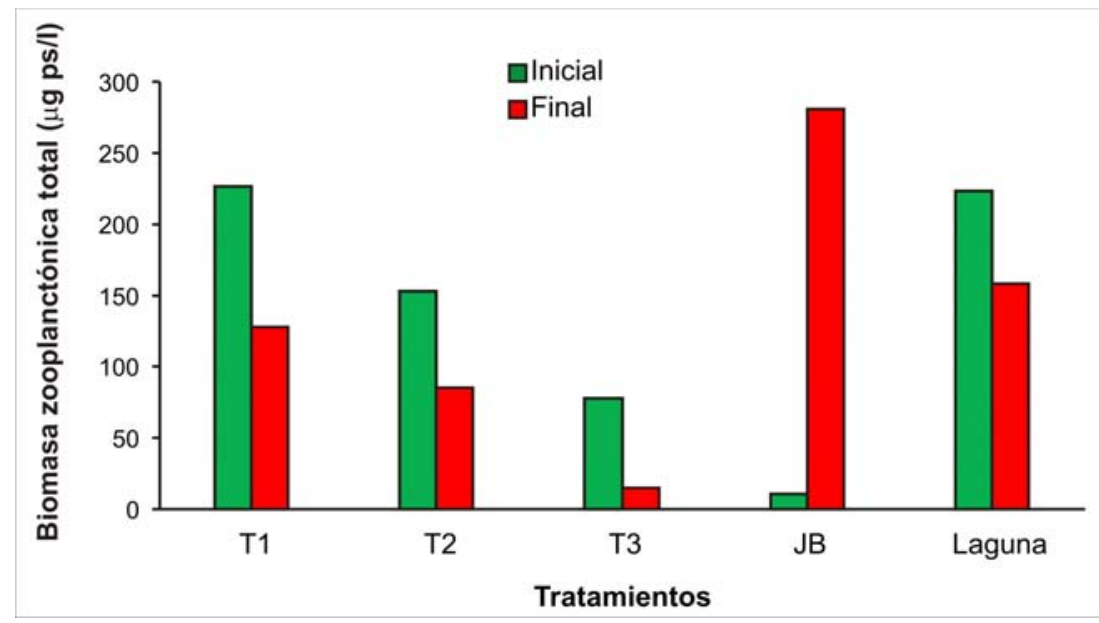

Figura VI.11: Biomasa zooplanctónica promedio $(\mu \mathrm{g} \mathrm{ps} / \mathrm{l})$ inicial y final por tratamiento. 
Tabla VI.3: Porcentajes de disimilitud (SIMPER) en cuanto a la biomasa zooplanctónica, entre tratamientos.

\begin{tabular}{cccccc}
\hline & Laguna & T1 & T2 & T3 & JB \\
\hline Laguna & 0 & & & & \\
T1 & 47,3 & 0 & & & \\
T2 & 46,3 & 46,1 & 0 & & \\
T3 & 47,0 & 46,6 & 39,3 & 0 & \\
JB & 45,8 & 51,7 & 48,9 & 51,8 & 0 \\
\hline
\end{tabular}

Tabla VI.4: Especies discriminantes en términos de biomasa zooplanctónica (SIMPER) (Aportan más del 10\% a la disimilitud entre tratamientos) identificadas en las comparaciones entre JB y todas las JP (T1, T2 y T3)

\begin{tabular}{|l|l|}
\hline & \multicolumn{1}{c|}{ JB } \\
\hline \multirow{2}{*}{ T1 } & Metacyclops mendocinus (copepoditos) \\
\hline & Acanthocyclops robustus \\
\hline & Bosmina huaronensis \\
\hline \multirow{3}{*}{ M2 } & Moina micrura \\
\hline & Moina micrura \\
\hline \multirow{5}{*}{ T3 } & Acanthocyclops robustus \\
\hline & Larvas Nauplii de copépodos \\
\hline & Metacyclops mendocinus (copepoditos) \\
\hline & Moina micrura \\
\hline & Bosmina huaronensis \\
\hline & Larvas Nauplii de copépodos \\
\hline
\end{tabular}

En cuanto a la contribución porcentual a la BZ por categoría de tamaño, al inicio del experimento se observó un predominio de individuos de tallas grandes (III) en la laguna y las JP y de clase I en las JB. Después de la segunda semana de experimentación los ítems pequeños en la laguna y en las JP y los individuos medianos y grandes (II y III) en las JB (Figura VI.12) fueron dominantes. 

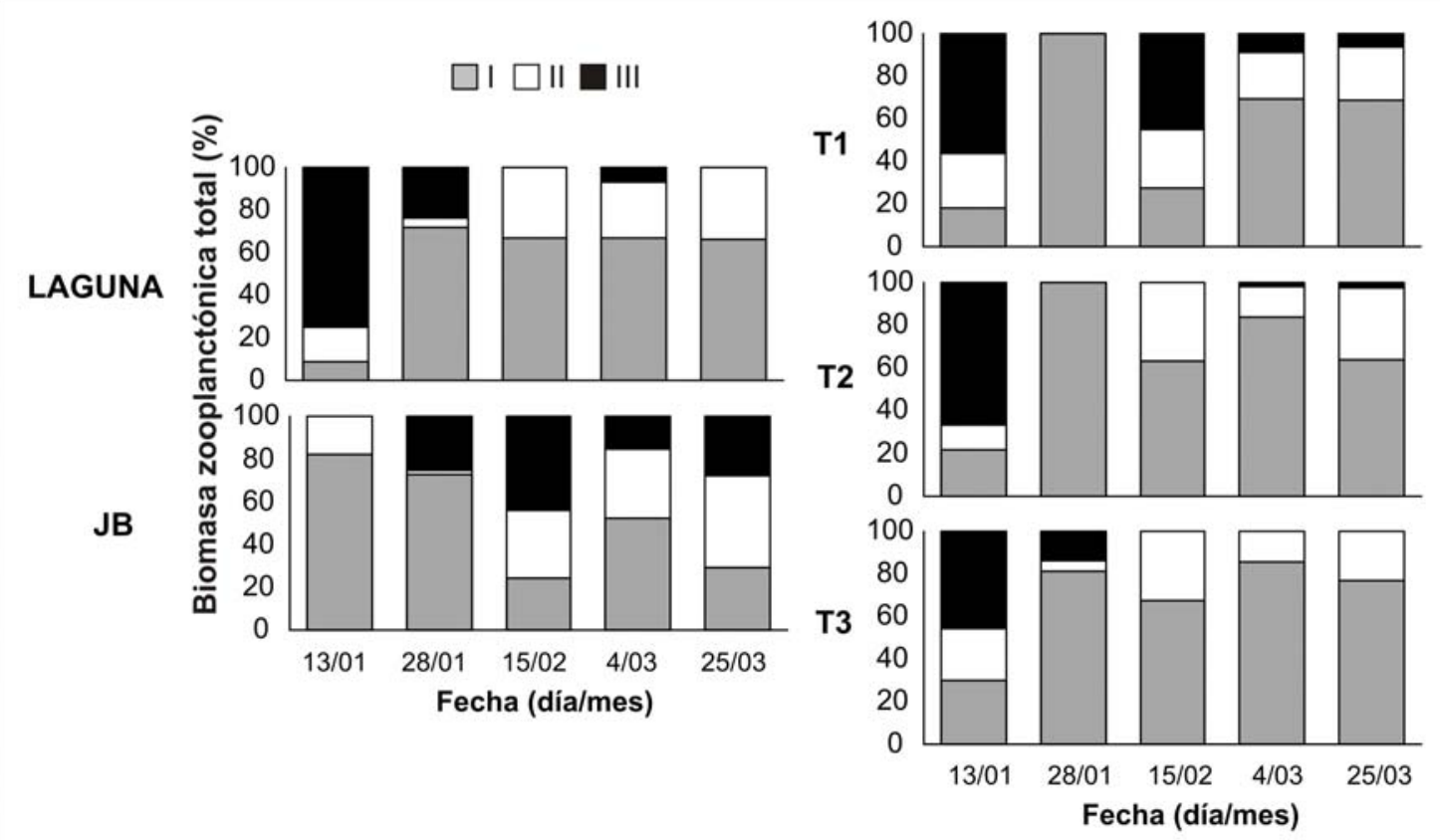

Figura VI.12: Contribución porcentual por categorías de tamaño del zooplancton a la BZ (laguna, JP y JB) en cada fecha de muestreo.

\section{Alimentación del pejerrey cultivado en jaulas}

Se analizaron un total de 76 contenidos digestivos pertenecientes a pejerreyes de 50 , 76 y 113 días de vida, criados bajo los tres tratamientos de densidad. Los ítems consumidos pertenecieron a la comunidad zooplanctónica y su composición específica fue diferente al zooplancton registrado dentro de las jaulas (ANOSIM, R $=0,865 ; p<0,01$ ), sugiriendo una fuerte selección de presas por parte del pejerrey (Figura VI.13). La composición de la dieta, a nivel específico, fue diferente entre tratamientos, sólo en la última fecha de muestreo, cuando los peces criados tenían 113 días de vida (ANOSIM, $\mathrm{p}<0,01$ ) (Figura VI.13). 


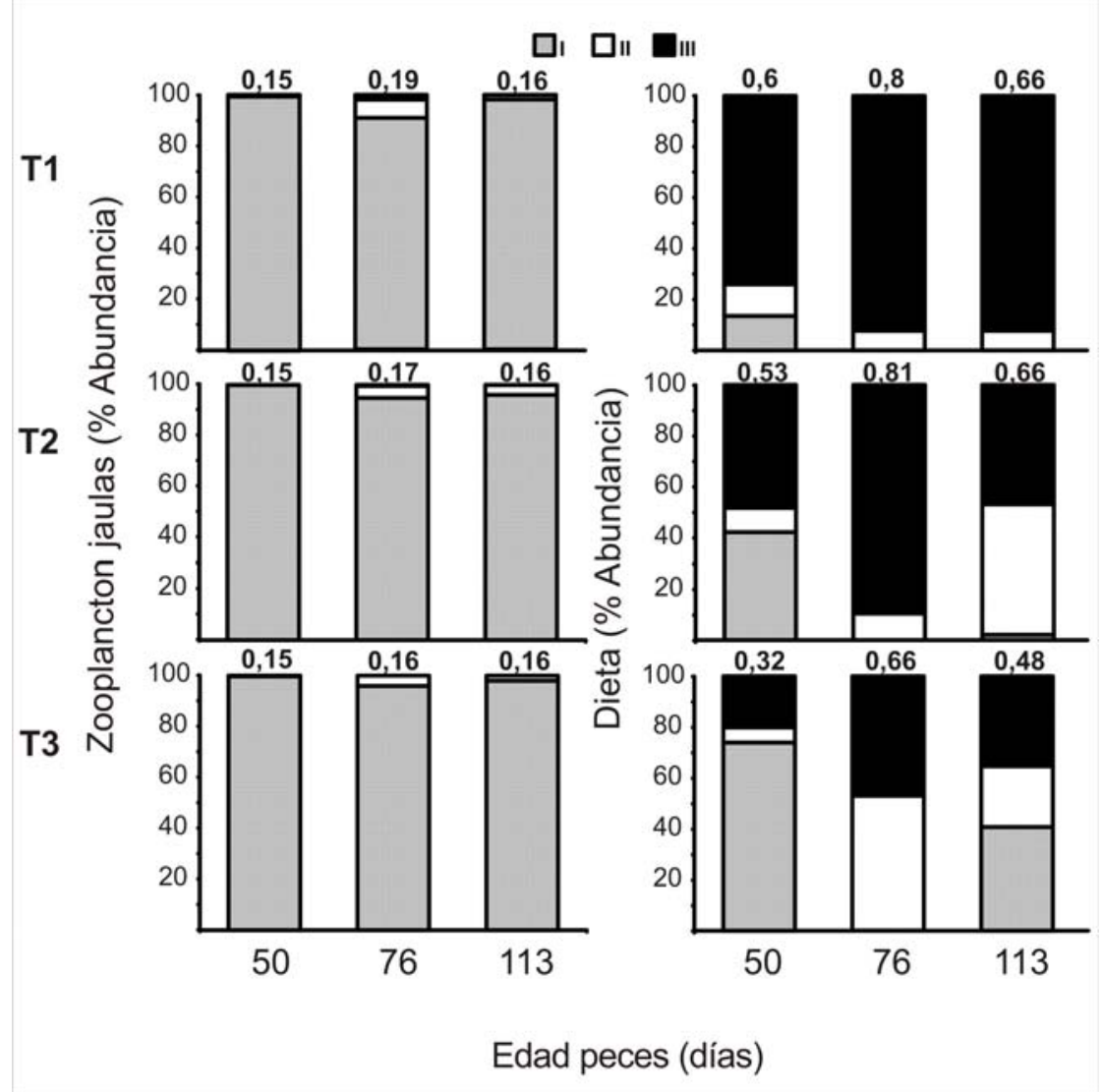

Figura VI.13: AZ porcentual (\%) por categorías de tamaño (I, II y III) registrada en las muestras tomadas dentro de las jaulas con peces y composición porcentual de la dieta (\%) de los pejerreyes criados, registrada en tres momentos (edad pez: 50, 76 y 113 días). El tamaño medio del zooplancton (TMZ, en mm) y el tamaño medio de las presas (TMP, en $\mathrm{mm}$ ) están indicados en negrita arriba de cada columna correspondiente.

El análisis SIMPER mostró una disimilitud del 87,4\% en promedio, entre lo encontrado en el ambiente y lo que fue consumido por los peces, siendo $B$. havanaensis y $A$. robustus las especies que más contribuyeron a dicha diferencia (Tabla VI.5).

Tabla VI.5: Resultado de los análisis multivariados con los que se comparó la abundancia zooplanctónica de las jaulas (AZJ) y los contenidos digestivos (CD) de los pejerreyes cultivados bajo los diferentes tratamientos.

\begin{tabular}{cccc}
\hline & T1 & T2 & T3 \\
\hline $\begin{array}{c}\text { ANOSIM (p<0.01) } \\
\text { (Valor de R) }\end{array}$ & 0,878 & 0,967 & 0,775 \\
SIMPER & & & 85,86 \\
(porcentaje de disimilitud) & 86,58 & 90,37 & \\
$\begin{array}{c}\text { SIMPER } \\
\text { (especies discriminantes) }\end{array}$ & $\begin{array}{c}\text { Brachiouns havanaensis } \\
\text { Acanthocyclops robustus }\end{array}$ & $\begin{array}{c}\text { Brachiouns havanaensis } \\
\text { Acanthocyclops robustus }\end{array}$ & $\begin{array}{c}\text { Brachiouns havanaensis } \\
\text { Bosmina huaronensis }\end{array}$ \\
\hline
\end{tabular}

La diferencia también se vio reflejada en el tamaño medio de presa (TMP), el cual fue similar en T1 y T2 pero diferente (menor) en T3. Pudo verificarse una relación negativa entre 
el TMP y la densidad de los depredadores, independientemente de la edad de los peces, aunque, a la mayor densidad (T3) los ítems del zooplancton más pequeños y medianos (clases I y II) fueron elegidos por pejerreyes de todas las edades (Figura VI.13).

Al analizar los resultados de los índices de amplitud trófica y selectividad alimentaria (Tabla VI.6), se observó que en la dieta de los pejerreyes criados en las jaulas, la mayor amplitud trófica (Índice Levins H') se dio en los peces de mayor edad y en aquellos a mayores densidades (T3). A su vez, el índice de forrajeo óptimo (FR) indicó que los rotíferos y las larvas nauplii de copépodos (zooplancton de categoría I) no fueron parte de la dieta o incluso fueron seleccionados negativamente, mientras que el zooplancton de tallas II y III fueron siempre positivamente seleccionados.

Tabla VI.6: Índice de Levins (H') y de forrajeo óptimo (FR) calculados para cada edad de pez (fecha de muestreo) y talla, en cada tratamiento de densidad

\begin{tabular}{|c|c|c|c|c|c|c|}
\hline \multirow{2}{*}{ Tratamiento } & \multirow{2}{*}{ Edad (días) } & \multirow{2}{*}{$\begin{array}{l}\text { Rango de } \\
\text { talla (cm) }\end{array}$} & \multirow{2}{*}{$\begin{array}{l}\text { Î́ndice de } \\
\text { Levins }\left(\mathrm{H}^{\prime}\right)\end{array}$} & \multicolumn{3}{|c|}{ Índice de forrajeo óptimo (FR) } \\
\hline & & & & I & II & III \\
\hline \multirow{5}{*}{ T1 } & 50 & 5 & 1,52 & 0,29 & 2,12 & 15,89 \\
\hline & 50 & 6 & 1,18 & 0,01 & 1,46 & 23,30 \\
\hline & 76 & 7 & 1,24 & 0,0 & 1,49 & 46,62 \\
\hline & 113 & 8 & 2,13 & 0,17 & 35,16 & 244,82 \\
\hline & 113 & 9 & 1,55 & 0,15 & 16,33 & 464,31 \\
\hline \multirow{3}{*}{ T2 } & 50 & 5 & 1,39 & 0,15 & 3,03 & 20,43 \\
\hline & 76 & 7 & 1,37 & 0,00 & 2,47 & 97,77 \\
\hline & 113 & 8 & 2,01 & 0,05 & 16,91 & 670,50 \\
\hline \multirow{5}{*}{ T3 } & 50 & 4 & 1,30 & 0,72 & 2,34 & 14,67 \\
\hline & 50 & 5 & 1,93 & 0,12 & 7,25 & 40,17 \\
\hline & 76 & 6 & 1,45 & 0,00 & 14,48 & Sin valor \\
\hline & 113 & 7 & 2,20 & 0,36 & 104,82 & 33,31 \\
\hline & 113 & 8 & 1,44 & 0,10 & 19,65 & 105,21 \\
\hline
\end{tabular}

El hecho de que se haya identificado a $A$. robustus como especie discriminante de las diferencias entre lo "ofrecido" por el ambiente y lo consumido por los peces, y a su vez de las diferencias entre tratamientos de densidad (en AZ y BZ), motivó un examen más detallado de la especie. Al analizar sus distribuciones de tallas para las JB y las JP (Figura VI.14) se observó, mediante un test de Kolmogorov-Smirnov, la existencia de diferencias al comparar JB con T1 y T3 $(p<0,05)$, y ausencia de diferencias al comparar JB con T2. Sin embargo, al realizar la comparación separando machos y hembras de la especie se detectaron diferencias $(p<0,05)$ en el caso de los machos (tallas medias (en micras): JB =909,3; T2 $=850,2$ ), y no en las hembras (tallas medias (en micras): JB =1098,6; T2 =1122,1). 


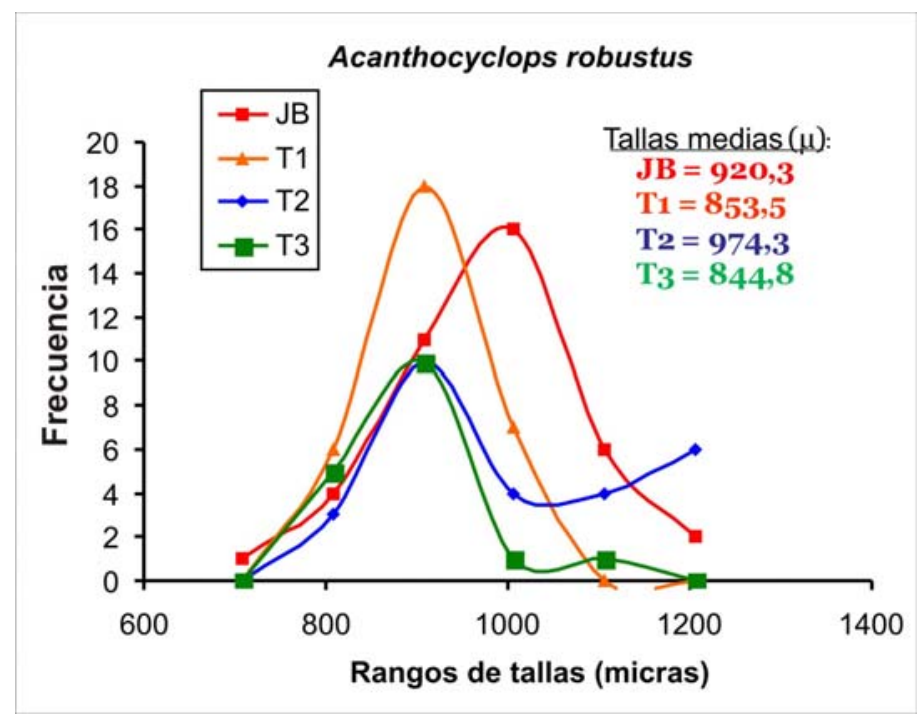

Figura VI.14: Distribuciones de tallas y tallas medias (expresadas en micras) de Acanthocyclops robustus en las JB y en los tres tratamientos de JP (T1, T2 y T3).

Al comparar la contribución porcentual de machos y hembras de A. robustus tanto en la "oferta" (AZJ) como en la dieta de los pejerreyes criados (Figura VI.15), se pudo observar que en los contenidos digestivos dominaron siempre los machos, y que dicha dominancia fue disminuyendo con el paso del tiempo, mientras que el consumo de las hembras fue en aumento. Dicha comparación entre la oferta y el consumo también se evaluó mediante el cálculo del índice de selectividad de Strauss (L), utilizando las proporciones de consumo y oferta, sólo teniendo en cuenta a los machos y hembras de A. robustus (Figura VI.15). Dicho índice tiene la ventaja de ser aplicable en los casos donde no se registra el ítem en la oferta (lo que no ocurre con el índice de forrajeo óptimo, FR, que no puede ser calculado con valores de "0" en la oferta). 


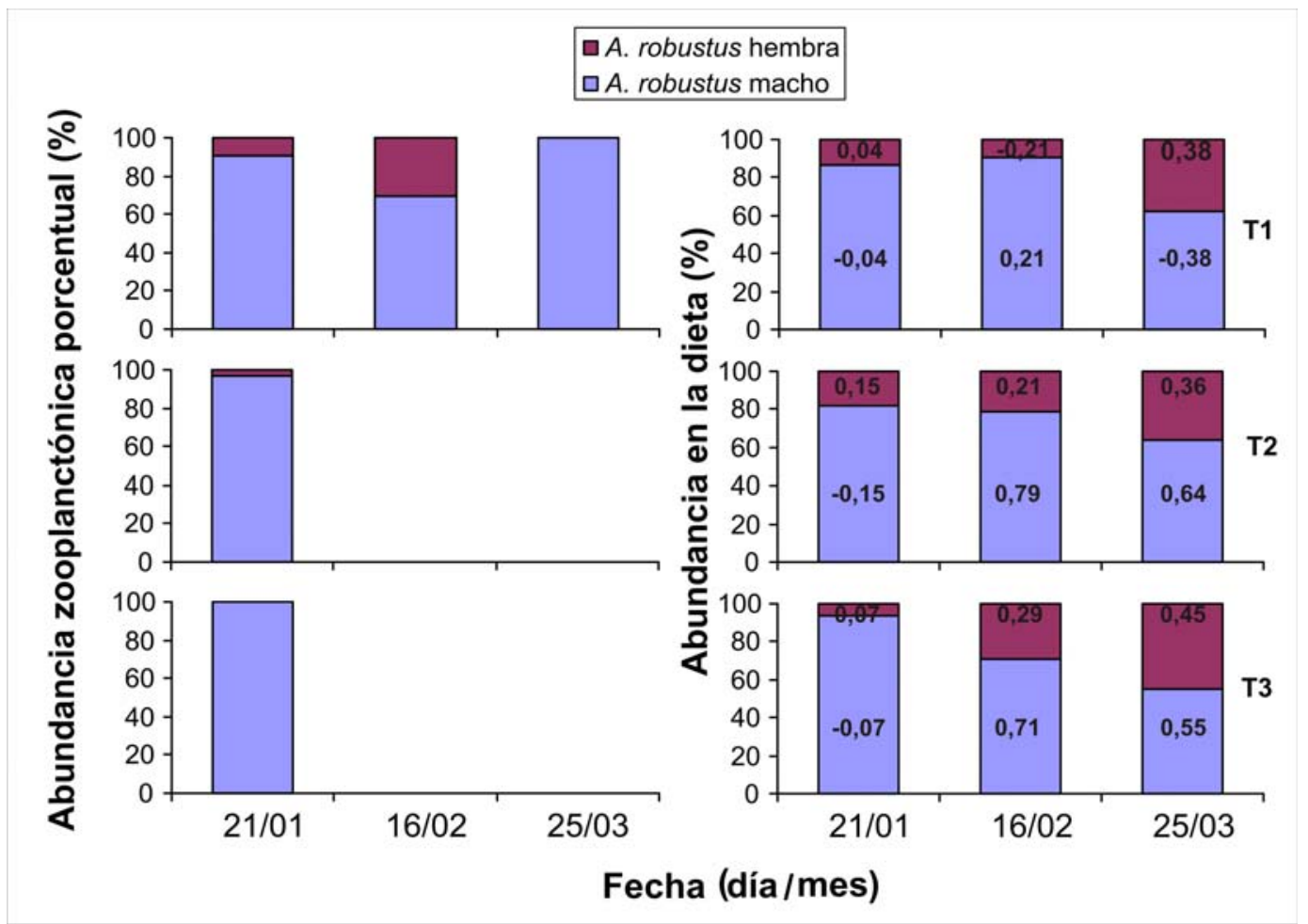

Figura VI.15: Abundancia porcentual de machos y hembras de A. robustus en las jaulas y en la dieta de los pejerreyes criados, para cada fecha de muestreo y tratamiento de densidad. En las columnas de la dieta se expresan los valores del índice de selectividad de Strauss (L).

Al comparar la AZ de machos y hembras de A. robustus en todos los tratamientos se observó una interacción positiva entre el tiempo y el sexo en la laguna y en las jaulas T1, pero no se encontraron diferencias en las jaulas T2, T3 y JB (Para más detalles de los ANOVA de medidas repetidas y test de Bonferroni realizados ver Tabla VI.7). 
Tabla VI.7: Resultados de los Anova de medida repetidas (RM ANOVA) comparando la abundancia de machos y hembras del copépodos A. robustus en cada tratamiento. Las comparaciones de a pares por fecha se realizaron mediante el test de Bonferoni, las diferencias se indican: $\mathrm{S}=$ Significativa, NS = No significativa. Las cuatro fechas de muestreo se indican como t (tiempo) del 1 al 4.

\begin{tabular}{|c|c|c|}
\hline Tratamiento & Resultado RM ANOVA entre sexos & $\begin{array}{l}\text { Resultado comparciones } \\
\text { de a pares por fecha }\end{array}$ \\
\hline Laguna & $F$ interacción $(3,18)=5,9 ; p<0,05$ & $\begin{array}{l}\mathrm{t} 1=\mathrm{S}\left(\hat{\jmath}^{\lambda}>+\right) \\
\mathrm{t} 2=\mathrm{NS} \\
\mathrm{t} 3=\mathrm{S}\left(\hat{\jmath}^{\lambda}>0\right) \\
\mathrm{t} 4=\mathrm{NS}\end{array}$ \\
\hline T1 & $F$ interacción $(2,42)=4,6 ; p<0,05$ & $\begin{array}{l}\mathrm{t} 1=\mathrm{S}\left(\mathrm{J}^{1}>+\right) \\
\mathrm{t} 2, \mathrm{t} 3, \mathrm{t} 4=\mathrm{NS}\end{array}$ \\
\hline T2 & $F(1,10)=2,8 ; p=0,12$ & $\begin{array}{l}\mathrm{t} 1=\mathrm{S}\left(\hat{\jmath}^{\hat{\lambda}}>+\right) \\
\mathrm{t} 2, \mathrm{t} 3, \mathrm{t} 4=\mathrm{NS}\end{array}$ \\
\hline T3 & $F(1,6)=4,3 ; p=0,08$ & $\begin{array}{l}\mathrm{t} 1=\mathrm{S}(\hat{\mathrm{d}}>\mathrm{P}) \\
\mathrm{t} 2, \mathrm{t} 3, \mathrm{t} 4=\mathrm{NS}\end{array}$ \\
\hline $\mathrm{JB}$ & $F(1,6)=2,2 ; p=0,18$ & $\mathrm{t} 1, \mathrm{t} 2, \mathrm{t} 3, \mathrm{t} 4=\mathrm{NS}$ \\
\hline
\end{tabular}

\section{Crecimiento del pejerrey cultivado en jaulas}

Las LT promedio obtenidas con 50 días de edad (primer muestreo) no fueron diferentes entre tratamientos (ANOVA anidado, $F_{(2,171)}=4,1 ; p=0,08$ ), mientras que sí lo fueron en los otros muestreos (ANOVA anidado, $F_{(2,126)}=13,9 ; p<0,05$ y $F_{(2,228)}=15,3 ; p<0,05$, a los 76 y 113 días de edad, respectivamente) (Figura VI.16). La diferencia entre tratamientos aumentó a medida que pasó el tiempo, lo cual pudo observarse por el grado de significancia de los test post hoc (SNK) (Figura VI.17). El peso medio mostró diferencias entre tratamientos en todas las fechas de muestreo (ANOVA anidado, $F_{(2,24)}=21,9 ; p<0,05, F_{(2,24)}=15,3 ; p<0,05$ y $F_{(2,171)}=212,4 ; p<0,05$, a los 50, 76 y 113 días de edad, respectivamente) (Figura VI.17). 


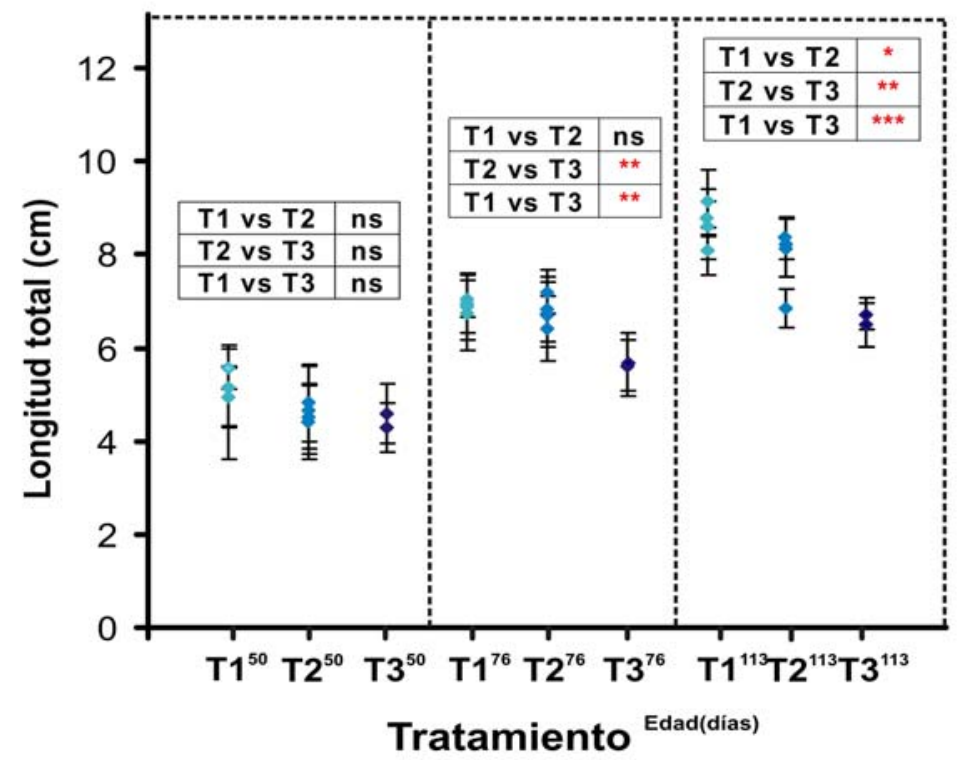

Figura VI.16: Longitudes totales individuales (promedios y desvíos) de los pejerreyes criados en cada jaula, en cada tratamiento a los 50, 76 y 113 días de edad. Diferencias entre tratamientos (SNK test): ns = no significativa, ${ }^{*} p<0,05,{ }^{* *} p<0,01 y * * * p<0,001$.

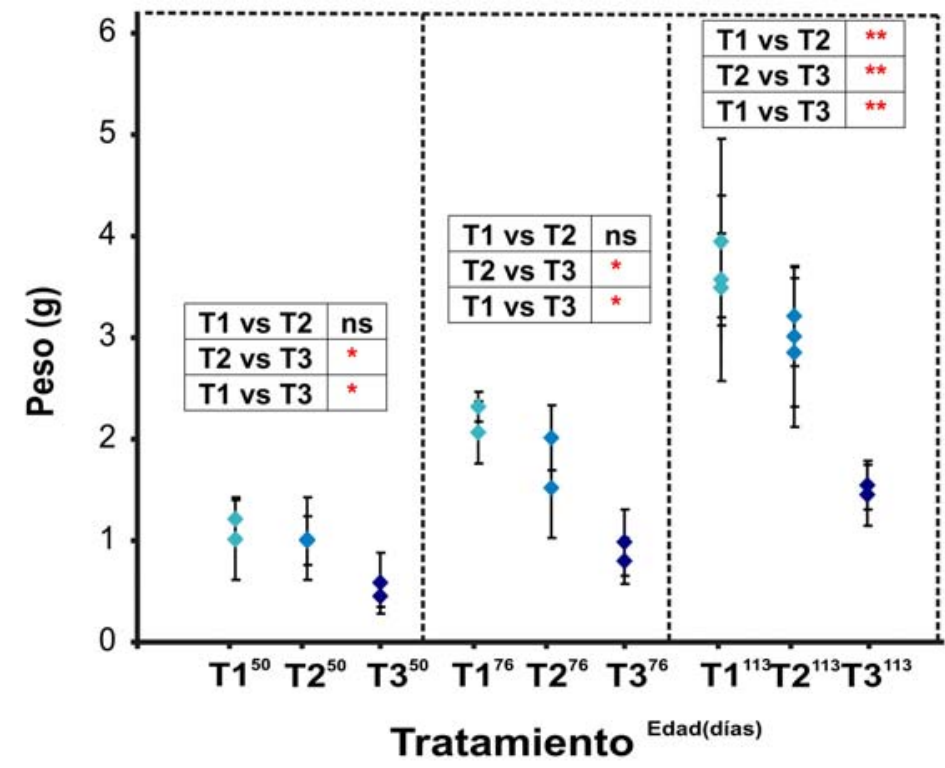

Figura VI.17: Pesos individuales (promedios y desvíos) de los pejerreyes criados en jaulas, en cada tratamiento a los 50, 76 y 113 días de edad. Diferencias entre tratamientos: ns = no significativa, ${ }^{*} p<0,05$ y ** $p<0,01$.

Las tasas de crecimiento específicas en largo y peso (TCEL y TCEW) tuvieron sus valores máximos en la primera fecha de muestreo (Tabla VI.8). Se observaron algunas diferencias entre los tratamientos (RM ANOVA, $F_{(2,5)}=15,2 ; p<0,05$ y $F_{(2,5)}=17,2 ; p<0,05$, para TCEL y TCEW, respectivamente). Al comparar de a pares, se observó por ejemplo que en la 
primer fecha de muestreo, el valor de TCEW de T3 fue diferente de los otros tratamientos (Bonferroni test, $\mathrm{p}<0,05)$ (tabla VI.8).

Tabla VI.8: Tasas de crecimiento específicas (TCE), en largo y peso, para cada tratamiento y edad de pez. Se muestran los valores medios y sus desvíos estándar. Letras iguales indican diferencias no significativas $(p>0,05)$ y letras diferentes diferencias significativas $(p<0,05)$.

\begin{tabular}{lcccc}
\hline & & \multicolumn{3}{c}{ Edad pez (días) } \\
\cline { 3 - 5 } & Tratamiento & 50 & 76 & 113 \\
\cline { 3 - 5 } TCEL (cm/día) & T1 & $0,031 \pm 0,004 \mathrm{a}$ & $0,010 \pm 0,004 \mathrm{ab}$ & $0,005 \pm 0,001 \mathrm{a}$ \\
& $\mathrm{T} 2$ & $0,027 \pm 0,002 \mathrm{ab}$ & $0,015 \pm 0,001 \mathrm{~b}$ & $0,004 \pm 0,003 \mathrm{a}$ \\
& $\mathrm{T} 3$ & $0,025 \pm 0,002 \mathrm{bc}$ & $0,008 \pm 0,001 \mathrm{ac}$ & $0,005 \pm 0,001 \mathrm{a}$ \\
\hline \multirow{2}{*}{ TCEW (g/día) } & $\mathrm{T} 1$ & $0,100 \pm 0,004 \mathrm{a}$ & $0,024 \pm 0,005 \mathrm{a}$ & $0,010 \pm 0,005 \mathrm{a}$ \\
& $\mathrm{T} 2$ & $0,095 \pm 0,001 \mathrm{a}$ & $0,022 \pm 0,006 \mathrm{a}$ & $0,011 \pm 0,009 \mathrm{a}$ \\
& $\mathrm{T} 3$ & $0,065 \pm 0,008 \mathrm{~b}$ & $0,021 \pm 0,001 \mathrm{a}$ & $0,014 \pm 0,005 \mathrm{a}$ \\
\hline
\end{tabular}

El análisis de regresión múltiple identificó dos variables independientes como significativas en cuanto a su influencia sobre la variación en las TCE: los pesos secos promedio del zooplancton (BZ) de las categorías III (positiva) y I (negativa) encontrados en la laguna (BZLN, $R^{2}=0,935, n=22, F_{(2,19)}=136,97, p<0,05$, en largo y $R^{2}=0,93, n=22, F_{(2,19)}=$ $128,82, p<0,05$, en peso), siendo el modelo ajustado (Figura VI.18):

$\mathrm{TCE}=a+x 1$ BZLN III $+x 2$ BZLN I

donde, (TCEL) para el crecimiento en longitud: $a=0,011806 ; x 1=0,000134(p \leq 0,05) ; y$ x2 = $-0,000069$ ( $p=0,000246) ; y(T C E W)$ para el crecimiento en peso: $a=0,020284 ; x 1=0,000425$ $(p \leq 0,05) ; y \times 2=-0,000083(p=0,039049)$. 


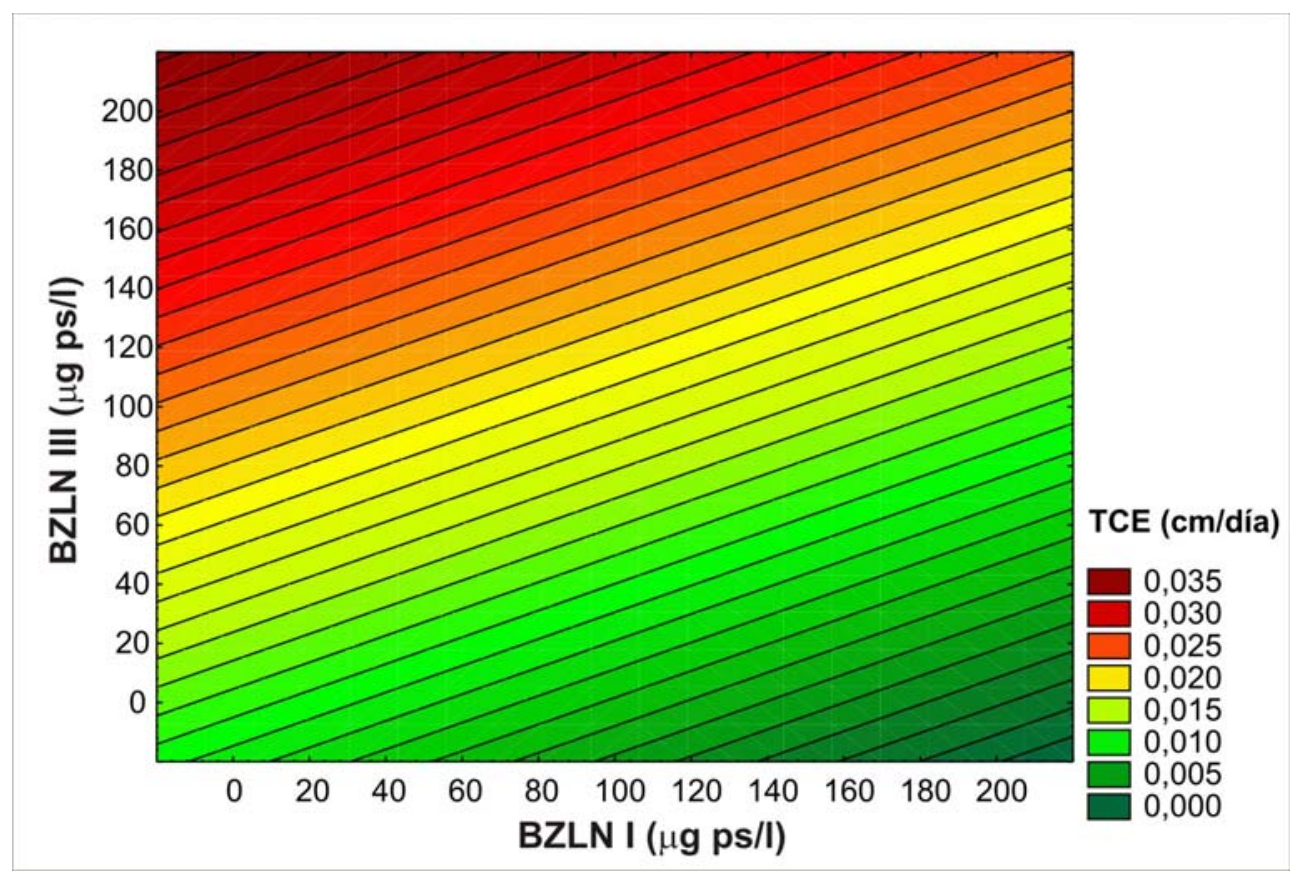

Figura VI.18: Gráfico de contornos 3D donde se observa el modelo de la regresión múltiple que indica que las mejores tasas de crecimiento (TCE) se dan a los mayores valores de biomasa promedio de la categoría III en la laguna (BZLN III) y a los menores valores de biomasa promedio de la categoría I en la laguna (BZLN I).

Una regresión simple entre TCE y CD III mostró el mejor y más significativo ajuste a un modelo exponencial $\left(R^{2}=0,80 ; F_{(1,11)}=25,8 ; p<0,05\right)$ :

$\mathrm{TCE}=0,00153 \exp (2,36085 \mathrm{CD}$ III)

La condición de los pejerreyes fue buena durante todo el experimento (WrS cercano o superior a 1), pero se observó un descenso en el valor de WrS a lo largo del tiempo (Tabla VI.9).

Tabla VI.9: Índice de condición por stanzas (promedios y desvíos) para cada tratamiento y cada fecha de muestreo (edad de peces).

\begin{tabular}{cccc}
\hline Tratamiento & $\begin{array}{c}\mathbf{2 1 / 0 1 / 2 0 1 0} \\
\text { (50 días) }\end{array}$ & $\begin{array}{c}\mathbf{1 6 / 0 2 / 2 0 1 0} \\
\text { (76 días) }\end{array}$ & $\begin{array}{c}\mathbf{2 5 / 0 3 / 2 0 1 0} \\
\text { (113 días) }\end{array}$ \\
\hline $\mathrm{T} 1$ & $1,20 \pm 0,06$ & $1,20 \pm 0,08$ & $1,08 \pm 0,07$ \\
$\mathrm{~T} 2$ & $1,24 \pm 0,05$ & $1,15 \pm 0,07$ & $1,09 \pm 0,07$ \\
$\mathrm{~T} 3$ & $1,20 \pm 0,10$ & $1,12 \pm 0,12$ & $1,02 \pm 0,06$ \\
\hline
\end{tabular}


El mayor número final de pejerreyes fue obtenido en jaulas de T3 (655 ind./jaula, en promedio), la supervivencia media fue más alta en T1 (84,9\%) y la biomasa media final fue mayor en T2 (1145,5 g) (Tabla VI.10).

Tabla VI.10: Parámetros finales del experimento: número final promedio (ind./jaula), supervivencia promedio (\%) y biomasa media (gramos) por tratamiento.

\begin{tabular}{llll}
\hline Tratamiento & $\mathrm{T} 1$ & $\mathrm{~T} 2$ & $\mathrm{~T} 3$ \\
\hline Número final promedio (ind./jaula) & 254,7 & 432,2 & 655 \\
Supervivencia media (\%) & 84,9 & 72 & 72,7 \\
Biomasa media (g) & 876,3 & 1145,5 & 982,5 \\
\hline
\end{tabular}




\subsection{Discusión}

Durante la etapa "nursery" se observó que la comunidad zooplanctónica estuvo dominada por rotíferos, y que con el pasar de los días la composición específica del zooplancton dentro de las jaulas fue tornándose diferente a la de afuera de las mismas. Esto pudo deberse al efecto de los peces sobre el zooplancton y probablemente también a un efecto de aislamiento que provocó el "fouling" de las jaulas (un "taponamiento" generado por el crecimiento de perifiton en las paredes de las jaulas) lo cual pudo evidenciarse por la correlación encontrada entre el tiempo de instalación de las jaulas "nursery" y el valor de R del ANOSIM de la comparación entre AZL y AZJ. Además, estas observaciones son coincidentes con el hecho de que se encontró mayor BZ en las jaulas, respecto de la laguna, en la primer fecha de muestreo, inverso a lo que ocurre al final de esta etapa, cuando la BZ de las jaulas es menor que la de la laguna (Figura VI.5). Resulta importante destacar en este punto que este posible efecto de taponamiento observado en estas jaulas "nursery" no se evidencia tan claramente en las jaulas durante las etapas experimentales de este y otros experimentos realizados. En cuanto al pejerrey, este modo de obtención de postlarvas en jaulas "nursery" ha permitido obtener tallas mayores en el mismo tiempo, en comparación con las criadas en cavas cuyos resultados fueron mostrados en los capítulos IV y V.

En la etapa experimental se han observado importantes variaciones en las $A Z$ y $B Z$, aunque siguiendo un patrón similar dentro y fuera de las jaulas (Figuras VI.9 y VI.10). Dicha similitud ha demostrado que durante esta etapa, los peces tuvieron dentro de las unidades de cría una disponibilidad similar de zooplancton a la de la laguna. Por su parte, la composición taxonómica registrada y sus AZ fueron similares a las de otros ambientes lagunares pampeanos (Claps et al. 2004, Ardohain 2008, Diovisalvi et al. 2010) y a lo encontrado el año anterior en esta época (verano) en La Salada de Monasterio (capítulo V). El zooplancton pequeño (particularmente los rotíferos), domina en las lagunas pampeanas, probablemente como consecuencia de mecanismos de control de tipo "Top-down" llevados a cabo por especies planctívoras como el pejerrey y el bagarito ( $P$. valenciennis) (Quirós et al. 2002a). Resulta interesante destacar que la moderada presencia de microcrustáceos, con consecuentes bajos valores de BZ total, fue también similar a otras lagunas pampeanas estudiadas como Chascomús (Diovisalvi et al. 2010) y Lacombe (Ardohain 2008). Sin embargo 
fue diferente por ejemplo a El Carpincho (laguna conectada a otra) donde hubo una importante presencia de cladóceros grandes durante el verano (Quirós et al. 2002a), y San Miguel del Monte (con presencia de macrófitas sumergidas) (Claps et al. 2004), donde existió un pico de BZ en esta estación.

La comunidad zooplanctónica de las jaulas estaría siendo estructurada, tal cual postula la hipótesis de eficiencia por tamaños $(\mathrm{SEH})$, por una relación inversa entre la densidad de peces depredadores y el $\mathrm{TMZ}$, como resultado de una depredación selectiva sobre las presas más grandes. Dicha relación probablemente también esté modelando la comunidad zooplanctónica de la laguna La Salada de Monasterio, en relación con el pejerrey y otros peces zooplanctívoros, e incluso la de otras lagunas pampásicas.

Las diferencias halladas entre los tratamientos testeados en el presente capítulo permiten decir que la depredación dentro de las jaulas está directamente relacionada con la densidad de "stock", afectando diferencialmente la composición del zooplancton dentro de las jaulas, y funcionando como un "filtro". Cabe aclarar en este punto, que en un experimento de diseño aleatorio como el presente, se asume que la cantidad de alimento (en este caso zooplancton) que pasa a través de las mallas es similar para todas las unidades experimentales. El hecho de que las mayores diferencias se observaran al comparar las JB con las JP permite inferir un "efecto refugio" generado en las JB ante la ausencia de depredadores, lo cual se evidencia con el aumento de la BZ al final del experimento en las JB (Figura VI.10). Además, los cambios en la contribución porcentual de categorías de tallas a lo largo del tiempo (Figura VI.12) también encuentran su explicación en la depredación por parte de los pejerreyes, ya que en las JP al principio (50 días de edad) el zooplancton mayor (Categoría III) fue dominante, y al final dichos ítems desaparecieron en T3 y estuvieron muy escasamente representada en T1 y T2. Por su parte, en las JB las categorías II y III fueron siendo cada vez más importantes con el paso del tiempo, lo mismo que ocurrió en la dieta de los pejerreyes criados (Figura VI.13).

Los resultados obtenidos en cuanto a los CD indicaron que la composición de los mismos fue claramente diferente a la composición del zooplancton dentro de las jaulas (Figura VI.13), cuya AZ estuvo dominada por zooplancton pequeño. Los pejerreyes tuvieron una tendencia a la diversificación del tamaño de presa dependiendo del tamaño del pez y de su densidad de cría, a pesar de que al mismo tiempo se observó un patrón subyacente de 
reducción en la proporción de presas pequeñas ingeridas, a medida que los peces crecieron en edad y talla.

Se observó también que existieron restricciones con respecto a la talla de consumo sólo en las primeras etapas de crecimiento de la especie. A los 50 días de vida el tamaño influyó sobre el TMP en este primer período en las jaulas, ya que aunque las tres categorías de tamaño de zooplancton se encontraron representadas en los CD, la categoría III estuvo mejor representada en los peces del T1. Estos pejerreyes a menor densidad tuvieron el máximo crecimiento, y por ende mayores probabilidades de acceder al zooplancton de mayor tamaño. Dabrowski \& Bardega (1984) y Kozlowski et al. (2000) han realizado similares observaciones para otros grupos de peces (ciprínidos y coregónidos, respectivamente). La densidad tuvo su efecto sobre la disponibilidad de presas de talla III, siendo ésta mayor en las jaulas con menor densidad, debido a que el forrajeo sobre ellas fue menor (densodependencia), lo cual se vincula con que la escasa biomasa de peces por jaula a los 50 días de edad haya resultado en una mínima competencia por las presas. Esto último en cuanto a la $A Z$, aunque seguramente el crecimiento diferencial observado haya sido resultado de diferencias en cuanto a la "calidad" del zooplancton consumido.

A medida que los peces crecieron (76 y 113 días de edad) fueron capaces de capturar e ingerir ítems de las tres clases de tamaño, sin embargo el TMP resultó ser mayor a los 76 días de edad para los tres tratamientos. El TMP tuvo casi el mismo valor para T1 y T2 a los 76 y 113 días de edad, mientras que en T3 se observó un valor menor, indicando que la competencia por el alimento allí sí afectó el acceso al mismo. De hecho, el TMP mostró una relación negativa con la densidad de cría, mientras que el zooplancton de clase I se convirtió en un recurso alternativo cuando aumentó la competencia interindividual (Figura VI.13). Esta observación es consistente con la Teoría de Forrajeo Óptimo (Pyke 1984, Stephens \& Krebs 1986 y Beauchamp et al. 2007), que establece que un determinado ítem va a ser incluido en la dieta si el beneficio neto que le brinda consumir ese ítem (dado que ya lo encontró) es mayor a lo que le aportan el conjunto de los ítems en promedio (considerando el costo de seguir buscando) (Begon et al. 2006).

Lo antedicho acerca de la diversificación del tamaño de presa dependiente de la talla de los peces y de su densidad de cría fue confirmado no sólo por la composición de los CD, particularmente a los 113 días de edad en el T3 (Figura VI.13), sino también por el índice de amplitud trófica (Levins). La expansión del nicho trófico de la especie se vinculó con la 
creciente densidad de cultivo, probablemente asociado con la competencia interindividual por el acceso a las presas disponibles (implicando una disminución del TMP). Además, aunque fueron encontrados ítems de categoría I en los CD, los valores del índice de forrajeo óptimo (FR), indicaron que dicha categoría fue seleccionada negativamente, ya que ante la elevada oferta de zooplancton pequeño en el ambiente, la cantidad ingerida fue distinta. Con relación a esto, resulta importante destacar que ante la dominancia en número en las lagunas pampeanas y a pesar de haber sido seleccionados negativamente por pejerreyes de más de 4 $\mathrm{cm}$ de $\mathrm{LT}$, los rotíferos son un componente importante de la dieta del pejerrey durante los estadíos tempranos del desarrollo (Zagarese 1991; capítulo $V$ de la presente tesis) y, como se mencionó previamente, pueden volver a formar parte de la dieta bajo determinadas condiciones, como la elevada densidad de cría. En este caso la selectividad alimentaria en los peces criados a altas densidades disminuyó a medida que crecieron, ocurriendo además un cambio en su dieta, incorporando (o re-incorporando), a modo de compensación, ítems de pequeño tamaño, al mismo tiempo que las presas más grandes comenzaron a desaparecer (clase III).

En relación con el zooplancton grande (clase III), al analizar $A$. robustus en detalle, se obtuvieron diferentes resultados al considerar a los machos y las hembras en conjunto o por separado. Dichas diferencias brindan una posible evidencia en cuanto a las preferencias alimentarias, las cuales según lo registrado por otros autores para otras especies de peces planctívoros, pueden estar vinculadas con el tamaño y la velocidad de escape de las presas. Las hembras de los copépodos son más grandes que los machos y al cargar con los sacos ovígeros se vuelven más visibles y más lentas, lo cual las hace más vulnerables a la depredación (Maier 1998), características que a su vez, según otros autores, causa diferencias en la proporción de sexos de la especie en el ambiente, debido a la depredación selectiva por peces zooplanctívoros (Hairston et al. 1983, Vuorinen et al. 1983, Hairston 1988). En los CD dominaron siempre los machos (Figura VI.15), pero dicho predominio fue disminuyendo con el paso del tiempo, mientras que el consumo de las hembras fue en aumento. Esto significa que los pejerreyes fueron aumentando la ingesta de copépodos de mayor tamaño a medida que fueron creciendo. En la comparación entre la oferta y el consumo, también se observó que hubo consumo de hembras cuando su presencia en la oferta fue muy escasa o incluso inexistente. Analizando los resultados del índice de selectividad de Strauss (L), se vio que la selectividad fue diferente para machos y hembras, siendo positiva en algunos momentos y 
negativa en otros. En el primer muestreo los valores estuvieron muy cercanos al cero, indicando una cierta "indiferencia" en el consumo respecto de la oferta, consumiendo lo ofrecido sin seleccionar. Para los siguientes muestreos, en términos generales, la selectividad hacia los machos aumentó del primer al segundo muestreo pero luego disminuyó, mientras que la elección de las hembras fue negativa en el segundo muestreo de T1 para luego ser positiva en el tercer muestreo, y para los otros dos tratamientos fue siempre en aumento (Figura VI.15). Analizando las similitudes y diferencias halladas en la AZ de $A$. robustus machos y hembras por tratamiento (Tabla VI.7), es posible concluir que la selectividad hacia uno u otro de los sexos no sólo se debió a su tamaño sino también a su disponibilidad, ya que en los tres tratamientos con peces hubo diferencias en la $A Z$ entre sexos de $A$. robustus en la primer fecha de muestreo de zooplancton(antes de la primer fecha de muestreo de los peces), y no hubo diferencias entre sexos ni en las otras fechas de muestreo zooplancton en las JP, ni en todo el experimento en las JB.

Por otro lado, otros autores han argumentado recientemente que las habilidades individuales de escape de los integrantes del zooplancton serían poco efectivas en ambientes donde no es tan factible el encuentro de "zonas seguras", mientras que las adaptaciones a nivel poblacional, como cambios en el ciclo de vida (por ejemplo diapausa y migraciones), serían las que realmente les permitirían evitar a los predadores (Pasternak et al. 2006). Esto permitiría inferir una explicación ante la escasa representatividad de cladóceros medianos y grandes en la dieta de los pejerreyes criados en este experimento, en comparación con aquellos criados en la misma laguna en otros años y momentos del año, como en La Salada en el experimento 3 del capítulo IV, y en otros estudios realizados (Grosman 1995b). Estas últimas observaciones, sumadas a la existencia del zooplancton clase III a lo largo de la mayoría del tiempo de experimentación en las jaulas blanco, demuestran que el zooplancton en estos sistemas no tiene una zona segura y coinciden con lo postulado por otros autores de que en los sistemas pampeanos las macrófitas no funcionan como zona de refugio para el zooplancton ya que albergan gran cantidad de depredadores, tanto invertebrados como vertebrados (González Sagrario et al. 2009, González Sagrario \& Balseiro 2010). Es así que la exclusión de los peces en las jaulas blanco demuestra la liberación de la presión de planctivoría y depredación existente en la laguna.

La utilización diferencial de los recursos por parte de los juveniles de pejerrey también se vio evidenciada en los modelos de regresión resultantes. Allí se observaron dos efectos 
sobre las tasas de crecimiento: un efecto positivo (directo) de la BZ del zooplancton de talla III (BZLN III, particularmente A. robustus) y un efecto inverso de la disponibilidad de zooplancton de clase I (BZLN I, principalmente B. havanaensis como lo mostró el análisis SIMPER). Estos resultados resaltan la importancia de la calidad del zooplancton, en términos de talla y BZ, en la producción de pejerrey, por medio del cultivo extensivo en jaulas.

En cuanto al crecimiento, los peces crecieron más en largo y peso a la densidad más baja (T1). El máximo número de peces se obtuvo a la máxima densidad (T3), mientras que la densidad intermedia (T2) resultó ser la más apropiada para maximizar la producción. Otros autores, trabajando con otras especies a diferentes densidades, obtuvieron resultados diferentes. Entre ellos, algunos no encontraron diferencias entre distintas densidades de siembra (Fermin et al. 1996, Sagratzki Cavero, et al. 2003, Gomes et al. 2006) y otros no llegaron a un límite superior de densidad (Hengsawat et al. 1997, Gomes et al. 2006). Otros autores incluso obtuvieron sus mejores producciones a las más altas densidades utilizadas, encontrando una relación positiva entre la densidad de "stock" y la producción, en especies como O. niloticus (tilapia) (por ejemplo Watanabe et al. 1990, Gibtan et al. 2008), O. spilurus (otra tilapia) (Cruz \& Ridha 1991) y Pangasius sutchi (un bagre) (Islam et al. 2006). En el presente estudio las condiciones de T2 fueron las más apropiadas en términos del aprovechamiento eficiente de los recursos con los que contó el sistema, sacando un máximo provecho de su capacidad de carga. 


\section{VII}

DESARROLLO ALIMENTARIO DEL PEJERREY: comparaciones en la dieta de pejerreyes silvestres y criados de modo extensivo

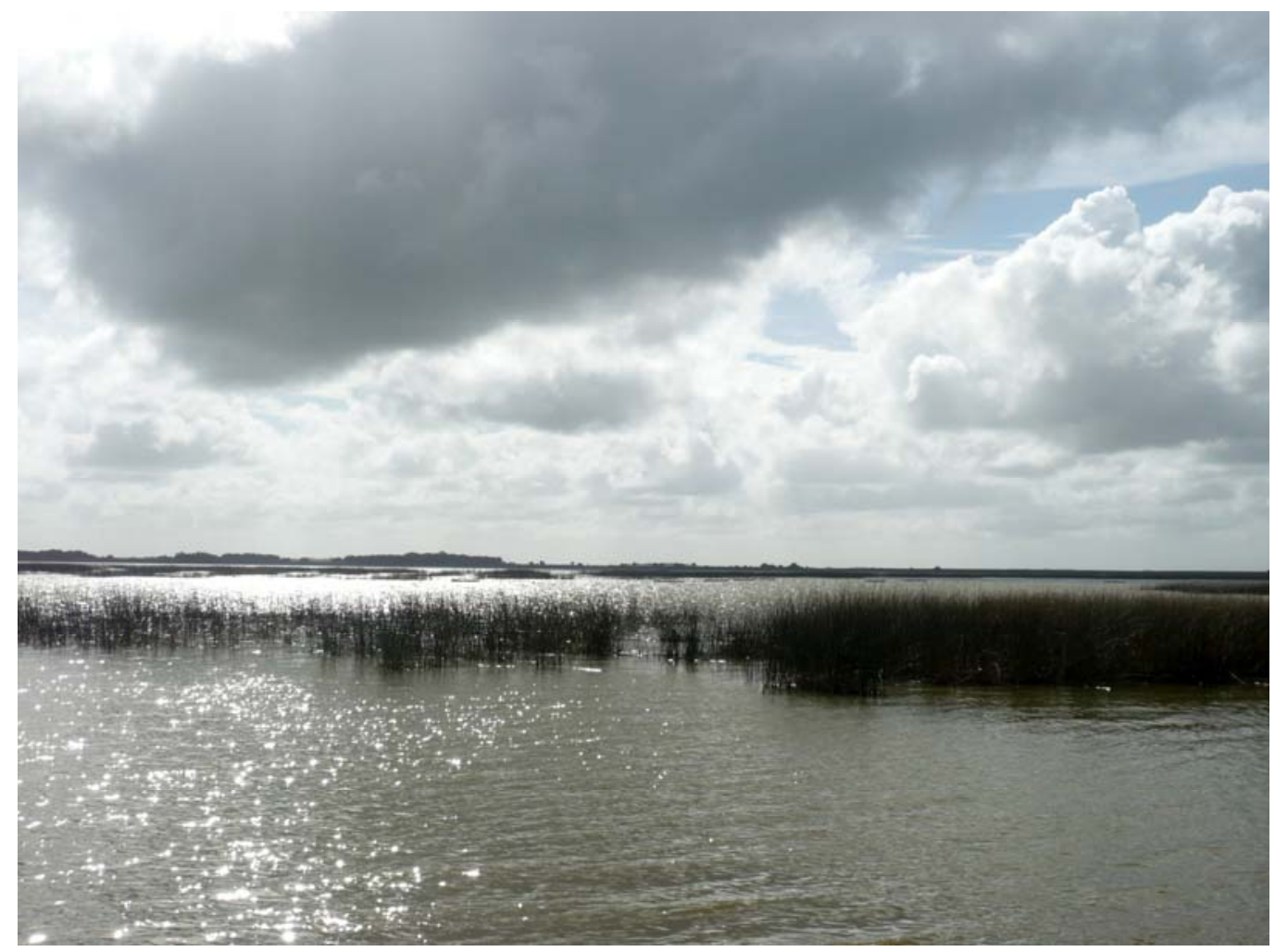




\section{Capítulo VII: DESARROLLO ALIMENTARIO DEL PEJERREY: comparaciones en la dieta de pejerreyes silvestres y criados de modo extensivo}

\subsection{Introducción}

La mayoría de las larvas de teleósteos no están bien desarrolladas al momento de la eclosión, presentando boca y mandíbulas no formadas, ojos no pigmentados, saco vitelínico grande y aleta "primordial" que se extiende casi por todo el cuerpo (Nakatani et al. 2001). Las larvas deben pasar por una etapa de desarrollo y diferenciación adicional antes de comenzar a ingerir alimento exógeno que pueda ser digerido y absorbido eficazmente. La larva recién eclosionada depende del vitelo, cuándo éste se agota precisa del alimento exógeno para satisfacer las demandas crecientes de energía. La sucesión gradual de cambios en los hábitos alimentarios, producidos a medida que el animal se desarrolla puede denominarse "desarrollo alimentario" (en inglés: "feeding development").

La adquisición de los nutrientes es crucial para la supervivencia, esto genera que los mecanismos de alimentación estén en constante presión selectiva para mejorarse a cada paso del desarrollo en donde los nutrientes son obtenidos externamente (Lowry \& Motta 2007). Es por eso que el desarrollo alimentario incluye todo lo relacionado con la evolución del nicho ecológico de la especie, que ocurre a medida que crece. De los numerosos estudios donde analizan la alimentación del pejerrey bonaerense (Ringuelet 1942, Destefanis \& Freyre 1972, Ringuelet et al. 1980, Escalante 1985, Aquino 1991, Grosman 1995b, Colautti \& Remes Lenicov 2000, Sagretti \& Bistoni 2001, Grosman \& Sanzano 2003, Romero 2012, entre otros), pocos han investigado estos posibles cambios en relación con la ontogenia de la especie. Ringuelet et al. (1980) diferenciaron las etapas de alimentación del pejerrey, definiendo que se trata de un pez que pasa de ser zooplanctívoro visual estricto a ampliar su espectro trófico para luego pasar a ser piscívoro facultativo a partir del cuarto año de vida. Romero (2012) profundiza el estudio encontrando diferencias no sólo en cuanto a la ontogenia sino también en cuanto a la zona del ambiente donde se encuentran, separando aquellos de $<4,5 \mathrm{~cm}$ (Lst) de aquellos $>4,5 \mathrm{~cm}$ (Lst) en cuanto a que los primeros consumieron cladóceros de menor tamaño que los segundos. La autora expone que la zona litoral posee condiciones más propicias para el desarrollo de estadíos tempranos de la especie y que los peces se desplazan 
a la zona pelágica con un mayor tamaño que les permite incorporar presas más grandes, encontrándo así que la diferenciación en tamaños y el uso de zonas coincidió con un consumo diferencial de presas. Sin embargo todavía es escasa la información acerca de la alimentación de la especie en los estadíos más tempranos, lo cual por ejemplo ha sido evaluado por Zagarese (1991) en mesocosmos. El mencionado autor enontró por ejemplo que las larvas de $O$. bonariensis consumen relativamente poco alimento, como lo hacen los depredadores invertebrados, pero que mediante dicho consumo afectan a la comunidad zooplanctónica del mismo modo que lo hacen otros predadores vertebrados. Por otro lado observó que en las primeras fechas de muestreo de sus experimentos, ante una comunidad zooplanctónica todavía no afectada por la depredación, los peces consumieron presas de tamaño máximo menor al tamaño máximo de presas disponibles, mientras que de allí en adelante, con presas disminuídas en su tamaño medio por efecto de la depredación, pudieron consumir iguales o mayores tallas máximas a las encontradas en la disponibilidad. Además encontró que las tasas de crecimiento de las larvas estuvieron inversamente afectadas por el peso de las presas, lo cual, aunque inconsistente con la teoría de forrajeo óptimo, podría ser explicado por la ineficiencia gástrica de las larvas de peces (Mills et al. 1984).

En la acuicultura existe un período crítico que se encuentra entre la finalización de la fase vitelina y el comienzo de la alimentación exógena. Limitaciones morfológicas, como el tamaño de la boca que restringe el número y tamaño de presas disponibles, y fisiológicas, como el desarrollo incompleto de las glándulas digestivas, pueden causar altas tasas de mortalidad en esta fase, lo mismo que probablemente ocurra en la naturaleza. En el caso del pejerrey se trata de una limitación en su acuicultura que aún no termina de superarse, pero para la cual se han obtenido resultados promisorios aplicando la técnica de cría extensiva en cavas (Garcia de Souza et al. 2009) y jaulas flotantes (Colautti et al. 2009a, Colautti et al. 2010, Garcia de Souza et al. 2013).

El objetivo del presente capítulo es profundizar acerca del estudio de la dieta del pejerrey criado de manera extensiva en cavas y jaulas flotantes (experimentos ya presentados en los capítulos anteriores) y contrastar lo observado con los hábitos alimentarios de ejemplares de tallas comparables de la especie viviendo libremente en el mismo ambiente, 


\subsection{Metodología particular}

Durante el año 2009 y 2010 se realizaron muestreos utilizando las redes de arrastre descriptas en el capítulo III (A1 y A2), en las lagunas de Chascomús y La Salada de Monasterio, con periodicidad estacional. De los pejerreyes capturados se seleccionaron aquellos de tallas comparables con los obtenidos en los experimentos en curso, durante las respectivas estaciones, y se analizaron sus contenidos digestivos (CD). Los CD de los pejerreyes silvestres (CDsil) fueron evaluados mediante métodos multivariados (CLUSTER, ANOSIM, SIMPER, etc.) de acuerdo a rangos de tallas (promedios redondeados al centímetro) y a las fechas de muestreo (meses y años), en cuanto a las proporciones de los ítems encontrados, por especies y por categorías de tamaño del zooplancton (I, II y III). También fueron comparados con la AZ de la laguna (AZL) mediante ANOSIM y el índice de selectividad de Strauss, con el fin de indagar acerca de la selectividad alimentaria en pejerreyes silvestres. Además la dieta de los pejerreyes silvestres fue comparada con la registrada en los experimentos en jaulas (CDjau), utilizando también métodos multivariados. 


\subsection{Resultados}

Se analizaron los CDsil de 9 pejerreyes de entre 1 y $4 \mathrm{~cm}$ de LT promedio en Chascomús, y de 24 pejerreyes de entre 1 y $11 \mathrm{~cm}$ de LT en La Salada de Monasterio. En ambos casos se observó una marcada diferenciación por tallas de zooplancton ingerido en función de la talla del pez (Figura VII.1). También se observaron diferencias en cuanto a las categorías taxonómicas consumidas (Figura VII.2).

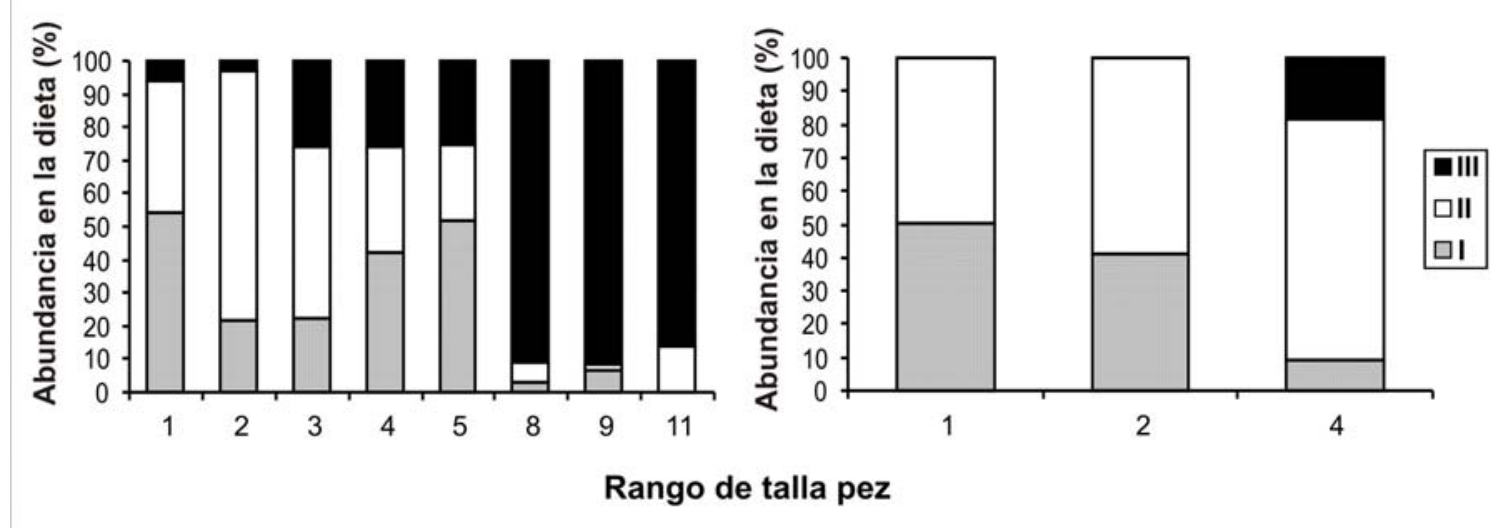

Figura VII.1: Abundancia zooplanctónica porcentual en la dieta, por categorías de tamaño, en función de los rangos de talla promedios de los pejerreyes silvestres seleccionados, en La Salada (gráfico de la izquierda) y en Chascomús (gráfico de la derecha).

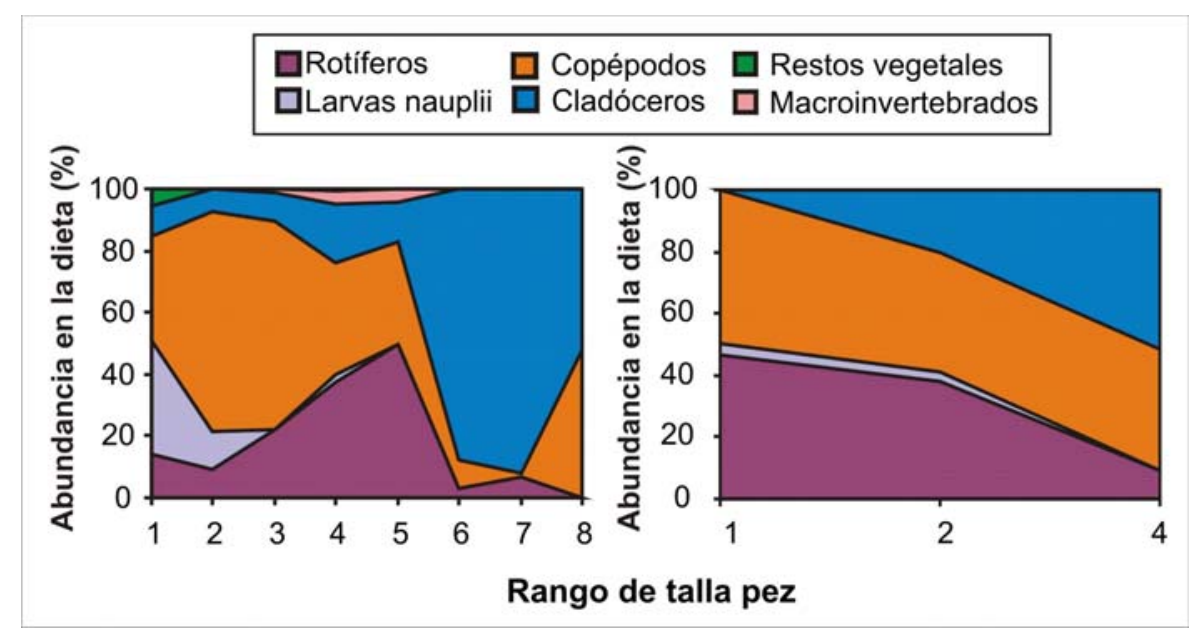

Figura VII.2: Abundancia zooplanctónica porcentual por categorías taxonómicas en función de los rangos de talla promedio de los pejerreyes silvestres seleccionados en La Salada (gráfico de la izquierda) y Chascomús (gráfico de la derecha).

En Chascomús los rotíferos fueron mayormente consumidos por los peces más pequeños, los copépodos fueron consumidos en proporciones casi constantes en los tres 
rangos de talla evaluados, mientras que los cladóceros aumentaron en la dieta hacia las tallas mayores ( $4 \mathrm{~cm}$ de LT). En el caso de La Salada se observó una dominancia opuesta entre los copépodos y los cladóceros, estando los primeros mejor representados en las tallas menores (entre 1 y $5 \mathrm{~cm}$ de LT) y los segundos en las mayores (entre 5 y $8 \mathrm{~cm}$ de LT). Los rotíferos estuvieron presentes en todas las tallas, con mayor representatividad en las intermedias (entre 3 y $5 \mathrm{~cm}$ de LT). Esta observación motivó el estudio mediante métodos multivariados de los CDsil de La Salada de Monasterio, teniendo en cuenta no sólo las tallas de los peces sino el mes y el año en que fueron capturados. De allí se desprende la figuras VII.3, análisis de tipo CLUSTER teniendo en cuenta todos los ítems alimentarios encontrados (VII.3 a) y teniendo en cuenta las categorías de tamaño de dichos componentes de la dieta (VII.3 b). Se puede observar cómo las muestras se ordenan de acuerdo a los meses en que fueron tomadas (más importante que el año) y cómo también se agrupan por los rangos de tallas de los peces a los que corresponden los CDsil.
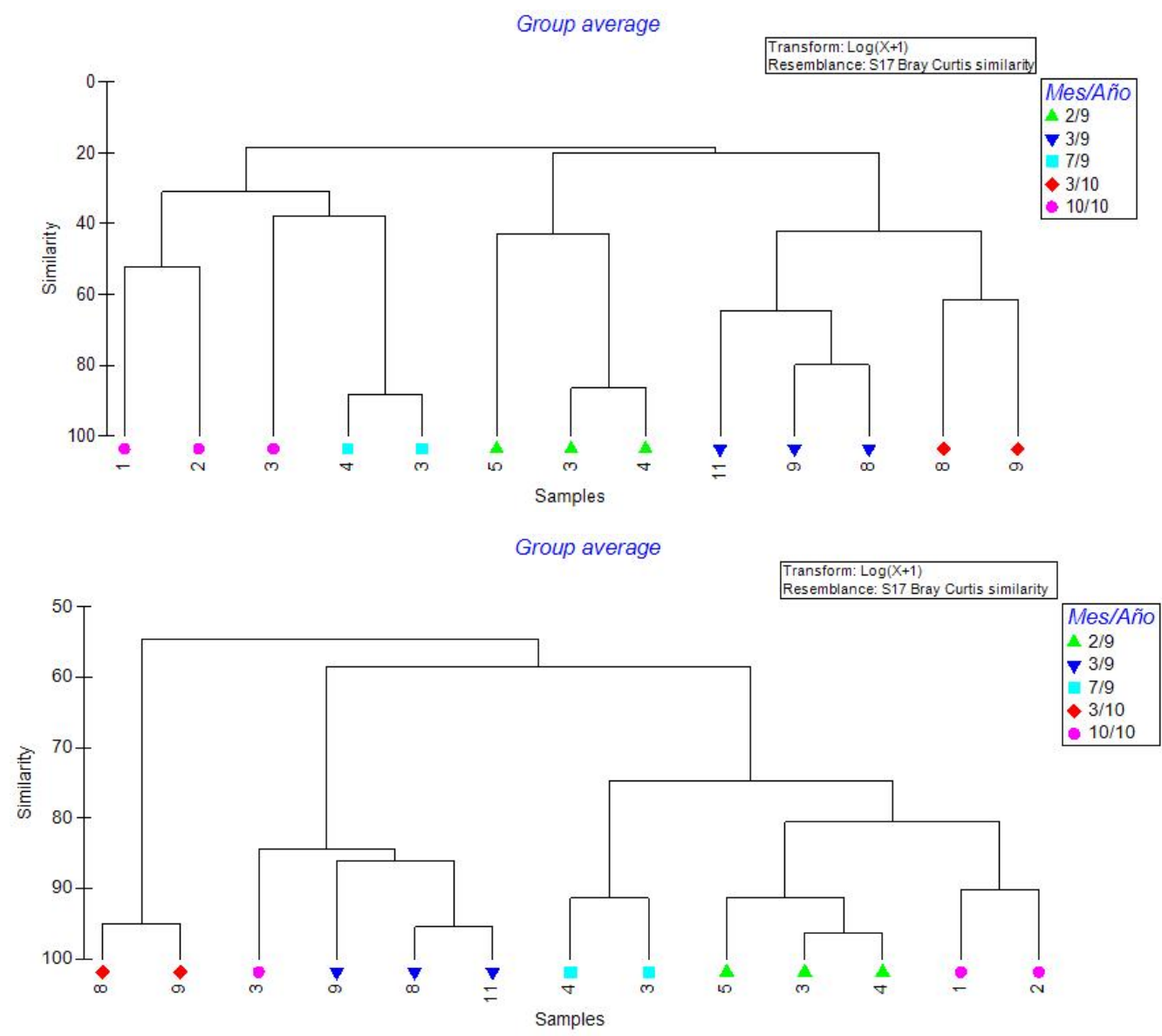

Figura VII.3: Gráficos de CLUSTER obtenidos para los contenidos digestivos de los pejerreyes silvestres seleccionados en La Salada de Monasterio, utilizando todos los ítems encontrados a nivel específico (a) o clasificados de acuerdo a las categorías de tamaño del zooplancton (I, II y III). 
En relación con estos ordenamientos se observa que cuando se ingresan en el análisis los ítems individualizados, o clasificados por tallas, los resultados son similares. En general se observa cómo los ejemplares se ordenan por su dieta de acuerdo al rango de talla al que pertenecen y a la fecha en la que fueron capturados, y también se puede destacar que los individuos de talla 3 tuvieron una dieta variable. Se buscó explicar esta variabilidad separando los datos por los años en los que fueron obtenidos (Figura VII.4), de modo que se observa como los pejerreyes de talla 3 capturados en verano e invierno de 2009 se alimentaron de manera diferente de aquellos capturados en primavera de 2010.

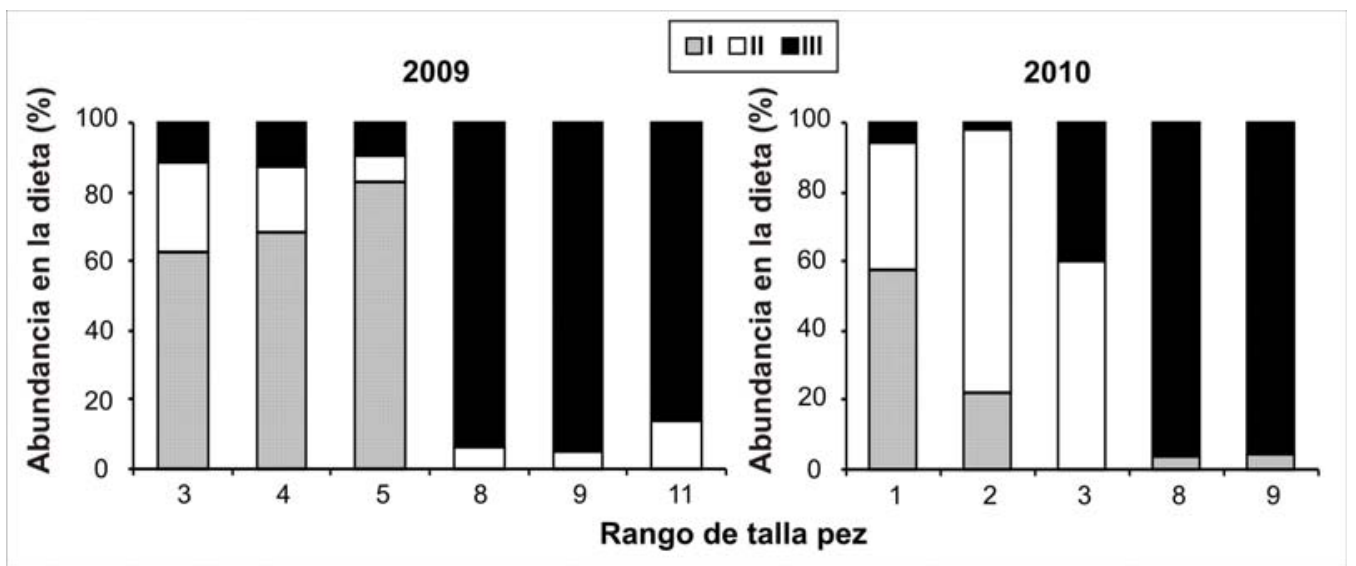

Figura VII.4: Abundancia porcentual de los ítems alimentarios clasificados de acuerdo a las categorías de tamaño del zooplancton para los años 2009 y 2010 por separado.

No se capturaron ejemplares de tallas 1 y 2 en 2009 ni de tallas 4 y 5 en 2010, y se pudo observar que en los dos años a partir de los $8 \mathrm{~cm}$ de LT la alimentación de los pejerreyes silvestres estuvo dirigida casi exclusivamente al zooplancton de mayor talla (III).

No existieron diferencias entre los CDsil de ejemplares pertenecientes a diferentes rangos de talla (ANOSIM, $\mathrm{p}>0,05$ ), teniendo en cuenta todos los ítems consumidos; sin embargo, al comparar los CDsil clasificados por categorías de tamaño de presa sí se encontraron diferencias entre las tallas de pejerrey (ANOSIM, $R=0,67 ; p<0,05$ ). Las comparaciones por pares resultantes del ANOSIM (Tabla VII.1) indican que existieron al menos dos tallas en las cuales la dieta de los pejerreyes silvestres se modificó, cuando pasaron de 1 a $2 \mathrm{~cm}$ de LT promedio y cuando superaron los $5 \mathrm{~cm}$. A su vez la tabla reafirma que los pejerreyes que se encuentran dentro del rango de los $3 \mathrm{~cm}$ de LT poseen dietas variables. 
Tabla VII.1: Significancias de las comparaciones por pares resultante del Análisis ANOSIM entre rangos de tallas de pejerrey considerando las categorías de tamaño de los ítems consumidos ( $\mathrm{S}=$ Significativa, NS = No significativa).

\begin{tabular}{c|cccccccc}
\hline Rango de Talla & $\mathbf{1}$ & $\mathbf{2}$ & $\mathbf{3}$ & $\mathbf{4}$ & $\mathbf{5}$ & $\mathbf{8}$ & $\mathbf{9}$ & $\mathbf{1 1}$ \\
\hline $\mathbf{1}$ & 0 & & & & & & & \\
$\mathbf{2}$ & $\mathrm{S}$ & 0 & & & & & & \\
$\mathbf{3}$ & $\mathrm{S}$ & $\mathrm{S}$ & 0 & & & & & \\
$\mathbf{4}$ & $\mathrm{S}$ & $\mathrm{S}$ & $\mathrm{NS}$ & 0 & & & & \\
$\mathbf{5}$ & $\mathrm{S}$ & $\mathrm{S}$ & $\mathrm{NS}$ & $\mathrm{NS}$ & 0 & & & \\
$\mathbf{8}$ & $\mathrm{S}$ & $\mathrm{S}$ & $\mathrm{NS}$ & $\mathrm{S}$ & $\mathrm{S}$ & 0 & & \\
$\mathbf{9}$ & $\mathrm{S}$ & $\mathrm{S}$ & $\mathrm{NS}$ & $\mathrm{S}$ & $\mathrm{S}$ & $\mathrm{NS}$ & 0 & \\
$\mathbf{1 1}$ & $\mathrm{S}$ & $\mathrm{S}$ & $\mathrm{NS}$ & $\mathrm{S}$ & $\mathrm{S}$ & $\mathrm{NS}$ & $\mathrm{NS}$ & 0 \\
\hline
\end{tabular}

Al realizar una observación particular de los ítems registrados en los CDsil se encontraron aquellos que pueden considerarse de "reemplazo" (ninfas, estadíos juveniles y partes de adultos de insectos), sólo en el verano y en el invierno, y en muy bajas proporciones.

Al comparar los CDsil con la AZL, teniendo en cuenta los momentos de muestreo, se encontraron diferencias (ANOSIM anidado de dos vías, $R=0,985 ; p<0,05$ ). El SIMPER indicó que los ítems discriminantes de dichas diferencias fueron $B$. havanaensis y las larvas nauplii de copépodos, ambos por presentar altas AZL y estar casi ausentes en los CDsil. El índice de selectividad de Strauss permitió indagar un poco más en estas diferencias, identificando aquellos ítems hacia los cuales el pejerrey mostró selectividad positiva dependiendo de su talla y la fecha de muestreo (Tabla VII.2).

Tabla VII.2: Especies seleccionadas positivamente por los pejerrreyes silvestres según su talla y la fecha de muestreo y los respectivos valores del índice de selectividad de Strauss

\begin{tabular}{lclc}
\hline Fecha (mes/año) & $\begin{array}{c}\text { Talla promedio } \\
\text { (cm de LT) }\end{array}$ & \multicolumn{1}{c}{ Ítem seleccionado } & $\begin{array}{c}\text { Índice de } \\
\text { Strauss }\end{array}$ \\
\hline \hline Febrero/2009 & 3,5 & $\begin{array}{l}\text { Brachionus plicatilis } \\
\text { Bosmina huaronensis }\end{array}$ & 0,40 \\
\hline Febrero/2009 & \multirow{2}{*}{5} & $\begin{array}{l}\text { Brachionus calyciflorus } \\
\text { Acanthocyclops robustus }\end{array}$ & 0,23 \\
\hline Marzo/2009 & 8,5 & Moina micrura & 0,21 \\
\hline Marzo/2009 & 11 & M. micrura & 0,15 \\
\hline Julio/2009 & 3,5 & Copepoditos Cyclopoida & 0,45 \\
\hline Marzo/2010 & 8,5 & M. micrura & 0,38 \\
\hline Octubre/2010 & 2 & B. calyciflorus & 0,54 \\
\hline
\end{tabular}


Se realizaron comparaciones entre los CDsil y los contenidos digestivos de los pejerreyes criados en jaulas flotantes (CDjau) de fechas y tallas equivalentes. Los resultados, expresados en la tabla VII.3, muestran que no hubo diferencias entre los CD comparados en febrero, marzo y julio de 2009, ni tampoco en marzo de 2010 cuando se comparó los CDsil con los CDjau del tratamiento de menor densidad (ANOSIM, p>0,05), pero sí las hubo al comparar los CDsil con los CDjau de los tratamientos de 50 y 75 ind./ $\mathrm{m}^{3}$ (capítulo VI) (ANOSIM, R = 0,99; $p<0,05$ ). Dichas diferencias correspondieron con un 75 y un $78 \%$ de disimilitud, respectivamente (SIMPER), siendo los ítems responsables de las diferencias $A$. robustus y $N$. incompositus, en ambos casos por tener elevadas abundancias en los CDjau y estar ausentes en los CDsil comparados.

Tabla VII.3: Resultado de los análisis ANOSIM comparando los contenidos digestivos de pejerreyes silvestres versus aquellos criados en jaulas considerando todos los ítems encontrados en fechas y tallas comparables.

\begin{tabular}{cccc}
\hline $\begin{array}{c}\text { Fecha } \\
\text { (mes/año) }\end{array}$ & $\begin{array}{c}\text { Densidad } \\
\text { (individuos/m3) }\end{array}$ & $\begin{array}{c}\text { Rango de tallas } \\
\text { (cm de LT) }\end{array}$ & ANOSIM \\
\hline \hline Febrero/2009 & 42 & 3 a 5 & $\mathrm{p}>0,05$ \\
Marzo/2009 & 42 & 6 a 11 & $\mathrm{p}>0,05$ \\
Julio/2009 & 42 & 2 a 3 & $\mathrm{p}>0,05$ \\
Marzo/2010 & 25 & 8 a 9 & $\mathrm{p}>0,05$ \\
Marzo/2010 & 50 & 7 a 8 & $\mathrm{p}<0,05 *$ \\
Marzo/2010 & 75 & 7 a 8 & $\mathrm{p}<0,05 *$ \\
\hline
\end{tabular}




\subsection{Discusión}

La existencia de zooplancton mediano y grande en los CD de pejerreyes silvestres de pequeño tamaño en La Salada hace pensar que el tamaño de la boca no les estaría restringiendo su consumo. La escasa representatividad de la clase III en las dos primeras tallas de pez ( 1 y $2 \mathrm{~cm}$ de LT) y el aumento proporcional de estas tallas de presas a medida que los peces crecen (Figura VII.1) hace pensar que aunque no estén restringidos por el tamaño de la boca, sí lo estarían por la capacidad de encuentro y manipulación de dichas presas. Esta capacidad de encuentro, manipulación e ingesta sería entonces no sólo dependiente de las habilidades natatorias de los peces (los peces de 1 y $2 \mathrm{~cm}$ de LT tienen un radio de acción mucho menor) y de las capacidades de escape de los ítems zooplanctónicos (los más grandes son más difíciles de capturar), sino también de la disponibilidad de presas. Los resultados indican que existiría un punto de inflexión en la dieta de los pejerreyes a los 2 cm de LT, a partir de la cual ingieren el plancton de mayor porte, que no estaría condicionado por el tamaño de la boca. Este punto de inflexión estaría sujeto a la oferta en el sistema y no a la capacidad de las postlarvas en capturar y consumir estas presas, las cuales aparecen en los CD en distintos momentos, sin embargo sería necesario realizar experimentos que permitan esclarecer aún más el tema. La vinculación con la disponibilidad ambiental coincide con lo registrado en las cavas en los experimentos de estacionalidad (capítulo V), y además con lo observado en el año 2010 (Figura VII.4), donde las tallas más pequeñas de pejerrey consumieron grandes cantidades de zooplancton II y III, lo que pudo estar vinculado con su disponibilidad en la época correspondiente con esos ejemplares (primavera de 2010, con abundantes copépodos y cladóceros de talla II y III).

A partir de las comparaciones realizadas (Tabla VII.1 y Figura VII.4, por ejemplo) se podría interpretar la existencia de otros puntos de inflexión en la dieta (por ejemplo al superar los $5 \mathrm{~cm}$ ), pero al estudiar dichos resultados en el contexto de la abundancia zooplanctónica se puede concluir que en realidad son puntos que dependerían de la disponibilidad de alimento. De acuerdo a la estación del año el pejerrey de vida libre puede incorporar mayores proporciones de ítems zooplanctónicos de mediano y gran tamaño (II y III) cuando alcanza los $3 \mathrm{~cm}$ de LT (en la primavera, con elevada disponibilidad de zooplancton de buena calidad) o recién cuando supera los $5 \mathrm{~cm}$ de LT (en verano e invierno, con escasa representatividad de zooplancton grande en el ambiente). Es decir que a la vista 
de los resultados, a los $3 \mathrm{~cm}$ de LT, la especie podría tomar un camino u otro (seguir consumiendo zooplancton pequeño o pasar a consumir presas mayores), de acuerdo a la disponibilidad en cantidad y calidad de zooplancton. Estas observaciones demuestran la gran plasticidad que posee la especie en relación a su desarrollo alimentario. Esta plasticidad alimentaria pudo comprobarse también al calcular el índice de selectividad de Strauss ya que permitió identificar diferentes ítems zooplanctónicos seleccionados positivamente por los pejerreyes de diferentes tallas y en diferentes momentos del año, aunque siempre eligiendo presas de talla I y II cuando tuvieron menos de $5 \mathrm{~cm}$ de LT (B. plicatilis, B. calyciflorus, B. huaronensis y copeditos Cyclopoida) y presas de talla III al superar esa longitud (A. robustus, y M. micrura).

Los CD de los pejerreyes silvestres presentaron ítems de reemplazo sólo en bajas proporciones y en las estaciones consideradas más desfavorables para las lagunas pampásicas. Estas desventajas se vuelven relativas al observar que el pejerrey logra obtener buenos crecimientos en dicha estación (capítulo $V$ ), a pesar de las elevadas temperaturas y bajas AZL III. De este resultado se desprende que durante el verano los pejerreyes silvestres están consumiendo el zooplancton mediano y grande a pesar de las bajas abundancias, ya que si bien se necesitan al menos 1000 ind $\mathrm{L}^{-1}$ no es sólo la cantidad sino la calidad del zooplancton lo que importa, y es por ello que en momentos de escases numérica los crecimientos de los peces fueron altos, porque se alimentaron de presas de alta calidad en términos de C:N:P. De todos modos, la escasa AZL III durante el verano puede deberse también a que el consumo por parte de los peces planctívoros se da a velocidades suficientemente elevadas como para que estos ítems casi no aparezcan en las muestras de zooplancton del ambiente, lo cual sería interesante testear en futuros trabajos. Lo que ocurre en el invierno por otra parte, se puede vincular con que efectivamente se trata de una estación desfavorable para el crecimiento, ante la baja productividad de las lagunas pampásicas por las bajas temperaturas, pero con especies zooplanctónicas que en algunos de estos ambientes logran tener sus picos de abundancia precisamente en el invierno (copépodos Calanoida en Lacombe, en Colautti et al. 2010), lo que hace que el pejerrey tenga la posibilidad de lograr buenas tasas de crecimiento a pesar de las condiciones. El hecho de que los llamados "ítems de reemplazo" no aparezcan en los CD de los peces criados en las jaulas no es un problema entonces, considerando que sus proporciones en los CD de los 
pejerreyes silvestres son tan bajas, y considerando el hecho de que se han obtenido buenas tasas de crecimiento en verano (capítulo V) y en invierno (Colautti et al. 2010).

La comparación entre los CDsil y CDjau arrojó dos resultados diferentes (Tabla VII.2), por un lado casos donde no hubo diferencias entre la dieta de los pejerreyes libres y los confinados a las jaulas y dos casos donde sí se encontraron diferencias. Esto último ocurrió al comparar los CDsil con los CDjau de pejerreyes criados a las densidades más altas (50 y 75 ind. $\left./ \mathrm{m}^{3}\right)$, correspondientes a los muestreos realizados en marzo de 2010 , donde la dieta de los pejerreyes silvestres de talla comparable estuvo compuesta por un 95\% de Moina micrura en promedio, y la de aquellos pertenecientes a los tratamiento T2 y T3 del experimento de densidades fue mucho más diversa, con promedios de 45,8\% de Copepoda Cyclopoida, $36,8 \%$ Harpacticoida, $13,2 \%$ Rotifera y 4,1\% Cladocera en T2 y $60 \%$ Rotifera, $24,8 \%$ Cyclopoida y 15,6\% Cladocera en T3. Estos resultados indican por un lado la fuerte selección que han hecho los pejerreyes silvestres hacia ese cladócero, y por el contrario la mayor diversidad en la dieta que presentan aquellos confinados a 50 y 75 ind. $/ \mathrm{m}^{3}$, resultado de una mayor competencia por los recursos y diferente disponibilidad de presas resultante, dentro y fuera de las unidades experimentales.

Los cladóceros tienen niveles altos de $\mathrm{P}$ y este elemento es muy necesario durante el crecimiento. Desde un punto de vista estequiométrico, los pejerreyes en plena etapa de crecimiento, y de tasas altas, necesita mucho $\mathrm{P}$, con lo cual las especies seleccionadas serán aquellas que sean ricas en este nutriente, en este caso M. micrura.

En cuanto a la diversificación en la dieta, ante una mayor restricción provocada por el confinamiento, el pejerrey tiene la posibilidad de ampliar su espectro trófico y diferenciarse en su alimentación de aquellos de vida libre, compensando la falta de ítems ricos en nutrientes ingiriendo otros de menor calidad. Es decir que incluso en el caso de que durante el confinamiento ocurra la eliminación de las presas más convenientes nutricionalmente, el pejerrey puede compensar este desbalance ingiriendo más presas de menor calidad nutricional. En este sentido, si la densidad de cría es menor a 50 ind. $/ \mathrm{m}^{3}$ las restricciones disminuyen, y su alimentación resulta similar a la de los pejerreyes silvestres. Resultados similares se observaron en las postlarvas criadas en cavas durante el otoño (capítulo V).

Los resultados obtenidos al comparar las dietas de pejerreyes silvestres con aquellos confinados en las jaulas proveen nuevos criterios que permiten monitorear si los ejemplares bajo cultivo están realizando un aprovechamiento eficiente de los recursos alimentarios 
disponibles. En este sentido, se observó que la alimentación de los pejerreyes cultivados presentó diferencias con la de los silvestres sólo en los momentos donde escaseó el alimento y cuando estuvieron confinados a altas densidades de cría, situación que provoca una elevada competencia por los recursos. Por este motivo, sería recomendable realizar monitoreos de esta naturaleza durante el cultivo, ya que si consideramos como "controles" a los ejemplares silvestres, al detectar diferencias con la dieta de los ejemplares cultivados, será necesario realizar ajustes (como variar la densidad) y así maximizar la eficiencia del sistema de cultivo.

Por último, considerando al desarrollo alimentario como la sucesión de cambios enlos hábitos de alimentación de las especies, se concluye que en el pejerrey existe un único cambio que se da a los $2 \mathrm{~cm}$ de LT, el cual le brinda una ventaja adaptativa, ya que le permite un rápido acceso al zooplancton más rico en términos nutricionales. 


\section{VIII}

CONCLUSIONES

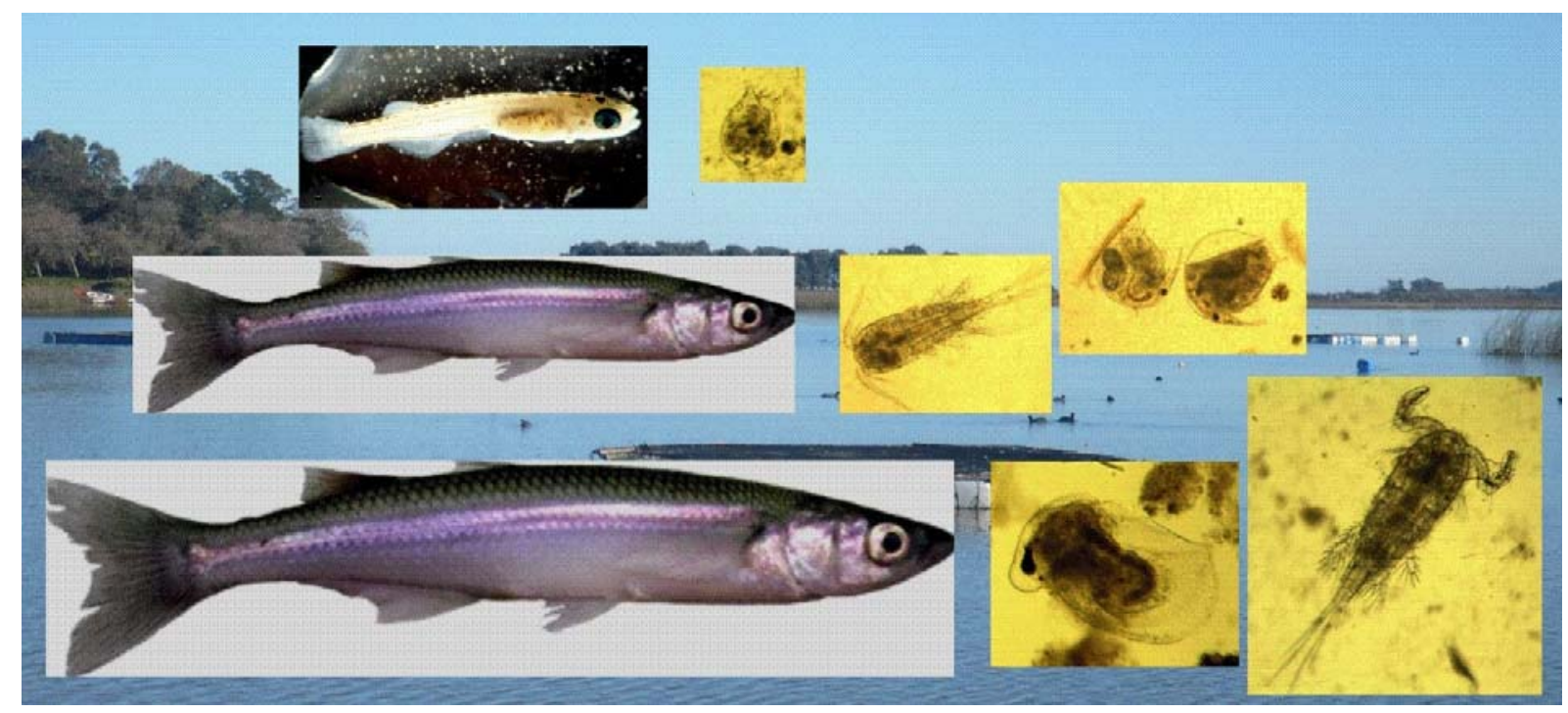




\section{Capítulo VIII: CONCLUSIONES}

Los experimentos realizados en la presente tesis permiten concluir sobre aspectos de la ecología trófica del pejerrey y el vínculo que esta especie posee con la comunidad zooplanctónica de las lagunas de la región Pampeana, y proveen elementos para perfeccionar la acuicultura extensiva de pejerrey en jaulas flotantes.

\subsection{Obtención de postlarvas de pejerrey en cavas}

- Si bien el invierno queda descartado para la obtención de postlarvas de pejerrey (ya que no hay eclosión en ese momento del año), existen efectos provocados por la estacionalidad que deben ser tenidos en cuenta en el manejo y la optimización de la obtención de postlarvas de pejerrey, para mejorar el aprovechamiento de los recursos:

Ante la relación hallada entre la cantidad y calidad del zooplancton y las diferencias en el crecimiento y supervivencia de las postlarvas, resulta fundamental el seguimiento exhaustivo de la comunidad zooplanctónica.

Ante la marcada influencia de la estacionalidad, resulta de gran importancia determinar los momentos ideales de llenado de las cavas y siembra de las larvas, así como definir las condiciones inadecuadas (aquellas presentes en el otoño). La elección de estos "momentos ideales" dependerá del destino de las postlarvas. Si el objetivo es que sean transportadas a jaulas flotantes para el cultivo de juveniles de manera extensiva, los parámetros de la primavera (ciclo 1 en el capítulo V) son las que permiten un mejor aprovechamiento de los recursos:

Llenado de cavas: 30 días antes de la finalización del invierno (22/08)

Siembra de las larvas: inicio de la primavera (26/09)

AZ óptima: > 1000 ind./l, compuesta principalmente por rotíferos.

Esto se define porque en la primavera se obtuvo la mejor supervivencia, directamente vinculada con altos valores de $A Z$, y porque a pesar de haber sido registrados mayores $A Z$, 
BZ, LT y W en el ciclo 2 (principios del verano), las postlarvas de dicho ciclo pasarían a la laguna en un momento menos favorable (mediados del verano).

- Las postlarvas de pejerrey presentan selectividad alimentaria desde el comienzo de la alimentación exógena, con preferencia por consumir rotíferos hasta los 1,5-2 cm (LT).

- Los importantes cambios en las limitaciones y necesidades alimentarias que presentan las postlarvas de pejerrey durante su desarrollo temprano, deben ser tenidos en cuenta para optimizar la eficiencia de las técnicas de producción de la especie. Dichas limitaciones y necesidades se vinculan con su talla y la disponibilidad, concluyendo que hasta no tener 1,5-2 cm (LT) el pejerrey no puede acceder a ítems de más de 0,7 mm (talla III).

\subsection{Cría extensiva de juveniles de pejerrey en jaulas flotantes}

La realización de diversos experimentos de cría de pejerrey en jaulas flotantes, utilizando sistemas que dependen enteramente del alimento natural, ha permitido incrementar la comprensión del vínculo "zooplancton-pejerrey" en lagunas pampásicas, y mejorar el rendimiento de este sistema de cría lográndose identificar y aislar dos tipos de variables de influencia, las extrínsecas al sistema y las intrínsecas al mismo:

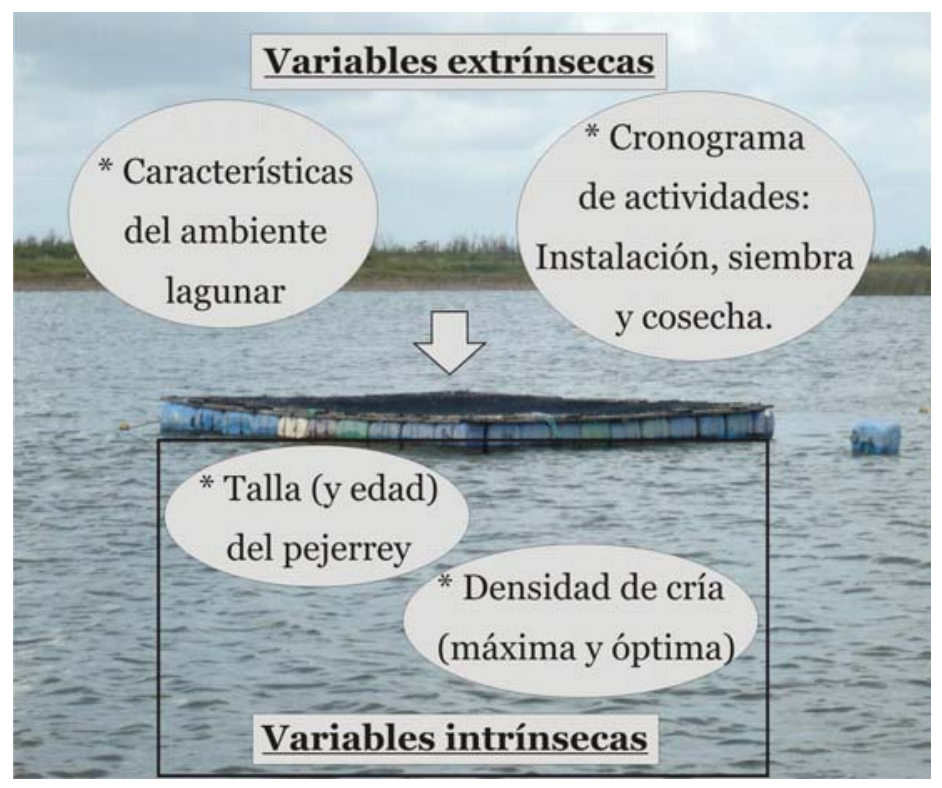




\subsubsection{La calidad del zooplancton en la cría extensiva de pejerrey}

La evaluación del efecto que tienen las mencionadas variables de influencia sobre la comunidad zooplanctónica resultó muy importante a la hora de definir los "dónde" y los "cuándo" del sistema de cría extensiva de pejerrey en jaulas flotantes, ya que los métodos de regulación de las poblaciones animales deben ser conocidos en la búsqueda de entender su naturaleza y poder predecir su comportamiento (Hairston et al. 1960). El estudio del zooplancton de lagunas pampásicas permitió además acuñar el término "calidad" referido al zooplancton disponible como alimento natural en la cría del pejerrey:
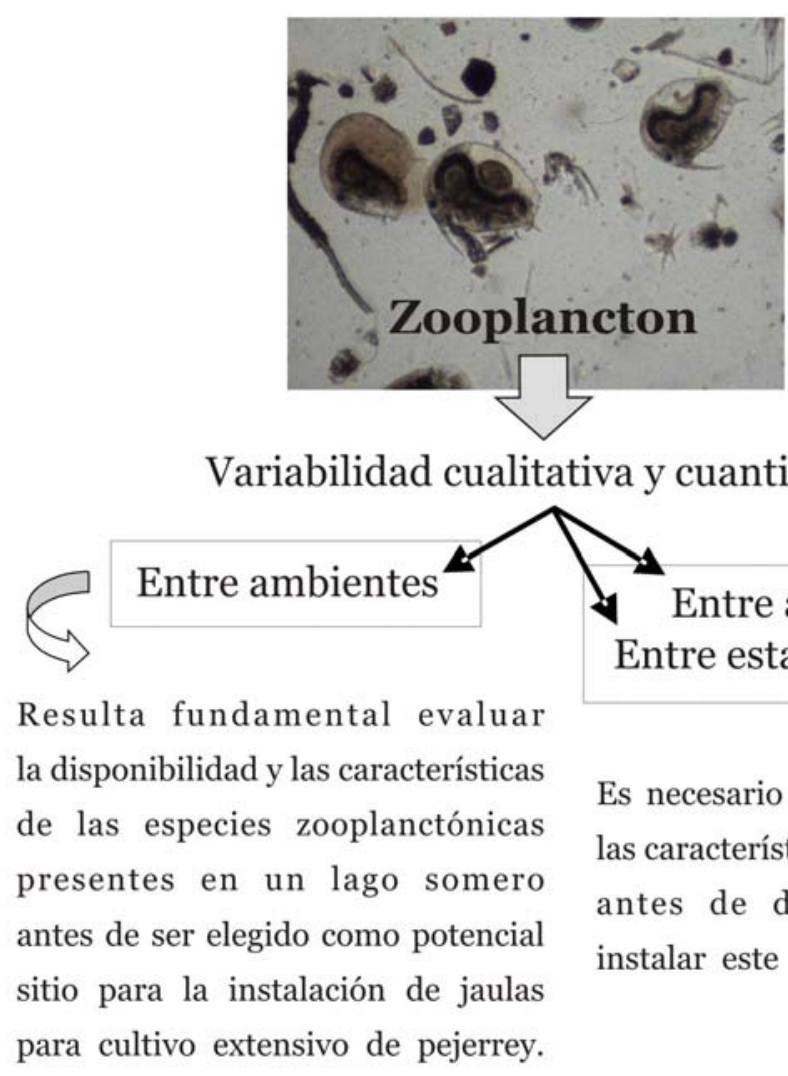

Es necesario tener en cuenta las características estacionales antes de decidir cuándo instalar este sistema de cría.

- A mayores biomasas zooplanctónicas totales, y mayor representatividad de especies zooplanctónicas grandes, se obtienen mejores tasas de crecimiento y producciones en la cría extensiva de pejerrey en jaulas.

Existen determinados ítems de la comunidad zooplanctónica que serían "mejores" como alimento del pejerrey (y por ende de otros peces zooplanctívoros) y cuya representatividad determinará la calidad del 
zooplancton. Dicha calidad dependerá de las características ambientales (estequiometría ambiental en la relación C:P:N), de la estacionalidad y de la estructura del ensamble íctico del ecosistema lagunar.

- La elevada presión de planctivoría que existe en estos ambientes fue evidenciada en el hecho de que las JB en La Salada (capítulo VI) presentaron presas de clase III durante todo el experimento, mientras que en el ambiente habían sido removidas. Las JB funcionaron como un refugio contra la depredación, mostrando que tanto en la laguna como en las JP la planctivoría es intensa y elimina al plancton grande.

- La biomasa de la categoría III de zooplancton (copépodos y cladóceros de más de $0,7 \mathrm{~mm}$ ) es lo que más influye sobre las tasas de crecimiento de los peces.

- El pejerrey muchas veces se inclinó por una especie de copépodo Cyclopoida (A. robustus), y en algunos casos donde la oferta de cladóceros fue elevada lo hizo hacia la especie C. dubia, cuando los peces tuvieron entre 46 y 67 días de vida (4,5-7,5 cm de LT) (capítulo IV, experimento 4, etapa experimental).

- La selección dirigida hacia $A$. robustus se dio en la mayoría de los casos, incluso a pesar de tener oferta de cladóceros y otros copépodos en la laguna La Salada [excepto a tallas pequeñas (capítulo IV), en épocas desfavorables (capítulo V) y a altas densidades de cría (capítulo VI)].

- En condiciones desfavorables (lagunas con baja oferta de microcrustáceos, estaciones climáticas como el otoño o el invierno, y densidades de cría muy elevadas como 75 ind. $/ \mathrm{m}^{3}$ ) los pejerreyes tienen la posibilidad de ampliar su espectro trófico como un intento de mantener la calidad de alimento elevada.

\subsubsection{La ecología trófica del pejerrey y su vínculo con la producción}

Los resultados del estudio de los contenidos digestivos y las comparaciones entre la oferta y lo consumido permiten arribar a conclusiones acerca de la composición de la dieta en términos de proporción de presas y la selectividad en la alimentación del pejerrey. 


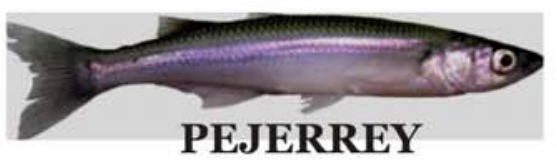

\section{Proporción de categorías de tamaño de presa}

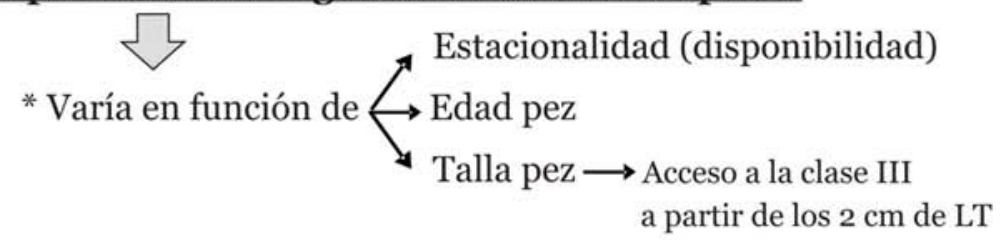

\section{Selectividad alimentaria}

* Desde el comienzo de la alimentación exógena

* Condicionada en las etapas más tempranas por la accesibilidad

Dieta monofágica los primeros días de vida dirigida a los rotíferos

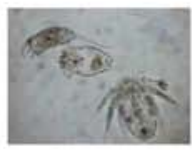

Esto sugiere que el tamaño apropiado para el manejo de primera alimentación de esta especie debe tener menos de $300 \mu \mathrm{m}$

* Está dirigida a los ítems de mayor tamaño a partir de los $2 \mathrm{~cm}$ de LT

* Depende de $\rightarrow$ Disponibilidad de zooplancton

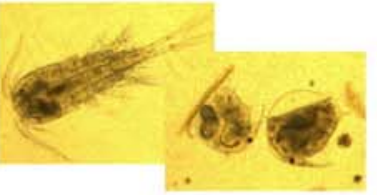
II Oferta zooplanctónica 』ISelectividad \Amplitud trófica Puede provocar la ingesta de ítems de reemplazo, como en el otoño (capítulo V) o en pejerreyes silvestres (VII)

Compensación $\longrightarrow$ Plasticidad en el desarrollo alimentario $\longrightarrow$ Competencia intraespecífica (aumenta con la densidad)

- A menor densidad prefirieron consumir zooplancton de mayor tamaño, independientemente de su edad.

- A mayores densidades consumieron ítems de pequeño y mediano tamaño.

- Existe una relación negativa entre TMP y densidad de pejerrey

Estas observaciones permiten asegurar la presencia de competencia por el alimento y de la utilización de los rotíferos como alimento alternativo cuando el pejerrey está siendo mantenido a altas densidades de cría

\section{Amplitud de nicho trófico}

* Aumenta en función del tamaño del pez y la densidad de cría 
- La selectividad alimentaria dirigida hacia los ítems de mayor tamaño se ha registrado también en otros peces planctívoros (Zaret 1980, Mageed \& Konsowa 2002), y particularmente en otros peces Neotropicales de agua dulce con selectividad hacia cladóceros y copépodos, y un consumo insignificante de rotíferos y protozoarios (Prieto Guevara \& Atencio-Garcia 2008); tal es el caso de Brycon siebenthalae (Yamú), Prochilodus magdalenae (Bocachico), Piaractus mesopotamicus (Pacú), Colossoma macropomum (Tambaqui) y Prochilodus scrofa (Curimba) (Atencio-Garcia et al. 2003a, Atencio-Garcia et al. 2003b, Fregadolli 1990, Pelli et al. 1996).

- El pejerrey criado extensivamente en jaulas, al superar el punto de inflexión de los 2 cm de LT, seleccionó para su consumo zooplancton de gran porte que representa un gran aporte nutricional: N. incompositus (Chascomús, verano 2008), A. robustus (Chascomús, primavera/verano de 2008/2009, La Salada, primavera/verano de 2008/2009 y verano de 2010), B. huaronensis (La Salada, verano 2008, primavera/verano de 2008/2009 y otoño 2009), C. dubia (La Salada, primavera/verano de 2008/2009). Esta preferencia por zooplancton grande puede deberse a una mayor eficiencia en el balance energético, ya que diversos estudios han mostrado que el consumo de zooplancton de mayor tamaño puede dar mejores tasas de crecimiento y sobrevivencia (Portella et al. 1997, Atencio-Garcia et al. 2003).

- La observación acerca del tamaño apropiado como primera alimentación no es coincidente con lo conocido para otras especies neotropicales como el bagre blanco (Sorubim cuspicaudus), que según Alcala \& Ortega (2002) comienza comiendo copépodos y cladóceros entre 250 y $450 \mu \mathrm{m}$. El tamaño apropiado para las postlarvas de pejerrey corresponde a rotíferos y larvas nauplii, a pesar de que estas últimas fueron muy pocas veces encontradas en los CD. Dichos ítems zooplanctónicos pequeños resultan adecuados para la primera alimentación de la especie, pero serían insuficientes para satisfacer las demandas energéticas de juveniles y adultos. Otros autores han observado que el elevado cociente entre área y volumen que presentan las presas pequeñas facilita la asimilación de la energía en el caso de las post-larvas, a pesar de su reducida eficiencia gástrica (Mills et al 1984, Zagarese 1991). 


\subsubsection{Manejo adaptativo del cultivo de pejerrey en jaulas flotantes, enfoque ecosistémico}

- Las tasas de crecimiento y la biomasa de peces producida de modo extensivo en las jaulas está regulada por la disponibilidad de zooplancton en cantidad y calidad.

El estudio de los CD y las TCE en conjunto, demuestra también la importancia del zooplancton de talla III: El consumo de elevadas proporciones de zooplancton III (>80\%) tiende a maximizar las TCE de manera exponencial (individuos de 76 y 113 días en el capítulo VI), mientras que aquellos que consumen principalmente las tallas I y II (>50\%) son menos eficientes, ya que esta fracción del zooplancton les alcanza casi únicamente para mantenerse vivos cuando superan los $4 \mathrm{~cm}$ de LT.

El modelo de regresión múltiple obtenido en el capítulo VI podría ser útil para predecir el crecimiento del pejerrey en jaulas flotantes, y refuerza la importancia de la elección de un ambiente lagunar con BZ de más de $200 \mu \mathrm{g}$ de zooplancton de clase III (buena calidad) para la instalación de un sistema de cultivo en jaulas exitoso (Capítulo IV).

- La densidad óptima de cultivo para el pejerrey dependerá del objetivo al que se oriente la cría: maximizar el crecimiento individual, la producción de biomasa o el número de peces por jaula.

\section{Considerando:}

Objetivos del sistema de cría

Composición cuali-cuantitativa del zooplancton

Manejo adecuado de las densidades de cría

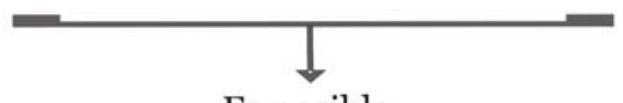

Es posible:

Controlar el crecimiento

Controlar la cantidad de individuos producidos

Maximizar la biomasa por unidad de cultivo 


\subsection{La estructuración del zooplancton debida a la ecología trófica del pejerrey}

Teniendo en cuenta las variables que regulan la estructura de la comunidad zooplanctónica (temperatura, alimento y depredación), la Hipótesis de Eficiencia por Tamaño y los resultados obtenidos en el presente trabajo en lo referido a la selectividad alimentaria del pejerrey, se llega a las siguientes conclusiones:

- La selectividad alimentaria del pejerrey tiene un efecto notable sobre la estructura de la comunidad zooplanctónica en las jaulas, mientras que en la laguna debe sumarse su efecto al de otros peces planctívoros y la carga de larvas del sistema.

Así como se demostró que el pejerrey tiene la plasticidad suficiente para adaptarse a diferentes disponibilidades de alimento de modo de poder mantener sus tasas de crecimiento altas, en el zooplancton ocurren recambios de especies tendientes a mantener una estructura de tallas similar con diferentes especies dominantes.

- Existen efectos altamente complejos en la definición del mecanismo de selección (como el encuentro, la captura y la ingesta, que definen la accesibilidad hacia las presas, la cual a su vez depende del tamaño de pez y de la disponibilidad de las presas), que se reflejan por ejemplo en la elección diferencial por tallas o sexos de $A$. robustus, señalada en el capítulo VI.

\subsection{Consideraciones finales}

En relación con las hipótesis planteadas en el capítulo I de esta tesis, se puede decir que efectivamente el pejerrey efectúa un uso selectivo de los recursos, y que este uso tiene efectos sobre la comunidad zooplanctónica. De acuerdo a las comparaciones realizadas entre las jaulas con peces y aquellas sin peces (JB) en el capítulo $V$, las modificaciones que se generan en el zooplancton por la planctivoría estarían vinculadas sobre todo con la reducción de la talla media del zooplancton, y por consiguiente con una modificación en la representatividad de las diferentes especies (por ejemplo en las JP los cladóceros llegaron a ser eliminados). Es por eso que se observaron mayores valores de BZ en las JB que en las JP, lo cual es coincidente con lo postulado con la SEH. Por otro lado, lo establecido por la teoría 
"match-mismatch" acerca del tamaño y cantidad de alimento ideal concuerda con lo observado en este trabajo para el pejerrey. La disponibilidad de alimento, que varía a lo largo del tiempo, junto con el tamaño del pez, determina la accesibilidad del pejerrey a las diferentes tallas de presa, y esta estacionalidad influye sobre el crecimiento del pez, lo cual se vincula con la segunda hipótesis.

Con respecto a la segunda hipótesis, quedó demostrado un efecto de la estacionalidad en el crecimiento del pejerrey, y esto estuvo mediado por la disponibilidad de alimento de alta calidad. Se demostró cómo la composición del zooplancton incide en la supervivencia y las tasas de crecimiento del pejerrey bajo cultivo extensivo, lo cual condujo a determinar los momentos más propicios para la instalación de jaulas (primavera y verano).

En relación con la tercera hipótesis, resulta claro que se puede determinar un umbral de biomasa de pejerrey en jaulas a partir del cual su producción depende más de la cantidad y calidad de zooplancton, específicamente de aquel compuesto por copépodos y cladóceros (A. robustus y C. dubia), que de la densidad de cría (capítulo VII).

Los resultados obtenidos demuestran que las similitudes y diferencias encontradas entre el zooplancton de la laguna y el de las jaulas dependen de varios factores como: el tiempo desde la instalación de las jaulas, el tamaño (y la edad) de los peces, la época del año y la densidad de pejerrey, factores que fueron cambiando a lo largo de los experimentos realizados.

Las lagunas estudiadas presentan características limnológicas y comunidades zooplanctónicas similares a otras lagunas pampásicas (Claps et al. 2004, Colautti et al. 2010, Diovisalvi et al. 2010). Por ende, los resultados sugieren que el método de cría extensiva de pejerrey en jaulas flotantes puede ser aplicado en otras lagunas de la región. Previo a la instalación de un sistema de dichas características emerge como un paso fundamental la evaluación cuali-cuantitativa de la comunidad zooplanctónica que permita obtener una medida de la disponibilidad de alimento que posee el ambiente. De esa manera será posible determinar la sustentabilidad que puede tener el cultivo extensivo de pejerrey en jaulas en dicho ambiente. Esto último vale para los diferentes estadíos de desarrollo ontogenético de la especie, ya sea para la obtención de postlarvas en jaulas nursery o para la cría de juveniles de hasta un año de vida en jaulas con malla de tipo mosquitero y/o antigranizo. Del mismo modo, dicha evaluación previa permitirá decidir la densidad de siembra adecuada en pos de optimizar el aprovechamiento de los recursos disponibles. 
Por otro lado, resulta importante realizar un seguimiento durante el proceso de cultivo, que incluya no sólo el estudio del zooplancton del ambiente sino el análisis de los contenidos digestivos, a intervalos regulares de tiempo. Esto hará posible corroborar efectivamente la distribución por clases de tamaño de los ítems alimentarios y de este modo conocer no sólo la calidad del alimento disponible sino la de aquel al que efectivamente estén accediendo los peces. Esto además permitirá establecer si la densidad de cultivo es la apropiada para aprovechar eficientemente los recursos disponibles, ya que en este trabajo se demuestra que la especie amplía el nicho trófico cuando el alimento preferido no es suficiente. Este mecanismo de evaluación es una herramienta que potencialmente brindaría los criterios para maximizar la eficiencia del sistema de cultivo. Los resultados de las regresiones múltiples confirman además que esta información ( $B Z L$ y $C D$ ) resulta útil para predecir las tasas de crecimiento y la producción en los cultivos de pejerrey en jaulas.

Finalmente, se observa que el método de cría extensiva se podría incorporar en el ciclo de producción del pejerrey para sobrepasar algunas de las limitaciones que existen actualmente utilizando los métodos intensivos tradicionales. En relación a las densidades de cultivo se concluye que manejando las densidades de cría de un modo dinámico, y teniendo en cuenta las características del zooplancton y de la dieta de los peces, resulta viable optimizar en tiempo real la eficiencia de la acuicultura extensiva del pejerrey en jaulas. A su vez resulta posible centrar los objetivos del sistema en maximizar el crecimiento, la producción o el número final, de acuerdo con las necesidades del acuicultor. Por ello, la densidad óptima de cultivo dependerá de los objetivos a alcanzarse. En otras palabras, de acuerdo con Costa-Pierce \& Page (2012), los resultados obtenidos dan la pauta de que sería posible llevar a cabo un manejo adaptativo basado en los cambios ecosistémicos, y esto podría ser la clave para el desarrollo de una acuicultura ecológica (basada en el ecosistema) para la especie. Este modelo de cría de peces más moderno, que tiene en cuenta las influencias del ambiente sobre el cultivo, emerge como un paso necesario de dar a la hora de desarrollar nexos entre ambiente y sociedad, y promover roles complementarios en la acuicultura que contribuyan con la sustentabilidad, la rehabilitación y la mejora de los cuerpos de agua, y que incrementen la educación y la participación pública. 


\subsection{Perspectivas a futuro}

Teniendo en cuenta los resultados obtenidos en este trabajo resultaría interesante continuar el estudio de la ecología del pejerrey y de los ambientes donde vive, y optimizar el sistema de cría de pejerrey en jaulas flotantes, mediante:

- Novedades tecnológicas que puedan ser incorporadas al sistema: paneles de iluminación que atraen al zooplancton de noche (Fermin et al. 1996), bombas que colectan y concentran el zooplancton circundante (Skrzypczak et al. 1998), etc.

- Determinación de los momentos del año y las tallas de pejerrey óptimas para realizar el pasaje de un sistema de tipo extensivo a uno semi-intensivo (Colautti et al. 2009a, Solimano 2013).

- Intensificación en el estudio de los mecanismos alimentarios del pejerrey y así comprender de un modo más claro su carácter de zooplanctívoro (visual o no) y los efectos que su depredación tiene sobre la comunidad zooplanctónica.

- Estudio de los parámetros bioenergéticos de la especie (Beauchamp et al. 2007).

- Profundización del estudio del ecosistema lagunar y de las variables de influencia sobre el sistema de cría, en pos de alcanzar el desarrollo de una acuicultura ecológica que pueda ser transferida a la comunidad. 


\section{Bibliografía}

Alaimo S. \& Freyre L.R. 1969. Resultados sobre la estimación de la numerosidad de peces en la laguna Chascomús (Provincia de Buenos Aires). Physis 29 (78):197-212.

Alcalá A., Ortega A. 2002. Influencia de la densidad de siembra y la alimentación en la larvicultura del bagre blanco Sorubim cuspicaudus (Littmann, Burr \& Nass, 2000). Trabajo de Pregrado. Monteria, Colombia: Universidad de Córdoba.

Allende L., Tell G., Zagarese H., Torremorell A., Pérez G., Bustingorry J., Escaray R. \& Izaguirre I. 2009. Phytoplankton and primary production in clear-vegetated, inorganic-turbid, and algal-turbid shallow lakes from the pampa plain (Argentina). Hydrobiologia 624:45-60.

Andersen T. \& Hessen D.O. 1991. Carbon, Nitrogen, and Phosphorus Content of Freshwater Zooplankton. Limnology and Oceanography 36(4): 807-814.

APHA. 1995. Standard Methods for Analysis of Water and Wastewater, 19 edn. American Public Health Association, Washington, DC, USA.

Aquino A.E. 1991. Alimentación de Odontesthes bonariensis (Cuv. \& Val., 1835) (Osteichthyes, Atherinidae) en el embalse El Candillal (Tucumán, Argentina). Biología Acuática 15 (2): 176-177.

Ardohain D.M. 2008. Respuesta del zooplancton en su estructura y dinámica a factores clave en una laguna arreica (pcia. de Buenos Aires). Tesis doctoral N 961. Facultad de Ciencias Naturales y Museo (UNLP). $272 \mathrm{pp}$.

Arthur D.K. 1976. Food and feeding of larvae of three fishes occurring in the California current, Sardinops sagax, Engraulis mordax, and Trachurus symmetricus. Fish. Bull. 74: 517-530.

Atencio-García V.J., Kerguelen E., Wadnipar L., Narvaez A. 2003a. Manejo de la primera alimentación del bocachico (Prochilodus magdalenae). Rev MVZ Córdoba 8(1): 254-60.

Atencio-Garcia V.J., Zaniboni-Filho E., Pardo-Carrasco S.C., Arias-Castellanos A. 2003b. Influência da primeira alimentação na larvicultura e alevinagem do yamú Brycon siebenthalae (Characidae). Maringá, Brasil. Acta Scientiarum. Animal Sciences 25(1): 61-72.

Baigún C.R.M., Colautti D.C. \& Grosman F. (2009) Assessment of condition in pejerrey Odontesthes bonariensis (Atheriniformes: Atherinopsidae) populations: which index works best? Neotropical Ichthyology, 7(3): 439-446.

Balseiro E., Modenutti B., Queimaliños C. \& Reissig M. 2007. Daphnia distribution in Andean Patagonian lakes: effect of low food quality and fish predation. Aquat. Ecol. 41: 599-609.

Barcellos L.G., Kreutz L.C., Quevedo R.M., Fioreze I., Cericato L., Soso A.B., Fagundes M., Conrad J., Krammer Baldfisera R., Bruschi A. \& Ritter F. 2004. Nursery rearing of jundiá Rhamdia quelen (Quoy \& Gaimard) in cages: cage type, stocking density and stress response to confinement. Aquaculture 232: 383-394. 
Barros S. E., Regidor H. \& Iwaszkiw J. 2004. Biología pesquera del Pejerrey Odontesthes bonariensis (Cuvier y Valenciennes, 1835) en el subtrópico de Argentina. Revista AquaTIC 20: 32-37.

Bayne D.R., Joshi P.L., Rai A.K., William J.C. 1991. Growth and food habits of cage-cultured bighead carp X silver carp hybrids in ponds or varying trophic status. Aquaculture 1: 45-55.

Beauchamp D.A., Wahl, D. H. \& Johnson B. M. 2007. Predator-Prey Interactions. In: Analysis and Interpretation of Inland Fisheries Data, 961pp (edited by C.S. Guy, M.L. Brown) 765-842.

Begon M., Townsend C. R. \& Harper J. L. 2006. Ecology. From individuals to ecosystems. Cuarta edición. Blackwell Publishing. 759 pp.

Benítez H.H. \& Claps M.C. 2000. Zooplancton de una laguna pampásica (Monte) y su afluente (El Totoral). Caracterización estructural en un ciclo anual. Diversidad y Ambiente 1: 87-96.

Berasain G.E. \& Colautti D.C. 1999. Laguna Salada de Monasterio, partido de Chascomús. Campaña de relevamientos limnológicos e ictiológicos. Informe Técnico. Dirección de desarrollo pesquero. Subsecretaria de Pesca y Recursos Naturales. Buenos Aires, Argentina.

Berasain G.E., Colautti D.C., Remes Lenicov M. \& Velasco C.A. 2005. Variaciones estacionales e históricas de las especies ícticas de la laguna Chascomús. Biología Acuática 22:47-58.

Berasain G.E., Velasco C., Shiroyo Y., Colautti D. \& Remes Lenicov M. 2006. Cultivo intensivo de juveniles de pejerrey (Odontesthes bonariensis) en estanques. Actas del IV Congreso Iberoamericano Virtual de Acuicultura. http://www.civa2006.org (accessed 1 April 2008).

Berasain G.E., Velasco C., Mir F. \& Padin D. 2008. Producción intensiva de ovas embrionadas de pejerrey (Odontesthes bonariensis) a partir de reproductores mantenidos en cautiverio. Biología Acuática 24: 1116.

Berlow E.L., Dunne J.A., Martinez N.D., Stark P.B., Williams R.J., \& Brose U. 2009. Simple prediction of interaction strengths in complex food webs. PNAS 106: 187-191.

Beveridge M.C.M. \& Little D.C. 2002. Aquaculture in traditional societies. In: Ecological Aquaculture (Ed. By B.A. Costa-Pierce), 3-29. Blackwell, Oxford.

Beveridge M.C.M. 2004. Cage Aquaculture. Tercera edición. Blackwell Publishing, Oxford, UK, 346pp.

Blumenshine S.C. \& Hambright K.D. 2003. Top-Down in pelagic systems: a role for invertebrate predation. Hydrobologia: 347-356.

Bollens S.M., Frost B.W., Schwaninger H.R., Davis C.S., Way K.J. \& Landsteiner M.C. 1992. Seasonal plankton cycles in a temperate fjord and comments on the match-mismatch hypothesis. Journal of Plankton Research 14(9): 1279-1305.

Boltovskoy A., Dippolito A., Foggetta M., Gómez N. \& Alvarez G. 1990. La laguna Lobos y su afluente: limnología descriptiva, con especial referencia al plancton. Biología Acuática 14: 3-38.

Bonetto A.A. \& Castello H.P. 1985. Pesca y piscicultura en aguas continentales de América Latina. Secretaria General de la Organización de los Estados Americanos, Washington, DC, USA, 118pp. 
Borer E.T., Seabloom E.W., Shurin J.B., Anderson K.E., Blanchette C.A., Broitman B., Cooper S.D. \& Halpern B.S. 2005. What determines the strength of a trophic cascade?Ecology 86(2): 528-537.

Bottrell H.H., Duncan A., Gliwicz Z.M., Grygierek E., Herzig A., Hillbricht-Ilkowska A., Kurasawa H., Larsson P. \& Weglenska T. 1976. A review of some problems in zooplankton production studies. Norwegian Journal of Zoology 24: 419-456.

Boveri M. B. \& Quirós R. 2002. Trophic interactions in pampean shallow lakes: Evaluation of silverside predatory effects in mesocosm experiments. Verh. Internat. Verein. Limnol. 28: 1-5.

Boveri M. B. 2008. Estudios experimentales en mesocosmos para el desarrollo de técnicas de biomanipulación aplicables a lagunas de la región central de Argentina. Tesis de doctorado. Facultad de Agronomía (UBA).

Bowen S. H. 1996. Quantitative description of the diet. 513-532 in: B. R. Murphy and D. W. Willis, editors. Fisheries techniques, $2^{\text {nd }}$ edition. American Fisheries Society, Bethesda, Maryland.

Brandl Z. 1998. Feeding strategies of planktonic cyclopoids in lacustrine ecosystems. Journal of Marine Systems 15: 87-95.

Brett M.T. \& Goldman C.R. 1996. A meta-analysis of the freshwater trophic cascade. Proc. Natl. Acad. Sci. 93: 7723-7726.

Brooks J.L. \& Dodson S.L. 1965. Predation, body size, and composition of plankton. Science 150: 28-35.

Bulleri F., Chapman M.G. \& Underwood A.J. 2005. Intertidal assemblages on seawalls and vertical rocky shores in Sydney Harbour, Australia. Austral Ecology 30: 655-667.

Cabrera A.L. 1971. Fitogeografía de la República Argentina. Bol. Soc. Arg. Bot. 14: 1-43.

Calvo J. \& Morriconi E. 1972. Fenómenos reproductivos en el pejerrey (Basilichthys bonariensis). III. Estudio de la fecundidad, época y número de desoves. Anales de la Sociedad Científica Argentina 93: 75-84.

Carpenter S.R, Kitchell J.F. \& Hodgson J.R. 1985. Cascading Trophic Interactions and Lake Productivity. BioScience 35(10): 634-639.

Carpenter, S.R. \& Kitchell J.F. 1996. The trophic cascade in lakes. Cambridge University Press, Cambridge, 399 pp.

Casco M.A., Mac Donagh M.E., Cano M.G., Solari L.C., Claps M.C. \& Gabellone N.A. 2009. Phytoplankton and Epipelon Responses to Clear and Turbid Phases in a Seepage Lake (Buenos Aires, Argentina). Internat. Rev. Hydrobiol. 94(2): 153-168.

Chamberlain G.W. 1978. The Use of Caged Fish for Mariculture and Environmental Monitoring in a Power Plant Cooling Water System. MSc thesis, Texas A \& M University, College Station, TX.

Chang K.H. \& Hanazato T. 2005. Impact of selective predation by Mesocyclops pehpeiensis on a zooplankton community: experimental analysis using mesocosms. Ecol. Res. 20: 726-732.

Charnov E.L., Turner T.F. \& Winemiller K.O. 2001. Reproductive constraints and the evolution of life histories with indeterminant growth. Proc. Natl. Acad. Sci. U.S.A. 98: 9460-9464. 
Chick J.H. \& Van den Avyle M.J. 1999. Effects of Zooplankton Spatial Variation on Growth of Larval Striped Bass: An Experimental Approach. Transactions of the American Fisheries Society 128: 339-351.

Chornomaz E.M., Etchepare M.E, Escaray R.V., Bustingorry J.F. \& Conzonno V.H. 2002. Efectos de la inundación ocurrida durante el año 2001 sobre la laguna de Chascomús (Pcia. de Buenos Aires): 53-59 en: Fernández Cirelli, A \& G Chalar Marquisá (eds.). El agua en Iberoamérica. De la limnología a la gestión en Sudamérica. Buenos Aires: CYTED XVII, Centro de estudios Transdiciplinrios del Agua, Facultad de Ciencias Veterinarias.

Claps M., Benítez H. \& Gabellone N. 2002. Vertical distribution of zooplankton in a pampasic shallow lake (Argentina). Verh. Inter. Ver. Limnol. 28: 1032-1036.

Claps M.C., Gabellone N.A. \& Benítez H.H. 2004. Zooplankton biomass in an eutrophic shallow lake (Buenos Aires, Argentina): spatio-temporal variations. Annales de Limnologie. International Journal of Limnology 40: 201-210.

Clarke K.R. \& Warwick R.M. 2001. Change in Marine Communities: An Approach to Statistical Analysis and Interpretation. $2^{\text {nd }}$ Edition. PRIMER-E: Plymouth.

Colautti D. \& Remes lenicov M. 2000. Primeros resultados sobre cría de pejerreyes (Odontesthes bonariensis) en jaulas, Crecimiento, supervivencia, producción y alimentación. En: Fundamentos Biológicos, Económicos y Sociales para una correcta gestión del recurso pejerrey. Ed. Fabián Grosman. 212p.

Colautti D.C., Garcia de Souza J.R. \& Miranda L. 2009a. Sistema de cultivo mixto en jaulas y estanques para el pejerrey Odontesthes bonariensis. Biología Acuática 26: 47-54.

Colautti D.C., Garcia de Souza J.R., Balboni L. \& Baigún C.R.M. 2010. Extensive cage culture of pejerrey (Odontesthes bonariensis) in a shallow pampean lake in Argentina. Aquaculture Research 41: 376-384.

Colautti D.C., Garcia de Souza J.R., Solimano P.J., Maiztegui T. \& Baigún C.R.M. 2009b. Influencia de la estacionalidad ambiental sobre el cultivo extensivo de juveniles de pejerrey Odontesthes bonariensis en lagunas pampeanas. Libro de resúmenes de la 2da Conferencia Latinoamericana sobre Cultivo de Peces Nativos. Chascomús, Argentina.

Colautti D.C., Remes Lenicov M. \& Berasain G. 2003. Vulnerabilidad del pejerrey Odontesthes bonariensis a la pesca deportiva en función de su condición. Biología Acuática 20: 49-55.

Cortés E. 1997. A critical review of methods of studying fish feeding based on analysis of stomach contents: application to elasmobranch fishes. Canadian Journal of Fisheries and Aquatic Sciences 54: 726-738.

Cortés E. 1999. Starndardized diet compositions and trophic levels of sharks. ICES Journal of Marine Science 56: 707-717.

Costa-Pierce B.A. \& Effendi P. 1988. Sewage fish cages of Kota Cianjur, Indonesia. NAGA 11(2): 7-9.

Costa-Pierce B.A. 2002. Sustainability of cage aquaculture ecosystems for large-scale resettlement from hydropower dams: an Indonesian case study. In: Ecological Aquaculture (Ed. By B.A. Costa-Pierce), 286313. Blackwell, Oxford. 
Costa-Pierce B.A. and G.G. Page. 2012. Sustainability science in aquaculture, p. 564-581. In: Costa-Pierce B.A. (ed.) Ocean Farming and Sustainable Aquaculture Science and Technology. Encyclopedia of Sustainability Science and Technology. Springer Science, N.Y.

Cottenie K. 2002. Local and regional processes in a zooplancton metacommunity. Tesis doctoral de la Universidad de Leuven. Belgium. 189pp.

Coulibaly A., Ouattara I.N., Kone. T., N'Douba V., Snoeks J., Goore. Bi G. \& Kouame.lan E.P. 2007. First results of floating cage culture of the African catfish Heterobranchus longiclis (Valenciennes 1840): efect of stocking density on survival and growth rates. Aquaculture 263: 61-67.

Cushing D. H. 1972. The production cycle and the numbers of marine fish In: Edwards, R. W., Garrod, D.J. (eds.) Conservation and productivity of natural waters. Pergamon Press, Oxford, p. 213-232.

Cushing D.H. 1990. Plankton production and year-class strength in fish populations: an update of the match/mismatch hypothesis. Advances in Marine Biology 26: 250-293.

Dabrowski K. \& Bardega R. 1984. Mouth size and recommendation of feed size preferences in three cyprinid fish. Aquaculture 40: 27-40.

Dangavs N.V., Blasi A.M. \&. Merlo D.O. 1996. Geolimnología de la laguna Chascomús, Provincia de Buenos Aires, Argentina. Revista Mus. La PLata (NS), Geología XI. (113): 167-195.

Dangavs, N.V. 1976. Descripción sistemática de los parámetros morfométricos considerados en las lagunas pampásicas. Limnobios 1 (2): 35-59.

De Melo \& Hebbert. 1994. A taxonomic reevaluation of the North American Bosminidae. Can. J. Zool. 72: 18081825.

Destefanis S. \& Freyre L. 1972. Relaciones tróficas de los peces de la laguna de Chascomús con un intento de referenciación ecológica y tratamiento bioestadístico del espectro trófico. Acta Zoológica Lilloana XXIX.

Diovisalvi N., Berasain G., Unrein F., Colautti D., Fermani P., Llames M., Torremorell A., Lagomarsino L., Pérez G., Escaray R., Bustingorry J., Ferraro M., \& Zagarese H. 2010. Chascomús: estructura y funcionamiento de una laguna pampeana turbia. Ecología Austral 20: 115-127.

Diovisalvi N. 2013. Estructura y dinámica del zooplancton en una laguna turbia: Laguna Chascomús. Trabajo de tesis doctoral. Facultad de Ciencias Exactas y Naturales, Universidad Nacional de Mar del Plata.

Diovisalvi N., Bohn V.Y., Piccolo M.C., Perillo G.M.E., Baigún C.R.M. \& Zagarese H.E. 2014. Shallow lakes from the Central Plains of Argentina: an overview and worldwide comparative analysis of their basic limnological features. Hydrobiologia. DOI 10.1007/s10750-014-1946-x.

Dodson S.E. 1970. Complementary feeding niches sustained by size-selective predation. Limnol. Oceanogr. 15: 131-137.

Drago F.B. 2004. Dinámica estacional y ecología de las poblaciones de parásitos del pejerrey, Odontesthes bonariensis (Cuvier \& Valenciennes, 1835), en lagunas de la provincia de Buenos Aires. Tesis doctoral. Facultad de Ciencias Naturales y Museo. UNLP. 
Drener R.W. \& Kettle F.D. 1982. Selective impact of filter-feeding gizzard shad on zooplankton community structure. Limnol. Ocenaogr. 27(5): 965-968.

Drenner R.W. \& Hambright K.D. 2002. Piscivores, trophic cascades and lake management. The Scientific World Journal 2: 284-307.

Dumont H.J. 1994. On the diversity of the Cladocera in the tropics. Hydrobiologia 272: 27-38.

Dumont H.J., Van De Velde I. \& Dumont S. 1975. The dry weight estimate of biomass in a selection of Cladocera, Copepoda and Rotifera from the plankton, periphyton and benthos of continental waters. Oecología (Berl.) 19: 75-97.

Eggers D.M. 1977. The nature of prey selection by planktivorous fish. Ecology 58(1): 46-59.

El-Sayed A.M. 2002. Effects of stocking density and feeding levels on growth and feed efficiency of Nile tilapia (Oreochromis niloticus L.) fry. Aquaculture Research 33: 621-626.

Escalante A.H. 1985. Alimentación del pejerrey Basilichthys bonariensis bonariensis (Osteichthyes: Atherinidae) del Embalse de Río Tercero, provincia de Córdoba. Neotrópica 31(85): 22-26.

Escalante A.H. 2001. Alimentación natural del pejerrey. En: Fundamentos biológicos, económicos y sociales para la correcta gestión del recurso pejerrey (ed. F. Grosman), 67-75. Editorial Astyanax, Azul, Argentina.

Eskinazi-Sant Anna E.M., Menezes R., Soares Costa I., Panoso R.F., Florêncio Araújo M. \& de Attayde J.L. 2007. ComposiÇao da comunidade zooplanctônica em reservatórios eutróficos do semi-arido do Rio Grande do Norte. Oecol. Bras. 11(3): 410-421.

Fabián D. \& Cruz-Pizarro L. 1997. Variaciones espaciales y temporales del zooplancton en un lago monomíctico eutrófico (Lago Ton-Ton, Uruguay). Liminetica 13(1): 55-68.

Feniova I.Y., Palash A.L., Razlutskij V.I., Dzialowski A.R. 2013. Effects of temperature and resource abundance on small- and large-bodied cladocerans: Community stability and species replacement. Open Journal of Ecology 3(2): 164-171.

Fermin A., Bolivar M. E. C. \& Gaitan A. 1996. Nursery rearing of the Asian sea bass, Lates calcacifer, fry in illuminated floating net cages with different feeding regimes and stocking densities. Aquat. Living Resour. 9: 43-49.

Fernández Cirelli, A \& P Miretzky. 2002. Lagos poco profundos de la Pampa Argentina. Relación con aguas subterráneas someras. 43-52 en: Fernández Cirelli, A \& G Chalar Marquisá (eds.). El agua en Iberoamérica. De la limnología a la gestión en Sudamérica. Buenos Aires: CYTED XVII, CETA - Centro de estudios Transdiciplinarios del Agua, Facultad de Ciencias Veterinarias.

Fex de Santis R. 1991. Crecimiento y sobrevivencia de larvas de cachama (Colossoma macropomum) con alimento vivo y no vivo. Boletín Red de Acuicultura 5(2): 9-12.

Frank K.T. \& Leggett W.C. 1982. Effect of prey abundance and size on the growth and survival of larval fish: an experimental study employing large volume enclosures. Mar. Ecol. Prog. Ser. 34: 11-22. 
Fregadolli CH. 1990. Estudo comparativo do comportamento alimentar de larvas de pacu Piaractus mesopotamicus (Holmberg, 1887) e Tambaqui Colossoma macropomum (Cuvier, 1818) em laboratório. Dissertação. (Tesis de Maestria) Salvador BA. Universidade Federal da Bahia.

Frenguelli J. 1950. Rasgos generales de la morfología y la geología de la Provincia de Buenos Aires. LEMIT. La Plata, Buenos Aires. Serie II (33): 1-72.

Freyre L.R., Colautti D.C., Maroñas M.E., Sendra E.D. \& Remes Lenicov M. 2009. Seasonal changes in the somatic indices of the freshwater silverside, Odontesthes bonariensis (Teleostei, Atheriniformes) from a Neotropical shallow lake (Argentina). Braz. J. Biol. 69(2): 389-395.

Freyre L.R., Maroñas M.E., Mollo S.M., Sendra E.D. \& Dománico A.A. 2003. Variaciones supra-anuales de la ictiofauna de lagunas bonaerenses Biología Acuática 20(63).

Fukushima M., Takamura N., Sun L., Nakagawa M., Matsushige K. \& Xie P. 1999. Changes in the plankton community following introduction of filter-feeding planktívorous fish. Freshwater Biology 42: 719-735.

Fukusho K. 1989. Biology and mass production of the rotifer, Brachionus plicatilis. International Journal of Aquaculture and Fisheries Technology 1: 232-240.

Gabellone N.A., Solari L.C. \& Claps M.C. 2001. Planktonic and physical-chemical dynamics of a markedly fluctuating backwater pond associated with a lowland river (Salado River, Buenos Aires, Argentina). Lakes \& Reservoirs 6:133-142.

Gannon J.E. 1971. Two counting cells for the enumeration of zooplankton microcrustacea. Transactions of the American Microscopy Society 90: 486-490.

Garcia de Souza J.R., Solimano P.J., Maiztegui T., Baigun C.R.M. \& Colautti D.C. 2009. Selectividad alimentaria en postlarvas de pejerrey (Odontesthes bonariensis) criadas bajo régimen de cultivo extensivo. II Conferencia sobre el Cultivo de Peces Nativos. 2 y 3 de noviembre, Chascomús, Bs. As. Argentina.

Garcia de Souza J.R., Solimano P.J., Maiztegui T., Baigún C.R.M. \& Colautti D.C. 2013. Effects of stocking density and natural food availability on the extensive cage culture of pejerrey (Odontesthes bonariensis) in a shallow Pampean lake in Argentina. Aquaculture Research doi:10.1111/are.12286.

Geiger J. G. 1983. A review of pond zooplankton production and fertilization for the culture of larval and fingerling striped bass. Aquaculture 35: 353-369.

Geiger J. G., Turner C.J., Fitzmayer K. \& Nichols W.C. 1985. Feeding habits of larval and fingerling striped bass and zooplankton dynamics in fertilized rearing ponds. Progressive Fish-Culturist 47: 213-223.

Geiger J.G. \& Turner C.J. 1990. Pond fertilization and zooplankton management techniques for production of fingerling striped bass and hybrid striped bass. In: Culture and Propagation of Striped Bass and its Hybrids. R. M. Harrell, J. H. Kerby and R. V. Minton (Editors).Striped Bass Committee, Southern Division, American Fisheries Society, Bethesda, MD. 323 pp.

Ghersa C.M., Ferraro D.O., Omacini M., Martınez-GhersamM.A. \& Perelman S. 2002. Farm and landscape level variables as indicators of sustainable land-use in the Argentine Inland-Pampa. Agric. Ecosyst. Environ. 
93(1-3): 279-293.

Gibtan A., Getahun A. \& Mengistou S. 2008. Effect of stocking density on the growth performance and yield of Nile tilapia [Oreochromis niloticus (L., 1758)] in a cage culture system in Lake Kuriftu, Ethiopia. Aquaculture Research 39: 1450-1460.

Gillooly J.F. \& S.I. Dodson 2000. Latitudinal patterns in the size distribution and seasonal dynamics of new world, freshwater cladocerans. Limnology and Oceanography 45: 22-30.

Gliwicz Z.M. \& Pijanowska J. 1989. The role of predation in zooplankton succession. P. 253-296. En; U. Sommer (ed). Plankton Ecology. Springer-Verlag.

Gomes L.C., Campos Chagas E., Martins-Junior H., Roubach R., Akifumi Ono E. \& Lourrenço J.N.P. 2006. Cage culture of tambaqui (Colossoma macropomum) in a central Amazon floodplain lake. Aquaculture 253: 374-384.

González de Infante A. 1988. El plancton de las aguas continentales. Secretaría General de la Organización de los Estados Americanos. Programa Regional de Desarrollo Científico y Tecnológico. Serie de Biología. Monografía N³3. 130pp.

González Sagrario M.A. \& Balseiro E. 2003. Indirect enhancement of large zooplankton by consumption of predacious macroinvertebrates by litoral fish. Arch. Hydrobiol. 158: 551-574.

González Sagrario M.A. 2004. Rol de las macrófitas sumergidas en las interacciones tróficas de lagos someros. Tesis doctoral. Universidad Nacional del Comahue.

González Sagrario M.A., Balseiro E., Ituarte R \& Spivak E. 2009. Macrophytes as refuge or risky area for zooplankton: a balance set by littoral predacious macroinvertebrates. Freshwater Biology 54: 10421053.

González Sagrario M.A. \& Balseiro E. 2010. The role of macroinvertebrates and fish in regulating the provision by macrophytes of refugia for zooplankton in a warm temperate shallow lake". Freshwater Biology 55: 2153-2166.

Grosman F. 1995a. El pejerrey. Ecología, cultivo, pesca y explotación. Ed. Astyanx, 132 pp.

Grosman F. 1995b. Variación estacional en la dieta del pejerrey Odontesthes bonariensis. Rev. Asoc. Cienc. Nat. Litoral 26(1): 9-18.

Grosman F., Sanzano P., Agüeria D., González G. \& Sergueña S. 2001. Ecología reproductiva, edad, crecimiento, condición y alimentación del pejerrey (Odontesthes bonariensis) en un ambiente del SO de la provincia de Buenos Aires, Argentina. Revista AquaTIC nº 12.

Grosman F. \& Sanzano P. 2003. ¿El pejerrey puede causar cambios estructurales en un ecosistema? Biología Acuática 20: 2003-37.

Gutreuter S. \& Childress W.M. 1990. Evaluation of condition indices for estimation of growth of largemouth bass and white crappie. North American Journal of Fisheries Management. 10: 434-441. 
Gyllström M., Hansson L.-A., Jeppesen E., García-Criado F., Gross E., Irvine K., Kairesalo T., Kornijow R., Miracle M.R., Nykänen M., Noges T., Romo S., Stephen D., Van Donk E. \& Moss B. 2005. The role of climate in shaping zooplankton communities of shallow lakes. Limnology and Oceanography 50(6): 2008-2021.

Hairston N.G. 1988. Interannual variation in seasonal predation: Its origin and ecological importance. Limnol. Oceanogr. 33(6, part 1): 1245:1253.

Hairston N.G., Smith F.E. \& Slobodkin L.B. 1960. Community Structure, Population Control, and Competition. The American Naturalist 94(879): 421-425.

Hairston N.G., Walton W.E. \& Kao T.L. 1983. The causes and consequences of' sex-specific mortality in a freshwater copepod. Limnol. Oceanogr. 28(5): 935-947

Hall A.J., Rebella C.M., Ghersa C.M. \& Culot J. 1992. Field-crops systems of the pampas. En: Field Crop Ecosystems (ed Pearson C.J.), pp. 413-450. Elsevier, New York.

Hart R.C. 1986. Zooplankton abundance, community structure and dynamics in relation to inorganic turbidity, and their implications for a potential fishery in subtropical Lake Le-Roux, South-Africa. Freshwater Biology 16: 351-371.

Havens K.E \& Beaver J.B. 2010. Composition, size, and biomass of zooplankton in large productive Florida lakes. Hydrobiologia. DOI: 10.1007/s10750-010-0386-5.

Havens K.E., Elia A., Taticchi M. \& Fulton R. 2009. Zooplankton-phytoplankton relationships in shallow subtropical versus temperate lakes Apopka (Florida, USA) and Trasimeno (Umbria, Italy). Hydrobiologia 628: $165-175$.

Hengsawat K., Ward F.J. \& Jaruratjamorn P. 1997. The effect of stocking density on yield, growth and mortality of African catfish (Clarias gariepinus Burchell 1822) cultured in cages. Aquaculture 152: 67-76.

Hessen D.O. 2008. Efficiency, energy and stoichiometry in pelagic food webs; reciprocal roles of food quality and food quantity. Freshwater Reviews 1: 43-57.

Hessen D.O., Elser J.J., Sterner R.W. \& Urabe J. 2013. Ecological stoichiometry: An elementary approach using basic principles. Limnology and Oceanography 58(6): 2219-2236.

Hjort J. 1914. Fluctuations in the great fisheries of northern Europe reviewed in the light of biological research. Rapp. P.-V. Réun. Cons. Int. Explor. Mer . 20: 1-228.

Hopkins K.D. 1992. Reporting fish growth: A review of the basics. Journal of the World Aquaculture Society 23(3): 173-179.

Houde E.D. \& Zastrow C.E. 1993. Ecosystem- and taxon-specific dynamic and energetics properties of larval fish assemblages. Bull. Mar. Sci. 53: 290-335.

Houde E.D. 1987. Fish early life dynamics and recruitment variability. Amer. Fish. Sot. Symposium 2: 17-29.

Hrbáček J., Dvorakova V., Korinek \& Prochazkova L. 1961. Demonstration of the effect of the fish stock on the species composition of zooplankton and the intensity of metabolism of the whole plankton association. Verh. int. Ver. Limnol. 14: 192-195. 
Hrbáček J. 1962. Species composition and the amount of the zooplankton in relation to the fish stock. Rozpr. CSAV, Ser. Mat. Nat. Sci. 72 (10): 1-117.

Hurlbert S.H. \& Mulla M.S. 1981. Impacts of mosquitofish (Gambusia affinis) predation on plankton communities. Hydrobiologia 83:125- 151.

Hurlbert S.H. 1984. Pseudoreplication and the design of ecological field experiments. Ecological Monographs 54: 187-211.

Hyslop E., J. 1980. Stomach contents analysis, a review of methods and their application. J. Fish Biol. 17: 411429.

Iglesias C. 2010. Cascading effects of predators in temperate and subtropical shallow lakes. PhD Thesis. Faculty of Sciences AARHUS University.

Iglesias C., Mazzeo N., Meerhoff M., Lacerot G., Clemente J.M., Scasso F., Kruk C., Goyenola G., García-Alonso J., Amsinck S.L., Paggi J.C., José de Paggi S. \& Jeppesen E. 2011. High predation is of key importance for dominance of smallbodied bzooplankton in warm shallow lakes: evidence from lakes, fish exclosures and surface sediments. Hydrobiologia 667: 133-147.

INDEC. 2010. Censo Nacional de Población, Hogares y Viviendas 2010 http://www.censo2010.indec.gov.ar/index cuadros 2.asp).

Iriondo MH. 1989. Quaternary lakes of Argentina. Paleogeogr. Paleoclimateol. Paleoecol. 70: 81-88.

Islam M.S., Rahman M.M. \& Tanaka M. 2006. Stocking density positively influences the yield and farm profitability in cage aquaculture of sutchi catfish, Pangasius sutchi. J. Appl. Ichthyol. 22: 441-445.

Iwaszkiw J.M. \& Freyre L.R.. 1980. Fecundidad del pejerrey Basilichthys bonariensis bonariensis (Pisces Atherinidae) del embalse río Tercero, Córdoba. Limnobios 22(1): 36-49.

Jeppesen E. 1998. The Ecology of Shallow Lakes - Trophic Interactions in the Pelagial. Libro. Ministry of Environment and Energy. National Environmental Research Institute.

Jeppesen E., Jensen J.P., Sondergaard M., Lauridsen T., Petersen L.J. \& Jensen L. 1997. Top-down control in freshwater lakes: role of nutrient state, submerged macrophytes and water depth. Hydrobiologia 342/343: 151-164.

Jeppesen E., Søndergaard M., Jensen J.P., Mortensen E., Hansen A. \& Jørgensen T. 1998. Cascading trophic interaction from fish to bacteria and nutrients after reduced sewage loading: An 18-year study of a shallow hypertrophic lake. Ecosystems 1: 250-267.

Kane J. 1984. The feeding habits of co-occurring cod and haddock larvae from Georges Bank. Marine Ecology Progress Series 16: 9-20.

Kerfoot W.C. \& Sih A. 1987. Predation: Direct and indirect impacts on aquatic communities. Editors. University Press of New England. 386 pp.

Koste W. 1978. Rotatoria. Die Radertiere Mitteleuropas. Uberordnung Monogononta. Suttgart: 1-629.

Kottek M., Grieser J., Beck C., Rudolf B., \& Rubel F. 2006. World map of Koppen-Geiger climate classification 
updated. Meteorologische Zeitschrift 15: 259-263.

Kozlowski J., Mamcarz A., Poczyczynski P \& Dostatni D. 2000. Feeding of tank-cage and cage reared whitefish in two lakes of different trophic status. Folia Universitatis Agriculturae Stetinensis 27: 125-134.

Kulikivsky Z., Wohlfarth G.W. \& Avtalion R.R. 1994. The association between weight and growth in tilapias during communal testing. II. Cage testing. Israeli Journal of Aquaculture 46: 89-94.

Lacerot G., 2010. Effects of climate on size structure and functioning of aquatic food webs. PhD thesis, Wageningen University: 98.

Lampert W. \& Sommer U. 1997. Limnoecology. Oxford University Press.

Lawrence S.G., Malley D.F., Findlay W.J., Maciver M.A, \& Delbaere I.L. 1987. Method for estimating dry weight of freshwater planktonic crustaceans from measures of length and shape. Can. J.Fish. Aquat. Sci. 44: 267274.

Lazzaro X. 1987. A review of planktivorous fishes: Their evolution, feeding behaviours, selectivities, and impacts. Hydrobiologia 146: 97-167.

Lazzaro X. 1997. Do the trophic cascade hypothesis and classical biomanipulation approaches apply to tropical lakes and reservoirs? Verhandlungen der internationale Vereiningung für Limnologie 26: 719-730.

Leatherland J.F. \& Cho C.Y. 1985. Effect of rearing density on thyroid and interrenal gland activity and plasma hepatic metabolite levels in rainbow trout, Salmo gairdneri, Richardson. J. Fish. Biol. 27: 583-592.

Levins R. 1968. Evolution in Changing Environment. Princenton, New Jersey, USA.

Little D. \& Muir J. 1987. A guide to integrated warm water aquaculture. Insitute of Aquaculture Publications, University of Stirling, Scotland.

Llames M.E., Lagomarsino L., Diovisalvi N., Fermani P. \& Torremorell A.M. 2009. The effects of different degrees of light availability in shallow, turbid waters: a mesocosm study. J. Plankton Res. 31(12): 1517-1529.

López H.L. \& García M.L 2001. Aspectos históricos e importancia regional del pejerrey bonaerense, In: Fundamentos biológicos, económicos y sociales para una correcta gestión del recurso pejerrey (ed. By F. Grosman), pp.15-20. Editorial Astyanax, Buenos Aires, Argentina.

Lowry D. \& Motta P.J. 2007. Ontogeny of feeding behavior and cranial morphology in the whitespotted bambooshark Chiloscyllium plagiosum. Mar. Biol. 151: 2013-2023.

Magurran A.E. 2004. Measuring biological diversity. Blackwell Science Ltd. 215 pp.

Maier G. 1998. Differential success of cyclopoid copepods in the pelagic zone of eutrophic lakes. Journal of Marine Systems 15: 135-138.

Maizels P., Etchepare E., Chornomaz E., Bustingorry J., Escaray R. \& Conzonno V. 2003. Parámetros abióticos y biomasa planctónica en la Laguna Chascomús (Pcia de Buenos Aires). Período de inundación 2002. Biología Acuática 20:6-11.

Mamczarz A. \& Nowak M. 1987. New version of an illuminated cage for coegonid rearing. Aquaculture 65: 183188. 
Mancini M., Nicola I, Salinas V. \& Bucco C. 2009. Biology of silverside Odontesthes bonariensis (Pisces, Atherinopsidae) in the shallow lake "Los Charos" (Córdoba, Argentina). Rev. peru. biol. 15(2): 065-071.

Maroñas ME. 1984. Relevamiento pesquero de cuencas naturales. Informe final de pasantía otorgada por la Comisión de Investigaciones Científicas del a Provincia de Buenos Aires.

Masser M. \& Bridger C. J. 2007. A review of cage aquaculture: North America. In: Cage Aquaculture edited by Halwart M, Soto D \& Arthur J. R. FAO, Rome 105-123.

Masser M.P. 2012. Cage culture in freshwater and protected marine areas. En: Aquaculture production systems (Chaper 6). Edited by James H. Tidwell. John Wiley \& Sons, Inc. 421pp. 2121 State Avenue, Ames, Iowa 50014-8300, USA.

Matthews W.J. 1998. Patterns in freshwater fish ecology. Library of Congress Cataloging-in-Publication Data. $668 \mathrm{pp}$.

Mazzeo N., Iglesias C., Teixeira-de Mello F., Borthagaray A., Fosalba C., Ballabio R., Larrea D., Vilches J., García S., Pacheco J. \& Jeppesen E. 2010. Trophic cascade effects of Hoplias malabaricus (Characiformes, Erythrinidae) in subtropical lakes food webs: a mesocosm approach. Hydrobiologia 644: 325-335.

Mc Cauley E. 1984. The estimation of the abundance and biomass of zooplankton in samples. In : Downing \& Rigler (eds), A manual on methods for the assessment of secondary productivity in fresh waters, IBP 17, Blackwell Scientific Publications : 228-265

Mcqueen D.J., Post J.R. \& MILLS E.L. 1986. Trophic relationships in freshwater pelagic ecosystems. Can. J. Fish. aquat. Sci. 43: 1571-1581.

Meerhoff M., Clemente J., Teixeira de Mello F., Iglesias C., Pedersen A.R. \& Jeppesen E. 2007a. Can warm climate-related structure of littoral predator assemblies weaken the clear water state in shallow lakes? Global Change Biology 13: 1888-1897.

Meerhoff M., Iglesias C., Teixeira de Mello F., Clemente J., Jensen E., Lauridsen T.L. \& Jeppesen E. 2007b. Effects of habitat complexity on community structure and predator avoidance behaviour of littoral zooplankton in temperate versus subtropical shallow lakes. Freshwater Biology 52: 1009-1021.

Mills E.L., Confer J.L. \& Ready R.C. 1984. Prey selection by young yellow perch: the influence of capture success, visual acuity, and prey choice. Trans. Am. Fish. Soc. 113: 579-587.

Miranda L.A., Berasain G.E., Velasco C.A.M., Shirojo Y. \& Somoza G.M. 2006. Natural spawning and intensive culture of pejerrey Odontesthes bonariensis juveniles. Biocell 30: 157-162.

Moore M.V., Folt C.L. \& Stemberger R.S. 1996. Consequences of elevated temperatures for zooplankton assemblages in temperate lakes. Archiv Fur Hydrobiologie 135: 289-319.

Morrás H.J.M. 1999. Geochemical differentiation of Quaternary sediments from the Pampean region based on soil phosphorus contents as detected in the early 20th century. Quaternary International 62: 57-67

Morris J.E. \& Mischke C.C. 1999. Plankton management for fish culture ponds. Technical Bulletin Series 114. Ames, Iowa. 
Nakatani K., Agostinho A., Baumgartner G., Bialetzki A., Sanches P., Makrakis M., Pavanelli C. 2001. Ovos e larvas de peixes de água doce, desenvolvimento e manual de identificação. Maringa (Brasil): Eduem. p. 378.

Nogrady T. \& Segers H. 2005. Guides to the identification of the microinvertebrates of the continental waters of the world. Coordinating editor: H.J.F. Dumont. Backhuys Publishers, Leiden, The Netherlands.

North B.P., Turnbull J.F., Ellis T., Porter M.J., Migaud H., Bron J. \& Bromage N.R. 2006. The impact of stocking density on the welfare of rainbow trout (Oncorhynchus mykiss). Aquaculture 255: 466-479.

Northcote G. 1988. Fish in the structure and function of freshwater ecosystems: a "top-down" view. Can. Fish. Aquat. Sci. 45: 361-379.

Olivier S. 1961. Estudios limnológicos en la laguna Vitel (Pdo. Chascomús-Buenos Aires). Agro 6: 1-128.

Ouattara N. I., Teugels G. G., N’Douba V. \& Philippart J-C. 2003. Aquaculture potential of the black-chinned tilapia, Sarotherodon melanotheron (Cichlidae). Comparative study of the effect of stocking density on growth performance of landlocked and natural populations under cage culture conditions in Lake Ayame (Côte d'Ivoire). Aquaculture Research 34: 1223-1229.

Paggi J.C. 1995. Biodiversidad del zooplancton en los ecosistemas acuáticos continentales de la región neotropical: revisión de las especies del género Notodiaptomus Kiefer (Copepoda, Calanoida). Tesis para la obtención del grado académico de mágister en el campo de ecología acuática continental. Instituto Nacional de Limnología. Santa Fé, Argentina.

Paine R. 1980. Food webs: linkage, interaction strength and community infrastructure. J. Animal Ecology 49: 667-685.

Palkovacs E.P. \& Post D.M. 2008. Eco-evolutionary interactions between predators and prey: can predatorinduced changes to prey communities feed back to shape predator foraging traits? Evolutionary Ecology Research 10: 699-720.

Pasternak A.F., Mikheev V.N. \& Wanzenböck J. 2006. How Plankton Copepods Avoid Fish Predation: from Individual Responses to Variations of the Life Cycle. Journal of Ichthyology 46(2): 220-226.

Pelli A., Dumont-Neto R., Silva J., Gonçalves S., Souza D., Barbosa N. 1996. Início de ingestão de ração por pacú (Piaractus mesopotamicus Holmberg, 1887), curimba (Prochilodus scrofa Steinchdacner, 1881) e piau (Leporinus friderici Bloch, 1794). Em condições de criação semi-intensiva. In: Memorias de Simpósio Brasileiro de Aqüicultura 9: 88.

Pinkas L., Oliphant M.S. \& Iverson I.L.K. 1971. Food habits of albacore, bluefin tuna and bonito in Californian waters. California Fish and Game 152: 1-105.

Portella M.C., Cestarolli M.A., Verani J.R., Rojas N.E. 1997. Produção de organismos planctónicos para alimentação inicial de larvas de peixes de agua doce. Boletim Instituto de Pesca 24: 79-89. Único. São Paulo (Bra). 
Post J.R. \& Mcqueen D.J. 1987. The impact of planktivorous fish on the structure of a plankton community. Freshwater Biology 17: 79-89.

Prieto Guevara M.J. \& Atencio-Garcia V.J. 2008. Zooplancton en la larvicultura de peces neotropicales. Rev.MVZ Córdoba 13(2): 1415-1425

Prieto Guevara M.J., Rosa Logato P.V., Ferreira de Moraes G., Del Okamura, Guedes de Araújo F. 2006. Tipo de alimento, sobrevivência e desempenho inicial de Pós-larvas de pacu (Piaractus mesopotamicus). LarvasBrasil: Ciência e Agrotecnologia 30(5): 1002-1007.

Prieto M., Cruz LDI, Morales M. 2006. Cultivo experimenta del cladócero Moina sp. alimentado con Ankistrodesmus sp. y Saccharomyces cerevisiae. Rev MVZ Córdoba 11: 705-714.

Pyke G.H. 1984. Optimal Foraging Theory: A Critical Review. Annual Review of Ecology and Systematics 15: 523575.

Quinn G. \& Keough M. 2002. Experimental Design and Data Analysis for Biologists. Cambridge University Press, Cambridge, UK. 537pp.

Quirós R. \& Boveri M.B. 1999. Fish effects on reservoir trophic relationships. Theoretical Reservoir Ecology and its Applications 529-546.

Quirós R. \& Drago E. 1999. The environmental state of Argentinean lakes: An overview. Lakes and Reservoirs: Res. and Manage. 4: 55-64.

Quirós R. 1991. Empirical relationships between nutrients, phytoplankton and zooplankton, and relative fish biomass in lakes and reservoirs of Argentina. Verh. Internat. Verein. Limnol. 24: 1198-206.

Quirós R. 1995. The effects of fish assemblage composition on lake water quality. Lake and Reservoir Manage. 11: 291-298.

Quirós R. 1998a. Trophic cascade effects in a continuous series of temperate-subtropical water-bodies. Verh. Internat. Verein. Limnol. 26: 2315-2319.

Quirós R. 1998b. Fish effects on trophic relationships in the pelagic zone of lakes. Hydrobiologia 361: 101-111.

Quirós R., Rosso J.J., Rennella A., Sosnovsky A. \& Boveri M. 2002a. Análisis del estado trófico de las lagunas pampeanas (Argentina). Interciencia 27(11): 584-591.

Quirós R., Rennella A.M., Boveri M.B., Rosso J.J., \& Sosnovsky A. 2002b. Factores que afectan la estructura y el funcionamiento de las lagunas pampeanas. Ecología Austral 12: 175-185.

Rahman M.M., Kadowaki S., Balcombe S.R. \& Wahab M.A. 2010. Common carp (Cyprinus carpio L.) alters its feeding niche in response to changing food resources: direct observations in simulated ponds.

Rai A.K. 1999. Evaluation of natural food for planktivorous fish in Lakes Phewa, Begnas, and Rupa in PokharaValley, Nepal. Limnology 1: 81-89.

Reartes J.L. 1995. El pejerrey (Odontesthes bonariensis): Métodos de cría y cultivo masivo. COPESCAL (FAO) Documento Ocasional, 9, 35pp.

Reay P. 1979. Aquaculture. Edward Arnold, London. 
Reid J.W. 1985. Chave de identificação e lista de referências bibliográficas para as espécies continentais sulamericanas de vida livre da ordem Cyclopoida (Crustacea, Copepoda). Bolm. Zool. Univ. S. Paulo 9: 17-143.

Reiriz L., Nicieza A.G. \& Braña F. 1998. Prey selection by experienced and naive juvenile Atlantic salmon. Journal of Fish Biology 53: 100-114.

Reissig M. 2005. Análisis de los efectos de cascada trófica en cadenas alimentarias planctónicas de lagos oligotróficos. Tesis doctoral. Universidad Nacional del Comahue.

Rejas D.S., declerck J., Auwerkerken P., Tak \& De Meester L. 2005. Plankton dynamics in a tropical floodplain lake: fish, nutrients, and the relative importance of bottom-up and top-down control. Freshwater Biology 50: 52-69

Remes Lenicov M. \& Colautti D.C. 2005. Influencia de la disponibilidad natural de zooplancton sobre el cultivo del pejerrey Odontesthes bonariensis, en jaulas flotantes. III Congreso Argentino de Limnología. Chascomús.

Renella A. \& Quirós R. 2006. The effects of hydrology on plankton biomass in shallow lakes of the Pampa Plain. Hydrobiologia 556: 181-191

Rennella A. 2007. Relevancia de las interacciones tróficas en la determinación de la estructura del zooplancton en grandes lagunas pampeanas. Trabajo de tesis doctoral, Universidad de Buenos Aires, Buenos Aires, $115 p p$.

Rennella A.M. \& Quirós R. 2002. Relations between planktivorous fish and zooplankton in two very shallow lakes of the Pampa Plain. Verh. Internat. Verein. Limnol. 28: 1-5.

Resetarits W. R. Jr. \& Fauth J.E. 1998. From cattle tanks to Carolina bays: the utility of model systems for understanding natural communities. 133-151 in W. J. Resetarits, Jr., and J. Bernardo, editors. Ecological experiments: issues and perspectives. Oxford University Press, New York, New York, USA.

Reynolds C.S. 2006. The Ecology of Phytoplankton. Cambridge University Press, New York.

Richter H., Luckstadt C., Focken U.L. \& Becker K. 2000. An improved procedure to assess fish condition on the basis of length-weight relationships. Archive of Fishery and Marine Research. 48(3): 226-235

Ricker W.E. 1979. Growth rates and models. In: Hoar, W.S., Randall, D.J., Brett, J.R. (eds.) Fish Physiology, Vol. VIII. London, Academic Press Inc Ltd. 677-743.

Ringuelet R. A. 1942. Ecología alimentaria del pejerrey (Odontesthes bonariensis) con notas limnológicas sobre la laguna de Chascomús. Rev.Mus. La Plata, Sec. Zool.: 427-461.

Ringuelet R.A. 1958. Los crustáceos copépodos de las aguas continentales de la República Argentina. Sinópsis sistemática. Serie Zoología 1(2), 126pp.

Ringuelet R. A. 1962. Ecología Acuática Continental. Manuales de la Editorial Universitaria de Buenos Aires (EUDEBA) IX. Buenos Aires. 138 pp.

Ringuelet R.A., Salibián A., Claverie E., Ilhero S. 1967. Limnología química de las lagunas pampásicas (provincia 
de Buenos Aires). Physis 27: 201-221.

Ringuelet R. A., Moreno I. \& Feldman E. 1972. El zooplancton de las lagunas de la Pampa Deprimida y otras aguas superficiales de la llanura bonaerense (Argentina). Physis 74: 187-200.

Ringuelet R.A., Iriart R. \& EscalanteA. 1980. Alimentación del pejerrey (Basilichthys bonariensis bonariensis) en la laguna de Chascomús (Buenos Aires, Argentina). Relaciones ecológicas de complementación y eficiencia trófica del plancton. Limnobios 1: 447-460.

Rojas A. \& Wadsworth S. 2007. A review of cage aquaculture: Latin America and the Caribbean In: Cage Aquaculture edited by Halwart M, Soto D \& Arthur J. R. FAO, Rome. pages 73-98.

Rojas A. \& Wadsworth S.A. 2007. A review of cage aquaculture: Latin America and the Caribbean (English) En: Cage Aquaculture. Regional reviews and global overview. FAO Fisheries Technical Paper (FAO) , no. 498: 73-100.

Romero E. 2012. Análisis de la predación selectiva de Odontesthes bonariensis sobre el zooplancton en la laguna pampeana de Gómez. Trabajo de Tesis Doctoral. Facultad de Agronomía, Universidad de Buenos Aires.

Romero M.C., Conzonno V., 1997. Light attenuation in the water column in Chascomús Pond (Argentina). Gayana, Bot. 54(1): 53-59.

Rosso J.J. \& Quirós R. 2010. Patrones de desplazamientos reproductivos en el pejerrey Odontesthes bonariensis. Interciencia 35(6): 407-413.

Ruohonen K. 1998. Individual measurements and nested designs in aquaculture experiments: a simulation study. Aquaculture 165: 149-157.

Ruttner-Kolisko A. 1977. Suggestions for biomass calculations of plankton rotifers. Arch. Hydrobiol. 8: 71-76.

Sagratzki Cavero B.A., Pereira-Filho M., Roubach R., Rabello Ituassú D., Lima Gandra A. \& Crescêncio R. 2003. Efeito da densidade de estocagem na homogeneidade do crescimento de juvenis de pirarucu em ambiente confinado. Pesquisa Agropecuária Brasileira 38(1).

Sarma S., Nandini S. \& Gulati R. 2005. Life history strategies of cladocerans: comparisons of tropical and temperate taxa. In Segers, H. \& K. Martens (eds), Aquatic Biodiversity II. Springer, Netherlands: 315-333.

Scheffer M. \& Carpenter S. 2003. Catastrophic regime shifts in ecosystems: linking theory to observation. Trends in Ecology \& Evolution. 18: 648-656.

Scheffer M. (1998). Ecology of shallow lakes. Chapman \& Hall. Great Britain: 1-357.

Scheffer M., Hosper S., Meijer M., Moss B. \& Jeppesen E. 1993. Alternative equilibria in shallow lakes. Trends in Ecology \& Evolution 8: 275-279

Scheffer M., Rinaldi S., Huisman J. \& Weissing F. J. 2003. Why plankton communities have no equilibrium: solutions to the paradox. In: E. Van Donk, M. Noersma \& P. Spaak (eds), Recent Developments in Fundamental and Applied Plankton Research. Hydrobiology, 491: 9-18.

Sendra E. 2003. Evolución de parámetros demográficos clave del pejerrey Odontesthes bonariensis de la laguna 
Chascomús a lo largo de tres décadas. Biología Acuática 20: 93-100.

Sherman K., MaurerR.R., Green J. 1981. Relationship between larvalfish communities and zooplankton prey species in an offshore spawning ground. Rapp. P.v. Reun. Cons. int. Explor. Mer 178: 289-294.

Shuter B.J., Lester N.P., LaRose J., Purchase C.F., Vascotto K., Morgan G., Collins N.C. \& Abrams P.A. 2005. Optimal life histories and food web position: linkages among somatic growth, reproductive investment, and mortality. Can. J. Fish. Aquat. Sci. 62: 738-746.

Sinclair M. \& Tremblay M.J. 1984. Timing of spawning of Atlantic herring (Clupea harengus harengus) populations and the match-mismatch theory. Can. J. Fish. Aquat. Sci. 41: 1055-1065.

Skrzypczak A., Mamcarz A., Kucharczyk D. \& Kujawa R. 1998. Use of a Floating Pump to Collect and Transfer Live Zooplankton as Food for Percid Larvae Reared in Net Cages. The Progressive Fish-Culturist 60: 239241

Sokal R.R. \& Rohlf F.J. 1995. Biometry: the principles and practice of statistics in biological research, 3rd edn. Freeman, New York, 887 pp.

Solari L., Claps M. \& Gabellone N. 2002. River backwater pond interactions in the lower basin of the Salado River (Buenos Aires, Argentina). Arch. Hydrobiol. Suppl. 141: 1-21.

Solimano P.J. 2013. Desarrollo de un sistema de cría semi-intensiva para producción de pejerrey (Odontesthes bonariensis) en jaulas flotantes. Trabajo de Tesis Doctoral. Facultad de Ciencias Naturales y Museo. Universidad Nacional de La Plata.

Solimano P.J., Garcia de Souza J.R., Baigun C.R.M. \& Colautti D.C. 2011. Efectos de la adición de diferentes raciones de alimento artificial sobre el cultivo del Pejerrey Odontesthes bonariensis, en jaulas flotantes. III conferencia Latinoamericana sobre el cultivo de peces nativos. 13 al 15 de Julio, Lavras, MG. Brasil.

Solimano P.J., Garcia de Souza J.R., Maiztegui T., Colautti D.C. \& Baigún C.R.M. 2009. Efecto del suministro de alimento sobre el crecimiento del pejerrey Odontesthes bonariensis, cultivado en jaulas flotantes. /I Conferencia Latinoamericana sobre el cultivo de especies nativas. 2 y 3 de noviembre. Chascomús, Bs. As. Argentina.

Sommer U. 1989. Plankton ecology. Succesion in plankton communities. Springer-Verlag.

Somoza G.M., Miranda L.A., Berasain G.E., Colautti D., Remes Lenicov M. \& Strüssmann C.A. 2008. Historical aspects, current status and prospects of pejerrey aquaculture in South America. Aquaculture Research 39: 784-793.

Soriano A. 1992. Río de la Plata grasslands. En: Ecosystems of the world 8A. Natural Grasslands. Introduction and Western Hemisphere (ed Coupland R.T.), pp. 367-407. Elsevier, New York.

Sosnovsky A. \& Quirós R. 2008. Effects of fish manipulation on the plankton community in small hypertrophic lakes from the Pampa Plain (Argentina). Limnologica 39: 219-229.

Sosnovsky A., Rosso J.J. \& Quirós R. 2010. Trophic interactions in shallow lakes of the Pampa plain (Argentina) and their effects on water transparency during two cold seasons of contrasting fish abundance. 
Limnetica 29: 233-246.

Stein R.A., DeVries D.R. \& Dettmers J.M. 1995. Food-web regulation by a planktivore: exploring the generality of the trophic cascade hypothesis. Can. J. Fish. Aquat. Sci. 52: 2518-2526.

Stephens D.W. \& Krebs J.R. 1986. Foraging Theory. Princeton University Press. 250 pp.

Strauss R.E. 1979. Reliability estimates for Ivlev's electivity index, the forage ratio, and a proposed linear index of food selection. Trans. Am. Fish. Soc. 108 (1): 344-352.

Strüssmann C.A. 1989. Basic studies on seed production of pejerrey Odontesthes bonariensis. Tesis Doctoral, Universidad de Pesquerías de Tokio, Tokio, 351 pp.

Struve M.R. \& Bayne D.R. 1991. Isolation columns as an alternative to replicate ponds in aquaculture research. Journal of Applied Aquaculture 1(4): 73-81.

Sumida B.Y. \& Moser H.G. 1980. Food and feeding of pacific hake larvae, Merluccius productus, off southern California and northern Baja California. Calif. Coop. Fish. Inv. Rep. 21: 161-165.

Toresani N.I.,. Lopez H.L \& Gomez S.E. 1994. Lagunas de la provincia de Buenos Aires. Min. de la Producción, prov. Buenos Aires, 108 pp.

Torrans E.L. 1986. Fish/plankton interactions. In: Principles and practices of Pond Aquaculture (J.E. Lannan, R.O. Smitherman and G. Tchobanoglous, editors), Oregon State University Press, Corvallis, Oregon, USA; pp. 67-81.

Torremorell A., Bustingorry J., Escaray R. \& Zagarese H. 2007. Seasonal dynamics of a large, shallow lake, laguna Chascomús: The role of light limitation and other physical variables. Limnologica 37(1): 100-108.

Torremorell A., Llames M.E., Pérez G.L., Escaray R., Bustingorry J. \& Zagarese H. 2008. Annual patterns of phytoplankton density and primary production in a large, shallow lake: the central role of light. Freshwat. Biol. 54: 437-449.

Tricart J. 1973. Geomorfología de la Pampa Deprimida. INTA. Colección Científica 12: 1-202.

Tsuzuki M.Y., Ogawa K., Strussman C.A., Maita M. \& Takashima F. 2001. Physiological responses during stress and subsequent recovery at different salinities in adult pejerrey Odontesthes bonariensis. Aquaculture. 200: 349-362.

Underwood A. J. 1997. Experiments in ecology: their logical design and interpretation using analysis of variance. Cambridge University Press 503 pp.

van Leeuwen E., Lacerot G., van Nes E.H., Hemerik L. \& Scheffer M. 2007. Reduced top-down control of phytoplankton in warmer climates can be explained by continuous fish reproduction. Ecological Modelling 206: 205-212.

Vasnetsov V.V. 1953. Developmental stages of bony fishes. I n "Ocherki poOhshchim Voprosam Ikhtiologii," pp. 207-217. Akademiya Nauk Press, Moscow (in Russian). FIDE: Ricker, W. E. 1979. Growth rates and models. In: Hoar, W.S., Randall, D.J., Brett, J.R. (eds.) Fish Physiology, Vol. VIII. London, Academic Press Inc Ltd. p. 677-743. 
Velasco C.A., Berasain G.E. \& Ohashi M. 2008. Producción intensiva de juveniles de pejerrey (Odontesthes bonariensis). Biología Acuática 24: 53-58.

Vervoorst F.B. 1967. Las comunidades vegetales de la Depresión del Salado (Provincia de Buenos Aires). En La vegetación de la República Argentina. Serie Fitogeográfica 7. Buenos Aires: Instituto Nacional de Tecnología Agropecuaria.

Vuorinen I., Rajasilta M., Salo J. 1983. Selective predation and habitat shift in a copepod species-support for the predation hypothesis. Oecologia 59: 62-64.

Watanabe T., Kitajima C. \& Fugita S. 1983. Nutritional values of live organisms used in Japan for mass propagation of fish. A review. Aquaculture 34: 115-143.

Watanabe W., Clark J., Dunham J., Wicklund R. \& Olla B. 1990. Culture of Florida red tilapia in marine cages: effect of stocking density and dietary protein on growth. Aquaculture 90: 123-134.

Weatherley.A.H. and Gill.H.S 1987. The Biology of Fish Growth. Academic Press, London.

Wells L. 1970. Effects of alewife predation on zooplankton populations in Lake Michigan. Limnol. Oceanogr. 15: 556-565.

Westers H. 2001. Production. Pp 31-90. En Wedemeyer G., editor. Fish hatchery management, segunda edición. American Fisheries Society, Bethesda, Maryland.

Wetzel R.G. \& Likens G.E. 1991. Limnological Analyses. Segunda edición. Springer-Verlag. Nueva York.

Wetzel R.G. 2001. Limnology. Lake and river ecosystems. Third edition. Academic Press. London. 1006 pp.

Wootton R.J. 1998. Ecology of Teleost Fishes. Fish and fisheries series No. 24, 2nd edition. Dordrecht, Kluwer Academic Publishers. 386 pp.

Yi Y., Kwei Lin C. \& Diana J.S. 1996. Influence of Nile tilapia (Oreochromis niloticus) stocking density in cages on their growth and yield in cages and in ponds containing the cages. Aquaculture 146: 205-215.

Zagarese H.E. 1989. Predación por larvas de peces, particularmente de bagre sapo, (Rhamdia sapo), y pejerrey, (Odontesthes bonariensis), y sus efectos sobre las comunidades zooplanctónicas de agua dulce. Trabajo de Tesis Doctoral. Facultad de Ciencias Exactas y Naturales. Universidad de Buenos Aires.

Zagarese H.E. 1991. Planktivory by larval Odontesthes bonariensis (Atherinidae: Pisces) and its effects on zooplankton community structure. Journal of Plankton Research 13(3): 549-560.

Zagarese H.E. 1996. Growth of Odontesthes bonariensis (Atherinidae) larvae feeding on suboptimal zooplankton densities. Environmental Biology of Fishes 45: 191-198.

Zaniboni Filho E. 2000. Larvicultura de peixes de água doce. Informe Agropecuario en: Acuicultura empresarial, pequisa e planejamiento 21(203): 69-77.

Zaret T. M. 1972. Predators, invisible prey, and the nature of polymorphism in the Cladocera (class crustacea) Limnology and oceanography 17(2): 171-184.

Zaret T.M. \& Kerfoot W.C. 1975. Fish predation on Bosmina longirostris: Body-size selection versus visibility selection. Ecology 56: 232-237. 
Zaret T.M. \& Suffern S. 1976. Vertical migration in zooplankton as a predator avoidance mechanism. Limnology and Oceanography 21(6): 804-813.

Zeng W., Li Z., Ye S., Xie S., Liu J., Zhang T. \& Duan M. 2010. Effects of stocking density on growth and skin color of juvenile darkbarbel catfish Pelteobagrus vachelli (Richardson). J. Appl. Ichthyol. 26: 925-929. 


\section{Anexo 1:}

Composición taxonómica por experimento y por laguna y categoría de tamaño en la que mayoritariamente se clasificó cada taxón por su talla media por muestreo.

\begin{tabular}{|c|c|c|c|c|c|c|c|c|c|c|c|c|}
\hline Composición taxonómica & 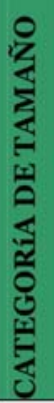 & 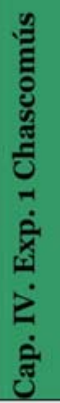 & 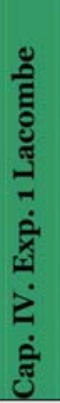 & 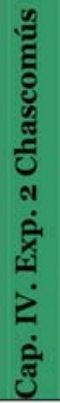 & 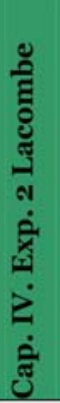 & 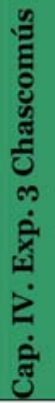 & 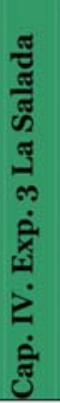 & 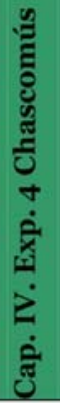 & 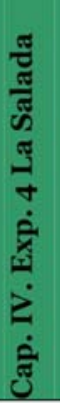 & 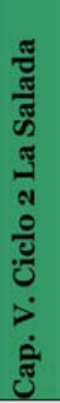 & 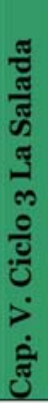 & 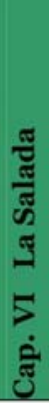 \\
\hline \multicolumn{13}{|l|}{ Rotifera } \\
\hline Brachionus plicatilis & I & $\mathrm{x}$ & $\mathrm{X}$ & & $\mathrm{X}$ & $\mathrm{X}$ & $\mathrm{X}$ & $\mathrm{X}$ & $\mathrm{X}$ & $\mathrm{X}$ & $\mathrm{X}$ & $\mathrm{x}$ \\
\hline B. caudatus & I & $\mathrm{X}$ & $\mathrm{X}$ & $\mathrm{X}$ & $\mathrm{X}$ & $\mathrm{X}$ & $\mathrm{X}$ & $\mathrm{X}$ & $\mathrm{X}$ & $\mathrm{x}$ & $\mathrm{X}$ & $\mathrm{x}$ \\
\hline B. calyciflorus & I & $\mathrm{X}$ & $\mathrm{X}$ & & & & & & & & $\mathrm{X}$ & $\mathrm{x}$ \\
\hline B. havanaensis & I & $\mathrm{X}$ & $\mathrm{X}$ & $\mathrm{X}$ & $\mathrm{X}$ & $\mathrm{X}$ & $\mathrm{X}$ & $\mathrm{X}$ & $\mathrm{X}$ & $\mathrm{X}$ & $\mathrm{X}$ & $\mathrm{x}$ \\
\hline B. quadridentatus & I & & $\mathrm{X}$ & & $\mathrm{X}$ & & & & & & & \\
\hline B. angularis & I & & & $\mathrm{X}$ & & & & & & $\mathrm{X}$ & $\mathrm{X}$ & $\mathrm{x}$ \\
\hline Keratella tropica & I & $\mathrm{x}$ & & $\mathrm{X}$ & $\mathrm{x}$ & $\mathrm{X}$ & $\mathrm{X}$ & $\mathrm{x}$ & $\mathrm{X}$ & $\mathrm{X}$ & $\mathrm{X}$ & $\mathrm{x}$ \\
\hline K. americana & I & $\mathrm{X}$ & & $X$ & & & $\mathrm{X}$ & & $\mathrm{X}$ & $\mathrm{X}$ & $\mathrm{X}$ & \\
\hline K. lenzi & I & & & & & $\mathrm{X}$ & & & & $\mathrm{X}$ & $\mathrm{X}$ & \\
\hline Polyarthra vulgaris & I & & $X$ & $X$ & $\mathrm{X}$ & $X$ & $X$ & $X$ & $\mathrm{X}$ & $X$ & $\mathrm{X}$ & $\mathrm{X}$ \\
\hline Trichocerca (Diurella) bidens & I & $X$ & $\mathrm{X}$ & & & & $X$ & & & & & $\mathrm{X}$ \\
\hline Filinia longiseta & I & $\mathrm{X}$ & $\mathrm{X}$ & & $\mathrm{X}$ & $X$ & $X$ & $X$ & & $\mathrm{X}$ & & \\
\hline Lecane hastata & I & & $X$ & & & & & & & $X$ & & \\
\hline L. luna & I & & $\mathrm{X}$ & & $\mathrm{X}$ & & & & & & & \\
\hline L. bulla & I & & & & & & $X$ & & & $\mathrm{X}$ & $X$ & $\mathrm{X}$ \\
\hline L. closterocerca & I & & & & & & & & & & & $\mathrm{X}$ \\
\hline Lepadella patella & I & & $\mathrm{X}$ & & $X$ & & & & & & & \\
\hline L. ovalis & I & & & & & & & & & $\mathrm{X}$ & & $\mathrm{X}$ \\
\hline Pompholyx sulcata & I & & & & & $\mathrm{X}$ & & & $\mathrm{X}$ & $\mathrm{X}$ & $\mathrm{X}$ & \\
\hline Hexarthra oxyuris & I & & & $X$ & & & $X$ & & & $X$ & & \\
\hline Cephalodella sp. & I & & & & $\mathrm{X}$ & & & & & & $\mathrm{X}$ & $\mathrm{X}$ \\
\hline Notholca acuminata & I & & & & & & $\mathrm{X}$ & & & & & \\
\hline Symchaeta sp. & I & & & & & & $\mathrm{X}$ & & $\mathrm{X}$ & $\mathrm{X}$ & $\mathrm{X}$ & \\
\hline
\end{tabular}




\begin{tabular}{|c|c|c|c|c|c|c|c|c|c|c|c|c|}
\hline Composición taxonómica & 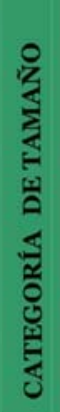 & 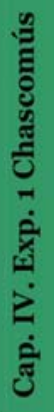 & 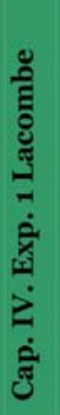 & 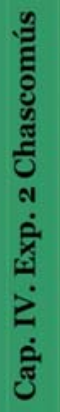 & 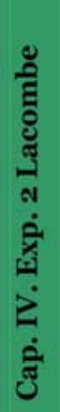 & 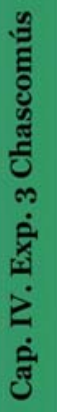 & 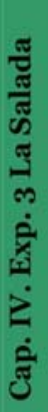 & 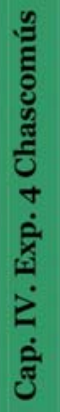 & 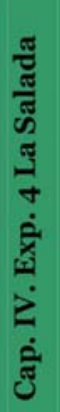 & 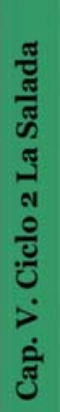 & 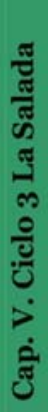 & 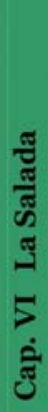 \\
\hline Asplanchna brightwellii & I & & & & & & & & & $\mathrm{X}$ & $\mathrm{X}$ & $\mathrm{x}$ \\
\hline Colurella uncinata & I & & & & & & & & & & & $\mathrm{X}$ \\
\hline \multicolumn{13}{|l|}{ Copepoda } \\
\hline Microcyclops alius & II & $\mathrm{X}$ & $\mathrm{X}$ & $\mathrm{X}$ & $\mathrm{X}$ & $\mathrm{X}$ & & & $\mathrm{X}$ & & $\mathrm{X}$ & $\mathrm{X}$ \\
\hline Metacyclops mendocinus & II & $\mathrm{X}$ & $\mathrm{X}$ & $\mathrm{X}$ & $\mathrm{X}$ & $\mathrm{X}$ & $\mathrm{X}$ & $\mathrm{X}$ & $\mathrm{X}$ & $\mathrm{X}$ & $\mathrm{x}$ & $\mathrm{x}$ \\
\hline Acanthocyclops robustus & & $\mathrm{X}$ & $\mathrm{X}^{*}$ & $\mathrm{X}$ & $\mathrm{X}$ & $\mathrm{X}^{*}$ & $\mathrm{X}$ & $\mathrm{X}^{*}$ & $\mathrm{X}$ & $\mathrm{X}$ & $\mathrm{X}^{*}$ & $\mathrm{x}$ \\
\hline Notodiaptomus incompositus & & $\mathrm{X}$ & $\mathrm{X}$ & $\mathrm{X}$ & $\mathrm{X}$ & $\mathrm{X}$ & & $\mathrm{X}$ & & & & \\
\hline Harpacticoida & II & $\mathrm{X}$ & $\mathrm{X}$ & & & & & $\mathrm{X}$ & & $\mathrm{X}$ & $\mathrm{X}$ & \\
\hline \multicolumn{13}{|l|}{ Cladocera } \\
\hline Bosmina huaronensis & II & $\mathrm{X}$ & & $\mathrm{X}$ & & $\mathrm{X}$ & $\mathrm{X}$ & $\mathrm{X}$ & $\mathrm{X}$ & $\mathrm{X}$ & $\mathrm{X}$ & $\mathrm{X}$ \\
\hline Moina micrura & & & $\mathrm{X}$ & & & $\mathrm{X}$ & & $\mathrm{X}$ & & $\mathrm{X}$ & & $\mathrm{x}$ \\
\hline Ceriodaphnia dubia & & & $\mathrm{X}$ & & & & & $\mathrm{X}$ & $\mathrm{X}$ & & & \\
\hline Diaphanosoma birgei & & & $\mathrm{X}$ & & $\mathrm{X}$ & $\mathrm{X}$ & & & & $\mathrm{X}$ & & $\mathrm{x}$ \\
\hline Coronatella rectangula & II & $\mathrm{X}$ & & $\mathrm{x}$ & $\mathrm{X}$ & $\mathrm{X}$ & & $\mathrm{X}$ & & $\mathrm{X}$ & $\mathrm{X}$ & $\mathrm{x}$ \\
\hline Alona glabra & II & & & $\mathrm{X}$ & $\mathrm{X}$ & $\mathrm{X}$ & & & & & & \\
\hline Leydigia sp. & II & & & & & & & $\mathrm{X}$ & & & & \\
\hline Macrotrix sp. & II & & & & & $\mathrm{X}$ & & & & & $\mathrm{X}$ & \\
\hline Daphnia spinulata & & & & & & & $\mathrm{X}$ & & $\mathrm{X}$ & & & \\
\hline
\end{tabular}

*Estuvieron presentes sólo estadíos juveniles de dicha especie en los casos indicados. 


\section{Anexo 2:}

Lista de abreviaturas utilizadas en este manuscrito, ordenadas alfabéticamente:

A1: Red de arrastre 1

A2: Red de arrastre 2

A3: Red de arrastre 3

AZ: Abundancia zooplanctónica

AZJ: Abundancia zooplanctónica de las jaulas

AZL: Abundancia zooplanctónica de la laguna

AZN: Abundancia zooplanctónica normalizada

BZ: Biomasa zooplanctónica

BZJ: Biomasa zooplanctónica de las jaulas

BZL: Biomasa zooplanctónica de la laguna

BZN: Biomasa zooplanctónica normalizada

CD: Contenidos digestivos

CDjau: Contenidos digestivos de los pejerreyes criados en jaulas

CDsil: Contenidos digestivos de los pejerreyes silvestres

CPN: Composición porcentual por número

CPP: Composición porcentual por peso

EE: Etapa experimental

EN: Etapa nursery

FO: Frecuencia de ocurrencia

IRI: Índice de importancia relativa

JB: Jaulas blanco

JP: Jaulas con peces

LSt: Longitud standar

LT: Longitud total

$\mathrm{N}$ : Número de individuos

P: Producción

S\%: Supervivencia porcentual

TCE: Tasa de crecimiento específico

TCEL: Tasa de crecimiento específico en largo

TCEW: Tasa de crecimiento específico en peso

TMP: Tamaño medio de presa

TMZ: Tamaño medio de zooplancton

W: Peso 